\title{
The co-creation of services
}

Citation for published version (APA):

Oertzen, A-S. (2020). The co-creation of services. [Doctoral Thesis, Maastricht University]. Off Page Amsterdam. https://doi.org/10.26481/dis.20200313ao

Document status and date:

Published: 01/01/2020

DOI:

10.26481/dis.20200313ao

Document Version:

Publisher's PDF, also known as Version of record

\section{Please check the document version of this publication:}

- A submitted manuscript is the version of the article upon submission and before peer-review. There can be important differences between the submitted version and the official published version of record.

People interested in the research are advised to contact the author for the final version of the publication, or visit the DOI to the publisher's website.

- The final author version and the galley proof are versions of the publication after peer review.

- The final published version features the final layout of the paper including the volume, issue and page numbers.

Link to publication

\footnotetext{
General rights rights.

- You may freely distribute the URL identifying the publication in the public portal. please follow below link for the End User Agreement:

www.umlib.nl/taverne-license

Take down policy

If you believe that this document breaches copyright please contact us at:

repository@maastrichtuniversity.nl

providing details and we will investigate your claim.
}

Copyright and moral rights for the publications made accessible in the public portal are retained by the authors and/or other copyright owners and it is a condition of accessing publications that users recognise and abide by the legal requirements associated with these

- Users may download and print one copy of any publication from the public portal for the purpose of private study or research.

- You may not further distribute the material or use it for any profit-making activity or commercial gain

If the publication is distributed under the terms of Article $25 \mathrm{fa}$ of the Dutch Copyright Act, indicated by the "Taverne" license above, 


\section{The Co-Creation of Services}

Anna-Sophie Oertzen

School of Business and Economics, Maastricht University

Köln International School of Design, Technical University of Applied Sciences Cologne 


\title{
The Co-Creation of Services
}

\author{
Dissertation
}

to obtain the degree of Doctor at Maastricht University, on the authority of the Rector Magnificus Prof. Dr. Rianne M. Letschert in accordance with the decision of the Board of Deans,

to be defended in public on Friday the 13th of March 2020, at 12.00 hours.

(c) Anna-Sophie Oertzen, Maastricht 2020

All rights reserved. No part of this publication may be reprinted or utilized in any form or by any electronic, mechanical, or other means, now known, or hereafter invented, including photocopying and recording, or in any information storage or retrieval system, without permission from the copyright owner.

ISBN: 978-94-6182-996-2

Cover design and illustrations by Natalie Sketcher, Brisbane, Australia

Layout and printing by Off Page, Amsterdam, The Netherlands. 


\section{Supervisors:}

Prof. Dr. Gaby Odekerken-Schröder

Prof. Birgit Mager, Technical University of Applied Sciences Cologne

\section{Assessment Committee:}

Prof. Dr. Dominik Mahr, Chair

Prof. Dr. Elisabeth C. Brüggen

Prof. Dr. Mirella H.P. Kleijnen, Vrije Universiteit Amsterdam

Prof. Dr. Katrien Verleye, Ghent University

This project has received funding from the European Union's Horizon 2020 research and

innovation programme under the Marie Sklodowska-Curie grant agreement No 642116.

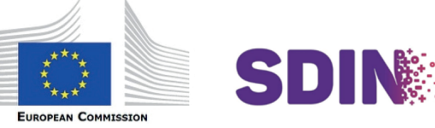




\section{Abstract}

Co-creating services has inspired great enthusiasm among both researchers and practitioners, making it a widely applied concept and an ideal cited by many. However, amid all the hype about co-creating services, there also is increasing recognition that not every co-creation effort leads to a successful outcome. People intuitively perceive the value of collaborating during the design, development, delivery, and consumption of services, yet understanding of how cocreation truly works remains limited. By bridging five research gaps, this dissertation clarifies, empirically validates, and advances understanding of the benefits and process of co-creating services. Its interdisciplinary, multi-method approach explicitly integrates the interrelated disciplines of service management/marketing, service design, and service innovation.

Four empirical chapters, each a separate manuscript, reveal how and why people co-create services. The first establishes a common foundation, with a focused literature review that synthesises previous conceptualisations of co-creation and related terminology into a novel definition of co-creating services. It also provides a typology of beneficial and counterproductive outcomes from co-creating services, along six dimensions. The second chapter explores why people display certain behaviours during services co-creation, using scenario-based experiments. By integrating insights gleaned from interactive research workshops with design professionals, it also proposes factors driving and inhibiting people's co-creation engagement and a typology of personas and anti-personas, based on their likelihood to engage in cocreation, as a result of their personality traits and demographics. The third chapter examines the underlying dynamics and possible risks of the co-creation process and how it integrates people's lived experience, specifically in a healthcare context, where the need to integrate users' situated insights into the design of services that affect them is especially crucial, due to its sensitive, often urgent nature. Using phenomenological interviews, this chapter identifies six interacting tensions associated with integrating lived experience through co-creation in healthcare innovation and seven possible strategies to integrate people's experience amid these tensions. Finally, the fourth chapter develops a post-adoption model for the phase after the initial adoption of a co-creative service, tested with a cross-sectional survey of current customers of a large bank.

By systematically synthesising the theoretical and empirical premises of these four chapters, this dissertation formulates eight holistic conclusions that extend and challenge current understanding of the benefits and process of co-creating services. First, genuine services co-creation that transcends tokenistic collaborative approaches demands multi-directional communication among involved parties, who must actively participate and engage in the cocreation process. Second, the human-centred perspective of service design contributes to cocreation as a process, a toolbox, and a mind-set. Third, co-creating services takes place in earlier phases of the service process, related to innovating, and in later phases, related to the delivery and consumption of services. Fourth, innovation is both a contextual stage for co-creating services and an outcome. Fifth, co-creating services depends on the participating party and the facilitating party. Sixth, there is no one best way to initiate co-creation; the first step can be taken by various actors, with varying implications. Seventh, through its beneficia outcomes, genuine services co-creation builds legitimacy, which supports institutional change. Eighth, the mental construction and social interaction inherent to co-creating services require paradoxical thinking to facilitate the co-creation process.

By clarifying the benefits of and process for co-creating services, this dissertation offers implications for academic developments related to the topic of co-creating services. The implications also can inform practical applications, whether by an individual to build a house, a healthcare organisation to innovate medical services, or policy makers to design people-centred services. 


\section{Acknowledgements}

Similar to designing, planning, and building a house, it takes more than one person to do a $\mathrm{PhD}$. I have been fortunate enough to have the support of an amazing construction team over the last years, which has greatly shaped this dissertation in many ways.

First and foremost, I would like to thank my fantastic supervisors Gaby Odekerken-Schröder and Birgit Mager, who have been there every step along the way, challenging me to strive for the stars and supporting me throughout the valleys.

Gaby, without you, I would not be where I am today. You have guided me through my Bachelor thesis, my Master thesis, and now my PhD thesis. You have taught me the art of academic writing, the diligence needed to set up a research project, and to have fun in the process. Way beyond your brilliant academic guidance though, you have been a true role model for me. Besides my family, you have had the largest impact on my life so far. Your professional and personal advice will always carry a high weight for me, and I am incredibly grateful that I got the opportunity to have such a wonderful person as a mentor and friend for six exciting years (and counting!).

Birgit, you are an absolute power woman, and I greatly admire your strength, energy, and the service design imperium that you have built. I could not have asked for a better coach on my journey to become a service designer. You are an excellent example of what is possible when you truly believe in a cause, which is an invaluable inspiration for me. I am so appreciative for your academic and practical guidance during my PhD journey - and for furthering my horizon with regard to French cheese, German wine, Israeli treats, and Italian coffee!

I would also like to express my deep appreciation to the members of the assessment committee Elisabeth Brüggen, Mirella Kleijnen, Dominik Mahr, and Katrien Verleye. Thank you for the time and effort you have invested in evaluating the quality of my dissertation!

As part of my PhD journey, I had the wonderful opportunity to be an Early Stage Researcher with the Service Design for Innovation Network (SDIN). I am very grateful for the generous funding from the European Union's Horizon 2020 research and innovation programme under the Marie Sklodowska-Curie grant agreement No 642116. Through SDIN, I met so many brilliant people that have greatly contributed to the current dissertation. Lia, thank you for setting up this fantastic network and for all our chats before I even joined SDIN. Jorge, thank you for welcoming me at FEUP for a semester, all the urgent e-mails, and always having an open ear for me. I would also like to thank the other academic and industry partners - António Birgit, Bo, Bård, Daniela, Dominik, Gaby, Katarina, Pedro, Stefan, and Tomas. Thank you to my fellow SDIN family - Ana, Filipe, Josina, Maira, Martina, Nabila, Nina, Sebastian, Susan,
Tim, and Vanessa. One of the best parts of my PhD was meeting you and all the great talks, collaborations, and fun we have had

I have been incredibly fortunate to receive instrumental mentorship from the service research community and call some brilliant scholars my co-authors. In particular, I would like to thank Jay Kandampully, whose guidance and advice have been central to the theoretical backbone of this dissertation. I am also very grateful to Rebekah Russell-Bennett for the amazing, on-going collaboration and all the feedback along the way. Furthermore, I would like to thank Tom Chen for so many thought-provoking chats and introducing me to the CCIS-CE community. Thank you to Martin Wetzels for his helpful advice on the data analysis stages of my quantitative studies. I also appreciate the great and intensive collaboration with Saara Brax and the resulting publication. Special thanks to Josina Vink, who has been a fantastic collaborator, co-author, and dear friend. Josina, I have learned so much from your beautiful mind and contagious enthusiasm! For their constructive feedback and scholarly guidance, I would also like to thank Matthew Alexander, Linda Alkire, Ray Fisk, Elina Jaakkola, Werner Kunz, Mekhail Mustak, Parsu Parasuraman, Chatura Ranaweera, and so many other brilliant scholars that I was lucky enough to meet at various international conferences and events.

I also owe my gratitude to the organisations that enabled the data collection for my empirical studies. I would like to thank Experio Lab, Flycatcher, Koos Service Design, SDN, and the Sparkasse Harburg-Buxtehude for their openness, involvement, and assistance with recruiting participants. Special thanks to Andreas Sommer, Andreas Hanowski, and EllenDenise Anwander for the great cooperation and to Jesse Grimes and Floor Smit for organising a memorable service design event in Amsterdam. I had a great time during my first secondment with the Service Design Network in Cologne. Particular thanks to Cristine for all the fun collaborations, talks, and dinners! I am also very grateful for the fantastic opportunity of spending a couple of months with Patient Innovation in Lisbon during my second secondment, enabling me to gather insights from some of the most inspirational human beings I have met so far.

To the Sedes girls Laura and Jenny, thank you for welcoming me with open arms in your cosy office in Cologne. Many thanks also to the awesome folks from the Service Science Factory. Sabine, I am warmly remembering our intense work sessions and Karaoke antics. Damien, it is always a pleasure to chat over service design and travelling. I would also like to extend my thanks to all the fantastic and inspiring colleagues of the Marketing and Supply Chain Management department in Maastricht, especially Pascalle and Nicole for always offering a helping hand. Thanks also to Kars and Martina for all the support. Furthermore, I would like to thank the CTF folks, particularly Rolf, for inviting me to a thought-provoking PhD retreat in the Norwegian woods and setting a record for most PhDs in a hot tub! 
A very special thanks goes to my paranymph Paula. We met on the first day in Maastricht in 2011, and I could not imagine my life without you anymore. You are the sister that I have always longed for. The last years would have been infinitely less exciting without our adventures (it is certainly best if I do not go into detail here), but you were also my rock in difficult times. Thank you for being an awesome best friend!

My fantastic friends from close by and far away, Adri, Alex, Caro, Clara, Franca, Franzi, Leni, Lena, Lisi, Mariam, Svenja, Torben, Vera - Thank you for the countless chats, visiting me, and generally being in my life - you are amazing!

Um enorme obrigada também à minha equipa de Lisboa (Ana, Carneiro, Catarina, Joana $\mathrm{F}$. plus one!, Joana M., MC, Ricardo, Rodrigo e Pipo) por me terem proporcionado a verdadeira experiência portuguesa, introduzindo-me a inúmeros pratos de bacalhau e a gostos musicais questionáveis. Vou sentir muito a vossa falta. O Oktoberfest está à vossa espera!

Gostaria também de agradecer à minha família portuguesa, que me recebeu de braços abertos e me fez sentir em casa. Obrigada Olívia, Alberto, Inês, e Daniel!

Mein besonderer Dank gilt meiner Familie. Liebe Omi, lieber Opi - ihr seid die besten Großeltern! Danke, dass ihr mir stundenlang zuhört, dass bei euch „die Zeit stillsteht“ und dass ich immer mit vollem Bauch und Herzen bei euch abreise.

Auch bin ich Jacky \& Oscar unsagbar dankbar. Die beiden Verrückten haben mir so viel Wärme, Liebe und Energie gegeben. Ich habe nie alleine an dieser These geschrieben, stundenlang hatte ich einen Schoß - oder Fußwärmer. Unzählige Male haben sie mich zum Lachen gebracht und sich meine verrückten Ideen angehört (die Armen!)

Liebe Mami, lieber Papi - ihr habt mich und meine Ziele immer unterstützt. Ihr seid einer der Gründe weshalb ich heute diese Danksagung schreiben darf. Ich kann kaum in Worte fassen, wie dankbar ich euch bin und wie sehr ihr mein Leben geprägt habt. In den letzten Jahren habt ihr mich ermutigt, Erfolge mit mir geteilt und mir die Kraft gegeben Hürden zu überwinden. Danke, dass ihr immer an mich geglaubt habt, auch wenn ich selber gezweifelt habe. Danke, dass ihr mir stets gezeigt habt, was wirklich wichtig ist im Leben. Danke für alles, was ihr für mich getan habt. Ihr seid die Besten!
Por último, mas não menos importante, estou-te muito grata, André. Durante os últimos anos tiveste que estar presente em várias frentes: Parceiro, amigo, colega de trabalho, colaborador, conselheiro, governanta, cozinheiro, revisor, paranymph, e a lista continua e continua. Estiveste o meu lado em todos os altos e baixos. Brindaste com as minhas conquistas. Ancoraste-me quando eu comecei a deslizar. Fizeste rock'n roll comigo durante a noite. Fizeste-me sorrir nos dias mais cinzentos. Obrigada. Esta é para ti.

Anna-Sophie Oertzen, Lisbon, Portugal 10th of January 2020 


\section{Table of Contents}

Introduction

What Is Co-Creation?

What Is Missing?

An Interdisciplinary, Multi-Method Research Approach

Empirical Context

Overview

Chapter 1 Co-Creating Services-Conceptual Clarification, Forms, and Outcomes Introduction

Focused Literature Review Approach

The Concept of Co-Creating Services and Related Terminology

Defining the Co-Creation of Services

A Typology of Outcomes from Co-Creating Services

Conclusion: An Integrative Framework for Co-Creating Services

Discussion

Chapter 2 Driving Users' Behaviours and Engagement in Co-Creating Services Introduction

Theoretical Background

Study 1: Scenario-Based Experiments

Study 2: Interactive Research Workshops

General Discussion

Chapter 2. Appendix

Chapter 3 Live and Let Live: Integrating Lived Experience through Co-Creation in Healthcare Innovation

Introduction

Theoretical Background

Methodology - Phenomenological Interviews

Findings

Discussion

Achieving Continued Usage in Online Banking: A Post-Adoption Study Introduction

Literature Review and Hypotheses Development

Methodology - Cross-Sectional Survey

Analysis and Results

Discussion and Implications

Conclusion 


\section{Table of Contents (continued)}

Conclusion

\section{Synopsis}

Final Thoughts

References

Valorisation Addendum

\section{List of Tables}

Introduction

Table I.1. Empirical contexts of the chapters

Table I.2. Overview of the chapters

Chapter 1 Co-Creating Services-Conceptual Clarification, Forms, and Outcomes Table 1.1. Two generations of provider-customer collaboration Table 1.2. Overview of the focused literature review process

Table 1.3. Publication outlets

Table 1.4. Methodological orientation of the reviewed studie Table 1.5. Co-creation of services terminology and associated themes Table 1.6. Explanation of the seven emerging themes in co-creation of services conceptualisations

Table 1.7. Comparison of the co-creation of services terminology

Table 1.8. Typology of outcomes from co-creating services

Table 1.9. Examples of industry practices for co-creating services

Chapter 2 Driving Users' Behaviours and Engagement in Co-Creating Services Table 2.1. Measurement model

Table 2.2. Structural mode

Chapter 3 Live and Let Live: Integrating Lived Experience through Co-Creation in Healthcare Innovation

Table 3.1. Overview of the participants $(n=23)$

Table 3.2. Phenomenological interview structure based on Bevan (2014)

Table 3.3. Data analysis process based on Goulding (2005) and Thompson (1997)

Table 3.4. Tensions of integrating lived experience through co-creation Table 3.5. Strategies for integrating lived experience through co-creation

Chapter 4 Achieving Continued Usage in Online Banking: A Post-Adoption Study Table 4.1. Validated scales

Table 4.2. Demographics of respondents $(n=750)$

Table 4.3. Measurement model

Table 4.4. Intercorrelations of the latent variables Table 4.5. Structural model

Table 4.6. Age-based multi-group analysis

Table 4.7. Analysis of competing structural models

Table C.1. Overview of the chapters: Gaps, research questions, and key premises 18

Valorisation Addendum

Table VA.1. Exemplary academic- and practitioner-oriented events 


\section{List of Figures}

Introduction

Figure I.1. MR Space Runway Adventures (Image courtesy of GE Healthcare)

Figure I2. Research objectives and research gap

Figure I.3. Interdisciplinary approach

Chapter 1 Co-Creating Services-Conceptual Clarification, Forms, and Outcomes

Figure 1.1. Number of reviewed articles published per year

Figure 1.2. Themes of the thematic analysis represented across the co-creation of services terminolog

Figure 1.3. Integrative framework of co-creating services

Chapter 2 Driving Users' Behaviours and Engagement in Co-Creating Services Figure 2.1. Conceptual model for Study 1

Figure 2.3. Traits and demographics of personas and anti-personas for 107 engagement in services co-creation

Figure 2.4. Users' likelihood to co-create based on elemental, compound, 109 and situational traits

Chapter 3 Live and Let Live: Integrating Lived Experience through Co-Creation in Healthcare Innovation

Figure 3.1. Conceptual framework of the dynamics of integrating lived experience through co-creation in healthcare innovation

Chapter 4 Achieving Continued Usage in Online Banking: A Post-Adoption Study Figure 4.1. Conceptual model

Figure 4.2. Validated model, including unstandardised estimates

\section{List of Appendices}

Chapter 2 Driving Users' Behaviours and Engagement in Co-Creating Services

Appendix A. Scenario description (adapted from Heidenreich et al., 2015)

Appendix B. Demographic profile for Study $1(n=633)$

Appendix C. Intercorrelations of the first-order constructs

Appendix D. HTMT values

Appendix E. Interactive research workshop protocol

Appendix F. Analyses of the interactive research workshops 


\section{Introduction}

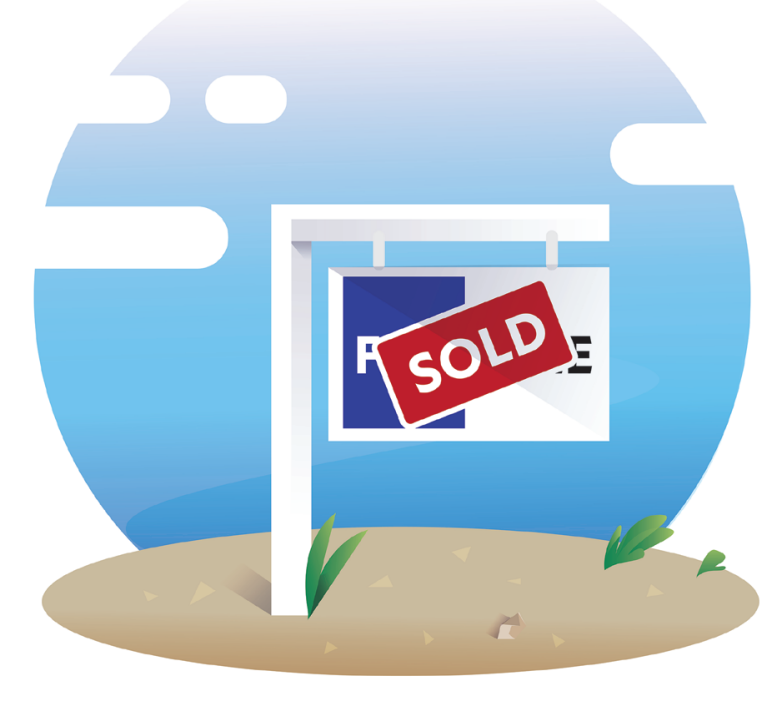




\section{What Is Co-Creation?}

When you hear the word "co-creation," what does it mean to you? Collaborating with different people to design and build a house? Using the Nike By You service to customise your sneakers? Something else? To illustrate what co-creation can mean-though it is not limited to these ideas-I start to introduce this dissertation with a story that has inspired me throughout the last years while pursuing my Ph.D. on the co-creation of services:

As a principal designer for GE Healthcare, the division of General Electrics that provides healthcare services, Doug Dietz had just spent two years designing a new, high-tech, magnetic resonance (MR) scanner to take images of almost any internal body part. After all his hard work, he was excited and proud to watch the painless sanning service in its actual environment at a hospital. Upon arriving to observe Dietz was told to wait a moment for a little girl, scheduled for an MR scan. He watched her and her parents arrive. The girl was weeping and visibly scared her parents tried to comfort her, telling her to be brave. Astounded, Dietz knelt down to take her perspective as the family entered the MR suite. What he saw was a scary machine, surrounded by black-and-yellow tape that resembled an accident scene in a bleached-out, dark room. His pride and excitement about his innovation immediately turned to shock and disbelief. The services of his awardwinning, well-intentioned innovation were traumatising vulnerable patients, so much so that the hospital had to sedate about 80 percent of the children who needed scans. Deeply moved by this revelation, he pursued a fundamental change to his innovation and turned to co-creation to tap into the experiences of different people who would be affected: brainstorming sessions at local day care centres with both children and child care workers, as well as various co-creation workshops with nurses, developers, and specialists. He observed actual experience of children and their parents and talked to them to understand these experiences. After learning what the children were afraid of, he re-designed the entire experience of using scanning services. The newly launched GE Adventure Series transformed treatment rooms into themes, such as the Jungle or Space Runway Adventures (Figure I.1). Using storytelling, sensory lights, aromatherapy, and visual techniques, the Adventure Series was able to reduce the number of patients needing sedation to less than 1 percent and increase patient satisfaction by 92 percent at a pilot hospital. In addition to the patients' and their parents experiences, the re-design improved the experiences of nurses and technologist operating the MR scanners. After installing the new design, Dietz came back to the hospital to see his innovation in practice; talking with some parents whose daughter just had her scan, he was gratified to hear the little girl, brimming with excitement, plead, "Can we come back tomorrow?" 


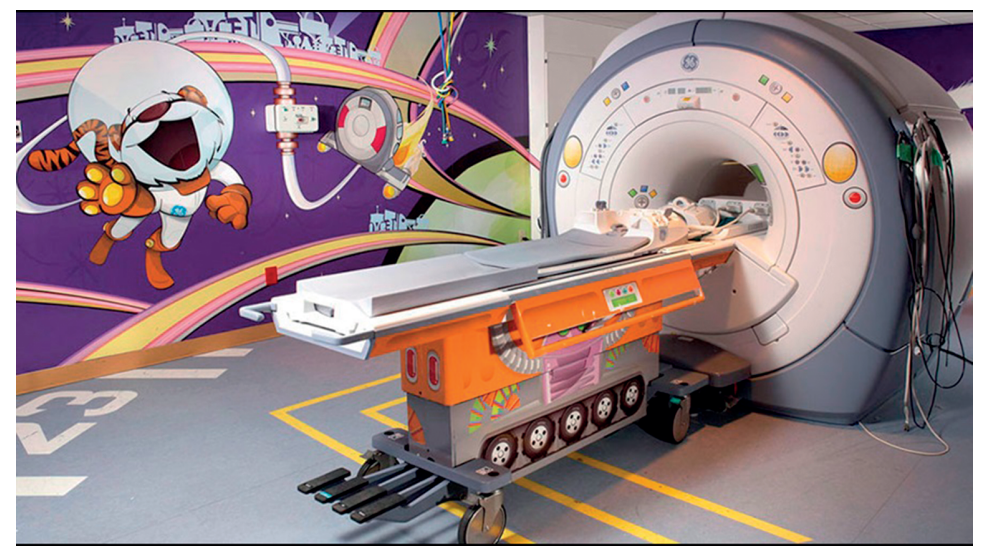

Figure I.1. MR Space Runway Adventures (Image courtesy of GE Healthcare)

In a deeply emotional way, this story illustrates the power of co-creation, involving different people, engaged in active, reciprocal, and genuine dialogue. To meet the needs of various people, including vulnerable children and their parents in this example, services must be informed by the experiences that these people actually have. We cannot assume that we know what other people need or want; we always risk projecting our own assumptions into our interpretations of other people's experiences. This same line of reasoning applies to virtually any service setting. Consider designing and building public housing for example. When a municipality tasks a builder with developing new housing, information exchange often takes place only among the municipality and the builder; however, it should also involve the specific, situated input of citizens who ultimately will live there.

Co-creation is not limited to designing and developing services though. It constitutes an integral part in the delivery and consumption of services as well, whereby services broadly refers to "deeds, processes, and performances" (Zeithaml et al., 2017, p. 4). Choosing from a pre-formatted, modular menu to customise new Nike sport shoes represents co-creation in service delivery. The shoes can reflect users' preferences, though the innovation opportunities ultimately are limited, given the available textiles, colours, or stitching. In healthcar contexts, collaborative care that actively fosters shared decision-making, mutual goals, and sustained relationships among patients, families, healthcare professionals, and other actor implies day-to-day co-creation when consuming healthcare services (McColl-Kennedy et al., 2017a). It represents a key factor in efforts to acknowledge and elevate the contributions of vulnerable people. In accordance with the vast variety in these diverse forms of co-creation, this dissertation takes a broad view on co-creating services, as an optional, collaborative act among two or more people, usually including a participating party (e.g., patients, families) and a facilitating party (e.g., the service provider GE Healthcare), during service processes and service innovation activities (Oertzen et al., 2018).

\section{What Is Missing?}

Across service industries worldwide, great enthusiasm surrounds co-creating the design, development, delivery, and consumption of services; many large organisations already have integrated co-creation into their business models. The Japanese information technology provider Fujitsu positions co-creation at the heart of its vision to drive human-centric innovation; BMW, the German automobile and motorcycle producer, launched the BMW Group Co-Creation Lab to co-create products and services with different groups of people; and the U.S. technology provider IBM considers co-creation, through a partnering strategy, as integral to its reinvented business model (Bartl et al., 2013; Fujitsu, 2019; Sargen, 2018). Labelled the "secret sauce to success," with "the power to change the world" (Crandell, 2016; Reinholds, 2019), services co-creation has become a widely used buzzword, linked to capitalising on the wisdom of the crowds and moving beyond traditional organisational boundaries (Quero and Ventura, 2015; Russo-Spena and Mele, 2012). Echoing this practical enthusiasm, academia has praised co-creation as an essential asset for service innovation (Ryzhkova, 2015), market performance (Carbonell et al., 2012), and service quality (Gill et al., 2011).

However, amid all this enthusiasm, there also is increasing understanding that co-creating services does not guarantee success. People might intuitively perceive that co-creating services offers great potential to add value, but it still is difficult to understand how its benefits materialise or how to facilitate its processes. These uncertainties intensify in adverse circumstances, such as when participants engage in deviant behaviours during co-creation (Gatzweiler et al., 2017) or display non-collaborative attitudes (Kristal et al., 2018), unsuitable people join the co-creation effort (Hoffman et al., 2010), the incentives are inappropriate (Füller, 2010), or management approaches are unsuitable (Mustak et al., 2016). Against this backdrop, this dissertation seeks to provide a better understanding of the benefits and process of co-creating services (Figure I.2). To systematically and holistically clarify, validate, and advance this knowledge domain, this dissertation addresses five research gaps over the course of four chapters: (1) lack of a definition of the co-creation of services (Galvagno and Dalli, 2014; Saarijärvi et al., 2013), (2) incomplete understanding of what drives people to co-create services (Füller, 2010; Jaakkola et al., 2015), (3) missing insights on the underlying dynamics of co-creating services (Gustafsson et al., 2012; Payne et al., 2008), (4) insufficient knowledge about the post-adoption phase of co-creative services (Tam and Oliveira, 2017a), and (5) the lack of an overview of the outcomes from co-creating services (Voorberg et al., 2015; Woodruff and Flint, 2006).

\section{An Interdisciplinary, Multi-Method Research Approach}

To address the aforementioned research gaps and contribute to a better understanding of the benefits and process of co-creating services, I tap into three adjacent disciplines: service management/marketing, service innovation, and service design (Figure I.3). Metaphorically, this effort is like building a house. It requires different perspectives, such as those of 


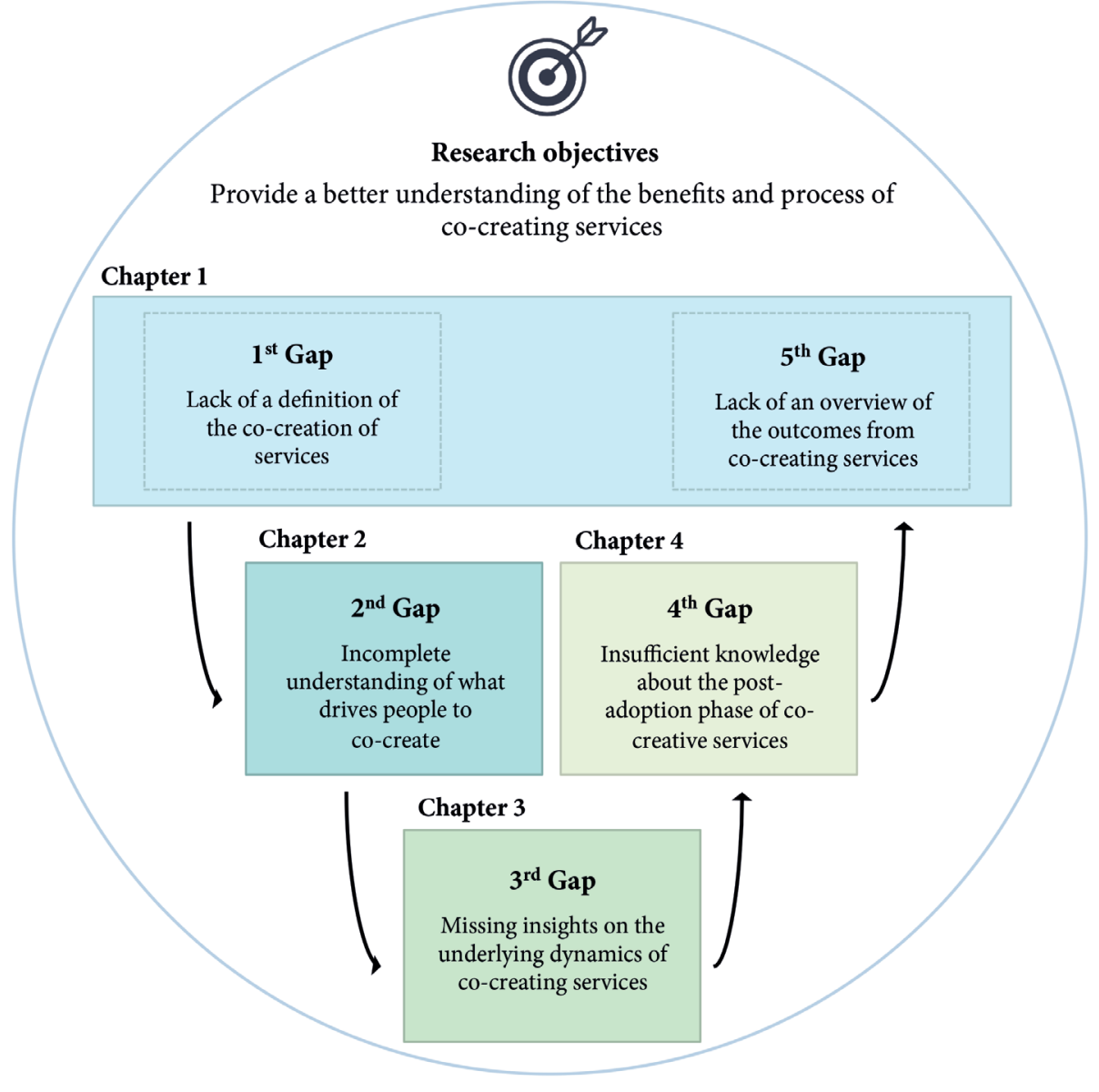

Figure I.2. Research objectives and research gaps addressed by this dissertation

the homeowner, the builder, and the architect, to design and plan the house. Exploring the multifaceted nature of co-creating services similarly requires a wide-ranging, interdisciplinary lens, because the benefits and process of co-creating services cannot be holistically clarified, validated, or advanced by any single discipline. Interdisciplinary service research entails the "interactive mutual theoretical development and integration among and on the fringes of different disciplines (with different concepts, methods, data and terms), organized into common effort on a common problem" (Gustafsson et al., 2016, p. 12); it has been advocated for more than 25 years, though with relatively modest progress (Gustafsson and Bowen, 2017; Ostrom et al., 2015). Rather than being pursued as a goal in itself, interdisciplinary research should function as a tool to reach a goal (Gustafsson and Bowen, 2017). To both leverage the advantages and overcome the challenges of interdisciplinary research, this dissertation (1) builds on past research on co-creation while embracing new aspects, (2) combines rigorou academic approaches with practical relevance, (3) pursues insights that reflect specific as well as broad knowledge, and (4) seeks to shift the very way co-creation is understood and applied in practice (Gustafsson and Bowen, 2017).

As Figure I.3 illustrates, the chapters in this dissertation leverage various perspectives, concepts, methods, and data gathered from the interrelated disciplines of service management/ marketing, service innovation, and service design. In turn, this dissertation develops a holistic understanding of the co-creation of services, acknowledges the complexity of modern services co-creation topics, and seeks to reach a wide audience. First, service management/marketing comprises the end-to-end management and facilitation of services, or value-supporting processes (Grönroos, 2006). Generally, the focus is on the interaction of the service provider with the customer, though other, related actors also may be included. Even as they become progressively more people-centred, concepts such as "offering," "customer participation," or even the "customer" remain mostly provider-oriented (Strandvik et al., 2012). Second, the adjoining research discipline of service innovation focuses on developing new services or improving

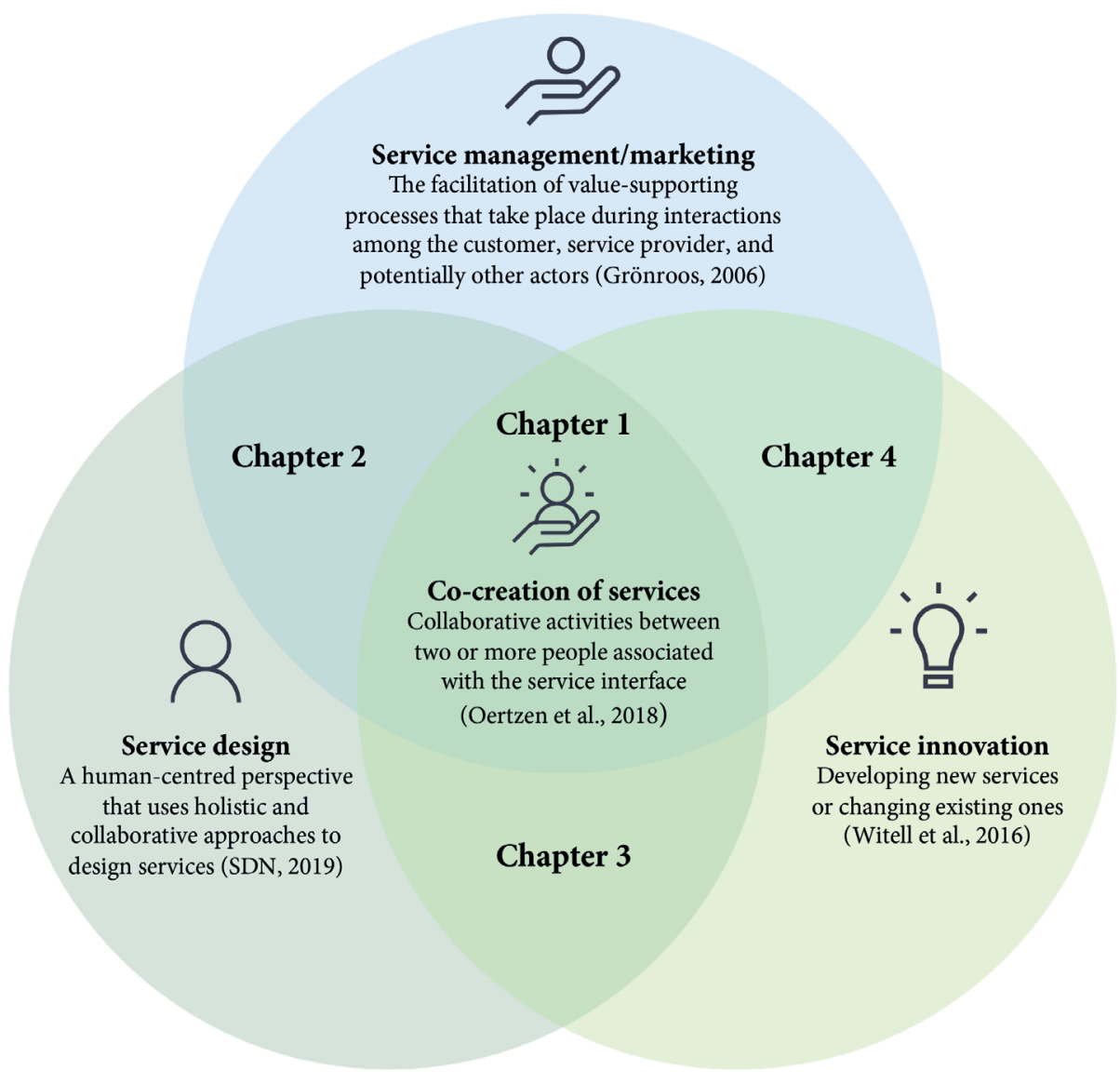

Figure I.3. Interdisciplinary approach 
existing ones (Witell et al., 2016). Recent efforts acknowledge that service innovations emerge from joint actions across a network, rather than within organisational borders, and highlight the creation of value and experiences beyond an innovation's features (Lusch and Nambisan, 2015). An invention must generate some profit or be applied in practice to be termed an innovation (Schumpeter, 1934; Toivonen and Tuominen, 2009). Third, instead of talking about customers, service design addresses people or users, pertaining to the development of people-centred systems by engaging people affected by these systems (Segelström, 2013). Historically, design served mainly stylistic or aesthetic purposes; today, its value as a process or strategy is evident, especially when designing services (Mager and Sung, 2011). Its humancentred perspective helps orchestrate people, processes, and interfaces through collaborative, contextual, and holistic properties (SDN, 2019). That is, service design aims strategically to innovate new and existing services by striking a balance across human needs, technologica capabilities, and business considerations (Stickdorn et al., 2018). Reflecting the differen research traditions and terminology contained within these three disciplines, Chapters 1-4 use terms such as customer, actor, user, and people synonymously, to refer to parties involved in co-creation.

\section{Empirical Context}

This dissertation investigates services co-creation in different empirical contexts (Table I.1) Chapters 1 and 2 (Study 2) take a generalist perspective, across various service industries; Chapters 2 (Study 1), 3, and 4 focus specifically on the fashion, healthcare, and finance industries, respectively. These service industries share similar settings, in the sense that they increasingly recognise the importance of co-creating services with multiple actors (Martovoy and Santos, 2012; McColl-Kennedy et al., 2017a; Ramaswamy and Gouillart, 2010). They also share a common theme of interactions during co-creation, the prioritisation of personal topics (Kellogg and Chase, 1995), and efforts to foster active, multi-directional, genuine dialogue. With a fundamental understanding that meeting people's needs requires services that have been informed by those people's unique, situated experiences, the studied empirical contexts provid a comprehensive view of different settings and activities for services co-creation. Furthermore, scholars and practitioners in these settings have identified ways to develop and deliver peoplecentric services and gain a competitive edge through co-creation efforts, from designing shoes (Ramaswamy and Gouillart, 2010), to creating a digital mental health service (Patrício et al., 2019), to personalising financial services (Mainardes et al., 2017).

Nevertheless, the specific service settings also feature informative differences, including their utilitarian/hedonic nature and the level of emotional involvement required. Utilitarian services generally are rational, functional, and efficient, designed to fulfil some necessary need; hedonic services meet needs for personal pleasure, enjoyment, or luxury (Babin et al., 1994). With regard to emotional involvement, the healthcare service setting in Chapter 3 explores initiatives
Table I.1. Empirical contexts of the chapters

\begin{tabular}{|c|c|c|c|c|c|c|}
\hline Part & $\begin{array}{l}\text { Service } \\
\text { industry }\end{array}$ & $\begin{array}{l}\text { Service } \\
\text { setting }\end{array}$ & Interaction & $\begin{array}{l}\text { Communication } \\
\text { direction }\end{array}$ & $\begin{array}{l}\text { Consumption } \\
\text { purpose }\end{array}$ & $\begin{array}{l}\text { Emotional } \\
\text { involvement }\end{array}$ \\
\hline $\begin{array}{l}\text { Chapter } 2 \\
\text { (Study 1) }\end{array}$ & Fashion & $\begin{array}{l}\text { Designing } \\
\text { sport shoes }\end{array}$ & Personal & $\begin{array}{l}\text { Multi- } \\
\text { directional }\end{array}$ & Hedonic & Low \\
\hline Chapter 3 & Healthcare & $\begin{array}{l}\text { Innovating } \\
\text { diverse } \\
\text { healthcare } \\
\text { services }\end{array}$ & Personal & $\begin{array}{l}\text { Multi- } \\
\text { directional }\end{array}$ & Utilitarian & High \\
\hline Chapter 4 & Finance & $\begin{array}{l}\text { Using } \\
\text { the electronic } \\
\text { post-box of } \\
\text { online banking }\end{array}$ & Personal & $\begin{array}{l}\text { Multi- } \\
\text { directional }\end{array}$ & Utilitarian & Low \\
\hline $\begin{array}{l}\text { Guiding } \\
\text { metaphor }\end{array}$ & Construction & $\begin{array}{l}\text { Building } \\
\text { a house and } \\
\text { living in it }\end{array}$ & Personal & $\begin{array}{l}\text { Multi- } \\
\text { directional }\end{array}$ & $\begin{array}{l}\text { Hedonic/ } \\
\text { utilitarian }\end{array}$ & High \\
\hline
\end{tabular}

that are deeply critical to people's everyday well-being, implying a very high level of emotional involvement. Designing a sports shoe (Chapter 2) demands much less emotional involvement. By varying the consumption purposes and levels of emotional involvement across studies, this dissertation produces more generalisable findings and supports some holistic conclusions across service industries in the concluding chapter.

The underlying metaphor, building a house, functions to facilitate theorising across the individual chapters and establishing synergies among them. Its intuitive, flexible application aims to emphasise different aspects of services co-creation. Construction services and the specific setting of building and living in a house offer an illustrative case that includes both utilitarian and hedonic elements, involves both short-term decisions and extended consumption, and requires intensive co-creation efforts among a myriad of actors.

\section{Overview}

Following this introduction, four chapters report on separate studies, after which this dissertation concludes with a synopsis of the key premises and their synthesis into holistic conclusions. Table I.2 outlines the research purpose of each chapter, corresponding to the research gaps in Figure I.2. In Chapter 1, I introduce a new definition for the co-creation of services and differentiate its potential outcomes. I identify the drivers of services cocreation, as well as evaluate the underlying dynamics, in Chapters 2 and 3. Chapter 4 completes the empirical part of the dissertation, such that I investigate continued usage of co-creative 
Table I.2. Overview of the chapters

\begin{tabular}{|c|c|c|c|c|}
\hline Part & Chapter 1 & Chapter 2 & Chapter 3 & Chapter 4 \\
\hline Purpose & $\begin{array}{l}\text { Introduce a definition and differentiate } \\
\text { the outcomes of co-creating services }\end{array}$ & $\begin{array}{l}\text { Identify the drivers of } \\
\text { co-creating services }\end{array}$ & Evaluate the dynamics of co-creating services & Investigate continued usage of co-creative services \\
\hline Phase of the service process & $\begin{array}{l}\text { Design, development, delivery, and } \\
\text { consumption of services }\end{array}$ & $\begin{array}{l}\text { Design, development, delivery, and } \\
\text { consumption of services }\end{array}$ & Design and development of services & Delivery and consumption of services \\
\hline Perspective & Dyad (customer and service provider) & $\begin{array}{l}\text { Dyad (participating and } \\
\text { facilitating parties) }\end{array}$ & Multi-actor & Customer \\
\hline Research design & Qualitative & (1) Quantitative and (2) qualitative & Qualitative & Quantitative \\
\hline Method & Focused literature review & $\begin{array}{l}\text { (1) Scenario-based experiments } \\
\text { (2) Interactive research workshops } \\
\text { using the critical incident technique, } \\
\text { affinity mapping technique, and } \\
\text { projective technique }\end{array}$ & Phenomenological interviews & Cross-sectional survey \\
\hline Sample & $\begin{array}{l}80 \text { qualifying articles of five service } \\
\text { research journals }\end{array}$ & $\begin{array}{l}\text { (1) } 633 \text { participants recruited } \\
\text { through a high-quality } \\
\text { consumer panel } \\
\text { (2) } 38 \text { design professionals recruited } \\
\text { through a hosted service } \\
\text { design event }\end{array}$ & $\begin{array}{l}23 \text { patients, family caregivers, designers, and } \\
\text { healthcare professionals recruited through two } \\
\text { institutions in Sweden and Portugal }\end{array}$ & 750 customers recruited through a large bank \\
\hline Participants' location & - & Western Europe & Europe, Africa, USA & Germany \\
\hline Analysis & Thematic analyses & $\begin{array}{l}\text { Quantitative: Partial least squares } \\
\text { structural equation modelling } \\
\text { Qualitative: General } \\
\text { inductive approach }\end{array}$ & Hermeneutic analyses & Structural equation modelling \\
\hline Publication status & $\begin{array}{l}\text { Oertzen, A.-S., Odekerken-Schröder, } \\
\text { G., Brax, S.A., and Mager, B. (2018), } \\
\text { "Co-creating services-conceptual } \\
\text { clarification, forms, and outcomes", } \\
\text { Journal of Service Management, } \\
\text { Vol. } 29 \text { No. 4, pp. 641-679. }\end{array}$ & $\begin{array}{l}\text { Oertzen, A.-S., Odekerken-Schröder, } \\
\text { G., and Mager, B. (forthcoming), } \\
\text { "Driving users' behaviours and } \\
\text { engagement in co-creating services", } \\
\text { accepted for publication in Journal of } \\
\text { Services Marketing. }\end{array}$ & $\begin{array}{l}\text { Oertzen, A.-S., Vink, J., Odekerken-Schröder, G., } \\
\text { Mager, B., and Azevedo, S. (2019), "Live and let live: } \\
\text { integrating lived experience through co-creation in } \\
\text { healthcare innovation", submission-ready. }\end{array}$ & $\begin{array}{l}\text { Oertzen, A.-S. and Odekerken-Schröder, G. (2019), } \\
\text { "Achieving continued usage in online banking: } \\
\text { a post-adoption study", International Journal of Bank } \\
\text { Marketing, Vol. } 37 \text { No. 6, pp. 1394-1418. }\end{array}$ \\
\hline
\end{tabular}

services. Each individual chapter focuses either on co-creation in earlier phases of the service process, related to the design and development of services; on later phases pertaining to delivery and consumption; or else on the entire service process. They address different views, across customer, dyadic, and multi-actor perspectives.

The four chapters also explicitly adopt different research designs, ranging from in-depth qualitative explorations to quantitative studies with large samples. In Chapter 1, a focused literature review of five service research journals enables synthesising the insights of 80 qualifying articles, according to thematic analyses. Chapter 2 reports on scenariobased experiments with 633 participants, recruited from a high-quality consumer panel, and analyses the data with partial least squares structural equation modelling. Inductive analyses also are conducted of feedback obtained from 38 design professionals, who attended interactive research workshops hosted specifically for this research and generated insights through critical incident, affinity mapping, and projective techniques. Chapter 3 draws on 23 in-depth, phenomenological interviews with patients, family caregivers, designers, and healthcare professionals, synthesising their rich descriptions through hermeneutic analyses. Finally, Chapter 4 relies on structural equation modelling of input from 750 current customers of a large bank who participated in cross-sectional surveying. The different data collection methods, samples, and analyses strengthen the external validity of the findings (Lynch 1999). In the following detailed overviews, I note the interdisciplinary aspects, outcomes, and contributions of each chapter in greater depth. 


\section{Overview of Chapter 1}

\section{Co-Creating Services-Conceptual Clarification} Forms, and Outcomes

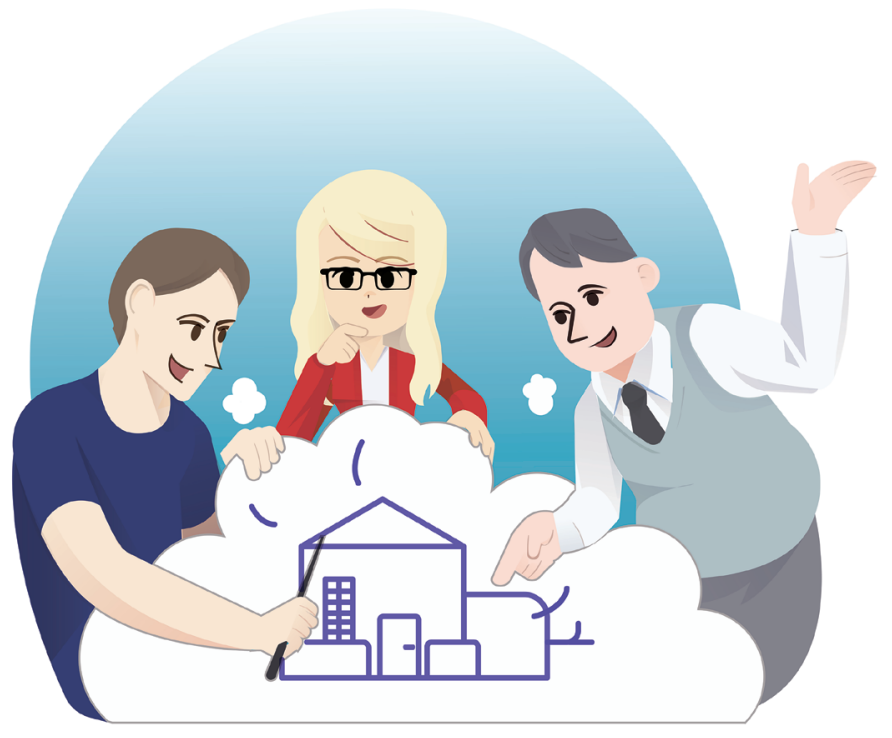

Before starting to build a house, the concept and design of the house have to be planned, documented, and shared with different people. Many aspects have to be considered, such as administrative, legal, and ecological aspects. The person contracting the builder, the builder constructing the house, and other parties that have a stake in it have to settle on the envisioned outcomes, making sure they match financial and bureaucratic boundaries, while also satisfying people's needs and wishes.
Similar to a mutually agreed upon concept for building a house, the first chapter of this dissertation begins by developing a shared definition for co-creating services, grounded in extant service research. Drawing on service management/marketing, service innovation, and service design perspectives, the shared definition provides a foundation for this dissertation, building on the interdisciplinary body of prior knowledge about co-creation, to shape continued research into the concept. Perceptions of what co-creation entails and the terminology used both vary widely in academia; some service marketing scholars refer to the creation of value at a more abstract level (Grönroos and Voima, 2013; Vargo and Lusch, 2016), but many service innovation studies specify co-creation as the joint development of services (Witell et al., 2011), and in service design research, it often refers to any form of collective creativity (Steen et al., 2011). The focused literature review of 80 articles published in five SSCI-rated, non-industryspecific service research journals in Chapter 1 produces a thematic analysis of these various conceptualisations of co-creation and related terminology. As a foundation for further studies, it proposes the following definition of co-creating services in a business context, as has been published in Journal of Service Management:

"The co-creation of services denotes collaborative activities in the customerprovider interface associated with the service; it necessitates the involvement, engagement, and participation of at least one customer and one service provider and may lead to beneficial and/or counterproductive outcomes through resource integration. In services, co-creation manifests itself in different forms depending on the phases of the service process (co-ideation, co-valuation, co-design, co-test co-launch, co-production, and co-consumption) and is influenced by a contextual, multi-actor network." (Oertzen et al., 2018, p. 657)

Analogous to settling on the envisioned design of a house, Chapter 1 also seeks to better understand what co-creation could lead to by providing an overview of the outcomes of cocreating services, which have not been broadly examined or consolidated before (Voorberg et al., 2015). This overview is grounded in the focused literature review; the 80 qualifying articles report 171 individual observations, capturing a broad range of co-creation outcomes. The final typology reveals that scholarly contributions emphasise personal, social, and pragmatic benefits for customers, as well as cognitive, economic, and pragmatic benefits for service providers. Counterproductive outcomes receive much less scholarly attention, and these studies mention only a few social and hedonic outcomes for customers or personal, social, economic, and pragmatic outcomes for service providers.

The proposed definition of co-creating services in turn is important for service research, to enable a shared understanding of co-creation (Saarijärvi et al., 2013) and support further interdisciplinary inquiry. The typology of outcomes strengthens and synthesises findings from previous studies, justifying further research by demonstrating the broad spectrum of possible beneficial outcomes, which legitimates the importance and relevance of the phenomenon 


\section{Overview of Chapter 2}

\section{Driving Users' Behaviours and Engagement in} Co-Creating Services

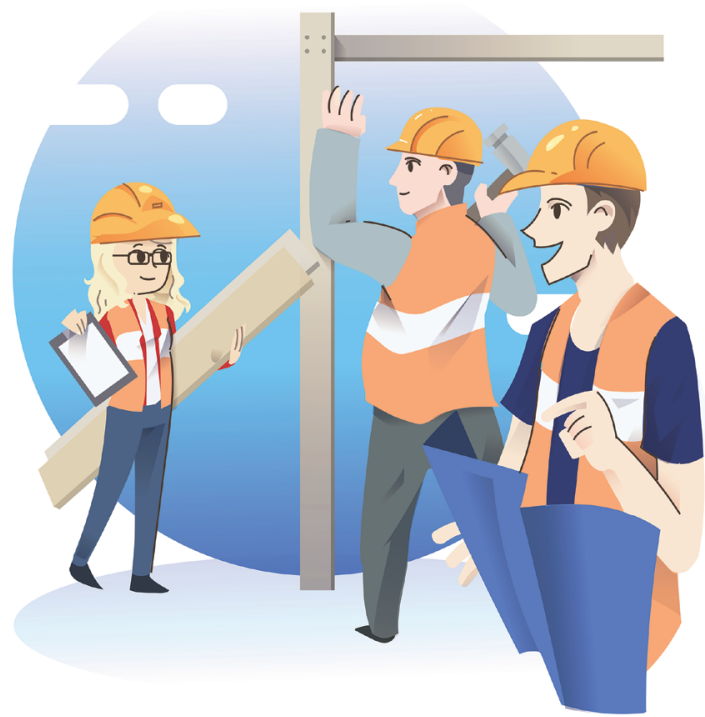

Once theoretical planning of the house has finished, the building starts, which requires workers who can construct the house. They must be motivated or stimulated to work together, because a house cannot be constructed in separate sections. All the elements are interconnected. Choosing the right people and getting them to engage in the collaboration to produce the end result is essential to success and a well-built structure.
After reviewing service research literature and preparing a common foundation in Chapter 1 , Chapter 2 turns to investigating the process of co-creating services with primary data and proposes that, comparable to construction workers jointly building a house, users participating in co-creation are critical to success, as are their specific behaviours and level of engagement. Yet there is a dearth of knowledge about who participates in co-creation and why, differences between participants and non-participants, and the sources of such differences (Füller, 2010) In particular, it remains unclear how to get "normal" users-that is, non-lead users (Enkel et al., 2005) - to engage in co-creation or which types of users are more likely to co-create, as a result of their personality traits and demographics (Füller et al., 2008; Neghina et al., 2017). Accordingly, Chapter 2 investigates which factors determine users' behaviours during services co-creation, as well as which ones might influence their engagement in such efforts.

To identify factors that encourage collaboration and enable purposeful selections of potential collaborators, I draw on research methodologies and data from service management/ marketing and service design. First, between-subjects, scenario-based experiments involve 633 participants recruited from a high-quality consumer panel in Western Europe. The data analyses rely on partial least squares structural equation modelling to identify factors that influence users' behaviours during co-creation. Second, 38 design professionals participated in two interactive research workshops, held as part of a service design event in Western Europe but designed to support this study. Critical incident and affinity mapping techniques reveal which factors influence users' co-creation engagement; projective techniques uncover the likelihood that different types of users will co-create.

The findings show that users' co-creation behaviours are influenced by their demographics and personality traits. Co-creation engagement can be driven or inhibited by factors related to the participating party (e.g., user) and to the facilitating party (e.g., service designer). For both parties, key factors entail aspects pertinent to the individual person, the co-creation context, or the co-creation activity. The resulting typology of personas and anti-personas specifies different users' likelihood to engage in co-creation, according to their personality traits and demographics. These insights can guide service designers and service providers to design more effective co-creation activities for different kinds of users, build conducive working environments, and select suitable users for their co-creation activities. Improving these practices ultimately can reduce the time and money needed to identify and integrate users in services co-creation, and it increases the chances of successful outcomes. 


\section{Overview of Chapter 3}

Live and Let Live: Integrating Lived Experience through Co-Creation in Healthcare Innovation

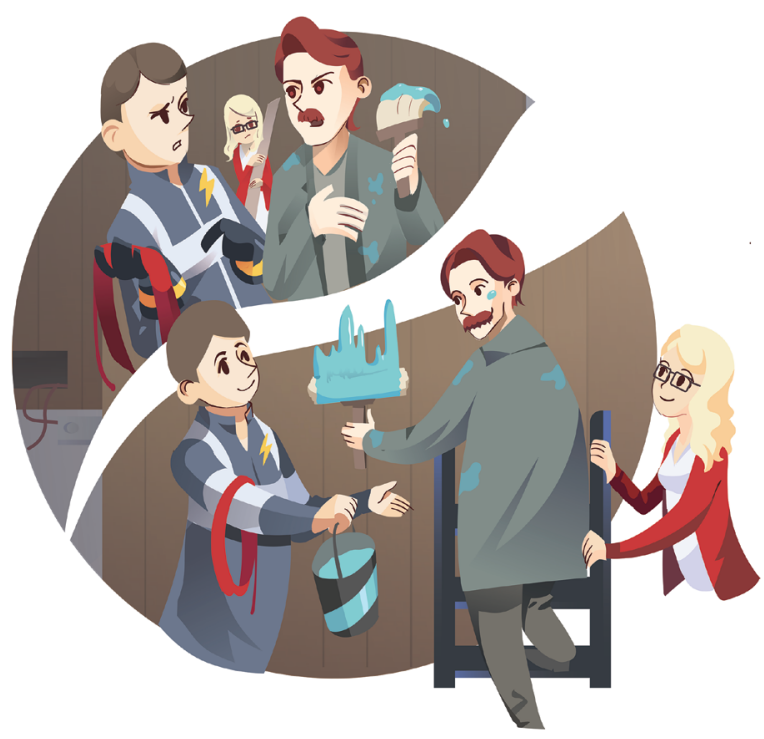

Building a house is a complex endeavour, and tensions often arise over permissions or finances, with neighbours, or among construction workers building the house. During the design and construction phase, the hiring process purposefully seeks out workers with the knowledge and skills required to build parts of the house. It can be

challenging to integrate these different knowledge sources though, due to power dynamics or misunderstandings. To navigate these tensions, the home-building team might employ several strategies, often unconsciously, such as empathising with someone else's position or actively exchanging experiences with one another.
Chapter 2 emphasises the importance of selecting and engaging suitable people in $\mathrm{co}_{-}$ creation, however it does not investigate how these people interact with one another during co-creation activities. In the metaphorical example, once suitable workers have been identified and contracted to construct the house, their interactions to integrate their varied knowledge largely determine how the building progresses. People co-create through interactions by sharing, building, and reflecting on their own lived experience, defined as direct, first-hand understanding of a certain condition, situation, or identity. Despite a general consensus about the importance of integrating people's lived experience in the design and development of services, the actual process of co-creating with multiple people when innovating services has received little research attention, which impedes effective management of the co-creation process (Kazadi et al., 2016; Witell et al., 2011). Especially in service settings that tend to prompt substantial emotional involvement, it is essential to integrate people's lived experience into the design and development of services to ensure that the resulting services meet their needs. As Table I.1 depicts, healthcare services are commonly associated with strong emotional intensity; patients who need these services often feel vulnerable due to their illness and lack of control over their own well-being (Anderson et al., 2018). Accordingly, Chapter 3 offers detailed insights into ways to integrate people's lived experience through co-creation in healthcare innovation.

To do so, it draws on the qualitative research traditions of service design and service innovation. To gain a deeper understanding of the general context and diverse spectrum of lived experience, my co-authors and I immersed ourselves in two healthcare organisations in Portugal and Sweden that offer good examples of the growing global movement towards people-centred health services. These local immersions lasted between five months and one year, and they allowed us to conduct phenomenological interviews with 23 patients, designers, family caregivers, and healthcare professionals who engage in co-creation efforts for diverse healthcare innovation initiatives. Hermeneutic analyses then synthesise the insights from these interviews into six tensions and seven strategies for integrating people's lived experience through co-creation in healthcare innovation.

The findings contribute to discourse about the process of co-creation (Gustafsson et al., 2012) by identifying the underlying dynamics of integrating people's lived experience and its practical tensions. They extend recent service research pertaining to how patients and family caregivers contribute to service innovation by demonstrating various strategies that people adopt to integrate lived experience in co-creation (McColl-Kennedy et al., 2017a). By suggesting ways to navigate the complex dynamics underlying co-creation efforts in healthcare innovation, this chapter supports a transformation of healthcare systems, from paternalistic control to shared decision-making models (Lukersmith et al., 2016), in a way that is safe, inclusive, and strategic 


\section{Overview of Chapter 4}

\section{Achieving Continued Usage in Online Banking:} A Post-Adoption Study

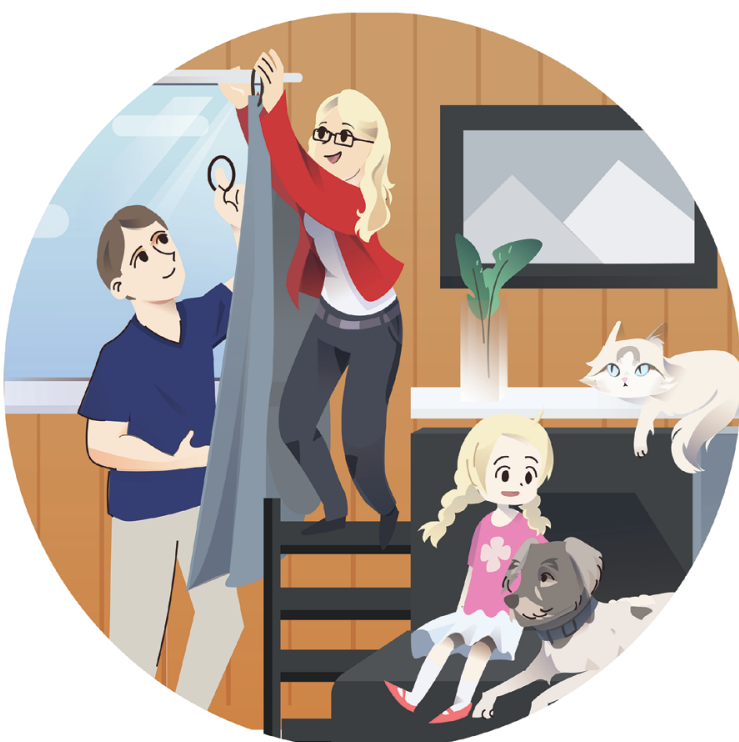

Once the house has been built, through the efforts of many, the new residents need to tailor it to their needs and preferences. After moving in, they continue to interact with different elements, whether by adding décor or planting a garden. They also interact with one another and other actors who might support their efforts. In the long term, these relationships that people form, with and within the house, transform a newly built house into a true home.
While Chapter 3 explores co-creation to design and develop services, Chapter 4 zooms in on co-creation in later stages of the service process, pertaining to the delivery and consumption of services. When building a house, after the planning and building periods, people move in and finally enter the living phase, during which they make the house their home. Continued interactions with and within the house, often over years or decades, allow people to build long-term relationships that in turn determine much of the house's value to them. Similarly, most innovations have value not because of some initial, brilliant idea but rather due to continued usage and the resulting relationships with service providers and other actors (Hausman and Johnston, 2014). This is also the case for co-creative services that customer continuously interact with over time, but with relatively low emotional involvement. An exemplary service is online banking (Table I.1), which is commonly accepted and routinely used (Al-Somali et al., 2009; Patel and Patel, 2018), and its worth stems not from the initia idea but rather from continued interactions that determine its success (Patel and Patel, 2018) Customers' decision to adopt online banking has been the subject of many studies, but the postadoption phase, after the initial adoption decision, that focuses on continued usage tends to be neglected (Tam and Oliveira, 2017a). Chapter 4 thus aims to determine factors that drive continued usage of a co-creative feature of online banking, which ultimately might enhance both customer retention and banking services (Mainardes et al., 2017; Martovoy and Sa ntos, 2012)

For this empirical study, I draw on perspectives and concepts from service management/ marketing and innovation adoption literature to develop a post-adoption model of the electronic postbox (e-postbox), a newly introduced, co-creative feature of online banking services. I test the model using structural equation modelling and a sample of 750 current customers of the e-postbox of a large German bank. The findings contribute to service research by holistically predicting post-adoption behaviours according to multiple task-, organisation-, and interpersonal communication-related drivers, as well as post-adoption attitudes. Service providers thus can gain a better understanding of how to encourage continued usage of a co-creative service, which affects their retention of current customers and attraction of new customers, ultimately enabling and supporting long-term relationships (Oertzen and Odekerken-Schröder, 2019).

In summary, and reapplying the metaphor of building a house, across these four chapters and diverse studies, I address efforts to plan the concept of the house and envision the outcomes, contract and engage workers to build the house collaboratively, overcome challenges when integrating the knowledge provided by different workers during the construction of the house, and form relationships with and within the house to make it a home. Analogously, I advance academic and practical discourses on the benefits and process of co-creating services by exploring a common definition of co-creating services, possible outcomes, drivers of co-creation behaviours and engagement, underlying dynamics in the form of tensions and strategies for integrating people's lived experience, and finally the continued usage of co-creative services. 


\section{Chapter 1}

\section{Co-Creating Services-Conceptual Clarification,}

Forms, and Outcomes

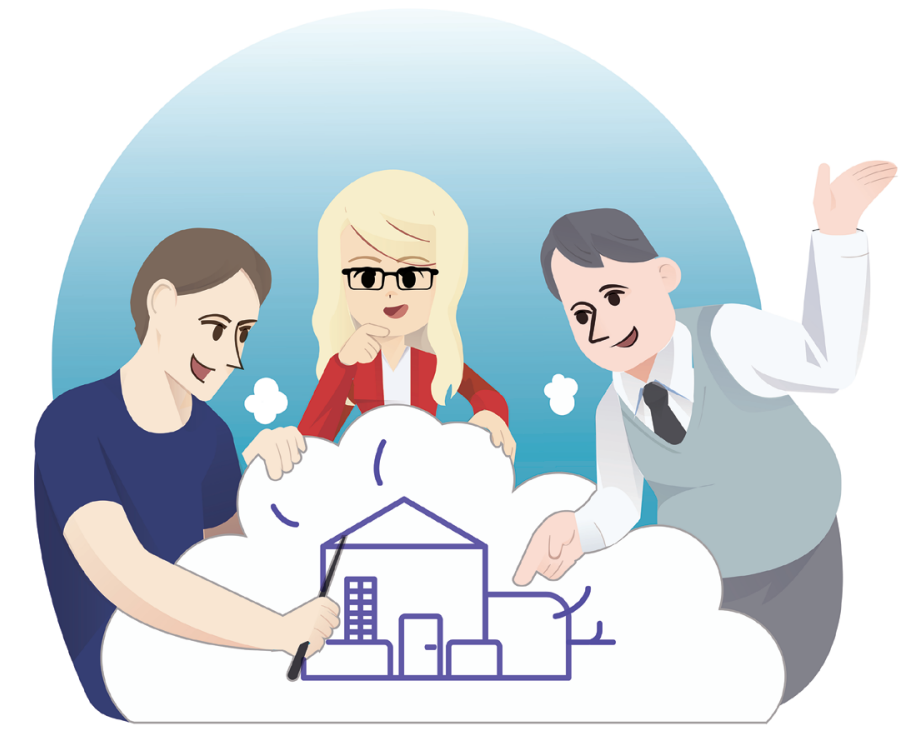

At the start of any building project, a mutually agreed on concept has to be designed and documented. The planned design is shared with different people, who integrate their ideas and to ensure compliance with administrative, legal, and ecological requirements. The person contracting the builder, the builder constructing administrative, legal, and ecological requirements. The person contracting the builder, the builder constructing
the house, and other parties that have a stake in it settle on the envisioned outcomes, in accordance with financial and bureaucratic boundaries, while satisfying people's needs and wishes. Analogously, this chapter seeks to develop a shared definition for the concept of co-creating services and to provide an overview of its possible outcomes. With a focused literature review, it assesses, clarifies, and consolidates the terminology around the co-creation of services

in existing service research, establishes its forms, and identifies its outcomes. 


\section{Chapter 1}

\section{Co-Creating Services-Conceptual Clarification,}

Forms, and Outcomes

Anna-Sophie Oertzen ${ }^{1,2}$, Gaby Odekerken-Schröder ${ }^{1}$, Saara A. Brax ${ }^{3}$, and Birgit Mager ${ }^{2}$

${ }^{1}$ Department of Marketing and Supply Chain Management, School of Business and Economics, Maastricht University, Maastricht, The Netherlands

${ }^{2}$ Köln International School of Design, Technical University of Applied Sciences Cologne, Cologne, Germany

${ }^{3}$ School of Business and Management, Lappeenranta University of Technology, Lappeenranta, Finland 


\section{Introduction}

Organisations are increasingly adopting strategies to co-create with their customers: to improve the service experience, DHL hosts co-design workshops with customers; LEGO develops new offerings with lead users; and Netflix launched a competition to improve its services with its online community (Chesbrough, 2011; DHL Solutions \& Innovations, 2017; Prpić et al., 2015). Co-creation is rooted in the verb create, which is defined as bringing something into existence, causing something to happen as a result of one's actions, and in $c 0-$-, which means together with another or others (Oxford Dictionaries, 2018). In service management, co-creation refers to the service process and the service product; service providers aim to co-create with customers and other actors to create distinctive services, reduce costs, or improve service performance. Co-creation has become a central theme in service management literature because customers and other actors function as active participants in services (Galvagno and Dalli, 2014; Grönroos and Voima, 2013; Vargo and Lusch, 2016).

The first chapter of this dissertation sets out to organise the conceptual pluralism hindering the development of the research topic. Despite the increasing attention on the concept of cocreation in services, the published reviews (e.g., Galvagno and Dalli, 2014; Ranjan and Read, 2016; Voorberg et al., 2015), and the conceptual works (e.g., Grönroos and Voima, 2013; Payne et al., 2008; Prahalad and Ramaswamy, 2004a, b), the extant literature has not been consolidated into a shared definition and a comprehensive analysis of the phenomenon. This causes different delineations to proliferate, increasing confusion around "co-creation" (Dong and Sivakumar, 2017; Saarijärvi et al., 2013; Voorberg et al., 2015).

The purpose of the current research is to synthesise and develop knowledge about the cocreation of services, that is, the activity, practice, or process of jointly creating services in specific business contexts. Here, co-creation of services is not examined as the abstract and universa principle of value creation often manifested in the literature inspired by the service-dominant (S-D) logic approach (cf. Vargo and Lusch, 2004), but as an optional collaborative act in the customer-provider interface (a detailed discussion follows in the subsequent section). This research, in turn, makes a clear distinction between the co-creation of value and the cocreation of services. The value co-creation view presumes that the provider joins the customer's value creation activities as a co-creator of value during the consumption process (Grönroos and Voima, 2013). The co-creation of services view does not specify whether the provider joins the customer's sphere or vice versa; instead, it concentrates on the mutual creation of services during service processes and service innovation activities.

To transform the relatively abstract discussions on co-creating services to applicable frameworks serving further theoretical and practical analyses, the present research considers three main questions: 
RQ1. How does the concept of the "co-creation of services" relate to other terms that address the collaboration of the service provider and the customer(s) in a service process or a service event?

RQ2. How can the co-creation of services be defined?

RQ3. What outcomes may follow from co-creating services?

In line with MacInnis' (2011) notion of different types of conceptual advancement, the present study offers four contributions to service management literature: first, it reduces conceptual pluralism around co-creating services by delineating its relationship to related terminology, such as involvement, engagement, participation, co-design, co-production, and co-consumption; second, it identifies an explicit definition of the co-creation of services; third, it provides a differentiated terminology on the outcomes from co-creating services; and finally, it develops an integrative framework that offers a holistic explanation of the co-creation of services.

In response to the research questions, the current focused literature review builds on extan conceptualisations of co-creation and related terminology in service literature. This focused review imitates the systematic review method (SLR) but is not framed as exhaustively; to effectively direct the focus of the analysis on co-creation of services and to ensure the analysis focuses on high-quality scholarly contributions, the study targets the five Social Science Citation Index (SSCI) rated "generic," i.e., not industry specific, service research journals: Journal of Service Management, Journal of Services Marketing, Journal of Service Research Journal of Service Theory and Practice, and Service Industries Journal.

This chapter begins with an overview of the services research literature that examine the collaborative act in the customer-provider interface, outlining its evolution and pointing tensions. This is followed by the methodology section, which explains the focused literature review approach. Moving to the findings, first the terminology parallel to or corresponding with co-creation of services is examined and reflected against the broader literature base. Second, the results of the thematic analysis of qualifying articles that discovers 63 conceptualisation of co-creation and related terminology are reported and an explicit definition of co-creating services is developed. Third, the review results extend Verleye's (2015) work on the dimensions of the co-creation experience by arranging both beneficial and counterproductive outcomes in the literature into a typology of outcomes in co-creating services in a business context. Finally, the findings of the focused literature review are combined into an integrative conceptua framework. The research concludes by discussing promising opportunities for service research, managerial takeaways, and limitations.

\section{Evolution and Tensions of the Services Co-Creation Literature}

The participation or involvement of customers in the processes of service providers has been a much-discussed topic for decades. Fuchs (1968) was the first to specifically propose the consumer as a factor in production in his seminal work on the service economy. In the 1970s, Levitt (1976) and Lovelock and Young (1979) suggested industrialising personal service to improve productivity for providers. In the 1980s, to increase productivity and customer satisfaction, Mills and Morris (1986) recommended considering customers as temporary, partial employees. In the 1990s, Dabholkar (1990) and Cermak et al. (1994) claimed that the inclusion of customers in the service production and delivery phases enhances service quality perceptions, repurchases, and referrals.

The current analysis recognises that with the start of the 2000s, the mind-set around customer-provider collaboration shifted. Instead of viewing customers as productivity inputs and resources to rationalise production processes (here labelled as the first generation perspective), they were more broadly recognised as active collaborators in the business system and co-creation efforts became emphasised as the next frontier of competitive strategy (second generation) (Bendapudi and Leone, 2003; Prahalad and Ramaswamy, 2000, 2004a; Zwick et al. 2008). Table 1.1 provides a detailed comparison of the two generations of theorising around the collaborative act in the customer-provider interface.

While the first generation view considers the customer as a temporary participant and resource in the actual service process (Kelley et al., 1990; Mills and Morris, 1986), the second generation promotes involving the customer in the service system more broadly and in various stages and functions of the service value chain. This involvement of customers can extend throughout the entire innovation process for a service, from idea generation to the end use (Mele et al., 2014). Correspondingly, the communication between the provider and customer has evolved from sporadic, unidirectional, and less transparent to frequent, bidirectional, and transparent dialogue (Chathoth et al., 2013; Gustafsson et al., 2012; Prahalad and Ramaswamy, 2004a). Both parties must perceive their relationship as beneficial in order to continue (De Wulf et al., 2001), which highlights the customer as part of the social relations of production (Zwick et al., 2008).

These generations of thought are reflected in the normative and managerially targeted content in this body of knowledge. During the first generation of customer-provider collaboration the collaboration was steered by a provider-centric mind-set (Dabholkar, 1990; Lovelock and Young, 1979). This changed with the second generation; the collaboration focus is now rather oriented towards the customer and experiences (Chathoth et al., 2013; Prahalad, 2004). With a change in focus came also a transformation in collaboration initiation. Before, the provider enabled and invited the customer to participate (Normann and Ramirez, 1993; Ramirez, 1999). This changed to a more variable constellation, in which the provider or the customer may initiate collaboration (Kazadi et al., 2016; Oliveira and von Hippel, 2011), the provider may only offer the platform for collaboration (Ogawa and Piller, 2006), or the customer may engage in collaboration outside of the provider focus (Zwass, 2010). 
Another important facet of the evolvement is that the customer-provider collaboration developed from a focus on the dyad to a more encompassing picture that considers the influence of a multi-actor context (Mills and Morris, 1986; Pirinen, 2016). The service context is described as a multifaceted and dynamic social and economic system that is composed of an actor network and guiding institutions (Akaka and Vargo, 2015).

Finally, the desired outcomes following the process of co-creating services have changed from mainly economical nature (Dabholkar, 1990; Lovelock and Young, 1979) to being much more multidimensional. For the second generation of customer-provider collaboration, desired outcomes are considered for both the provider and the customer, and they anticipate wellbeing, relationship quality, and innovation, among others (Engström and Elg, 2015; Ordanini and Parasuraman, 2011; So et al., 2016).

Changes in the style of debate can also be associated with the generations of thought. During the first generation, the tension is framed between the establishing service field towards the traditional disciplines that, allegedly, considered goods and service contexts as no different. After entering the second generation view of co-creation, tensions were reframed within the stream of service research. In particular, current literature features an ongoing debate about the true meaning of co-creation (Galvagno and Dalli, 2014), marked by a lack of conceptual clarity between two perspectives; whether co-creation denotes the joint creation of services or the creation of value at a more abstract level (Mustak et al., 2013). This tension is apparent in the discourse between the S-D logic and its rival theories. The S-D logic insinuates that the customer is always a co-creator of value (Vargo and Lusch, 2004, 2008, 2016). Grönroos and co-authors developed a competing view; their service logic suggests that value co-creation occurs more specifically in the joint sphere of customer-provider interaction (Grönroos and Ravald, 2011; Grönroos and Voima, 2013).

Besides the debate on the conceptual clarification of co-creation, there is dispute on the forms of co-creation. While some publications implicitly assume that co-creation is the same as involvement, participation, or co-production (Chang and Taylor, 2016; Dong and Sivakumar, 2017; Voorberg et al., 2015), other publications argue that the terms differ (Etgar, 2008; Grönroos and Voima, 2013; Lusch and Vargo, 2006). The inconsistent use of terms to signify the collaborative act in the customer-provider interface has led to conceptual pluralism in the service management domain. This can reduce consistency and decelerates the development of contributions to the topic.

Finally, existing conceptual overviews have not broadly analysed and consolidated the potential, realistic outcomes of co-creating services (Voorberg et al., 2015). The interactive nature of services urges managers to understand co-creation to target the right customers and to recognise the expected benefits (Matthing et al., 2004). By co-creating services, service providers can realise beneficial outcomes, such as gaining a better understanding of their
Table 1.1. Two generations of provider-customer collaboration

\begin{tabular}{|c|c|c|c|}
\hline & & $\begin{array}{l}\text { 1st generation on customer-provider } \\
\text { collaboration }\end{array}$ & $\begin{array}{l}\text { 2nd generation on customer-provider } \\
\text { collaboration }\end{array}$ \\
\hline (1) & $\begin{array}{l}\text { Representation } \\
\text { of terminology }\end{array}$ & $\begin{array}{l}\text { Customer involvement, customer } \\
\text { participation, co-production, customers } \\
\text { as (partial) employees, joint production }\end{array}$ & $\begin{array}{l}\text { Customer involvement, customer } \\
\text { participation, co-creation, co- } \\
\text { innovation, co-ideation, co-valuation, } \\
\text { co-design, co-test, co-launch, } \\
\text { co-investment, co-production, co- } \\
\text { consumption }\end{array}$ \\
\hline (2) & $\begin{array}{l}\text { Collaboration } \\
\text { duration }\end{array}$ & $\begin{array}{l}\text { Temporary (Kelley et al., 1990; Mills and } \\
\text { Morris, 1986) }\end{array}$ & Temporary or continuous (Mele et al., 2014) \\
\hline (3) & $\begin{array}{l}\text { Collaboration } \\
\text { communication }\end{array}$ & $\begin{array}{l}\text { Sporadic, unidirectional, and less transparent } \\
\text { (Kelley et al., 1990; Mills and Morris, 1986; } \\
\text { Prahalad and Ramaswamy, 2004a) }\end{array}$ & $\begin{array}{l}\text { Frequent, bidirectional, and transparent } \\
\text { dialogue (Chathoth et al., 2013; } \\
\text { Gustafsson et al., 2012; Prahalad and } \\
\text { Ramaswamy, 2004a) }\end{array}$ \\
\hline (4) & $\begin{array}{l}\text { Collaboration } \\
\text { relationship }\end{array}$ & $\begin{array}{l}\text { The partial employee (Mills and Morris, } \\
\text { 1986), putting customers to work to } \\
\text { rationalise production processes (Zwick } \\
\text { et al., 2008) }\end{array}$ & $\begin{array}{l}\text { "Reconfiguring social relations of } \\
\text { production" that foster contingency, } \\
\text { playfulness, and experimentation (Zwick } \\
\text { et al., 2008, p. 184) }\end{array}$ \\
\hline (5) & $\begin{array}{l}\text { Collaboration } \\
\text { focus }\end{array}$ & $\begin{array}{l}\text { Provider-centric (Cermak et al., 1994; } \\
\text { Lovelock and Young, 1979) }\end{array}$ & $\begin{array}{l}\text { Customer-centric and experience-centric } \\
\text { (Chathoth et al., 2013; Prahalad, 2004) }\end{array}$ \\
\hline (6) & $\begin{array}{l}\text { Collaboration } \\
\text { stage }\end{array}$ & $\begin{array}{l}\text { In the service production and service } \\
\text { delivery stages (Dabholkar, 1990; } \\
\text { Lovelock and Young, 1979) }\end{array}$ & $\begin{array}{l}\text { From co-ideation to co-consumption } \\
\text { (Quero and Ventura, 2015; Russo-Spena } \\
\text { and Mele, 2012) }\end{array}$ \\
\hline & $\begin{array}{l}\text { Collaborating } \\
\text { actors }\end{array}$ & $\begin{array}{l}\text { Provider-customer (e.g., Kelley et al., } \\
\text { 1990; Mills and Morris, 1986) }\end{array}$ & $\begin{array}{l}\text { Multi-actor network (Pirinen, 2016; } \\
\text { Quero and Ventura, 2015) }\end{array}$ \\
\hline (8) & $\begin{array}{l}\text { Collaboration } \\
\text { initiation }\end{array}$ & $\begin{array}{l}\text { The provider enables the involvement } \\
\text { and invites the customer to participate } \\
\text { (Normann and Ramirez, 1993; } \\
\text { Ramirez, 1999) }\end{array}$ & $\begin{array}{l}\text { Involvement may be initiated by } \\
\text { the provider inviting actors to participate } \\
\text { (Kazadi et al., 2016), the provider } \\
\text { offering a platform for co-creation } \\
\text { (Ogawa and Piller, 2006), the customer } \\
\text { initiating the co-creation (Oliveira } \\
\text { and von Hippel, 2011), or co-creation } \\
\text { happening outside of the provider's } \\
\text { focus, such as in online communities } \\
\text { and the commons (Zwass, 2010). }\end{array}$ \\
\hline (9) & $\begin{array}{l}\text { Desired } \\
\text { outcomes }\end{array}$ & $\begin{array}{l}\text { Desired outcomes for the provider are of } \\
\text { economical nature and include productivity } \\
\text { and process gains, such as savings in } \\
\text { time, money, and effort (Dabholkar, 1990; } \\
\text { Lovelock and Young, 1979) }\end{array}$ & $\begin{array}{l}\text { Diverse set of desired outcomes for } \\
\text { the provider and the customer, such as } \\
\text { well-being (Engström and Elg, 2015), } \\
\text { relationship quality (So et al., 2016), } \\
\text { innovation (Ordanini and Parasuraman, } \\
\text { 2011), and launch support } \\
\text { (Rusanen et al., 2014) }\end{array}$ \\
\hline
\end{tabular}

clientele, improving user-service fit, and enhancing service performance (Dong et al., 2015 Edvardsson et al., 2013; Hoyer et al., 2010; Moeller et al., 2013). For example, DHL, the world's 
largest mail and logistics company, runs co-creation workshops with its customers. One of the solutions that emerged from this practice was the Parcelcopter, a drone that enables rapid delivery of parcels to geographically secluded areas that are challenging to reach for postal trucks, and thus improves the service experience for remote customers (Deutsche Post DHL Group, 2017; DHL Solutions \& Innovations, 2017). Nonetheless, co-creation may also lead to counterproductive outcomes, such as uncertainty about service ownership and diminished efficiency and service performance (Carbonell et al., 2012; Dong and Sivakumar, 2015; Dong et al., 2015; Hurmelinna-Laukkanen and Ritala, 2010). Osei-Frimpong et al. (2015) suggested that successfully performed co-creation improves service outcomes, but unsuccessful executions can prompt value destruction. For example, the large German manufacturer Henkel ran an open co-creation contest to find a new label sticker for its Pril dish detergent, but the platform was engulfed by inappropriate propositions, such as "Pril tastes like chicken," which was voted as the top slogan by the online community (Gatzweiler et al., 2013; Verhoef et al., 2013). These counterproductive outcomes suggest that a comprehensive assessment of possible outcomes is vital for the successful management of co-creating services.

For the remainder of this chapter, the authors focus on the second generation of customerprovider collaboration and direct the analysis towards a way that is meaningful for decisionmaking in service management. In order to facilitate further theoretical and practical development, the co-creation of services includes frequent, bidirectional, and transparent dialogue between customers and providers, is customer and experience centric, may occur in phases beyond service delivery and production, includes a diverse set of desired outcomes, and is influenced by a multi-actor network.

Given the increasing number of contributions, the field needs integrative analyses to introduce conceptual coherence. Due to inconsistent use of terms and lack of shared definitions, comparing findings from the different studies on co-creating services is problematic. Despite that some literature reviews and several conceptual studies on co-creation of services have been published, conceptual inconsistency continues to exist in the research stream. Conceptual papers have explored the underpinning logic of co-creation (Grönroos, 2008, 2011, 2012; Grönroos and Ravald, 2011; Saarijärvi et al., 2013; Vargo and Lusch, 2008), the interrelation between co-creation and other terms, such as co-design and co-production (Chathoth et al., 2013; Lusch and Vargo, 2006; O'Hern and Rindfleisch, 2010), and the embeddedness of cocreation in social service systems (Edvardsson et al., 2011; Maglio and Spohrer, 2008; Vargo et al., 2008). Existing reviews concentrate on classifying and synthesising the diverse disciplinary roots of co-creation (Galvagno and Dalli, 2014; Greenhalgh et al., 2016; Ind and Coates, 2013; Ranjan and Read, 2016) and on developing co-creation models for different business modes and industries (Greenhalgh et al., 2016; Romero and Molina, 2011). Out of the six reviews identified, only Voorberg et al. (2015) focused on the outcomes following co-creation. However, their examination of co-creation outcomes is limited to the context of citizen participation in public innovation, inviting further explorations on the outcomes of co-creation in the service industries more broadly.

Regarding methodological choices, existing co-creation reviews use search strategies based on pre-set search terms to identify the literature using search engines: Galvagno and Dalli (2014) used "co-creation"; Voorberg et al. (2015) used "co-creation" and "co-production"; and Ranjan and Read (2016) added "value-in-use" to these search terms. Other reviews on related terms have also included "co-creation" as a search term, for example, Dong and Sivakumar (2017) searched for "participation," "co-production," and "co-creation" in their customer participation review and Chang and Taylor (2016) used "participation," "involvement," "co-production," "crowdsourcing," and "co-creation" in their meta-analysis on customer participation. Both the diversity of the pre-set search terms used for systematic analyses and the increasing number of conceptual contributions on the interrelations between co-creation and related terms highlight the existing debate on the forms of co-creation (Etgar, 2008; Galvagno and Dalli, 2014; Grönroos and Voima, 2013; Payne et al., 2008; Saarijärvi et al., 2013; Voorberg et al., 2015). A gap remains in differentiating, synthesising, explicating, and organising the terminology on the forms of services co-creation. To address this gap, the current effort follows an inductive and inclusive approach, allowing the terminology that addresses the collaborative act between customers and providers to emerge inductively through a focused literature review.

\section{Focused Literature Review Approach}

In response to the research questions, this research implements a systematic yet focused literature review approach. Focusing on the service research literature, its main purposes are: to assess, clarify, and consolidate the terminology around the co-creation of services and to assess and consolidate the forms and outcomes of co-creating services. By taking an inductive and inclusive approach, allowing similar and neighbouring terms to emerge from the literature set, this focused review seeks to disentangle the body of knowledge related to co-creating services and to reduce the existing conceptual pluralism. Because many relevant publications use other labels than co-creating services to denote forms of collaborative creation, using a pre-set keyword search would diminish the richness of the relevant co-creation terminology to be discovered by limiting the analysis to those studies that specifically mention the term. The focused literature review of all articles published in five service journals included the Journal of Service Management, Journal of Services Marketing, Journal of Service Research, Journal of Service Theory and Practice, and Service Industries Journal. Three criteria drove the selection of these journals: first, each journal had to be rated by the SSCI (Thomson Reuters, 2015); second, only journals focusing on services are included; and third, the journals are inclusive and generic service journals and not specific to any particular industry (e.g., healthcare).

While not exhaustive in terms of publication outlets, this review provides a lens to focus on the developments in co-creating services, specifically in the service literature, which is 
essential given the current confusion with regard to conceptualising co-creation (Dong and Sivakumar, 2017; Grönroos and Ravald, 2011; Saarijärvi et al., 2013) and calls for more research on the outcomes of co-creating services (Voorberg et al., 2015). The five publication outlet published 2,466 articles between January 2006 and August 2016-a time frame that included the appearance of most co-creation articles (Galvagno and Dalli, 2014). The body of the current theorising emerged from this set of articles through inductive analysis proceeding in stages, beginning with the analysis of the abstracts of all published articles. To include earlier years, the authors conducted a supplementary SCOPUS search in the five publication outlets of al years before 2006, using all terms identified in the previous analysis as search terms beside cocreation

To ensure an appropriate structure and objectivity in the selection of literature, the focused literature review followed the four consecutive stages proposed by Booth et al. (2016): literature search, appraise the evidence base, analyse the findings, and synthesise the results. To extend coverage in time, a fifth stage that comprised the supplementary SCOPUS analysis of articles prior to 2006 was added. Table 1.2 provides an overview of the activities during each of the stages.

Stage 1 included an initial inspection of the titles, keywords, and abstracts that were accumulated during the literature search. During this first review, publications were included in the set for the next review step if the focal concept co-creation/cocreation of services was present and the paper included content focusing on outcomes of co-creation; or other relating terms that pointed to collaborative customer-provider creation were identified, including its outcomes; or the publications clearly reflected the results of customer-provider co-creation despite lacking a specific keyword pointing to co-creation. If any ambiguity was perceived, the whole publication was skimmed to determine suitability. Stage 1 resulted in a set of 138 articles.

In Stage 2, the introduction, literature review, and methodology sections of the articles were examined. In this inspection, 54 articles were excluded for three reasons. First, scrutinising several conceptualisations in more detail led to the exclusion of studies that did not relate to collaborative co-creation in practice, such as the customer empowerment study by O'Cass and Ngo (2011). Second, the search targeted co-creation of services in the customer-provider interface, but several articles examined co-creation between employees or firms instead (e.g.) Mukherjee and Malhotra, 2006). Third, some articles featured related terms that incorporated meanings different from co-creating services, such as the involvement definition by Zaichkowsky (1985) that presents involvement as the person's perceived relevance of an object: mere perception of relevance lacks the collaborative aspect in services co-creation. Thus, 84 articles remained for further analysis.
Table 1.2. Overview of the focused literature review process

\begin{tabular}{|c|c|}
\hline Stages & Research procedures \\
\hline $\begin{array}{l}\text { Stage 1: } \\
\text { Identification and } \\
\text { screening of abstracts }\end{array}$ & $\begin{array}{l}\text { - Five target journals: Journal of Service Management, Journal of Services } \\
\text { Marketing, Journal of Service Research, Journal of Service Theory and Practice, and } \\
\text { Service Industries Journal. } \\
\text { - Time frame: January } 2006 \text {-August 2016, containing 2,466 articles } \\
\text { - Initial inspection based on title, keywords, and abstract: an article was included, } \\
\text { if it addressed some form of collaborative act in the customer-service provider } \\
\text { interface, and indicated that some kind of outcome(s) resulted from this co- } \\
\text { creation. Articles that discussed value co-creation on an abstract level, without } \\
\text { addressing a service event or episode that yielded some kind of outcomes or } \\
\text { consequences from the co-involvement of the customer and the service provider, } \\
\text { were excluded from the literature set } \\
\text { - If ambiguity prevailed during the initial inspection, the whole publication was } \\
\text { skimmed for its suitability } \\
\text { - Citation management software (EndNote X7) was used to store and explore } \\
\text { the literature effectively } \\
\text { - A single line was written about each publication and its relation to the outcomes } \\
\text { of co-creating services to attain a reference point. } \\
\text { - Result: } 138 \text { articles }\end{array}$ \\
\hline $\begin{array}{l}\text { Stage 2: } \\
\text { Screening and } \\
\text { analysis of article } \\
\text { content }\end{array}$ & $\begin{array}{l}\text { - Secondary inspection of articles, arranged in chronological order, based on } \\
\text { reading the introduction, literature review, and methodology parts } \\
\text { - For each article, the definitions, explanations, and descriptions of "co-creating } \\
\text { services" were entered into a spreadsheet file } \\
\text { - During this closer inspection of the article content, the articles were excluded } \\
\text { for the following reasons: (a) co-creation was not addressed; (b) co-creation was } \\
\text { addressed, but not between the customer and the service provider; (c) words } \\
\text { interpreted as terminology typically associated with co-creation of services were } \\
\text { used in in another meaning or context } \\
\text { - Result: } 84 \text { articles }\end{array}$ \\
\hline $\begin{array}{l}\text { Stage 3: } \\
\text { Screening and } \\
\text { analysis of } \\
\text { the findings }\end{array}$ & $\begin{array}{l}\text { - Tertiary inspection based on reading the analysis, results, and discussion } \\
\text { sections of all articles in sequence of their assigned numbers } \\
\text { - Following the tertiary inspection, } 10 \text { articles were excluded for the following } \\
\text { reasons: (a) no outcomes of co-creating services addressed; or, (b) has outcomes } \\
\text { of co-creating services, but not for the customer or the service provider } \\
\text { - Result: } 74 \text { articles }\end{array}$ \\
\hline $\begin{array}{l}\text { Stage 4: } \\
\text { Synthesising } \\
\text { the findings }\end{array}$ & $\begin{array}{l}\text { - Discussion on the terminology determined through the focused review found to } \\
\text { be related to co-creating services (Section 3) } \\
\text { - Explicit definition of co-creating services based on thematic analysis of the forms } \\
\text { and themes of extant conceptualisations (Section 4) } \\
\text { - Typology of the beneficial and counterproductive customer and provider outcomes } \\
\text { of co-creating services based on thematic analysis of the outcomes and classified after } \\
\text { the co-creation experience dimensions of Verleye (2015) (Section 5) } \\
\text { - Integrative framework for the co-creation of services based on the prior review } \\
\text { findings and the comparison between the different terms (Section 6) }\end{array}$ \\
\hline
\end{tabular}


Table 1.2. (continued)

\begin{tabular}{ll}
\hline Stages & Research procedures \\
\hline Stage 5: & - SCOPUS search of all targeted publication outlets of the years before 2006 \\
Supplementary & - Searched keywords: co-creation/cocreation OR involvement, engagement, \\
SCOPUS search & participation, co-design/codesign, co-production/coproduction, co- \\
& consumption/coconsumption, pro-sumption/prosumption, AND outcome \\
& $\begin{array}{l}\text { The SCOPUS search identified 14 articles of which six articles passed } \\
\text { the screening (as above) and were added to the dataset and syntheses of Stage 4 } \\
\end{array}$ \\
& Result of supplementary review: 6 articles added, total 80 articles \\
\hline
\end{tabular}

The inspection during Stage 3 included reading of the analysis, results, and discussion sections, following the sequence of their assigned numbers. Ten articles were omitted from further analysis because they did not specify services co-creation outcomes for the customer or the service provider. Stage 3 resulted in the final set of 74 articles.

The fourth stage contained the synthesis of the findings, which is presented in the following four sections. Section 3 introduces the identified terminology associated with co-creation in services. Section 4 comprises a thematic analysis of the forms and themes of extant conceptualisations discovered in the 80 articles and develops an explicit definition of co-creating services. Further thematic analysis of the outcomes in Section 5 then provides a typology of beneficial and counterproductive customer and service provider outcomes of co-creating services, classified according to the co-creation experience dimensions of Verleye (2015) and discusses how the terminology of co-creating services differs across the outcomes. Finally, Section 6 develops an integrative framework capturing the identified co-creation forms and outcomes.

In the last stage, to develop a comprehensive picture of the development of the co-creation theme in the five journals, the researchers performed a focused, supplementary SCOPUS search to cover the relevant articles published before 2006. As the searched keywords the authors used the terms that had emerged in the analysis, introduced in the subsequent section, and the word "outcome" to ensure that all publications included both co-creation of services and addressed consequent outcomes. Six articles passed the screening, growing the data set from 74 to 80 articles, and were further included in the syntheses of Stage 4 .

Before entering the in-depth conceptual review findings, a brief overview of the reviewed studies is provided here in the form of descriptive statistics. Table 1.3 demonstrates how the identified co-creation literature spreads across the five journals. Figure 1.1 shows the total number of co-creation articles published per year (full years only). Table 1.4 presents the methodological orientation of the articles, showing that 95 percent of the reviewed articles are empirical research.
Table 1.3. Publication outlets

\begin{tabular}{lll}
\hline Journal & Number of publications & Percentage \\
\hline Service Industries Journal & 21 & 26.25 \\
Journal of Service Management $^{a}$ & 19 & 23.75 \\
Journal of Service Research $_{\text {Journal of Services Marketing }}$ & 15 & 18.75 \\
Journal of Service Theory and Practice $^{b}$ & 14 & 17.50 \\
Total & 11 & 13.75 \\
\hline
\end{tabular}

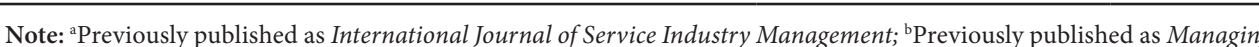
Service Quality.

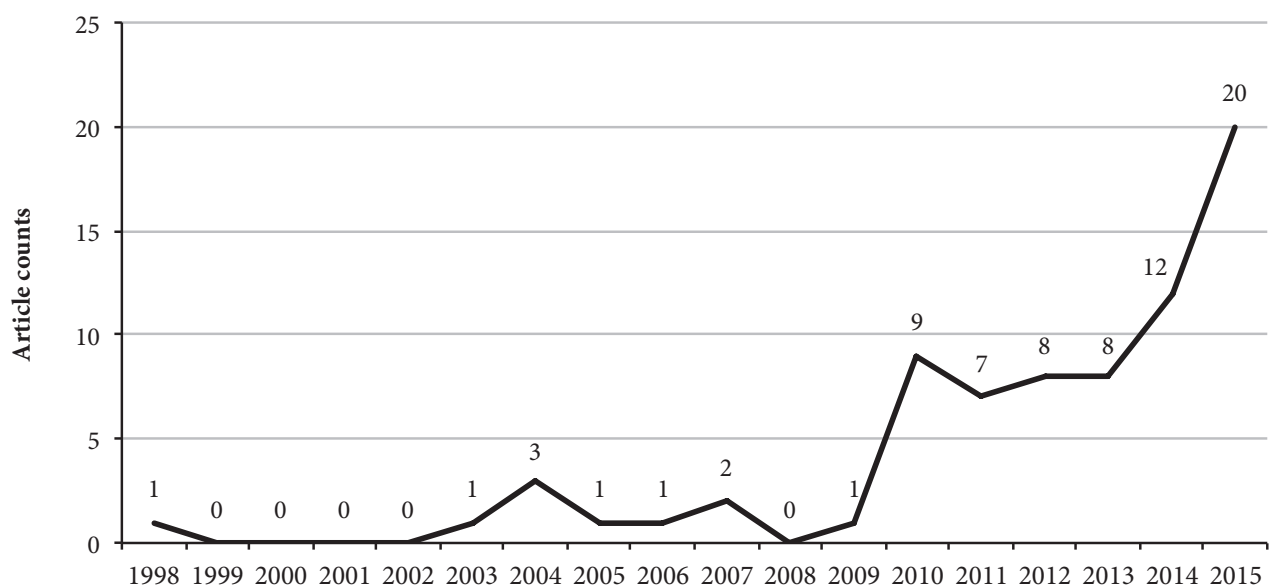

199819992000200120022003200420052006200720082009201020112012201320142015

Year of publication

Figure 1.1. Number of reviewed articles published per year

Table 1.4. Methodological orientation of the reviewed studies

\begin{tabular}{lll}
\hline Research approach & Number of publications & Percentage \\
\hline Conceptual & 4 & 5.00 \\
Empirical & 76 & 95.00 \\
$\quad$ Qualitative & 23 & \\
$\quad$ Quantitative & 38 & \\
$\quad$ Mixed & \multicolumn{2}{c}{15} \\
Total & 80 & 100 \\
\hline
\end{tabular}




\section{The Concept of Co-Creating Services and Related Terminology}

In response to the first research question, the focused literature review identified several term that subject to a similar meaning as the co-creation of services. The terms that appeared most frequently in the reviewed 80 articles are co-creation (e.g., Russo-Spena and Mele, 2012; Witel et al., 2011), involvement (e.g., Carbonell et al., 2012; Cheng et al., 2012), engagement (e.g., Jahn and Kunz, 2012; O’Brien et al., 2015), participation (e.g., Dong and Sivakumar, 2015; Engström and Elg, 2015), co-design (e.g., Gebauer et al., 2010; Quero and Ventura, 2015), co-production (e.g., Guo et al., 2013; Mende and van Doorn, 2015), and co-consumption/pro-sumption (Quero and Ventura, 2015; Witell et al., 2011). Other terms brought up in the literature, although less frequently, are servuction (Gebauer et al., 2010), collaboration (Ordanini and Parasuraman, 2011), interaction (Alam, 2011), and cooperation (Hsieh et al., 2013).

When scrutinising the literature of the focused review and of other reviews on the topic, it becomes apparent that there is much debate on the terminological relatedness between the terms. Some authors treat the terms as inclusive, such as when Dong and Sivakumar (2017) suggested using customer participation to encompass co-production and co-creation; Gebauer et al. (2010) proposed that co-creation integrates salient aspects of co-production; RussoSpena and Mele (2012) depicted co-creation as an overall concept for customer involvement; and Chang and Taylor (2016) implicitly recognised co-creation, co-production, and customer involvement as synonyms for customer participation and included them as equal search criteria in their meta-analysis. In their systematic review, Voorberg et al. (2015) showed that researchers often use co-creation and co-production interchangeably. Similarly, Dong and Sivakumar (2017) demonstrated how a multitude of terms have been used to describe customer participation, such as customer engagement, co-production, and co-creation, and Mustak et al. (2013, p. 354) denoted co-design, co-development, and customer engagement as "other terminology to study the same subject [customer participation]."

This interchangeable use of terms has led to increasing confusion about their conceptual content and blurred the resulting analyses and outcomes. To reduce this misperception, many authors have tried to disentangle the terminology. For example, Dong and Sivakumar (2017) recognised that co-creation, customer participation, and co-production belong to the same meaning cluster, while they differentiated customer engagement and customer innovation as related but distinct terms. Regarding customer participation in co-creation, Mustak et al. (2013) differentiated between participation in creating offerings and participation in creating value. Lusch and Vargo (2006) also described two components of co-creation: co-creation of value and co-production. The first is more encompassing and can be determined only by the customer during the consumption process, whereas the latter denotes participation through co-design or shared inventiveness in creating the offering. Similarly, in Etgar's (2008) model of consumer engagement in co-production, co-creation of value occurs in the consumption stage, but co-production happens during the production process, before usage. Finally, Grönroos and Ravald (2011) and Grönroos and Voima (2013) argued that through interaction in a joint creation process, the customer can get involved as a co-designer, co-developer, and co-producer in the service provider's processes, while the service provider can participate as a value cocreator in the customer's processes.

This research suggests that none of the terms are direct synonyms for co-creating services, but that involvement, engagement, and participation act as necessary prerequisite-forms (in short prerequisites) for the co-creation of services to occur. Co-design, co-production, and coconsumption are considered specific forms of the co-creation of services that further describe in which phase of the service process co-creating services is taking place. Consider DHL's cocreation workshops with customers as an example: Customers and DHL employees must be involved in the workshop to take part in co-creating services; actively participate in services cocreation; and finally, be engaged cognitively, behaviourally, or affectively (or all at once) before they can be prompted to co-create. Once these prerequisites are fulfilled, customers jointly collaborate with DHL in a process of co-creation; specifically, they co-design solutions during the design and development phases (DHL Solutions \& Innovations, 2017).

In an attempt to clarify the concept of co-creation of services and disentangle the conceptual pluralism surrounding it, the following sections compare and contrast the different associated terms based on the 80 articles accumulated through this focused review.

\section{Defining the Co-Creation of Services}

In response to the second research question, the authors conduct a thematic analysis of the forms and themes of co-creating services that aims to pinpoint and understand where and how service literature converges and diverges (Green et al., 2017). A thematic analysis is a theoretically flexible approach that enables the identification and description of patterns within a literature stream (Braun and Clarke, 2006; Fereday and Muir-Cochrane, 2006). As a first step in moving towards a definition of the co-creation of services, emerging themes in existing conceptualisations enabled the authors to provide new clarity about the phenomenon of co-creating services. Then, the researchers could synthesise and translate key themes in the different conceptualisations, even if they were expressed using different wording (Thomas and Harden, 2008). The thematic analysis involved careful reading and re-reading of the identified conceptualisations of co-creating services, as summarised in Table 1.5. The label "term" (Column 1, Table 1.5) refers to the seven terms that relate to the co-creation of services (co-creation, involvement, engagement, participation, co-design, co-production, and co-consumption). The label "conceptualisation of the term" (Column 2) indicates which one of the seven terms in Column 1 is cited by the conceptualisation in a particular publication. The different "themes within the conceptualisation" (Columns 4-10) provide an overview; these themes may or may not be captured by a specific conceptualisation. The following paragraphs explain the procedure of the thematic analysis in more detail. 


\begin{tabular}{|c|c|c|c|c|c|c|c|c|c|}
\hline \multirow[b]{2}{*}{ Term } & \multirow[b]{2}{*}{ Conceptualisation of the term } & \multirow[b]{2}{*}{ Publication } & \multicolumn{7}{|c|}{ Themes within the conceptualisation } \\
\hline & & & $\begin{array}{l}\text { Customer- } \\
\text { provider } \\
\text { emphasis }\end{array}$ & $\begin{array}{l}\text { Multi- } \\
\text { actor } \\
\text { emphasis }\end{array}$ & $\begin{array}{l}\text { Emphasis } \\
\text { on resource } \\
\text { integration }\end{array}$ & $\begin{array}{l}\text { Emphasis } \\
\text { on joint } \\
\text { creation }\end{array}$ & $\begin{array}{l}\text { Emphasis } \\
\text { on customer } \\
\text { creation }\end{array}$ & $\begin{array}{l}\text { Entire } \\
\text { service } \\
\text { process }^{a}\end{array}$ & $\begin{array}{l}\text { Phases of } \\
\text { the service } \\
\text { process }\end{array}$ \\
\hline \multirow[t]{23}{*}{ Co-creation } & Mutually created value & Grönroos and Helle (2010) & $\mathrm{x}$ & & & $\mathrm{x}$ & & & \\
\hline & Co-creation & Gebauer et al. (2010) & $\mathrm{x}$ & & & $\mathrm{X}$ & & & \\
\hline & Cocreation & Hoyer et al. (2010) & $\mathrm{x}$ & & & $\mathrm{X}$ & & & $\mathrm{x}$ \\
\hline & Co-creation for others & Witell et al. (2011) & $\mathrm{X}$ & & & $\mathrm{X}$ & & & $\mathrm{x}$ \\
\hline & Co-creation for use & Witell et al. (2011) & & & & & $\mathrm{x}$ & & \\
\hline & Co-creation for others & Elg et al. (2012) & $\mathrm{x}$ & & & $\mathrm{X}$ & & & $\mathrm{x}$ \\
\hline & Customer co-creation & Gustafsson et al. (2012) & $\mathrm{x}$ & & & $\mathrm{x}$ & & & $\mathrm{x}$ \\
\hline & Passive co-creation & Gustafsson et al. (2012) & $\mathrm{x}$ & & & & $\mathrm{x}$ & & \\
\hline & Joint perspective of co-creation & Russo-Spena and Mele (2012) & & & $\mathrm{X}$ & $\mathrm{X}$ & & & \\
\hline & Value co-creation & Alves (2013) & $\mathrm{x}$ & & & $\mathrm{x}$ & & & \\
\hline & Co-creation for others & Edvardsson et al. (2013) & $\mathrm{x}$ & & & $\mathrm{x}$ & & & $\mathrm{x}$ \\
\hline & Joint value creation & Moeller et al. (2013) & $\mathrm{x}$ & & & $\mathrm{x}$ & & & \\
\hline & Co-creation in actor value network & Pinho et al. (2014) & & $\mathrm{x}$ & $\mathrm{X}$ & & & & \\
\hline & Cocreation & Xia and Suri (2014) & $\mathrm{x}$ & & & $\mathrm{x}$ & & & $\mathrm{x}$ \\
\hline & Co-recovery & Xu et al. (2014) & $\mathrm{x}$ & & & $\mathrm{x}$ & & & $\mathrm{x}$ \\
\hline & Co-creation for others & Melton and Hartline (2015) & $\mathrm{x}$ & & & $\mathrm{X}$ & & & $\mathrm{x}$ \\
\hline & Co-creation & Mulder et al. (2015) & $\mathrm{X}$ & & & $\mathrm{X}$ & & & \\
\hline & Co-creation & Osei-Frimpong et al. (2015) & $\mathrm{X}$ & & & $\mathrm{X}$ & & & \\
\hline & Co-creation & Quero and Ventura (2015) & & $\mathrm{x}$ & & & & $\mathrm{x}$ & \\
\hline & Customer value cocreation & Sweeney et al. (2015) & & & $\mathrm{x}$ & $\mathrm{x}$ & & & \\
\hline & Co-creation & Verleye (2015) & $\mathrm{x}$ & & & $\mathrm{x}$ & & & $\mathrm{x}$ \\
\hline & Co-creation & Åkesson et al. (2016) & & $\mathrm{x}$ & $\mathrm{X}$ & $\mathrm{X}$ & & & \\
\hline & Co-creation & Tari Kasnakoglu (2016) & $\mathrm{X}$ & & & $\mathrm{X}$ & & & \\
\hline \multicolumn{10}{|c|}{ Prerequisites for the co-creation of services } \\
\hline \multirow[t]{6}{*}{ Involvement } & Customer involvement & Terziovski and Dean (1998) & $\mathrm{X}$ & & & & & $\mathrm{x}$ & \\
\hline & User involvement & Magnusson et al. (2003) & $\mathrm{x}$ & & & $\mathrm{x}$ & & & $\mathrm{x}$ \\
\hline & Customer involvement & Graf (2007) & & & & & $\mathrm{x}$ & & \\
\hline & Customer involvement & Carbonell et al. (2012) & $\mathrm{x}$ & & & $\mathrm{x}$ & & $\mathrm{x}$ & \\
\hline & Customer involvement & Cheng et al. (2012) & $\mathrm{X}$ & & & $\mathrm{X}$ & & & $\mathrm{x}$ \\
\hline & Customer involvement & Chen et al. (2016) & $\mathrm{X}$ & & & $\mathrm{X}$ & & & $\mathrm{x}$ \\
\hline \multirow[t]{7}{*}{ Engagement } & Customer engagement & Gebauer et al. (2010) & $\mathrm{X}$ & & & $\mathrm{X}$ & & & \\
\hline & Fan-page engagement & Jahn and Kunz (2012) & & $\mathrm{x}$ & & $\mathrm{X}$ & & & \\
\hline & Customer engagement behaviours & Jaakkola and Alexander (2014) & $\mathrm{X}$ & $\mathrm{x}$ & & $\mathrm{X}$ & $\mathrm{x}$ & & \\
\hline & Customer engagement & Jaakkola and Alexander (2014) & $\mathrm{x}$ & $\mathrm{x}$ & & $\mathrm{X}$ & $\mathrm{x}$ & & \\
\hline & Customer engagement & Harwood and Garry (2015) & $\mathrm{X}$ & & & $\mathrm{X}$ & & & \\
\hline & Engagement & O’Brien et al. (2015) & $\mathrm{x}$ & & & $\mathrm{x}$ & $\mathrm{x}$ & & \\
\hline & Customer engagement & So et al. (2016) & $\mathrm{x}$ & & & $\mathrm{X}$ & & & \\
\hline \multirow[t]{3}{*}{ Participation } & Customer participation & Yen et al. (2004) & & & & & $\mathrm{x}$ & & $\mathrm{x}$ \\
\hline & Customer participation & Hsieh et al. (2004) & & & & $\mathrm{X}$ & & & $\mathrm{x}$ \\
\hline & Customer participation & Yoon et al. (2004) & $\mathrm{x}$ & & & & & & $\mathrm{x}$ \\
\hline
\end{tabular}


Themes within the conceptualisation

\begin{tabular}{|c|c|c|c|c|c|c|c|c|c|}
\hline \multirow[b]{2}{*}{ Term } & \multirow[b]{2}{*}{ Conceptualisation of the term } & \multirow[b]{2}{*}{ Publication } & \multicolumn{7}{|c|}{ Themes within the conceptualisation } \\
\hline & & & $\begin{array}{l}\text { Customer- } \\
\text { provider } \\
\text { emphasis }\end{array}$ & $\begin{array}{l}\text { Multi- } \\
\text { actor } \\
\text { emphasis }\end{array}$ & $\begin{array}{l}\text { Emphasis } \\
\text { on resource } \\
\text { integration }\end{array}$ & $\begin{array}{l}\text { Emphasis } \\
\text { on joint } \\
\text { creation }\end{array}$ & $\begin{array}{l}\text { Emphasis } \\
\text { on customer } \\
\text { creation }\end{array}$ & $\begin{array}{l}\text { Entire } \\
\text { service } \\
\text { process }^{a}\end{array}$ & $\begin{array}{l}\text { Phases of } \\
\text { the service } \\
\text { process }\end{array}$ \\
\hline & Customer participation & Hsieh and Yen (2005) & & & & $\mathrm{x}$ & & & $\mathrm{x}$ \\
\hline & Customer participation & Chien and Chen (2010) & $\mathrm{x}$ & & & $\mathrm{x}$ & & $\mathrm{X}$ & \\
\hline & User participation & Hwang and Kim (2011) & $\mathrm{x}$ & & & $\mathrm{x}$ & & $\mathrm{X}$ & \\
\hline & Consumer participation & Dabholkar and Sheng (2012) & & & & & $\mathrm{x}$ & & $\mathrm{x}$ \\
\hline & Patient participation & Chang et al. (2013) & $\mathrm{x}$ & & & & & & \\
\hline & Customer participation & Eisingerich et al. (2014) & $\mathrm{x}$ & & & & & & $\mathrm{x}$ \\
\hline & Consumer participation & Sheng and Zolfagharian (2014) & & & & & $\mathrm{x}$ & & $\mathrm{x}$ \\
\hline & Customer participation & Bone et al. (2015) & $\mathrm{x}$ & & & & $\mathrm{x}$ & & \\
\hline & Customer participation & Dong (2015) & $\mathrm{x}$ & & & $\mathrm{x}$ & $\mathrm{x}$ & & $\mathrm{x}$ \\
\hline & Customer participation & Dong and Sivakumar (2015) & $\mathrm{x}$ & & & $\mathrm{x}$ & $\mathrm{x}$ & & $\mathrm{x}$ \\
\hline & Customer participation & Dong et al. (2015) & $\mathrm{x}$ & & & $\mathrm{x}$ & $\mathrm{x}$ & & $\mathrm{x}$ \\
\hline & Customer participation & Engström and Elg (2015) & $\mathrm{x}$ & & & $\mathrm{x}$ & & & $\mathrm{x}$ \\
\hline \multicolumn{10}{|c|}{ Specific forms of the co-creation of services } \\
\hline \multirow[t]{3}{*}{ Co-design } & Co-design & Gebauer et al. (2010) & $\mathrm{x}$ & & & $\mathrm{x}$ & & $\mathrm{X}$ & \\
\hline & Co-design & Russo-Spena and Mele (2012) & & $\mathrm{X}$ & & $\mathrm{x}$ & & & $\mathrm{x}$ \\
\hline & Co-design & Quero and Ventura (2015) & & $\mathrm{X}$ & & $\mathrm{x}$ & & & $\mathrm{x}$ \\
\hline \multirow[t]{6}{*}{ Co-production } & Co-production & Chien and Chen (2010) & $\mathrm{x}$ & & & $\mathrm{x}$ & & & $\mathrm{x}$ \\
\hline & Co-production & Gebauer et al. (2010) & & & & & $\mathrm{x}$ & & $\mathrm{x}$ \\
\hline & Co-production & Chien and Chao (2011) & $\mathrm{x}$ & & & & & & $\mathrm{x}$ \\
\hline & Co-production & Guo et al. (2013) & $\mathrm{x}$ & & & $\mathrm{x}$ & & & $\mathrm{x}$ \\
\hline & Co-production & Chen et al. (2015) & $\mathrm{x}$ & & & & & & $\mathrm{x}$ \\
\hline & Co-production & Mende and van Doorn (2015) & $\mathrm{x}$ & & & $\mathrm{x}$ & & $\mathrm{X}$ & \\
\hline Co-consumption/ & Pro-sumption & Gebauer et al. (2010) & & & & & $\mathrm{X}$ & & $\mathrm{x}$ \\
\hline \multirow[t]{2}{*}{ Pro-sumption } & Prosumption & Witell et al. (2011) & & & & $\mathrm{x}$ & $\mathrm{X}$ & & $\mathrm{x}$ \\
\hline & Co-consumption/pro-sumption & Quero and Ventura (2015) & & & & $\mathrm{x}$ & & & $\mathrm{x}$ \\
\hline Total count & & & 44 & 8 & 4 & 46 & 16 & 7 & 33 \\
\hline
\end{tabular}

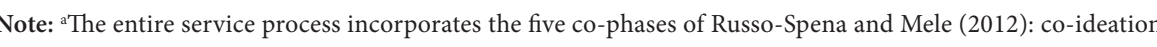

co-valuation, co-design, co-test, and co-launch and the co-production and co-consumption phases suggested

by Chen et al. (2015) and Quero and Ventura (2015).

First, the authors identified which of the selected articles in the focused review provide a conceptualisation related to the co-creation of services. Of the 80 articles selected, 51 articles provide 63 conceptualisations that are coded into seven categories depicting a concept or a term: co-creation, involvement, engagement, participation, co-design, co-production, and co-consumption/pro-sumption. In total, 29 publications that addressed the collaborative act in the customer-service provider interface do not conceptualise specific terms or their terms occur only infrequently within all selected articles, such as customer cooperation by Hsieh et al. (2013) or collaboration by Ordanini and Parasuraman (2011). Especially for cooperation and collaboration, the low number of conceptualisations is likely because the terms are used rather unconsciously and are often not further delineated. The reliability of coding the 63 conceptualisations into their respective terms was evaluated using Cohen's Kappa $\kappa$. The resulting $\kappa=1$ implied perfect inter-rater agreement across the author team (Landis and Koch, 1977). Although the 51 articles provided 63 conceptualisations, not all articles proposed new definitions; some relied on previous works. For example, Edvardsson et al. (2013), Elg et al. (2012), and Melton and Hartline (2015) all cited Witell et al's (2011) definition. Yet, no conceptualisation appears more than four times across the set of articles, confirming the conceptual fragmentation and need for a consolidating definition. 
Second, these conceptualisations were coded according to seven emerging themes, as detailed in Table 1.6. The seven themes (Columns $4-10$, Table 1.5) were derived by reading and rereading all 63 conceptualisations for any common wording or meaning. For example, "joint," "customer," and "actor" appear multiple times, as do phrases related to the service process, such as "ideation," "design," "development," and "delivery." Using this common wording or meaning, the authors then developed the different themes. For the assessment of the interrater reliability of coding the conceptualisations into the seven themes, the Cohen's $\kappa$ value was 0.71, which denotes substantial agreement across the author team (Landis and Koch, 1977) Disagreements were mostly due to language misunderstandings, so they could be resolved by refining the choice of wording of the themes.

Third, the prevalence of each theme, in terms of its absolute number of occurrences, provides the basis for introducing an explicit definition of co-creating services grounded in extant insights.

The findings demonstrate a strong emphasis on customer-provider mutual creation, which is not surprising, considering the selection criteria of the focused review. However, the findings also reveal a growing focus on the influence of a multi-actor context (Åkesson et al., 2016;

Table 1.6. Explanation of the seven emerging themes in co-creation of services conceptualisation

\begin{tabular}{ll}
\hline Theme & Explanation \\
\hline $\begin{array}{l}\text { Customer-provider } \\
\text { emphasis }\end{array}$ & $\begin{array}{l}\text { The conceptualisation focuses on the collaborative act between the customer and } \\
\text { the service provider and does not specifically name other actors. }\end{array}$
\end{tabular}

Multi-actor emphasis The conceptualisation focuses specifically on more actors than just the customer and the service provider.

Emphasis on resource The concept of resource integration is mentioned within the conceptualisation integration

Emphasis on joint Co-creating services occurs on a joint interface through a collaborative act. creation

Emphasis on customer creation

Co-creating services occurs on the customer's side throughout the customer's

Entire service process Co-creating services takes place during the entire service process, denoting al phases such as co-ideation, co-valuation, co-design, co-testing, co-launching, co-production, and co-consumption of a service.

Selected phases of The conceptualisation specifically mentions co-creating services taking place the service process in a particular phase of the service process, for instance in the co-design or coconsumption phase.
Pinho et al., 2014). This finding is in line with the authors' presentation of the first and second generation of customer-provider collaboration. Initially, the customer-provider dyad was in the focus, which has shifted towards including the influence of a multi-actor network. Some authors cite resource integration (Pinho et al., 2014; Russo-Spena and Mele, 2012; Sweeney et al., 2015), but most conceptualisations have not adopted this specific term, yet. According to the S-D logic, when resources are integrated, value gets co-created (Vargo and Lusch, 2008), which is an implication similar to the contribution of information by customers (Chang et al 2013; Witell et al., 2011) or support received from the physical labour of other actors (Dong, 2015 ) in the co-creation of services. The analysis also reveals an emphasis on joint creation, contrary to mere customer creation, which reflects the focus of the second generation of customer-provider collaboration on the frequent, bidirectional, and transparent dialogue between the customer and provider in a joint interface (Chathoth et al., 2013; Gustafsson et al., 2012; Prahalad and Ramaswamy, 2004a).

Many studies concentrate on co-creating services during selected phases of the service process (Russo-Spena and Mele, 2012). This research labels these terms as specific forms of co-creating services. Such specific forms of co-creating services, either as new, revised, repeated services or even innovations, include the co-ideation phase (Moeller et al., 2013), co-valuation and co-design phase (Hsieh et al., 2013), co-test and co-launch phase (Xia and Suri, 2014), coproduction phase (Chen et al., 2015), and co-consumption phase of a service (Quero and Ventura, 2015). Because all phases are included, this analysis indicates that co-creating services can, but does not have to, manifest itself in all phases of the service process. Based on thi thematic analysis, the authors identify an explicit definition of co-creating services, as follows:

The co-creation of services denotes collaborative activities in the customerprovider interface associated with the service; it necessitates the involvement engagement, and participation of at least one customer and one service provider and may lead to beneficial and/or counterproductive outcomes through resource integration. In services, co-creation manifests itself in different forms depending on the phases of the service process (co-ideation, co-valuation, co-design, co-test, co-launch, co-production, and co-consumption) and is influenced by a contextual, multi-actor network.

During the thematic analysis, the authors further compared and contrasted the terms associated with co-creating services. Figure 1.2 depicts the percentage scores for the identified terminology across the seven themes discovered and Table 1.7 summarises these values as lowmedium-, and high-emphasis categories.

The co-creation terms are associated with the theme of customer-provider emphasis, with the exception of pro-sumption or, as Quero and Ventura (2015) named it, co-consumption. The three studies on co-consumption focus on specific phases rather than the whole 
service process, because co-consumption predominantly occurs during the use phase. Coconsumption and pro-sumption refer to "collaboration for use and consumption" (Quero and Ventura, 2015, p. 125). Literature covering specific phases of the service process further emphasises co-design and co-production terms, in addition to referring to co-consumption (Chien and Chen, 2010; Quero and Ventura, 2015; Russo-Spena and Mele, 2012). In contrast, the phases of the service process receive little mentioning by literature that uses co-creation, involvement, and engagement terms. This finding supports the authors' reasoning that codesign, co-production, and co-consumption are specific forms of the co-creation of services as they manifest themselves during particular phases of the service process.

Literature exploring the co-consumption term emphasises the consumption and use phase and pays less attention on customer-provider collaboration theme; instead, the studies addressing co-consumption focus on customer creation. Witell et al. (2011) suggested that the term focuses on customers' creation activities that lead to the production of offerings, which they finally consume; hence, they focus on the customer's side. The theme of customer creation also contains studies using the terms engagement and participation, but unlike studies on coconsumption, engagement and participation studies emphasise the customer-provider theme.

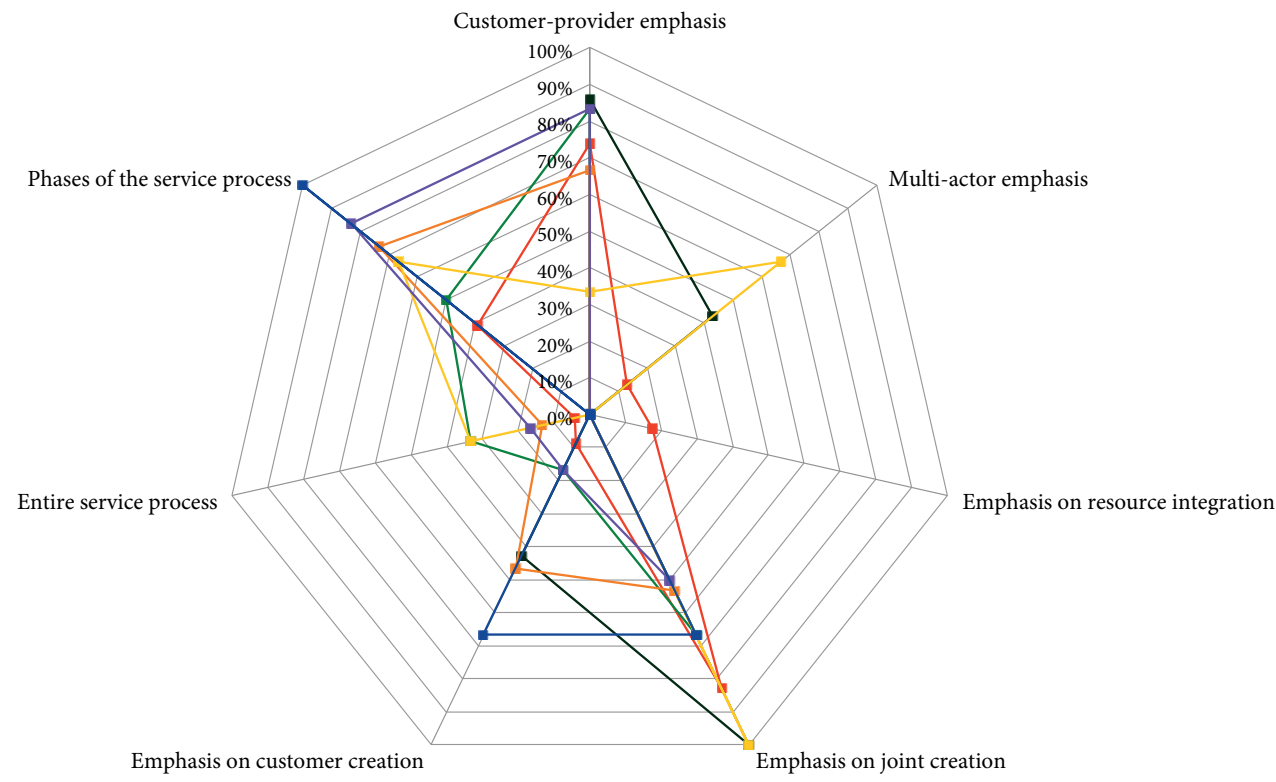

Figure 1.2. Themes of the thematic analysis represented across the co-creation of services terminology
The notion of multiple actors in the collaborative act is mostly emphasised by studies using the terms co-design and engagement, highlighting other actors beyond the dyadic customerprovider collaboration. As Quero and Ventura (2015, p. 125) explained, co-design "encompasses a wide range of practices based on the engagement of many actors linked by a shared context and interest."

Finally, all themes share the following three observations. First, co-creation is the only term that is frequently used in all seven themes, underlining both the versatility and the overarching nature of the term. Second, although the idea of resource integration has been advocated in some articles on co-creation, this theme draws only limited and sporadic attention (cf. Åkesson et al., 2016; Pinho et al., 2014) across the literature suggesting the different co-creation terms. Third, the theme that emphasises joint creation is common across the entire terminology; this expresses the frequent, bidirectional, and collaborative nature of co-creating services. Due to the recurrent emphasis of involvement, engagement, and participation terms on the joint customer-provider creation, the authors feel further supported in their claim that these three terms are necessary prerequisites for co-creating services, as without them no collaboration between service providers and customers is realisable.

\section{A Typology of Outcomes from Co-Creating Services}

To address the third research question, the study develops a typology of outcomes that result for both customers and service providers from co-creation in service provision. This typology synthesises Verleye's (2015) research on customer benefits that result from cocreating the service experience with further observations rooted in the current focused review. Analysing expected benefits from co-creation, Verleye (2015) identified six co-creation experience dimensions that influence the overall co-creation experience, defined as follows: personal benefits: "gaining a better status and recognition"; social benefits: "being able to connect with other people"; hedonic benefits: "having pleasurable experiences"; cognitive benefits: "acquiring new knowledge/skills"; economic benefits: "compensation in line with effort made"; and pragmatic benefits: "solutions better meeting personal needs" (Verleye, 2015, pp. 323-324)

To construct the typology of co-creation outcomes for the current study, the authors used these co-creation experience dimensions as a foundation for the thematic analysis that categorises the varying outcomes of co-creating services. Given the current focused review approach, discussions on more generic types of service outcomes, common in the broader service literature beyond the co-creation theme, are not included-naturally, all service events should lead to the fulfilment of the value proposition and, subsequently, capture some intended economic or non-monetary value for the provider. 


\begin{tabular}{|c|c|c|c|c|c|c|c|}
\hline & \multirow[b]{2}{*}{ Co-creation } & \multicolumn{3}{|c|}{ Prerequisites of the co-creation of services } & \multicolumn{3}{|c|}{ Specific forms of the co-creation of services } \\
\hline & & Involvement & Engagement & Participation & Co-design & Co-production & Co-consumption \\
\hline Customer-provider emphasis $^{a}$ & High & High & High & High & Medium & High & - \\
\hline Multi-actor emphasis ${ }^{a}$ & Low & - & Medium & - & High & - & - \\
\hline Emphasis on resource integration $^{a}$ & Low & - & - & - & - & Low & - \\
\hline Emphasis on joint creation ${ }^{a}$ & High & High & High & Medium & High & Medium & High \\
\hline Emphasis on customer creation ${ }^{a}$ & Low & Low & Medium & Medium & - & Low & High \\
\hline Entire service process ${ }^{\mathrm{a}}$ & Low & Medium & - & Low & Medium & Low & - \\
\hline Phases of the service process ${ }^{a}$ & Medium & Medium & - & High & High & High & High \\
\hline Beneficial outcomes for the customer ${ }^{b}$ & $\begin{array}{l}\text { High on personal, social, economic, and } \\
\text { pragmatic dimensions } \\
\text { Low on cognitive dimension }\end{array}$ & $\begin{array}{l}\text { Low on hedonic } \\
\text { and pragmatic } \\
\text { dimensions }\end{array}$ & $\begin{array}{l}\text { High on social } \\
\text { dimension } \\
\text { Low on personal } \\
\text { dimension }\end{array}$ & $\begin{array}{l}\text { Low on personal, } \\
\text { social, hedonic, } \\
\text { and pragmatic } \\
\text { dimensions }\end{array}$ & - & $\begin{array}{l}\text { Low on personal } \\
\text { and pragmatic } \\
\text { dimensions }\end{array}$ & - \\
\hline Beneficial outcomes for the provider ${ }^{\mathrm{b}}$ & $\begin{array}{l}\text { High on cognitive, economic, and } \\
\text { pragmatic dimensionsLow on personal and } \\
\text { social dimensions }\end{array}$ & $\begin{array}{l}\text { High on } \\
\text { cognitive, } \\
\text { economic, } \\
\text { and pragmatic } \\
\text { dimensions }\end{array}$ & $\begin{array}{l}\text { Low on hedonic } \\
\text { dimension }\end{array}$ & $\begin{array}{l}\text { Low on personal, } \\
\text { economic and } \\
\text { pragmatic } \\
\text { dimensions }\end{array}$ & - & $\begin{array}{l}\text { Low on cognitive } \\
\text { and economic } \\
\text { dimensions }\end{array}$ & - \\
\hline $\begin{array}{l}\text { Counterproductive outcomes for } \\
\text { the customer }{ }^{\mathrm{b}}\end{array}$ & Low on pragmatic dimension & - & $\begin{array}{l}\text { Low on social } \\
\text { dimension }\end{array}$ & $\begin{array}{l}\text { High on } \\
\text { pragmatic } \\
\text { dimension }\end{array}$ & - & - & - \\
\hline $\begin{array}{l}\text { Counterproductive outcomes for } \\
\text { the provider }{ }^{\mathrm{b}}\end{array}$ & Low on economic dimension & $\begin{array}{l}\text { Low on economic } \\
\text { and pragmatic } \\
\text { dimensions }\end{array}$ & - & $\begin{array}{l}\text { High on social } \\
\text { dimension } \\
\text { Low on personal } \\
\text { and economic } \\
\text { dimensions }\end{array}$ & - & - & - \\
\hline
\end{tabular}

Notes: alow emphasis=1-32 percent, medium emphasis=33-65 percent, high emphasis=66-100 percent;

blow occurrence $=1-2$ outcomes, high occurrence $=3-4$ outcomes

First, in the 80 articles included, 171 individual observations capturing a broad range of cocreation outcomes were identified. Second, the observations were sorted using Verleye's (2015) co-creation experience dimensions. Third, as the observations included both positive and negative attributions, they were sorted to beneficial and counterproductive outcomes, respectively. Fourth, each observation was sorted in terms of its beneficiary, i.e., whether the outcome addressed the customer or the service provider. Finally, Verleye's (2015) dimensions were further developed by clustering the observations within each dimension. For example, the personal benefits for the customer include recognition, self-esteem, well-being, quality of life perception, and empowerment and ownership; all these concepts represent "gaining a better status and recognition" (Verleye, 2015, p. 324). Illustrated with selected quotations from the literature, Table 1.8 presents the typology of the beneficial and counterproductive outcomes of co-creating services for the customer and the service provider.
Table 1.8 reveals that for customers, scholarly contributions emphasise personal, social, and pragmatic benefits. Hedonic, cognitive, and economic benefits have received less attention, both in terms of absolute number of references and outcome diversity. For personal benefits, previous publications highlight customers' well-being, especially in terms of financial wellbeing (Guo et al., 2013; Mende and van Doorn, 2015). Customers' social benefits, such as the ability to connect with other people, predominantly appear as loyalty with the service provider (Harwood and Garry, 2015; O'Brien et al., 2015) and positive word-of-mouth (intentions) (Ferguson et al., 2010; Tari Kasnakoglu, 2016). The hedonic benefits acknowledge enjoyment and fun as outcomes (Sheng and Zolfagharian, 2014), while the cognitive benefits include new knowledge and skills as beneficial outcomes (Koelling et al., 2010). The economic benefits consist of improved economic gains for the customer (Moeller et al., 2013) and monetary compensation for their efforts (Xia and Suri, 2014). 
Table 1.8. Typology of outcomes from co-creating services

\begin{tabular}{|c|c|c|c|c|c|c|c|c|}
\hline \multirow{2}{*}{$\begin{array}{l}\text { Co-creation } \\
\text { experience } \\
\text { dimensions of } \\
\text { Verleye (2015) }\end{array}$} & \multicolumn{4}{|c|}{ Customer } & \multicolumn{4}{|c|}{ Service provider } \\
\hline & $\begin{array}{l}\text { Beneficial } \\
\text { outcomes }\end{array}$ & $\begin{array}{l}\text { Source } \\
\text { publication }\end{array}$ & $\begin{array}{l}\text { Counter-productive } \\
\text { outcomes }\end{array}$ & $\begin{array}{l}\text { Source } \\
\text { publication }\end{array}$ & $\begin{array}{l}\text { Beneficial } \\
\text { outcomes }\end{array}$ & $\begin{array}{l}\text { Source } \\
\text { publication }\end{array}$ & $\begin{array}{l}\text { Counter-productive } \\
\text { outcomes }\end{array}$ & $\begin{array}{l}\text { Source } \\
\text { publication }\end{array}$ \\
\hline \multirow[t]{5}{*}{ Personal } & Recognition & $\begin{array}{l}\text { Jaakkola and Alexander } \\
\text { (2014) }\end{array}$ & & & Decision support & Pinho et al. (2014) & Increased uncertainty & $\begin{array}{l}\text { Hurmelinna- } \\
\text { Laukkanen and } \\
\text { Ritala (2010) }\end{array}$ \\
\hline & Self-esteem & Guo et al. (2015) & & & Improved provider image & $\begin{array}{l}\text { Toivonen and Tuominen } \\
(2009)\end{array}$ & Need for service protection & $\begin{array}{l}\text { Hurmelinna- } \\
\text { Laukkanen and } \\
\text { Ritala (2010) }\end{array}$ \\
\hline & Well-being & $\begin{array}{l}\text { Engström and Elg (2015); } \\
\text { Guo et al. (2013); Mende } \\
\text { and van Doorn (2015); }\end{array}$ & & & Job satisfaction & Yoon et al. (2004) & Job stress & Hsieh and Yen (2005) \\
\hline & $\begin{array}{l}\text { Quality of life } \\
\text { perception }\end{array}$ & Sweeney et al. (2015) & & & & & & \\
\hline & $\begin{array}{l}\text { Empowerment, } \\
\text { ownership, and part- } \\
\text { taking }\end{array}$ & $\begin{array}{l}\text { Mulder et al. (2015); } \\
\text { Quero and Ventura } \\
\text { (2015) }\end{array}$ & & & & & & \\
\hline \multirow[t]{6}{*}{ Social } & Relationship quality & $\begin{array}{l}\text { Hoyer et al. (2010); So et } \\
\text { al. (2016) }\end{array}$ & $\begin{array}{l}\text { Relationship (trust } \\
\text { and commitment) }\end{array}$ & $\begin{array}{l}\text { Harwood and } \\
\text { Garry (2015) }\end{array}$ & Synergy & Hsieh et al. (2013) & $\begin{array}{l}\text { Service failures attributed } \\
\text { to provider }\end{array}$ & Yen et al. (2004) \\
\hline & Loyalty & $\begin{array}{l}\text { Harwood and Garry } \\
\text { (2015); Jahn and Kunz } \\
\text { (2012); O’Brien et al. } \\
\text { (2015); So et al. (2016) }\end{array}$ & Subversion & $\begin{array}{l}\text { Harwood and } \\
\text { Garry (2015) }\end{array}$ & Contract retention & Burdon et al. (2015) & Role conflict & $\begin{array}{l}\text { Hsieh et al. (2004); } \\
\text { Hsieh and Yen (2005) }\end{array}$ \\
\hline & Trust & $\begin{array}{l}\text { Dabholkar and Sheng } \\
\text { (2012) }\end{array}$ & & & $\begin{array}{l}\text { Consumer-company } \\
\text { identification }\end{array}$ & Tung et al. (2014) & & \\
\hline & $\begin{array}{l}\text { Identification with } \\
\text { the provider }\end{array}$ & Tung et al. (2014) & & & & & & \\
\hline & Engagement & Hoyer et al. (2010) & & & $\begin{array}{l}\text { Cross-functional } \\
\text { integration and teamwork }\end{array}$ & $\begin{array}{l}\text { Alam (2011); Chien and } \\
\text { Chen (2010) }\end{array}$ & & \\
\hline & $\begin{array}{l}\text { Word-of-mouth } \\
\text { (intentions) }\end{array}$ & $\begin{array}{l}\text { Ferguson et al. (2010); } \\
\text { Sweeney et al. (2015); } \\
\text { Tari Kasnakoglu (2016) }\end{array}$ & & & & & & \\
\hline Hedonic & Enjoyment and fun & $\begin{array}{l}\text { Chen et al. (2016); Sheng } \\
\text { and Zolfagharian (2014) }\end{array}$ & & & Working environment & $\begin{array}{l}\text { Jaakkola and Alexander } \\
\text { (2014) }\end{array}$ & & \\
\hline \multirow[t]{2}{*}{ Cognitive } & $\begin{array}{l}\text { New knowledge and } \\
\text { skills }\end{array}$ & $\begin{array}{l}\text { Gottfridsson (2014); } \\
\text { Koelling et al. (2010); } \\
\text { Verleye (2015) }\end{array}$ & & & New service development & $\begin{array}{l}\text { Åkesson et al. (2016); } \\
\text { Alves (2013); Carbonell } \\
\text { et al. (2012); Chen et al. } \\
\text { (2015); Cheng et al. (2012); } \\
\text { Ordanini and Parasuraman } \\
\text { (2011); Russo-Spena and } \\
\text { Mele (2012); Ryzhkova } \\
\text { (2015) }\end{array}$ & & \\
\hline & Less uncertainty & Koelling et al. (2010) & & & $\begin{array}{l}\text { Improvements to existing } \\
\text { services }\end{array}$ & $\begin{array}{l}\text { Cheng et al. (2012); Hu } \\
\text { and McLoughlin (2012) }\end{array}$ & & \\
\hline
\end{tabular}


Table 1.8. (continued)

\begin{tabular}{|c|c|c|c|c|c|c|c|c|}
\hline \multirow{2}{*}{$\begin{array}{l}\text { Co-creation } \\
\text { experience } \\
\text { dimensions of } \\
\text { Verleye (2015) }\end{array}$} & \multicolumn{4}{|c|}{ Customer } & \multicolumn{4}{|c|}{ Service provider } \\
\hline & $\begin{array}{l}\text { Beneficial } \\
\text { outcomes }\end{array}$ & $\begin{array}{l}\text { Source } \\
\text { publication }\end{array}$ & $\begin{array}{l}\text { Counter-productive } \\
\text { outcomes }\end{array}$ & $\begin{array}{l}\text { Source } \\
\text { publication }\end{array}$ & $\begin{array}{l}\text { Beneficial } \\
\text { outcomes }\end{array}$ & $\begin{array}{l}\text { Source } \\
\text { publication }\end{array}$ & $\begin{array}{l}\text { Counter-productive } \\
\text { outcomes }\end{array}$ & $\begin{array}{l}\text { Source } \\
\text { publication }\end{array}$ \\
\hline & & & & & Creativity and ideas & $\begin{array}{l}\text { Giannopoulou et al. } \\
\text { (2014); Magnusson et } \\
\text { al. (2003); Matthing et } \\
\text { al. (2006); Toivonen and } \\
\text { Tuominen (2009); Witell et } \\
\text { al. (2011) }\end{array}$ & & \\
\hline & & & & & $\begin{array}{l}\text { Knowledge exchange, } \\
\text { learning, and transformed } \\
\text { resources }\end{array}$ & $\begin{array}{l}\text { Elg et al. (2012); Kallio } \\
\text { and Lappalainen (2015); } \\
\text { Rusanen et al. (2014) }\end{array}$ & & \\
\hline \multirow[t]{6}{*}{ Economic } & Economic gains & $\begin{array}{l}\text { Guo et al. (2015); Moeller } \\
\text { et al. (2013) }\end{array}$ & & & Market performance & $\begin{array}{l}\text { Carbonell et al. (2012); } \\
\text { Edvardsson et al. (2013); } \\
\text { Gebauer et al. (2010); } \\
\text { Gottfridsson (2014); } \\
\text { Grönroos and Helle } \\
\text { (2010); Gustafsson et al. } \\
\text { (2012); Witell et al. (2011) }\end{array}$ & Market performance & Carbonell et al. (2012) \\
\hline & & & & & $\begin{array}{l}\text { New offering sales } \\
\text { performance }\end{array}$ & $\begin{array}{l}\text { Chien and Chao (2011); } \\
\text { Hwang and Kim (2011) }\end{array}$ & & \\
\hline & $\begin{array}{l}\text { Monetary } \\
\text { compensation }\end{array}$ & Xia and Suri (2014) & & & Time and cost savings & $\begin{array}{l}\text { Hoyer et al. (2010); Pinho } \\
\text { et al. (2014) }\end{array}$ & Offering success & $\begin{array}{l}\text { Gustafsson et al. } \\
(2012)\end{array}$ \\
\hline & & & & & Benefits of physical labour & $\begin{array}{l}\text { Bone et al. (2015); Dong } \\
\text { (2015); Graf (2007) }\end{array}$ & Perceived workload & Hsieh et al. (2004) \\
\hline & & & & & $\begin{array}{l}\text { Service advantage and } \\
\text { marketability }\end{array}$ & $\begin{array}{l}\text { Carbonell et al. (2012); } \\
\text { Melton and Hartline } \\
(2010)\end{array}$ & & \\
\hline & & & & & $\begin{array}{l}\text { Service quality } \\
\text { performance }\end{array}$ & $\begin{array}{l}\text { Terziovski and Dean } \\
\text { (1998) }\end{array}$ & & \\
\hline \multirow[t]{5}{*}{ Pragmatic } & Service-customer fit & $\begin{array}{l}\text { Alam (2011); Bryson and } \\
\text { Taylor (2010); Hoyer et } \\
\text { al. (2010) }\end{array}$ & Efficiency & $\begin{array}{l}\text { Dong and } \\
\text { Sivakumar } \\
\text { (2015) }\end{array}$ & Speed to market & $\begin{array}{l}\text { Carbonell et al. (2012); } \\
\text { Chien and Chen (2010); } \\
\text { Hu and McLoughlin } \\
\text { (2012) }\end{array}$ & Slow and diverse nature & $\begin{array}{l}\text { Toivonen and } \\
\text { Tuominen (2009) }\end{array}$ \\
\hline & Service quality & $\begin{array}{l}\text { Gill et al. (2011); Osei- } \\
\text { Frimpong et al. (2015) }\end{array}$ & Value destruction & $\begin{array}{l}\text { Osei- } \\
\text { Frimpong et } \\
\text { al. (2015) }\end{array}$ & Launch support & $\begin{array}{l}\text { Melton and Hartline } \\
\text { (2010); Rusanen et al. } \\
\text { (2014); Quero and Ventura } \\
\text { (2015) }\end{array}$ & Less producible ideas & $\begin{array}{l}\text { Magnusson et al. } \\
\text { (2003) }\end{array}$ \\
\hline & Repurchase intentions & $\begin{array}{l}\text { Dabholkar and Sheng } \\
\text { (2012); Tari Kasnakoglu } \\
\text { (2016); Xu et al. (2014) }\end{array}$ & $\begin{array}{l}\text { Perceived service } \\
\text { quality }\end{array}$ & $\begin{array}{l}\text { Dong et al. } \\
\text { (2015) }\end{array}$ & $\begin{array}{l}\text { Service diffusion and viral } \\
\text { actions }\end{array}$ & $\begin{array}{l}\text { Hu and McLoughlin } \\
\text { (2012); Russo-Spena and } \\
\text { Mele (2012) }\end{array}$ & & \\
\hline & Perceived user value & Magnusson et al. (2003) & Perceived ease of use & $\begin{array}{l}\text { Sheng and } \\
\text { Zolfagharian } \\
\text { (2014) }\end{array}$ & Efficiency and effectiveness & $\begin{array}{l}\text { Bone et al. (2015); Hoyer } \\
\text { et al. (2010) }\end{array}$ & & \\
\hline & & & & & Service effort & Yoon et al. (2004) & & \\
\hline
\end{tabular}


Finally, because co-created services can meet personal needs better, the pragmatic benefits include improved service-customer fit (Alam, 2011), service quality (Gill et al., 2011), and repurchase intentions (Tari Kasnakoglu, 2016). The beneficial outcomes for customers have received more attention than the counterproductive outcomes. As Table 1.8 demonstrates, the personal, hedonic, cognitive, and economic co-creation experience dimensions for customers contain no counterproductive outcomes. This finding supports Mustak et al. $(2013,2016)$ who observed a lack of research on counterproductive outcomes following co-creation. An example of a counterproductive social outcome is that following a lack of positive collaboration, customers' trust and commitment may decline; customers' frustrations may increase if they perceive their loyalty to be exploited (Harwood and Garry, 2015). Counterproductive pragmatic outcomes for customers may result from diminished efficiency (Dong and Sivakumar, 2015), possibly due to decreased ease of use (Sheng and Zolfagharian, 2014) or lower perceived service quality (Dong et al., 2015).

Table 1.8 also displays the outcomes following from the co-creation of services for service providers. The cognitive, economic, and pragmatic co-creation experience dimensions point towards several beneficial outcomes. The cognitive benefits for service providers include the knowledge and skills to develop new services and improve existing ones together with their customers (Hu and McLoughlin, 2012; Ryzhkova, 2015). Furthermore, the collaborative act with customers positively influences market performance (Carbonell et al., 2012), profit margins (Witell et al., 2011), and sales performance of the new offering (Chien and Chao, 2011)-all important economic benefits. Pragmatic benefits can be realised through shorter time-to-market when introducing new offerings (Chien and Chen, 2010), peer support for services (Melton and Hartline, 2010), and improved efficiency and effectiveness in operations (Bone et al., 2015). The literature rarely discusses hedonic benefits for service providers, although a case study of customer engagement behaviour (Jaakkola and Alexander, 2014) shows how co-creation leads to an improved working environment. Previous research suggests that the co-creation of services can lead to the personal benefits of improved decision support for the service provider (Pinho et al., 2014) and a better provider image (Toivonen and Tuominen, 2009). Social benefits identified include better synergy (Hsieh et al., 2013), contract retention with customers (Burdon et al., 2015), and cross-functional integration and teamwork within the service provider (Alam, 2011; Chien and Chen, 2010). A major counterproductive personal outcome for the service provider involves knowledge sharing, which leads to increased uncertainty about who owns the service and calls for better service protection against imitation (Hurmelinna-Laukkanen and Ritala, 2010). Possible counterproductive economic outcomes for the service provider that can follow from co-creation include declining market performance (Carbonell et al., 2012) and a negative effect on the product success of radical innovations (Gustafsson et al., 2012). Additionally, employees' job stress, role conflict, and perceived workload are interrelated counterproductive outcomes associated with personal, social, and economic outcome dimensions for providers (Hsieh et al., 2004; Hsieh and Yen, 2005). More specifically, Hsieh and Yen (2005) proposed that customer participation increases job stress of employees, due to role conflicts between customers and employees following changes in job characteristics.

To clarify the conceptual pluralism surrounding the concept of co-creation in services, the authors further compared and contrasted the identified outcomes against the terminology of co-creating services. Table 1.7, introduced in the previous section, summarises this comparison and reports on the occurrence of beneficial and counterproductive outcomes across the terminology for customers and service providers.

Cross-comparison of the identified outcomes against the terms used in the same study reveals that literature using the co-creation term suggests a variety of beneficial outcomes for nearly all customer and provider experience dimensions, except for the hedonic dimension. However, the publications addressing co-creation do not identify many counterproductive outcomes; Osei-Frimpong et al. (2015), on the possibility of value destruction, and Gustafsson et al. (2012), on diminished success of the offerings, are the only contributions of co-creation terms to counterproductive outcomes. This finding demonstrates the research gap between the investigation of beneficial and counterproductive outcomes, supporting earlier reviews (Mustak et al., 2013, 2016).

Interestingly, publications using the involvement term are predominantly suggesting outcomes for service providers, with only two publications contributing to customer outcomes-Chen et al. (2016) mentioned a positive effect on customers' moods and Magnusson et al. (2003) proposed improvements in perceived user value. Especially, for the cognitive, economic, and pragmatic experience dimensions, there is a broad body of involvement literature proposing outcomes for service providers.

Contrary to involvement literature, publications on the engagement term indicate hardly any outcomes for the service provider, with the exception of Jaakkola and Alexander (2014) who reported on a positive working atmosphere. There are several outcomes mentioned by engagement studies for customers, however, they are focused only on the personal and social experience dimensions. This comprises another difference between the engagement and involvement terms: while there are many outcomes from involvement publications for the cognitive, economic, and pragmatic experience dimensions, there are no outcomes from engagement publications on these dimensions. Analogously, there are no outcomes from involvement literature for the personal and social experience dimensions, but many outcomes from engagement literature for these dimensions.

For publications highlighting the participation term, the authors find that the outcomes are relatively evenly divided across the experience dimensions and the customer and service provider perspectives. Notably though, participation literature identifies more counterproductive outcomes than any other term. While counterproductive outcomes 
for the service provider are mostly suggested for the personal, social, and economic dimensions, counterproductive outcomes for the customer are proposed for the pragmatic experience dimension.

Finally, there are only few outcomes suggested by co-production articles and no outcomes specifically mentioned for co-design and co-consumption literature. One possible reason for this finding is that the publications that cover outcomes for co-design, co-production, and coconsumption rarely suggest these outcomes for the respective term alone. Any publication that named the same outcome for more than one term was not categorised by this research after a specific term, but under the category "Not specified." When scrutinising the publications in this category (Chien and Chen, 2010; Gebauer et al., 2010; Hwang and Kim, 2011; Russo-Spena and Mele, 2012; Quero and Ventura, 2015; Witell et al., 2011), many articles appear to include one or more terms of the co-design, co-production, and co-consumption terms. Chien and Chen (2010) reported on customer involvement, customer participation, and co-production; Gebauer et al. (2010) proposed co-creation, engagement, co-design, co-production, and coconsumption (pro-sumption); Russo-Spena and Mele (2012) covered co-creation and co-design and finally, Quero and Ventura (2015) suggested co-creation, co-design, and co-consumption. More specifically, Quero and Ventura (2015) proposed co-design and co-consumption as certain types of co-creation; Chien and Chen (2010) defined co-production as customers role in the early phases of developing new offerings; Russo-Spena and Mele (2012) termed co-design as a phase of the co-creative innovation process; and Witell et al. (2011) implicated that pro-sumption denotes co-creation, but only during the consumption phase. Conclusively these findings further support the authors' proposition that co-design, co-production, and coconsumption can be considered specific forms of co-creating services that occur in particular phases of the service process.

\section{Conclusion: An Integrative Framework for Co-Creating Services}

This focused review set out to conceptually clarify the co-creation of services and name its forms and outcomes. Grounded in the findings of the thematic analysis of forms, themes, and outcomes in the examined literature, the authors develop an integrative framework to achieve comprehensive conceptualisation of co-creation of services and the associated terminology (Figure 1.3) and further suggest examples of industry practices for the specific forms of cocreating services (Table 1.9)

\section{The Framework}

Figure 1.3 reflects the properties of the newly developed definition of co-creating services: service providers and customers integrate their resources collaboratively when and if they are involved, engaged, and participate in the co-creation of services. This co-creation of

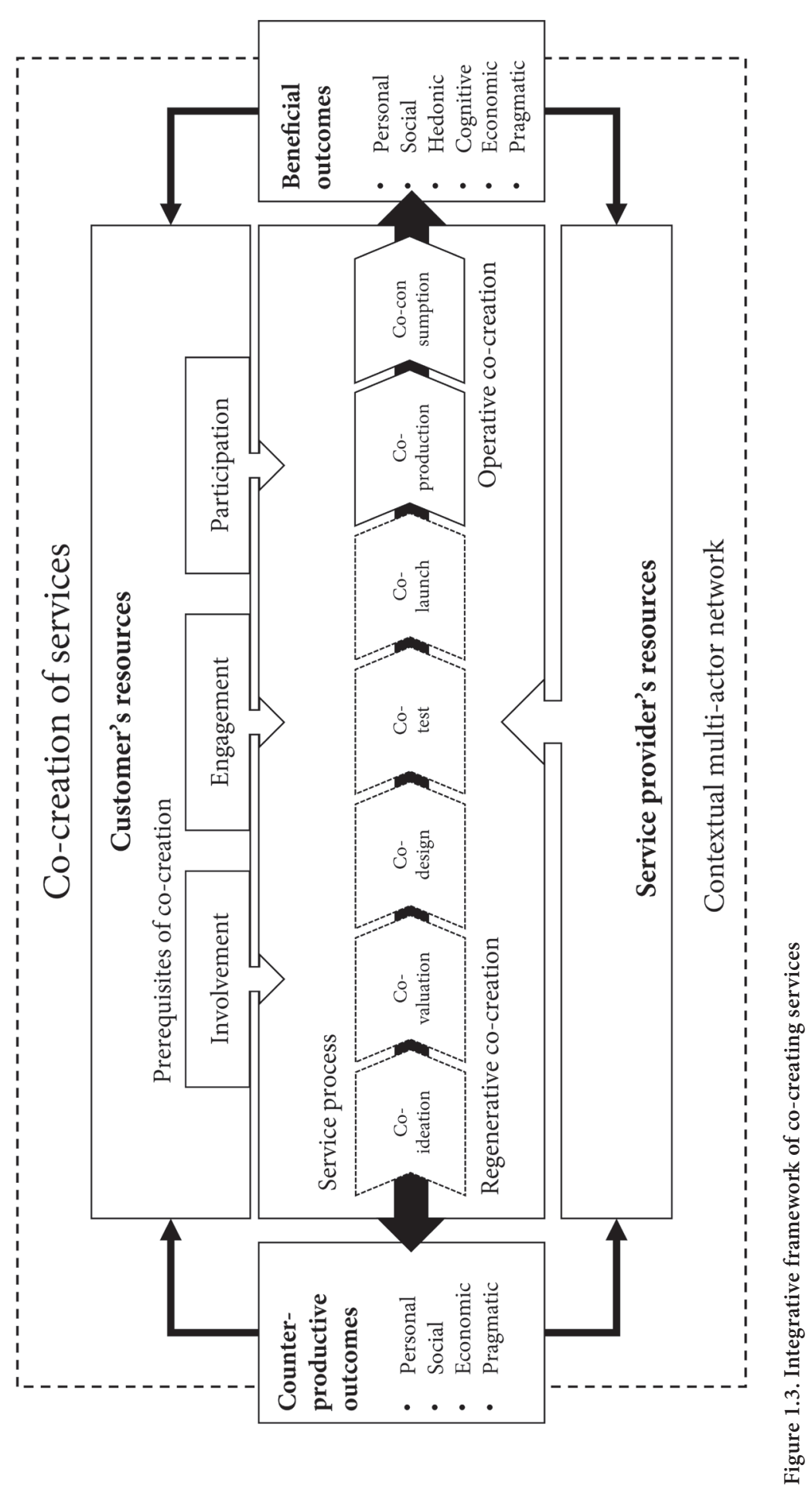


services may manifest itself in specific forms depending on the phases of the service process as co-ideation, co-valuation, co-design, co-testing, co-launching, co-production, and coconsumption. For customers and providers, the co-creation of services enables beneficial and counterproductive outcomes, which can be classified into personal, social, hedonic, cognitive, economic, and pragmatic experience dimensions. Finally, beyond the customer-provider dyad, the thematic analysis identified the theme of "multi-actor emphasis," which underlines the influence of a contextual, multi-actor network on all activities occurring as part of cocreating services.

In conclusion, involvement, engagement, and participation are necessary but not sufficien conditions that must be fulfilled altogether for the co-creation of services to occur (Verleye, 2015; Voorberg et al., 2015; Yi and Gong, 2013); yet these prerequisites cannot ensure that co-creation of services occurs. For beneficial co-creation to take place, both the customer and the service provider must be involved, engaged, and participating constructively and actively (Auh et al., 2007; Dong and Sivakumar, 2017). The co-creation of services can manifest itself in specific forms along the phases of the service process. More specifically, the authors use the label "regenerative co-creation"1 to refer to co-creation forms in earlier phases of the service proces that point towards innovating the service-co-ideation, co-valuation, co-design, co-test, and co-launch. "Operative co-creation"2 captures co-production and co-consumption and denotes a customer-specific service event or encounter that may occur again several times, leading at most to incremental innovation.

\section{Examples of Industry Practices}

Table 1.9 provides industry examples of the specific forms of co-creating services. As the examples demonstrate, co-creation can be induced to enhance both the core service as well as supporting and augmenting services (cf. Ozment and Morash, 1994). To collaboratively generate ideas (co-ideation), service providers can host open contests and crowdsourcing events, as E.ON did (Verrinder, 2012). Like LEGO, they could also limit participation to a selected user group (Chesbrough, 2011; Gyrd-Jones and Kornum, 2013). Threadless invited customers to vote, appraise, and evaluate ideas for t-shirt designs (co-valuation; Ogawa and Piller, 2006 Russo-Spena and Mele, 2012). Customers can be invited to co-design with the aim of bridging the gap between identified needs and feasible solutions (Russo-Spena and Mele, 2012). For example, Netflix held a competition inviting its audience to help develop recommendations (Prpić et al., 2015), and DHL invited selected stakeholder groups to participate in co-creative design workshops (DHL Solutions \& Innovations, 2017). Other specific forms of co-creating services include co-testing, where customers and providers collaboratively prototype the service

In Table I.2 synonymously referred to as co-creation in the design and development of services

2In Table I.2 synonymously referred to as co-creation in the delivery and consumption of services before its market introduction, and co-launching by integrating the customer in launch activities (Chesbrough, 2011; Ogawa and Piller, 2006; Russo-Spena and Mele, 2012). As an iconic example of co-production, IKEA redefined the roles and relationships of the traditiona furniture business beyond co-producing furniture (Normann and Ramirez, 1993). Finally, how Harley-Davidson interacts with its customers through the brand community HOG illustrates the co-consumption form (Fournier and Lee, 2009).

Table 1.9. Examples of industry practices for co-creating services

\begin{tabular}{|c|c|c|c|}
\hline $\begin{array}{l}\text { Specific forms of } \\
\text { co-creating services }\end{array}$ & $\begin{array}{l}\text { Industry } \\
\text { practice }\end{array}$ & Example & Source \\
\hline \multirow[t]{2}{*}{ Co-ideation } & $\begin{array}{l}\text { Idea } \\
\text { crowdsourcing }\end{array}$ & $\begin{array}{l}\text { E.ON launched an open idea submission } \\
\text { contest to find new services through its } \\
\text { online community }\end{array}$ & Verrinder (2012) \\
\hline & $\begin{array}{l}\text { Lead user } \\
\text { involvement }\end{array}$ & $\begin{array}{l}\text { LEGO Mindstorm supplies software } \\
\text { to members to reprogram and develop } \\
\text { programmable robots }\end{array}$ & $\begin{array}{l}\text { Chesbrough } \\
(2011) \text {; Gyrd- } \\
\text { Jones and } \\
\text { Kornum }(2013)\end{array}$ \\
\hline Co-valuation & $\begin{array}{l}\text { Commenting } \\
\text { and voting }\end{array}$ & $\begin{array}{l}\text { Users submit and vote for designs presented } \\
\text { by Threadless }\end{array}$ & $\begin{array}{l}\text { Ogawa and Piller } \\
\text { (2006); Russo- } \\
\text { Spena and Mele } \\
(2012)\end{array}$ \\
\hline \multirow[t]{3}{*}{ Co-design } & $\begin{array}{l}\text { Solution } \\
\text { crowdsourcing }\end{array}$ & $\begin{array}{l}\text { Netflix Prize was a competition to find } \\
\text { a solution to improving Netflix's accuracy } \\
\text { in predicting the enjoyment level for a user } \\
\text { for a given movie based on extant movie }\end{array}$ & Prpić et al. (2015) \\
\hline & Co-creation & preferences & DHL Solutions \\
\hline & workshops & $\begin{array}{l}\text { DHL fosters co-creation workshops with } \\
\text { customers to co-design solutions that } \\
\text { improve the service experience }\end{array}$ & $\begin{array}{l}\text { \& Innovations } \\
(2017)\end{array}$ \\
\hline Co-test & $\begin{array}{l}\text { Open service } \\
\text { innovation }\end{array}$ & $\begin{array}{l}\text { IBM and customers jointly develop and co-test } \\
\text { solutions and share the resulting knowledge as } \\
\text { part of the First-of-a-Kind initiative }\end{array}$ & $\begin{array}{l}\text { Chesbrough } \\
\text { (2011) }\end{array}$ \\
\hline Co-launch & Co-launch & $\begin{array}{l}\text { At Threadless, besides submitting and voting for } \\
\text { designs, users share responsibility for the launch } \\
\text { of the design by advertising, shooting for } \\
\text { catalogues, and wooing new customers }\end{array}$ & $\begin{array}{l}\text { Ogawa and Piller } \\
\text { (2006); Russo- } \\
\text { Spena and Mele } \\
(2012)\end{array}$ \\
\hline Co-production & Co-production & $\begin{array}{l}\text { IKEA co-produces improvements in family } \\
\text { living with its customers by guiding them to } \\
\text { assemble their own furniture }\end{array}$ & $\begin{array}{l}\text { Normann and } \\
\text { Ramirez (1993) }\end{array}$ \\
\hline Co-consumption & $\begin{array}{l}\text { Brand } \\
\text { communities }\end{array}$ & $\begin{array}{l}\text { The Harley Owners Group (HOG) by } \\
\text { Harley-Davidson connects highly engaged } \\
\text { customers and interacts with them through } \\
\text { online and offline channels }\end{array}$ & $\begin{array}{l}\text { Fournier and } \\
\text { Lee (2009) }\end{array}$ \\
\hline
\end{tabular}




\section{Discussion}

\section{Research Implications}

Reacting to the conceptual pluralism around the concept of co-creating services (Dong and Sivakumar, 2017; Galvagno and Dalli, 2014; Voorberg et al., 2015), this chapter clarifies, synthesises, and develops knowledge about co-creating services by investigating the existing body of knowledge in five scholarly service journals. First, the terminology for co-creating services emerged from the articles based on the workflow of inductive analysis. Further systematic analyses of the articles investigated the conceptualisations of the terminology; identified themes that illustrate how different aspects of co-creation are emphasised across the service literature set; developed a typology of co-creation outcomes; and synthesised an integrative conceptual framework for co-creating services to support the research streams investigating co-creation and the customer-provider interface in services.

This research extends the analyses on co-creation and related terminology (Chathoth et al., 2013; Lusch and Vargo, 2006; O'Hern and Rindfleisch, 2010) by providing several new theoretical contributions: first, the study reduces conceptual pluralism around co-creating services by clearly disentangling its relationship to related terminology, such as involvement, engagement, participation, co-design, co-production, and co-consumption. Second, the study develops an explicit definition of co-creating services based on conceptual analysis of the identified terminology and the thematic analysis of the literature. Third, the study develops a typology of co-creation outcomes by extending the co-creation experience dimensions of Verleye (2015) by adding the beneficial and counterproductive outcome dimensions and comparing the outcomes reported for customers and for service providers. Fourth, the study develops an integrative framework of co-creation of services to connect the terminology and to visualise the conceptual dynamics.

The findings of the review encourage using "co-creation of services" as an encompassing concept to integrate the other terms. The thematic analysis shows that the co-creation term as such is the only term that is utilised across all seven themes identified. Furthermore, cocreation has the broadest presence in the experience-centric outcome types identified for both service providers and customers.

Involvement, engagement, and participation are identified as necessary prerequisites to cocreate, while co-design, co-production, and co-consumption are considered specific forms of co-creating services that range from regenerative to operative in nature, depending on the phase of the service process. Comparing the terminology across the associated themes shows that literature using involvement, engagement, and participation terms recurrently highlights customer-provider collaboration, which underlines the importance of these terms for the co-creation of services. Literature exploring co-design, co-production, and coconsumption usually emphasises the respective phases of the service process, which further supports the proposition that co-design, co-production, and co-consumption can be considered specific forms of co-creating services.

In response to calls for a less abstract and shared understanding of co-creation (Galvagno and Dalli, 2014; Saarijärvi et al., 2013), this research examines the conceptualisations of cocreating services and shows that no definition appears more than four times across the 80 articles. To introduce conceptual coherence, a thematic analysis revealed emergent concepts associated with different conceptualisations of co-creating services, recognised similar themes that have been expressed using various wordings, and synthesised these patterns into an explicit definition of co-creating services (Fereday and Muir-Cochrane, 2006; Green et al., 2017; Thomas and Harden, 2008). The developed definition of co-creating services should increase consistency and support the comparison and synthesis of findings from studies using different terms.

By responding to calls for more research on co-creation outcomes (e.g., Voorberg et al., 2015), this research also differentiates, synthesises, and strengthens the body of knowledge discussing the outcomes that follow from co-creation. The authors extend existing reviews that cite the shortage of quantitative co-creation studies to consolidate the subsequent outcomes (Voorberg et al., 2015), by grounding the findings in 38 quantitative and 15 mixed methods articles. The typology of outcomes shows that there are beneficial outcomes for service providers and customers across all six co-creation experience dimensions. It further confirms the lack of counterproductive outcomes of co-creation and extends prior reviews that only suggest counterproductive outcomes for service providers, by noting some counterproductive outcomes for customers too (Mustak et al., 2013, 2016). Comparing the terminology across the typology of outcomes suggests that the involvement term is predominantly used to convey outcomes for service providers and focuses on the cognitive, economic, and pragmatic experience dimensions. On the contrary, the engagement term mostly relates to outcomes for customers and focuses on the personal and social experience dimensions. Finally, the participation term is associated with outcomes that are relatively evenly divided across the experience dimensions for service providers and customers. Interestingly, this finding shows that the involvement term is used more frequently to denote outcomes for the service provider's side, the engagement term to convey outcomes for the customer's side, and the participation term to refer to outcomes for both sides.

Finally, this research nurtures inquiries into the dynamics and content of co-creation (Payne et al., 2008; Pinho et al., 2014) by providing an integrative framework for the co-creation of services. The framework illustrates the newly developed definition of co-creating services, including its forms and outcomes. It further depicts the influence of the contextual multi-actor network, which has been emphasised in the literature using engagement and co-design terms. Overall, the integrated framework of co-creating services contributes to service management 
research by reducing the confusion around co-creation (Dong and Sivakumar, 2017; Saarijärvi et al., 2013; Voorberg et al., 2015) through the visual representation of its conceptual nature, forms, and outcomes.

\section{Managerial Implications}

Saarijärvi et al. (2013) argued that the emphasis on theorising around the concept of co-creation leaves practitioners wondering about its practical relevance. Much of this confusion arises from the conceptual pluralism and lack of integrative work. This research clarifies the dynamics of the terminology and arranges it in the form of an integrative framework, as visualised in Figure 1.3. Co-creation is connected to topics that are more familiar than "value," in essence the phases of the service process and the experience-centric typology of outcomes. The study also takes a step towards practice by connecting the various forms of co-creation with identified beneficial and counterproductive outcomes. Service providers must understand these outcomes in order to be able to mitigate counterproductive outcomes of co-creation and to assess the usefulness of their ideas to involve and engage their customers, and then incentivise them accordingly. Furthermore, knowledge of these outcomes may be leveraged to generate internal firm buy-in and motivate employees.

The typology of outcomes (Table 1.8) points to several ways to stimulate fruitful collaboration. Participating customers should be actively involved and engaged. Service managers can device different tactics to motivate customers to co-create, highlighting either the recognition customers can get from co-creating (personal dimension), the identification and improved relationship with the provider (social), the enjoyment experienced during collaborative activities (hedonic), the new knowledge and skills gained (cognitive), the monetary compensation offered (economic), or the improved service quality and service-customer fit (pragmatic).

There are also different tactics to motivate employees and garner top-level management support. To incentivise co-creating services in their organisation, service managers could emphasise the improved provider image and job satisfaction following co-creation (personal dimension), the potential for contract retention and synergy with customers (social), the improved working environment for employees (hedonic), the beneficial effect on new service development and creativity (cognitive), the accelerated market performance and service quality performance (economic), or the improved speed to market and support for novel services (pragmatic).

The suggested typology of outcomes raises awareness of counterproductive outcomes following the co-creation of services. Service organisations may avert counterproductive outcomes by developing strategies to foster trust and commitment to prevent customers feeling that their loyalty is exploited. Appropriate strategies are also needed to counter declining efficiency due to customers' perceptions of diminishing service quality and ease of use. In addition, service managers need to prevent uncertainty about service ownership through service protection. The success of co-creating services may further be improved by developing strategies to reduce role conflict with customers, which causes an increase in employees' work stress.

Finally, the findings of this review support service managers by exemplifying industry practices for the specific forms of co-creating services in Table 1.9. Service managers seeking to collaborate with customers must first decide in which service phase this co-creation should take place. Different forms of co-creating services may lead to different outcomes, which have to be assessed in order to determine the usefulness of the collaboration idea and effective incentives for participating customers and employees.

\section{Limitations}

As with all research, there are limitations that set boundaries for the generalisation of the current findings. First, the study focused on five service research journals to keep the scope of the inductive analysis step manageable. The set of articles thus is a representative and carefully chosen sample, not the entire population of articles on the subject, and hence literature beyond the studied journals could potentially contribute with further analytica content categories. The inductive aspects of the review process would have not been possible with more sources, considering that this study examined the abstracts of 2,466 service journal articles and fully analysed 80 articles. However, as the current number of articles analysed is sufficient, the literature analysed broadly cites studies beyond the journals examined, and most categories saturated strongly in the data set, it is reasonable to consider that the findings are robust. Second, to keep the conceptual complexity manageable during the analysis, this research analysed publications exploring the collaborative act in the customer-provider interface. Of course, while the vast majority of the literature focuses on customer-provider collaboration, other stakeholders exist in collaboration networks. Finally, the outcomes from co-creation may vary depending on the emotional intensity of the contexts and between commodity vs. noncommodity services. The 80 articles spread across 11 different service industries, whereas 27 studies did not specify one particular industry. Finance, healthcare, and telecommunications services lead with their 9-13 percent representations, which indicates that industry groups are too small for cross-comparison.

\section{Further Research}

The chapter discovers several avenues for further research. While the review concentrated on customer-provider co-creation, the thematic analysis reveals an emerging focus on co-creation in actor networks (e.g., Åkesson et al., 2016; Pinho et al., 2014), indicating that further research beyond the dyadic view is needed. The focused design of the current literature 
review invites a more exhaustive analysis to cover relevant research across a wider range of disciplines. Research is needed on the specific forms of co-creating services and subsequent outcomes. Aligning customers' co-creation efforts with requirements, providers need to anticipate which outcomes are most likely to accrue as a result of a specific co-creation form and whether outcomes differ between the forms of co-creation. The current analysis further identified a gap regarding the counterproductive or "negative" outcomes of co-creating services for the service provider or the customer, which should be more diligently investigated from the perspectives of all parties involved. Regarding the drivers of co-creating services, what stimulates involvement, engagement, and participation needs to be further specified. Service managers can use the typology of outcomes of this research to develop motivational strategies for customer-provider collaboration, but more research is needed on the relative importance of the outcome dimensions. Further empirical research should explore the dynamics of cocreating services in practice: how customers become involved, engaged, and participate in cocreating services. Also, moderating influences on the relationship between co-creating services and subsequent outcomes need to be explored, as disparities arise even in this rather narrow focus on customer-provider co-creation. For example, Carbonell et al. (2012) found that lead users have a positive effect on service newness, but relationally close customers beyond lead users do not. These outcomes of co-creating services are likely to vary between different contexts, especially due to their different emotional loadings. The dynamics of co-creation need empirical exploration comparing different service settings in order to formulate suitable strategies and approaches for different service contexts. 


\section{Chapter 2}

Driving Users' Behaviours and Engagement in Co-Creating Services

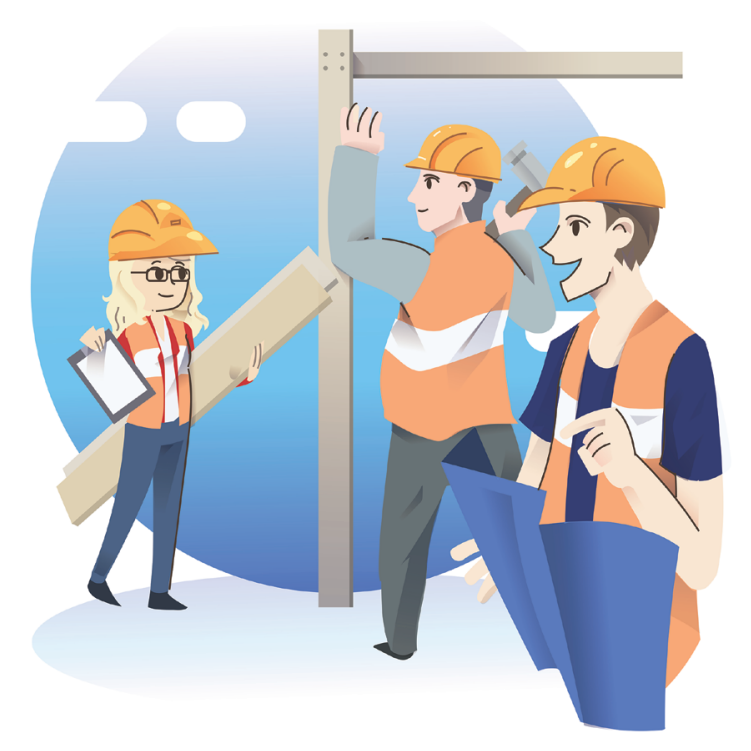

Following the theoretical planning of the house, workers have to be contracted, to build the house. They cannot work in isolation; the different elements and tasks in building a house are interdependent. It is thus essential that the workers want to work with one another. Choosing the right workers and engaging them to collaborate are driving forces of the success of a new house. In a similar manner, this chapter addresses the dearth of research pertaining to how to encourage co-creation behaviours by users and drive their engagement in such efforts. In a common user scenario of designing sport shoes, it investigates factors that determine users' behaviours during services co-creation. Furthermore, this chapter taps into the experience of design professionals and generates insights into the drivers and inhibitors of users' co-creation engagement; it also reveals the likelihood that different types of users engage in co-creation, as a result of their personality traits and demographics. 


\section{Chapter 2}

\section{Driving Users' Behaviours and Engagement in}

Co-Creating Services 


\section{Introduction}

"Normal" users, in contrast to lead users or professional developers (Enkel et al., 2005; Magnusson, 2009), increasingly must take an active role in the design and delivery of services to ensure the offerings meet their needs, which also allows service providers to establish competitive advantages (Carbonell et al., 2012; Prahalad and Ramaswamy, 2004b). In line with the definition developed in Chapter 1, co-creation of services, or services co-creation, refers to collaborative activities between a participating party, for instance a user, and a facilitating party, such as a service provider, within a contextual, multi-actor network that can lead to beneficial or counterproductive outcomes, through resource integration (Oertzen et al., 2018). Among other, the beneficial outcomes identified by prior research (Hoyer et al., 2010; Voorberg et al., 2015) include enhanced well-being (Engström and Elg, 2015), more innovative ideas (Witell et al., 2011), and competitive services (Carbonell et al., 2012). Nonetheless, Chapter 1 also suggested that co-creation may lead to counterproductive outcomes, as participants sometimes engage in deviant behaviours (Gatzweiler et al., 2017) or display non-collaborative behaviours (Kristal et al., 2018). In addition, many more users choose not to participate in co-creation than do participate (Kristal et al., 2016), and these two segments of users may differ notably in terms of their service demands (Carbonell et al., 2012; Enkel et al., 2005).

In this sense, despite growing scholarly attention devoted to co-creating services, the fundamental prerequisites for co-creation remain unclear, including who participates in co-creation, differences between participants and non-participants, and the source of such differences (Füller, 2010). Some studies predict effects of lead user characteristics or relational closeness to the service provider (Carbonell et al., 2012; Trischler et al., 2018a), but little research has attempted to specify how different factors, such as traits and demographics, might influence users' behaviours during co-creation (Neghina et al., 2017). This gap is problematic; positive co-creation outcomes require the inclusion of appropriate participants and their insights (Hoffman et al., 2010; Hoyer et al., 2010). Accordingly, researchers have called for greater insights into different antecedents of co-creation participation and their ability to transform users into co-creators (Gemser and Perks, 2015; Mustak et al., 2016). Therefore, this chapter asks,

\section{RQ1. What factors influence users' behaviours during services co-creation?}

Study 1 uses an experimental design with fictional scenarios, administered according to stratified sampling to a high-quality, online panel in Western Europe that provides a sample of 633 respondents with varied demographic traits.

This research also seeks to clarify the drivers and inhibitors of engagement in services cocreation, as well as which types of users are more likely to co-create. It does not distinguish different stages of the service process for co-creation; instead, the goal is to understand what 
makes users engage in it. Jaakkola and Alexander (2014) define engagement behaviours as voluntary resource contributions (e.g., to co-create) during interactions with a service provider, beyond mere transactions. Engagement behaviours thus have great potential value for service providers (Jaakkola and Alexander, 2014), yet relatively few users engage fully in co-creation (Hoyer et al., 2010), nor do scholarly insights reveal what causes them to do so (Füller et al., 2008; Neghina et al., 2017). Service providers therefore struggle to find and solicit suitable users as participants for co-creation activities. In line with extant calls for further research (Hoyer et al., 2010; Jaakkola et al., 2015), this research asks,

RQ2a. What drivers and inhibitors affect users' engagement in services co-creation? RQ2b. Which types of users are more or less likely to engage in services co-creation, according to their traits and demographics?

Study 2 in turn reports on the findings of two interactive research workshops with 38 design professionals conducted in a Western European country. The critical incident technique and affinity mapping technique provide insights into factors that influence users' engagement projective techniques (personas and anti-personas) shed light on the likelihood of different types of users to co-create, as a result of their traits and demographics.

By addressing these research questions, this chapter contributes to service research and practice in three main ways. First, it reveals how different factors influence users' behaviours during services co-creation. Practitioners, that is, service designers and service providers, can leverage these findings purposefully to design co-creation activities that match users behaviours, including those of people who are less likely to display certain behaviours. Second, the proposed framework of factors that drive or inhibit users' engagement in co-creation identifies task, person, and context determinants. It thus can guide practitioners to build conducive environments for co-creation. For example, person-related factors mostly depend on participating users, but task- and context-related factors generally are contingent on how the facilitating party (i.e., service designer or service provider) guides co-creation activity Third, a typology of users, according to their personas and anti-personas, indicates their likelihood to engage in co-creation, given their traits and demographics. Practitioners thus can select suitable participants in co-creation, which reduces the time and money investments required to identify and integrate potential collaborators, while also increasing the chances of a successful outcome.

Chapter 2 begins by reviewing extant literature on co-creating services and users' behaviours and their engagement in such efforts. This is followed by Study 1, which reports on a between-subjects, scenario-based experimental design to analyse the influence of situational, demographic, and dispositional factors on users' behaviours during services co-creation. Based on interactive research workshops, Study 2 examines the drivers and inhibitors of users' engagement in services co-creation and predicts the likelihood of different types of users to engage in co-creation. Finally, this paper concludes with a general discussion, implications, promising opportunities for further research, and limitations.

\section{Theoretical Background \\ Co-Creating Services}

Collaboration between providers and users is not new (Fuchs 1968), though early coproduction literature identified users as partial employees during service delivery (Mills and Morris, 1986), describing how they might visit a supermarket, select food, cart the food to the cashier, and transport it home (Bendapudi and Leone, 2003). Yet the role of users also has changed, from passive, isolated, and unaware to active, connected, and informed (Prahalad and Ramaswamy, 2004a). Co-creation participants in turn are more than production inputs that can increase operational efficiency; these well-informed agents can help service providers design and deliver superior offerings (Zwick et al., 2008). Users participate in co-creation activities spanning the entire service process, from ideation to consumption (Quero and Ventura, 2015 Russo-Spena and Mele, 2012), and produce diverse outcomes, such as innovative insights, launch support, and relationship quality (Ordanini and Parasuraman, 2011; Rusanen et al. 2014; So et al., 2016). In turn, inherent risks arise with any co-creation activity, because service providers must rely on the views and personalities of the participants, and face the challenge of serving a niche market only (Enkel et al., 2005). A clearer understanding of how to encourage co-creation behaviours more widely and facilitate appropriate participant selection may help mitigate these risks though (Enkel et al., 2005; Jaakkola et al., 2015; Neghina et al., 2017; Trischler et al., 2018a).

\section{Behaviours during Services Co-Creation}

Co-creation research often adopts macro- or meso-perspectives, rather than addressing microlevel interactions and behaviours (Neghina et al., 2017). Yet individual co-creation behaviours are critical, with notable effects on participants' enjoyment and satisfaction (Navarro et al., 2016; Yim et al., 2012). Yi and Gong (2013) propose that co-creation behaviours comprise both participation and citizenship behaviours. The former refer to the in-role behaviours needed for successful co-creation (Revilla-Camacho et al., 2015); the latter, extra-role behaviours that are voluntary and beyond participants' required roles (Bove et al., 2009). Human behaviour generally reflects the influences of three factors: (1) situational, such as the level of service customisation; (2) dispositional, including personality traits; and (3) demographic, for instance a person's age or gender (Mondak et al., 2010; Neghina et al., 2017). The precise effects of such situational, dispositional, and demographic factors on users' behaviours during co-creation are uncertain though, demanding more research attention, as addressed in Study 1 (Merz et al. 2018; Neghina et al., 2017; Sigala, 2009; Wu, 2011; Zhang et al., 2018). 


\section{Engagement in Services Co-Creation}

Two main challenges hinder users' efforts in services co-creation: (1) They are engaged but do not represent the target segment, or (2) they are representative of the typical target segment but not engaged. Some research suggests that 90 percent of people remain passive in response to online co-ideation solicitation, nine percent contribute a little, and only one percent actively engage (Kristal et al., 2016; Nielsen, 2006). Service providers may assume that the one percent contribution is sufficient for superior service design, especially if it comes from innovators or lead users, who tend to experience consumption needs ahead of trends and are early adopters of new offerings (Trischler et al., 2018a; Von Hippel, 1986). For instance, LEGO works with selected lead users in the Mindstorm User Group to encourage word-of-mouth and trust in new offerings (Gyrd-Jones and Kornum, 2013). However, focusing only on lead users or innovators may result in services that do not appeal to the majority (Magnusson, 2009). If the co-creators do not represent the entire target segment, service providers risk serving a niche market solely (Enkel et al., 2005). To avoid this possibility, they need to select potentia collaborators purposefully, to represent the targeted segment at large. The second challenge for service providers, as addressed in Study 2, arises due to a lack of insights into how users' co-creation engagement might be stimulated, which jeopardises provider-initiated co-creation due to difficulties in attracting and activating participants (Fu et al., 2018; Füller et al., 2008 Neghina et al., 2017). That is, service providers need more information about how users can be engaged in co-creation, as well as how to select them according to their likelihood to co-create.

\section{Study 1: Scenario-Based Experiments}

\section{Study Aim and Conceptual Model}

To investigate what transforms users into co-creators, Study 1 examines antecedent categories of co-creation behaviours (Gemser and Perks, 2015), according to the three groups of factors in Figure 2.1: situational, demographic, and dispositional.

\section{Behaviours during Services Co-Creation}

The multidimensional, third-order factor model proposed by Yi and Gong (2013) has been used frequently to measure co-creation behaviours (Delpechitre et al., 2018; Revilla-Camacho et al., 2015; Tommasetti et al., 2017). It formatively comprises participation and citizenship behaviours as second-order factors, each of which reflects four dimensions (Yi and Gong, 2013). Due to concerns about the validity of the third-order factor (Neghina et al., 2015) and the possibility of separating the second-order constructs (Yi and Gong, 2013), this study operationalises participation behaviours and citizenship behaviours as distinct dependent variables that represent users' behaviours during services co-creation. Furthermore, this experimental study assesses intended behaviours as a proxy for actual behaviours, a common

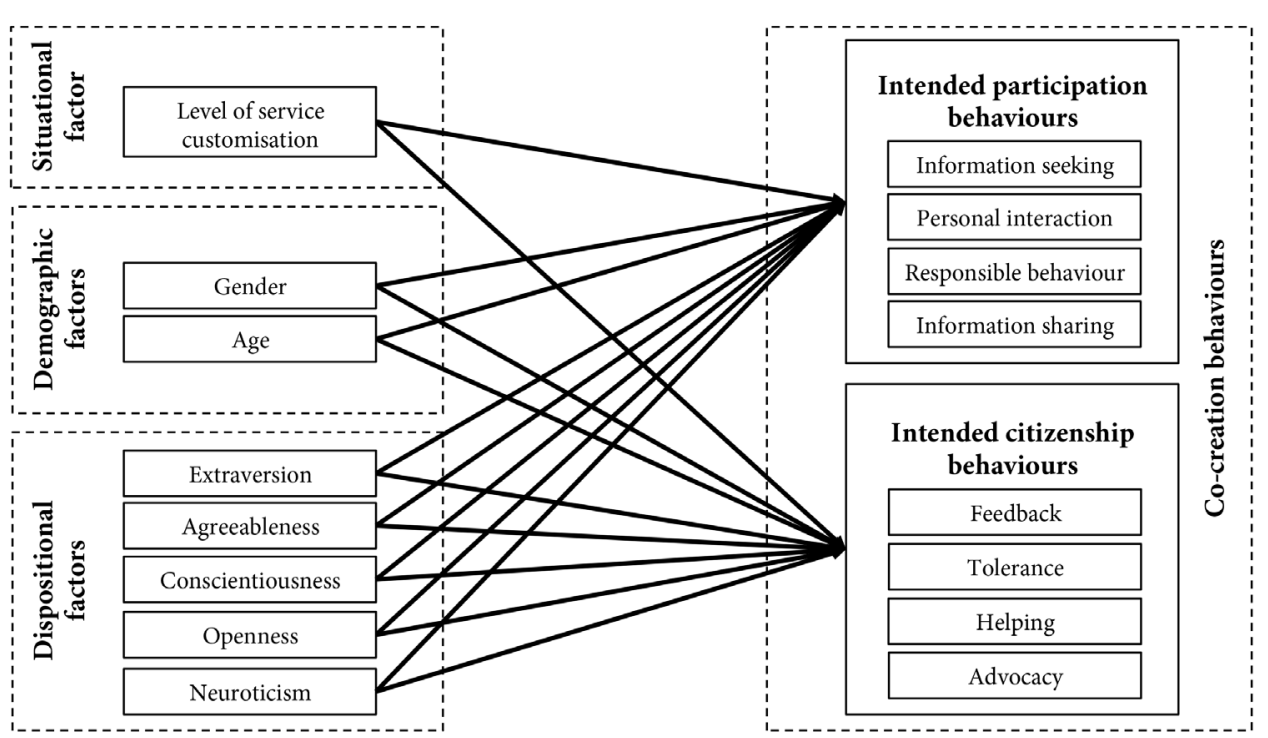

Figure 2.1. Conceptual model for Study 1

approach given the strong effect of intentions on behaviours (Ajzen 1991; Fishbein and Ajzen, 1975; Xie et al., 2008). Users' participation behaviours during co-creation comprise (1) information seeking regarding service requirements, (2) personal interactions with the service provider, (3) responsible behaviour that acknowledges their responsibilities, and (4) information sharing about their needs and expectations. Citizenship behaviours instead consist of (1) feedback including suggestions for long-term improvements to the service, (2) tolerance, such as patience when the service does not meet expectations, (3) helping others, and (4) advocacy or recommending the service to others (Yi and Gong, 2013).

\section{Situational Factor}

The focal situational factor is the level of service customisation (Etgar, 2008). According to expectancy theory (Vroom, 1964), engagement in activities depends on the desirability of the anticipated outcomes. Independent of service context-specific particularities, Heidenreich et al. (2015) suggest service customisation is the primary benefit and motivator of co-creation and effort and information provision are its primary costs. To attain the benefit (customised service), users accept the costs, imposed by specific behaviours. For services with greater customisation, users must invest relatively more effort and provide more information in exchange (Etgar, 2008; Heidenreich et al., 2015; Hoyer et al., 2010). Contrary to users participation behaviours, which are necessary behaviours (i.e., efforts) needed for successful cocreation, users' citizenship behaviours are voluntary (Revilla-Camacho et al., 2015). Reciprocity theory suggests that users engage in favourable behaviours in response to a perceived kindness 
(Falk and Fischbacher, 2006). As such, users are motivated to engage in citizenship behaviours based on performance perceptions of the service provider or a desire to support the service provider (Choi and Lotz, 2016). This link is also evident for the customisation of a servicefor instance, Oertzen and Odekerken-Schröder (2019) show that higher service customisation leads to an increase in users positively commenting to others about the service provider. Thus,

H1. For a highly customised service, users display more (a) participation and (b) citizenship behaviours than for a less customised service.

\section{Demographic Factors}

Demographics influence behavioural patterns (Cambra-Fierro et al., 2011, 2017). For example, women tend to want to be included in service decisions and are more democratic and participative than men (McColl-Kennedy et al., 2003). Fisher and Grégoire (2006) also find that men's satisfaction depends on their ability to impose their preferences, but for women, satisfaction requires cooperative behaviours. Women also tend to exhibit a communal orientation, emphasising relationship maintenance and social behaviours (Fisher and Grégoire, 2006; Rudman and Glick, 2001). Thus,

H2. Women are more likely than men to display (a) participation and (b) citizenship behaviours during services co-creation.

Despite its likely significance, age rarely has been investigated in studies of participation and citizenship behaviours (Delpechitre et al., 2018; Navarro et al., 2016; Revilla-Camacho et al., 2015; Vega-Vazquez et al., 2013; Yi and Gong, 2013). Understanding the impact of age on behaviours is essential though, especially in the context of globally aging populations (Simcock et al., 2006). With increasing age, people tend to become more conservative, with less ability to adapt after changes, and more reluctant to use technologies that might be used to facilitate co-creating services (Niessen et al., 2010; Simon and Usunier, 2007). Noting the often unpredictable, possibly chaotic nature of co-creation activities (Fisher and Smith 2011), age seemingly might hinder co-creation behaviours. That is, older users may display less participation and citizenship behaviours, due to their reduced adaptability and greater conservatism, compared with their younger counterparts. Thus,

H3. Users' age has a negative effect on their (a) participation and (b) citizenship behaviours during services co-creation.

The level of users' education is included as a control variable, due to its potential influence on behaviour patterns (Cambra-Fierro et al., 2011; Moliner-Velázquez et al., 2015), but lack of theoretical insight as to the direction of this influence.

\section{Dispositional Factors}

Personality traits are dispositional factors; they form part of a person's inherent character and reflect relatively stable patterns of thinking, feeling, and behaving (Costa and McCrae, 1995). Co-creating services depends on personality traits, because different participants influence the co-creation experience differently (Prahalad and Ramaswamy, 2004a, 2004b) such that their personality traits affect their responses and intentions (Ferguson et al., 2010). Successful co-creation also depends on personality dynamics (Etgar, 2008); some users exhibit higher probability of co-creating services due to their personality traits (Zhang et al., 2018). Understanding which personality traits tend to prompt beneficial co-creation behaviours thus is essential. Few empirical studies link personality traits to co-creation; many more call for further research on this topic (Merz et al., 2018; Wu, 2011; Zhang et al., 2018).

Considerable literature identifies the effects of personality traits on other constructs, such as divergent thinking (Chamorro-Premuzic and Reichenbacher, 2008), word-of-mouth (Ferguson et al., 2010), or relationship formation (Bove and Mitzifiris, 2007). The mixed results indicate significant effects of personality traits on behaviours (Chamorro-Premuzic and Reichenbacher, 2008; Ferguson et al., 2010) or not (Bove and Mitzifiris, 2007; Sergeeva and Radosavljevic, 2012). Accordingly, the current research explores the influence of the commonly used "Big Five" personality trait taxonomy (John and Srivastava, 1999) on participation and citizenship behaviours. The five traits can be described as follows (Bove and Mitzifiris, 2007; Costa and McCrae, 1995; John and Srivastava, 1999). First, extraversion implies being talkative, energetic, assertive, gregarious, outgoing, and enthusiastic; introversion instead signifies being shy and quiet. Second, agreeableness generally reflects good-natured, trusting, cooperative, compliant, modest, and tender attitudes, unlike a person who is demanding, stubborn, cold, and inflexible. Third, conscientiousness describes a person's sense of being dependable, responsible, deliberate, and orderly, rather than lazy and impulsive. Fourth, openness embodies artistic, curious, broad-minded, and intellectual traits, with a reverse pole of being closed to experience, such that the person is narrow-minded, unimaginative, and not open to change. Fifth, neuroticism, in contrast with emotional stability, captures a person who is anxious, easily upset, irritable, self-conscious, and moody. Because co-creation represents a sociable, cooperative, deliberate, but broad-minded activity, the first four traits should exert positive effects on co-creation behaviours, whereas neuroticism may have a negative effect, because neurotic people tend to feel anxious and shy (John and Srivastava, 1999) and are thus less likely to co-create. Similarly, neuroticism has a negative effect on divergent thinking, but extraversion and openness have positive influences (Chamorro-Premuzic and Reichenbacher, 2008). Thus,

H4. Being extraverted makes users more likely to display (a) participation and (b) citizenship behaviours during services co-creation.

H5. Being agreeable makes users more likely to display (a) participation and (b) citizenship behaviours during services co-creation. 
H6. Being conscientious makes users more likely to display (a) participation and (b) citizenship behaviours during services co-creation.

H7. Being open makes users more likely to display (a) participation and (b) citizenship behaviours during services co-creation.

H8. Being neurotic makes users less likely to display (a) participation and (b) citizenship behaviours during services co-creation.

\section{Research Setting}

The operationalisation of the conceptual model uses a between-subjects, scenario-based experiment that manipulates the level of service customisation (see Appendix A at the end of this chapter). Prior research also has used scenarios to study participation in co-creation activities (e.g., Bendapudi and Leone, 2003; Dong et al., 2015). The scenarios for this study describe DYS, the Design Your Shoes service, a fictional, Internet-based service that allows users to design a sports shoe, with different levels of customisation (Heidenreich et al., 2015). The service represents co-creation in later stages of the service process, during the service delivery, denoting a user-specific service event with limited potential for innovation (Oertzen et al., 2018). The scenarios and setting (1) are intuitive and easily understandable for participants of different ages, genders, and education levels; (2) have been established previously in a cocreation study by Heidenreich et al. (2015), which enhances their reliability and validity; and (3) represent a common context for co-creation research (Kristal et al., 2016)

The participants came from a non-commercial, online consumer panel in Western Europe, which offers stratified sampling and thus provided a representative sample in terms of age, gender, and education. The panel meets quality standards of the International Organization for Standardization (ISO), and helps reduce the risk of participant misbehaviour and invalid data participants receive invitations to complete no more than ten surveys each year, rather than self-selecting (Goodman and Paolacci, 2017).

\section{Data Collection and Measurements}

The questionnaire was developed in English and translated to the national language, after which it was internally pretested by the authors and researchers employed by the consumer panel, leading to minor wording changes. A first pretest $(n=96)$ showed that the manipulation was not sufficiently strong. The initial design included three service customisation levels (low, medium, high), but to reinforce the differences between the levels, the medium level was eliminated and the opposite poles were strengthened. A second pretest $(n=65)$ indicated significant differences for the low and high levels of service customisation, which required varying degrees of information provision and effort from participants (Dong et al., 2015; Heidenreich et al., 2015) (see Appendix A)
The introduction to the survey briefly described the setting and service. Participants then were assigned randomly to the low or high service customisation scenario and completed the manipulation and realism checks, followed by indicators of their intended co-creation behaviours. The survey finished with questions about the participants' personality traits, sports behaviours, and basic demographic information.

The level of service customisation was operationalised through dichotomous information in form of a dummy variable $(0=$ low, $1=$ high $)$. The scales for the other constructs were adapted from existing literature and used seven-point Likert scales ( $1=$ strongly disagree, $7=$ strongl $y$ agree). The manipulation check used three items adapted from Heidenreich et al. (2015), and the realism check relied on two items from Dabholkar and Bagozzi (2002). The 44 items in the Big Five inventory measured personality traits (John and Srivastava, 1999). The measures of intended participation and citizenship behaviours came from the multidimensional scale proposed by Yi and Gong (2013), but rather than actual behaviours, this research uses intended behaviours, as is common in previous studies, because fictional scenarios make it challenging to measure actual behaviours (Xie et al., 2008), but intentions have strong effects on behaviours (Ajzen 1991; Fishbein and Ajzen, 1975). Sports behaviour, which represents a control variable was measured with a single item: "I consider myself as someone with active sports behaviour." Finally, basic demographic information (age, gender, education) had been registered previously with the consumer panel; participants confirmed it at the end of the questionnaire.

\section{Results}

From the 1,190 people invited to participate, there was a 53.20 percent response rate, resulting in a final sample of 633 respondents (see Appendix B for the demographic profile) The manipulation of service customisation was effective $\left(\mathrm{M}_{\text {low }}=4.31, \mathrm{M}_{\text {high }}=4.95 ; F=3.35\right.$, $p<0.001)$, and the scenarios were perceived as realistic $\left(\mathrm{M}_{\text {realism }}=4.82\right)$. Partial least squares structural equation modelling (PLS-SEM) in SmartPLS Version 3 is well suited for this research, because the path model is complex, the number of constructs surpasses six, and the constructs have more than four items (Sarstedt et al., 2017). Moreover, PLS-SEM can test for hierarchical construct models, such as the second-order participation and citizenship behaviours constructs (Wetzels et al., 2009).

\section{Measurement Mode}

To purify the measurement model and establish unidimensionality, this study started with a confirmatory factor analysis. This led to the exclusion of 19 items pertaining to the personality traits, because their construct loadings were considerably below 0.63 , which is considered the threshold for very good factor loadings as it captures forty percent of overlapping variance (Comrey and Lee, 1992; Tabachnick and Fidell, 2013). Although seemingly substantial, this 
reduction is common for personality traits; for example, Bove and Mitzifiris (2007) exclude 22 items from their 39 personality measures. At least 4 items remain for each personality construct, which is sufficient for accurate predictions (Hair et al., 2014). The factor loadings sugges that the information seeking first-order construct does not load well on the participation behaviours second-order construct, so it was omitted from further analysis, as was the case in prior studies (Navarro et al., 2016; Revilla-Camacho et al., 2015; Vega-Vazquez et al., 2013). The first tolerance item and first information sharing item loaded sufficiently on the first-order construct but achieved a relatively low loading on their respective second-order constructs and thus were excluded.

In support of convergent validity, Table 2.1 shows that all the outer loadings exceed 0.60 and are statistically significant $(p<0.001)$, and the average variance extracted (AVE) for each construct surpasses the suggested threshold of 0.50 (Fornell and Larcker, 1981; Hair et al., 2014). Discriminant validity was assessed through two approaches. First, the Fornell-Larcker criterion, which requires that the square root of the AVE for any construct is greater than it correlations with other constructs in the model (Fornell and Larcker, 1981), was confirmed for all constructs (Appendix C). Second, the heterotrait-monotrait ratio of correlations (HTMT) provides an estimate of the construct correlations (Henseler, 2017), and the largest value is 0.67 (Appendix D), well below the threshold of 0.85 (Sarstedt et al., 2017). To construct confidence intervals for the HTMT values, a bootstrapping procedure included 5,000 samples (Sarstedt et al., 2017). Because the value 1.00 is not contained within any confidence interval, all the HTMT values are significantly different from one. Both approaches support the discriminant validity of the constructs. Furthermore, in support of reliability, the Cronbach's alpha $(\alpha)$ values are acceptable and range between 0.73 and 0.98 (Nunnally, 1978); the lowest composite reliability $\left(\rho_{c}\right)$ value is 0.83 , well above the expected threshold of 0.60 (Bagozzi and Yi, 1988); and the consistent reliability coefficient $\left(\rho_{\mathrm{A}}\right)$ values are all above the minimum level of 0.70 (Dijkstra and Henseler, 2015; Sarstedt et al., 2017). Thus, all constructs exhibit sufficient levels of reliability.

In an ex ante effort to reduce potential common method bias (CMB), extensive pretesting ensured that the items were easily understandable, participants were informed that there are no right or wrong answers, and anonymity was guaranteed (Podsakoff et al., 2012). Ex post, Harman's single-factor test (Podsakoff et al., 2003) affirms that no factor accounted for the majority of the items' covariance. In a full collinearity test, all constructs were linked to new, random dummy variable (Kock and Lynn, 2012). Because the variance inflation facto (VIF) values were lower than 3.30, CMB does not appear to be an issue. Finally, the construct intercorrelations (Appendix C) show no strong correlations (highest $r=0.69$ ), whereas $\mathrm{CMB}$ usually results in correlations greater than 0.90 (Pavlou et al., 2007). Thus, CMB is not a concern for this study.

\begin{tabular}{|c|c|c|c|c|c|c|}
\hline \multirow[b]{2}{*}{ First-order construct (mean; standard deviation) } & \multicolumn{3}{|c|}{ Convergent validity } & \multicolumn{3}{|c|}{ Reliability } \\
\hline & $\mathrm{OL}$ & $t$-value ${ }^{\mathrm{b}}$ & AVE & $\alpha$ & $\rho_{\mathrm{C}}$ & $\rho_{\mathrm{A}}$ \\
\hline Extraversion $(4.85 ; 0.95)$ & & & 0.56 & 0.81 & 0.86 & 0.85 \\
\hline I see myself as someone who... & & & & & & \\
\hline - is talkative. & 0.79 & 27.50 & & & & \\
\hline - is full of energy. & 0.75 & 24.55 & & & & \\
\hline - generates a lot of enthusiasm. & 0.83 & 41.92 & & & & \\
\hline - has a confident personality. & 0.62 & 13.04 & & & & \\
\hline - is outgoing, sociable. & 0.74 & 21.01 & & & & \\
\hline Agreeableness $(5.28 ; 0.82)$ & & & 0.56 & 0.73 & 0.83 & 0.74 \\
\hline - is helpful and unselfish with others. & 0.78 & 28.71 & & & & \\
\hline - has a forgiving nature. & 0.70 & 18.55 & & & & \\
\hline - is generally trusting. & 0.69 & 18.30 & & & & \\
\hline - is considerate and kind to almost everyone. & 0.81 & 38.47 & & & & \\
\hline Conscientiousness $(5.50 ; 0.72)$ & & & 0.53 & 0.78 & 0.85 & 0.78 \\
\hline - does a thorough job. & 0.76 & 25.82 & & & & \\
\hline - is a reliable worker. & 0.64 & 14.58 & & & & \\
\hline - perseveres until the task is finished. & 0.70 & 16.02 & & & & \\
\hline - does things efficiently. & 0.79 & 32.24 & & & & \\
\hline - makes plans and follows through with them. & 0.73 & 21.02 & & & & \\
\hline Openness $(4.85 ; 0.89)$ & & & 0.53 & 0.83 & 0.87 & 0.87 \\
\hline - is original, comes up with new ideas. & 0.79 & 34.53 & & & & \\
\hline - is curious about many different things. & 0.75 & 22.22 & & & & \\
\hline - is ingenious, a deep thinker. & 0.71 & 21.08 & & & & \\
\hline - has an active imagination. & 0.63 & 15.85 & & & & \\
\hline - is inventive. & 0.75 & 26.77 & & & & \\
\hline - likes to reflect, play with ideas. & 0.74 & 23.68 & & & & \\
\hline Neuroticism $(2.92 ; 1.02)$ & & & 0.58 & 0.82 & 0.87 & 0.85 \\
\hline - is depressed, melancholic. & 0.64 & 8.89 & & & & \\
\hline - is relaxed, handles stress well. ${ }^{a}$ & 0.83 & 23.19 & & & & \\
\hline - is emotionally stable, not easily upset. ${ }^{a}$ & 0.82 & 24.34 & & & & \\
\hline - remains calm in tense situations. ${ }^{a}$ & 0.81 & 19.96 & & & & \\
\hline - gets nervous easily. & 0.70 & 10.26 & & & & \\
\hline Personal interaction $(5.94 ; 0.89)$ & & & 0.92 & 0.98 & 0.98 & 0.98 \\
\hline When using the "DYS-Design Your Shoes" service, & & & & & & \\
\hline - I intend to be friendly to the employee. & 0.96 & 119.89 & & & & \\
\hline - I intend to be kind to the employee. & 0.96 & 95.29 & & & & \\
\hline - I intend to be polite to the employee. & 0.98 & 158.40 & & & & \\
\hline - I intend to be courteous to the employee. & 0.98 & 233.36 & & & & \\
\hline - I intend to not act rudely to the employee. & 0.93 & 66.79 & & & & \\
\hline
\end{tabular}




\section{First-order construct (mean; standard deviation)}

Responsible behaviour $(5.31 ; 1.22)$

When using the "DYS-Design Your Shoes" service

- I intend to perform all the tasks that are required.

- I intend to adequately complete all the expected behaviours. 0.94

- I intend to fulfil responsibilities to the business of

the "DYS-Design Your Shoes" service.

- I intend to follow the employe's directives or orders. 0.90

Information sharing $(5.77 ; 0.97)$

When using the "DYS-Design Your Shoes" service

together with an employee, I would

- give the employee proper information.

$\begin{array}{ll}0.94 & 97.27\end{array}$

provide necessary information so that the employee $\quad 0.96 \quad 145.8$

could perform his or her duties.

- answer all the employee's service-related questions.

Feedback $(5.51 ; 0.93)$

With further regard to using the "DYS-Design Your

Shoes" service in reality:

- If I have a useful idea on how to improve the "DYS-Design 0.80

Your Shoes" service, I would let the employee know

- When I receive good service from the employee, I

would comment about it.

- When I experience a problem, I would let

the employee know about it.

Tolerance (4.72; 1.21)

With further regard to using the "DYS-Design Your

Shoes" service in reality:

- If the employee makes a mistake while using the "DYS-Design Your Shoes" service, I would be willing to be patient.

- If I have to wait longer than I normally expected to receive the "DYS-Design Your Shoes" service, I would be willing to adapt.

Helping $(4.28 ; 1.40)$

If I were to use the "DYS-Design Your Shoes" service,

I would.

- assist other customers if they need my help.

- help other customers if they seem to have problem.

- teach other customers to use the service correctly.

teach other customers to use the
Reliability

Convergent validity $\quad$ Reliability

$\begin{array}{lllll}0.85 & 0.94 & 0.96 & 0.94\end{array}$

106.3

132.67
Table 2.1. (continued)

\begin{tabular}{|c|c|c|c|c|c|c|}
\hline \multirow[b]{2}{*}{ First-order construct (mean; standard deviation) } & \multicolumn{3}{|c|}{ Convergent validity } & \multicolumn{3}{|c|}{ Reliability } \\
\hline & $\mathrm{OL}$ & $t$-value ${ }^{\mathrm{b}}$ & AVE & $\alpha$ & $\rho_{\mathrm{C}}$ & $\rho_{\mathrm{A}}$ \\
\hline $\begin{array}{l}\text { Advocacy }(4.61 ; 1.19) \\
\text { If I were to use the "DYS-Design Your Shoes" service, I } \\
\text { would... }\end{array}$ & & & 0.88 & 0.93 & 0.96 & 0.93 \\
\hline $\begin{array}{l}\text { - say positive things about the "DYS-Design Your } \\
\text { Shoes" service and its employees to others. }\end{array}$ & 0.93 & 107.93 & & & & \\
\hline $\begin{array}{l}\text { - recommend the "DYS-Design Your Shoes" service } \\
\text { and its employees to others. }\end{array}$ & 0.97 & 269.31 & & & & \\
\hline $\begin{array}{l}\text { - encourage friends and relatives to use the "DYS- } \\
\text { Design Your Shoes" service. }\end{array}$ & 0.92 & 95.30 & & & & \\
\hline
\end{tabular}

\begin{tabular}{llllllll}
\hline & \multicolumn{3}{c}{ Convergent validity } & & \multicolumn{3}{c}{ Reliability } \\
\cline { 2 - 3 } \cline { 5 - 7 } Second-order constructs (mean; standard deviation) & $\mathrm{OL}$ & $\mathrm{AVE}$ & & $\alpha$ & $\rho_{\mathrm{C}}$ & $\rho_{\mathrm{A}}$ \\
\hline Participation behaviours $(5.67 ; 0.88)$ & & 0.66 & & 0.95 & 0.96 & 0.95 \\
- Personal interaction & 0.90 & & & & & \\
- Responsible behaviour & 0.84 & & & & & \\
- Information sharing & 0.83 & & & & & \\
Citizenship behaviours (4.78; 0.92) & & 0.51 & & 0.91 & 0.92 & 0.91 \\
- Feedback & 0.68 & & & & & & \\
- Tolerance & 0.66 & & & & & \\
- Helping & 0.85 & & & & & \\
- Advocacy & 0.86 & & & & & \\
\hline
\end{tabular}

Notes: OL, outer loading; AVE, average variance extracted; $\alpha$, Cronbach's alpha; $\rho_{C^{\prime}}$ composite reliability; $\rho_{A^{\prime}}$ consistent reliability coefficient using Mode A in SmartPLS. ${ }^{R}$ Reverse coded; ${ }^{t} t$-value $>2.57$ at $p<0.001$

\section{Structural Model}

Sports behaviour and levels of education were included as exogenous variables, to support predictions of the other latent constructs (Lin and Hsieh, 2011). Multicollinearity was not a concern, in that the highest VIF is 2.03, well below the conservative limit of 5.00 (Hair et al., 2014). Bootstrapping with 5,000 samples indicates the significance of the path coefficients and $t$-values, as listed in Table 2.2. The explained variance $\left(R^{2}\right)$ for both endogenous constructs is 0.22 (adjusted $R^{2}=0.21$ ); the exogenous constructs explain 22 percent of the variance in users' participation and citizenship behaviours during co-creation efforts. This percentage of explained variance is considered satisfactory for studying human behaviour, especially when involving predictions of personality traits (Meyer et al., 2001; Roberts et al., 2007).

The situational factor, level of service customisation, does not exert significant effects on any co-creation behaviours, so H1a and H1b cannot be confirmed. Gender has a positive effect, in line with $\mathrm{H} 2 \mathrm{a}$ and $\mathrm{H} 2 \mathrm{~b}$, such that women exhibit more participation and citizenship 


\begin{tabular}{|c|c|c|c|c|c|}
\hline Hypothesis & Path & $\begin{array}{l}\text { Path } \\
\text { coefficient }\end{array}$ & $t$-value & $p$-value & Result \\
\hline H1a & Level of service customisation ${ }^{a} \rightarrow \mathrm{PB}$ & -0.02 & 0.51 & 0.613 & Not supported \\
\hline $\mathrm{H} 1 \mathrm{~b}$ & Level of service customisation ${ }^{a} \rightarrow C B$ & -0.05 & 1.43 & 0.152 & Not supported \\
\hline $\mathrm{H} 2 \mathrm{a}$ & Gender $^{\mathrm{b}} \rightarrow \mathrm{PB}$ & 0.12 & 3.28 & 0.001 & Supported \\
\hline $\mathrm{H} 2 \mathrm{~b}$ & Gender $^{\mathrm{b}} \rightarrow \mathrm{CB}$ & 0.13 & 3.62 & 0.000 & Supported \\
\hline $\mathrm{H} 3 \mathrm{a}$ & $\mathrm{Age}^{\mathrm{c}} \rightarrow \mathrm{PB}$ & -0.08 & 1.89 & 0.059 & Supported \\
\hline $\mathrm{H} 3 \mathrm{~b}$ & $\mathrm{Age}^{\mathrm{c}} \rightarrow \mathrm{CB}$ & -0.06 & 1.31 & 0.191 & Not supported \\
\hline $\mathrm{H} 4 \mathrm{a}$ & Extraversion $\rightarrow \mathrm{PB}$ & -0.10 & 1.99 & 0.046 & Not supported \\
\hline $\mathrm{H} 4 \mathrm{~b}$ & Extraversion $\rightarrow \mathrm{CB}$ & 0.03 & 0.60 & 0.549 & Not supported \\
\hline $\mathrm{H} 5 \mathrm{a}$ & Agreeableness $\rightarrow \mathrm{PB}$ & 0.27 & 5.51 & 0.000 & Supported \\
\hline $\mathrm{H} 5 \mathrm{~b}$ & Agreeableness $\rightarrow \mathrm{CB}$ & 0.30 & 6.74 & 0.000 & Supported \\
\hline H6a & Conscientiousness $\rightarrow$ PB & 0.19 & 3.63 & 0.000 & Supported \\
\hline H6b & Conscientiousness $\rightarrow \mathrm{CB}$ & 0.01 & 0.17 & 0.865 & Not supported \\
\hline $\mathrm{H} 7 \mathrm{a}$ & Openness $\rightarrow$ PB & 0.13 & 2.91 & 0.004 & Supported \\
\hline $\mathrm{H} 7 \mathrm{~b}$ & Openness $\rightarrow \mathrm{CB}$ & 0.17 & 3.52 & 0.000 & Supported \\
\hline $\mathrm{H} 8 \mathrm{a}$ & Neuroticism $\rightarrow$ PB & -0.04 & 0.83 & 0.405 & Not supported \\
\hline $\mathrm{H} 8 \mathrm{~b}$ & Neuroticism $\rightarrow$ CB & 0.04 & 0.83 & 0.407 & Not supported \\
\hline \multicolumn{6}{|c|}{ Control variables } \\
\hline & Sports behaviour $\rightarrow \mathrm{PB}$ & -0.04 & 1.26 & 0.209 & No effect \\
\hline & Sports behaviour $\rightarrow \mathrm{CB}$ & 0.05 & 1.29 & 0.196 & No effect \\
\hline & Education $^{\mathrm{d}} \rightarrow \mathrm{PB}$ & 0.02 & 0.59 & 0.552 & No effect \\
\hline & Education $^{\mathrm{d}} \rightarrow \mathrm{CB}$ & -0.15 & 3.66 & 0.000 & Negative effect \\
\hline \multicolumn{2}{|c|}{ Endogenous latent variables } & & $R^{2}$-value & $t$-value & $p$-value \\
\hline \multicolumn{2}{|l|}{$\mathrm{PB}$} & & 0.22 & 5.09 & 0.000 \\
\hline \multicolumn{2}{|l|}{$\mathrm{CB}$} & & 0.22 & 6.68 & 0.000 \\
\hline \multicolumn{2}{|c|}{ Personal interaction } & & 0.81 & 40.59 & 0.000 \\
\hline \multicolumn{2}{|c|}{ Responsible behaviour } & & 0.70 & 20.82 & 0.000 \\
\hline \multicolumn{2}{|c|}{ Information sharing } & & 0.69 & 19.22 & 0.000 \\
\hline \multicolumn{2}{|l|}{ Feedback } & & 0.44 & 10.45 & 0.000 \\
\hline \multicolumn{2}{|l|}{ Tolerance } & & 0.44 & 10.78 & 0.000 \\
\hline \multicolumn{2}{|l|}{ Helping } & & 0.73 & 30.35 & 0.000 \\
\hline \multicolumn{2}{|l|}{ Advocacy } & & 0.73 & 32.72 & 0.000 \\
\hline
\end{tabular}

Notes: $\mathrm{PB}$, participation behaviours; $\mathrm{CB}$, citizenship behaviours. ${ }^{\mathrm{a}}$ Level of service customisation (base=low); ${ }^{\mathrm{b}} \mathrm{Gender}$ (base=male); ${ }^{\mathrm{C}} \mathrm{Age}$ (base=less than 30 years); ${ }^{\mathrm{d}}$ Education (base=low); ${ }^{\mathrm{N}}$ Negative significant effect, contrary to predictions

behaviours than men. Age has a weak, negative effect on participation behaviours but no effect on citizenship behaviours, so the findings support H3a and reject H3b. Among dispositional factors, extraversion has no effect on users' citizenship behaviours and a surprisingly negative effect on participation behaviours, so neither H4a nor H4b receives support. As hypothesised, users who score high on agreeableness and openness are more prone to exhibit participation and citizenship behaviours, in support of both predictions in H5 and H7. Conscientiousness has a positive effect on participation behaviours but not on citizenship behaviours (H6 supported; H6b not supported). Neither neuroticism (H8) nor sports behaviour, as a control variable, exerts any significant effect. Finally, the control variable education reveals a negative influence on citizenship behaviours; more educated users appear less likely to exhibit citizenship behaviours.

In summary, younger women with an agreeable, conscientious, and open but less extraverted personality are most likely to display participation behaviours during services co-creation. Younger women with less education and an agreeable and open nature also are likely to engage in citizenship behaviours.

\section{Discussion}

The findings are interesting as they are somewhat counterintuitive; users' co-creation behaviours appear to be mostly affected by their demographics and dispositions, whereas the level of service customisation seemingly has no significant effect. A potential explanation for the non-significant effect may be grounded in the nature of the research, as the levels of service customisation were manipulated through fictional scenarios. The means of the low and high levels of service customisation are statistically significantly different, both values are positive $\left(\mathrm{M}_{\text {low }}=4.31, \mathrm{M}_{\text {high }}=4.95\right)$. Therefore, it would be interesting for future researchers to test the influence of service customisation in more extreme comparisons of absent customisation versus high level of customisation. Especially in real-life situations, other situational variables, such as perceived waiting time or social anxiety through perceived crowding (Dabholkar and Bagozzi, 2002), might very well have salient effects on users' participation and citizenship behaviours during services co-creation.

The expected influences of the demographic factors are mostly supported. There is an interesting negative effect between the control variable education and users' citizenship behaviours. This unexpected finding may reflect the stronger economic and quantitative time orientation among educated people (Durrande-Moreau and Usunier, 1999), as users with higher educational backgrounds are considered to have an increased need for time optimisation due to perceiving time poverty (Weijters et al., 2007). Citizenship behaviours, such as giving feedback or helping others, are time consuming, so users with this time orientation may be negatively inclined towards these voluntary behaviours.

The dispositional factors have mixed effects on users' behaviours during services co-creation. Users' traits of being agreeable, conscientious, and open, positively influence all behaviours, with the exception of the non-significant relationship between conscientiousness and citizenship behaviours. Apparently, for this service scenario, there is no association between a person's 
characteristics of being dependable and responsible and voluntary extra-role behaviours. A potential explanation could be that the users' sense of responsibility is not being addressed in the provided service situation. Contrary to expectations, extraverted users are less likely to engage in participation behaviours during services co-creation. While counterintuitive at first, this finding may be explained by further dissecting what it means to score high on extraversion. Toegel and Barsoux (2012) suggest that extraverted personalities may listen less due to being overly talkative and domineering, which can negatively affect their participation behaviours when having to follow the lead of a service employee. Finally, users' neurotic personality trai does not have any significant effects, suggesting that a person's emotional stability does not impact their behaviours during services co-creation.

\section{Study 2: Interactive Research Workshops \\ Study Aim}

The Study 1 findings suggest that factors pertaining to the participating users themselves have a considerable impact on their co-creation behaviours, which provides further evidence for the pressing need of service providers to understand how to encourage users' engagement in co-creation. Accordingly, Study 2 starts by exploring drivers and inhibitors of users' cocreation engagement. Study 1 also suggests that dispositional factors, such as personality traits, determine users' co-creation behaviours, yet these traits often are difficult to assess for segmentation purposes. Therefore, to facilitate the selection of participants for co-creating services, Study 2 further explores which users are more or less likely to engage in co-creation, according to specific traits, such as their likes and abilities, and demographics. If few users are willing to engage fully in co-creation (Hoyer et al., 2010), selecting participants on the basis of their receptivity would help service providers find the "right" collaborators for successful cocreation (Cossío Silva et al., 2013; Hoffman et al., 2010).

\section{Research Setting}

The exploratory nature of Study 2 suggests the need for a phenomenological approach to explore participants' perceptions of drivers or inhibitors of engagement and whether certain traits make users more likely to co-create (Osei-Frimpong et al., 2018). Interactive research workshops can effectively generate new knowledge, facilitate information flows, and encourage unrestricted interactions among participants (Frow et al., 2015). This chosen qualitative, interpretative method thus aligns with Study 2's goal of generating new theory through inclusion and active interaction (Denzin and Lincoln, 2008). Furthermore, for this research context, workshops rather than more traditional qualitative methods (e.g., semi-structured interviews, focus groups) are preferable, to overcome disadvantages associated with collecting mere verbal articulation and encourage active engagement with generative techniques (Čaić et al., 2018).
Two interactive research workshops, with 38 design professionals, were conducted in English in a country in Western Europe. The design professionals all have experience with co-creation and encouraging others to participate; they also regard co-creation as especially relevant, as a driving force for integrating the experiences of multiple actors and thereby design services (Mager and Sung, 2011). In this sense, the design professionals provide representative insights for a wide array of users and service sectors.

To recruit these design professionals, the authors held a service design event focused on co-creation, promoted through a national chapter of the global Service Design Network using newsletters, social media, and the network websites. Registration and participation was voluntary; to help working professionals attend, the four-hour long event took place in the evening, on a weekday, in the nation's capital city. The participants featured an equivalent gender spread (male $=52.78$ percent; female $=47.22$ percent), and 20 of the 38 experts explicitly indicated their profession in service design, while the rest referred to user experience design industrial design, or design thinking. The two interactive research workshops ran in parallel, moderated by two experienced researchers from the author team, which minimises the potential for subjectivity biases. A third researcher visited both workshops to ensure consistency. The moderators followed the same research protocol, and participants were randomly divided across workshops. The average length of the workshops was 114 minutes. No compensation was given; people participated due to their own interest. Two presentations at the conclusion of the event presented co-creation topics, followed by networking. The premises, hosted in a service design consultancy, helped establish a creative, conducive working atmosphere, though the workshops were strictly for academic purposes, with no commercial affiliation.

\section{Data Collection}

The detailed protocol for the interactive research workshops is summarised in Appendix E. Phase A spans four parts, designed to investigate the drivers and inhibitors of engagement, as pertain to RQ2a. Then Phase B explores different users and their likelihood to engage in cocreation, in support of RQ2b.

\section{Phase A}

After the introduction to the workshop, outlining its goals and the agenda, Part 1 (Appendix E) applied the critical incident technique (CIT, Bitner et al., 1990) to collect rich insights on human behaviour from participants' perspective; the resulting findings should be more rigorous than those obtained from other qualitative approaches, due to the specific focus on a single phenomenon (Gremler, 2004). Participants had to recall their best and worst experiences engaging users in co-creation. They completed a template with three questions (what was the experience, where did it take place, and why was it good or bad), resulting in 38 positive 
and 38 negative incidents. With the CIT, they thus actively recalled a past situation related to co-creation and re-lived it by answering these questions, which constitutes a generative technique for developing a stimulus and documenting it (Bitner et al., 1990). In Parts 2 and 3 participants were randomly allocated to subgroups and guided through the affinity mapping technique (Gonzalez, 2015). The subgroups clustered the reasons provided by each respondent, regarding why an experience was good or bad, using pre-drawn flipchart templates. The clusters reflected drivers or inhibitors of engagement, and the participants labelled these clusters. Next, they transferred their cluster labels to a new template and prioritised drivers and inhibitors, according to their level of perceived importance. In the next step, they colour-coded all drivers and inhibitors as person-, context-, or task-dependent elements. By starting with CIT and then adding affinity mapping, this research approach is inclusive (i.e., encourages all subgroup members to participate) and sparks creativity (i.e., subgroup members listened to others' ideas) (Institute for Healthcare Improvement, 2019). Finally, with a layered cake technique (Yee, 2019), subgroups presented their three most important drivers and inhibitors, prompting a general discussion of the similarities and differences, as facilitated by the moderator.

\section{Phase $B$}

Projective techniques provide the creative stimulus to encourage participants to describe a user they consider likely or unlikely to engage in co-creation in Phase B. These techniques represent diagnostic tools that can uncover deep beliefs and thought processes. Participants receive an ambiguous stimulus and, to make sense of it, must complete a picture by projecting a part of themselves onto it (Haire, 1950). In the workshop task, participants received two empty persona templates (Appendix E), with demographic boxes for the name, age, gender, and education of the person; a heart that contained the words "characteristics, likes, dislikes"; and a bag with the words "skills, knowledge, abilities." Participants then had to craft both a persona likely to be engaged in co-creation and an anti-persona not likely to be thus engaged, such that the process produced 76 templates. The personas, or fictional persons, represent a group of people with shared behavioural patterns, demographics, and interests (Stickdorn et al., 2018); services marketing research has used personas to illustrate the findings of qualitative, phenomenological studies, intuitively and empathically (Trischler et al., 2018b). The anti-personas in turn depict the group of people for whom the system is not designed or who are not likely to display certain behaviour patterns (Russell-Bennett et al., 2017). Again, subgroup presentations and a group discussion followed, as part of the layered cake technique, during Part 6.

\section{Results}

The analyses used a general inductive approach (Thomas, 2006), which systematically condenses data into summary themes, links the themes to the research aim, and develops a structured framework, as detailed in Appendix F.

\section{Phase A}

The driver and inhibitor labels, documented in Part 3 of the data collection (Appendix E), were transferred onto Post-It notes by the author team. The 39 drivers and 36 inhibitors then were clustered further into factors, and the colour-coding from Part 3 that designates person-, context-, or task-dependent elements was added. The drivers and inhibitors are symmetrical, such that each factor includes both drivers and inhibitors (e.g., motivation is a driver, and the lack of motivation is an inhibitor). Thus, 17 factors include drivers and inhibitors of users' co-creation engagement, offering a response to RQ2a, as organised in the framework in Figure 2.2. Engaging users in co-creation depends on factors relating to themselves, such as their mind-set or motivation; contextual factors, such as feeling safe as part of the psychological environment; and task factors, or how emotionally involved participants become in specific co-creation activities. The workshop data also suggest that users' engagement stems from factors determined by the facilitating party. That is, the service designer's or service provider's level of preparation for and facilitation of the co-creation activity can strongly influence users' engagement. Furthermore, the preparation and physical environment of the surrounding context and of the co-creation activity itself considerably influence co-creation engagement. Thus, the engagement of users in services co-creation is driven and inhibited by factors related to the participating and facilitating parties, the person, the context, and the task.

\section{Phase $B$}

The demographic data indicate that the personas most likely to engage in co-creation are described mainly as highly educated women in their 30s. In contrast, the descriptions of the anti-personas cite highly educated men in their 40s and 50s. The authors transferred all characteristics, likes, and dislikes, as well as the skills, knowledge, and abilities, mentioned in the persona and anti-persona templates to Post-It notes, then clustered and labelled them, resulting in 40 labels for personas and 39 labels for anti-personas. The labels can be classified as minor, medium, and major, depending on the number of observations per cluster. Then to address RQ2b, the authors drew commonalities between the medium and major labels from the data, which is a common approach for developing personas from phenomenological sources (Trischler et al., 2018b). Figure 2.3 presents these commonalities for three personas likely to engage in co-creation and three anti-personas not likely to do so.

The imaginative adventurer is characterised as a talkative woman in her 30s, curious and open to learn and experience new things; she is creative and visual in her task approaches. The enthusiastic people connector also is very social and energetic, prefers working in teams, and triggers enthusiasm in others. Both the imaginative adventurer and enthusiastic people connector dislike being around "stiff" people. 

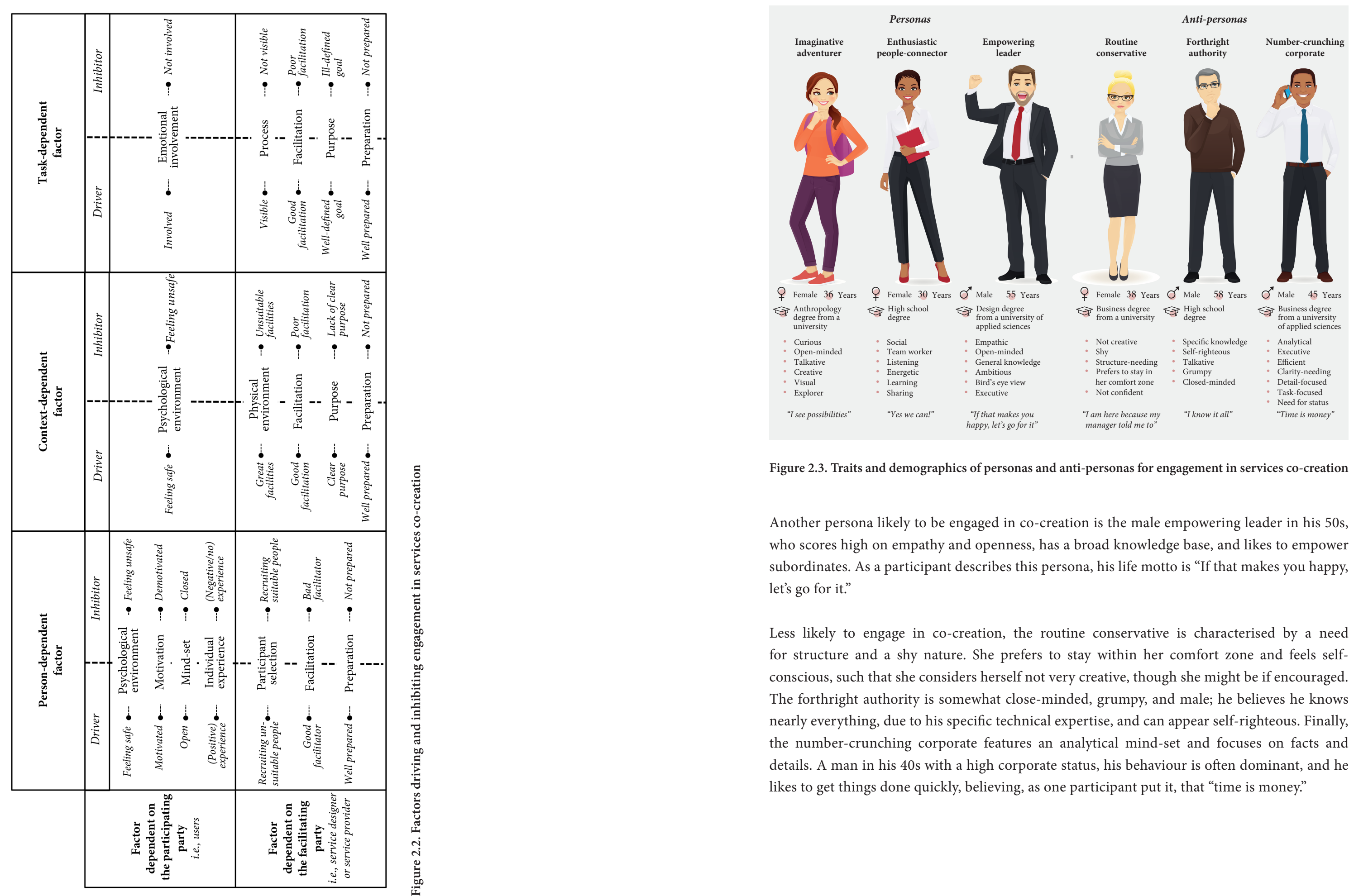

Figure 2.3. Traits and demographics of personas and anti-personas for engagement in services co-creation

Another persona likely to be engaged in co-creation is the male empowering leader in his $50 \mathrm{~s}$, who scores high on empathy and openness, has a broad knowledge base, and likes to empower subordinates. As a participant describes this persona, his life motto is "If that makes you happy, let's go for it."

Less likely to engage in co-creation, the routine conservative is characterised by a need for structure and a shy nature. She prefers to stay within her comfort zone and feels selfconscious, such that she considers herself not very creative, though she might be if encouraged. The forthright authority is somewhat close-minded, grumpy, and male; he believes he knows nearly everything, due to his specific technical expertise, and can appear self-righteous. Finally, the number-crunching corporate features an analytical mind-set and focuses on facts and details. A man in his 40 s with a high corporate status, his behaviour is often dominant, and he likes to get things done quickly, believing, as one participant put it, that "time is money." 


\section{General Discussion}

This research has sought to conduct a quantitative test of different factors and their influence on users' behaviours during services co-creation (RQ1), as well as a qualitative exploration of the drivers and inhibitors of their engagement in co-creation (RQ2a), along with the types of users who are more or less likely to engage in services co-creation, according to their traits and demographics (RQ2b).

\section{Demographic Factors and Effects on Services Co-Creation}

Both studies indicate that demographics strongly influence services co-creation. As hypothesised, the women in Study 1 are more likely to display participation and citizenship behaviours, and Study 2 confirms this finding, in that the anti-personas that are less likely to co-create tend to be men, whereas women represent the personas likely to co-create. Older users exhibit less participation behaviours, as also supported by Study 2, because the anti-personas are older on average (40s-50s) than the personas favouring co-creation (30s). Study 1 further indicates a negative association between users' education level and citizenship behaviours and suggests as a possible explanation the stronger economic and quantitative time orientation among educated people (Durrande-Moreau and Usunier, 1999), as manifested in the statement "time is money" (Weijters et al., 2007, p. 6). The descriptions of the anti-personas in Study 2 offer some support for this apparently negative correlation between time pressures and cocreation likelihood, such as predictions that these anti-personas would say things like, "I don' have time for this," "Sorry, we need to do this fast!," and "Time is money." On average though both personas and anti-personas were represented as highly educated, which may indicate a respondent bias, in that all the Study 2 participants were educated design professionals.

\section{Dispositional Factors and Effects on Services Co-Creation}

Studies 1 and 2 also reveal impacts of dispositional factors on behaviours during co-creation Study 1 tests the Big Five personality traits; Study 2 explores more concrete traits. The trait can be classified according to Mowen's (2000) hierarchical model of personality, which includes (1) elemental traits, such as the Big Five, that are genetically inherited or learned very early; (2) compound traits, which are unidimensional predispositions that result from the elemental traits, learning history, and culture; and (3) situational traits that are unidimensional predispositions in general, situational contexts. The Big Five-related findings from Study 1 together with the 48 major and medium labels for the personas and anti-personas from Study 2 lead to the hierarchical pyramid in Figure 2.4, by trait levels (Mowen, 2000). Thus a person's elemental trait might be openness, which provides a general reference for co-creating services. The compound traits provide a second reference point for co-creating services, such that a person's social and creative traits likely influence the likelihood to co-create and co-

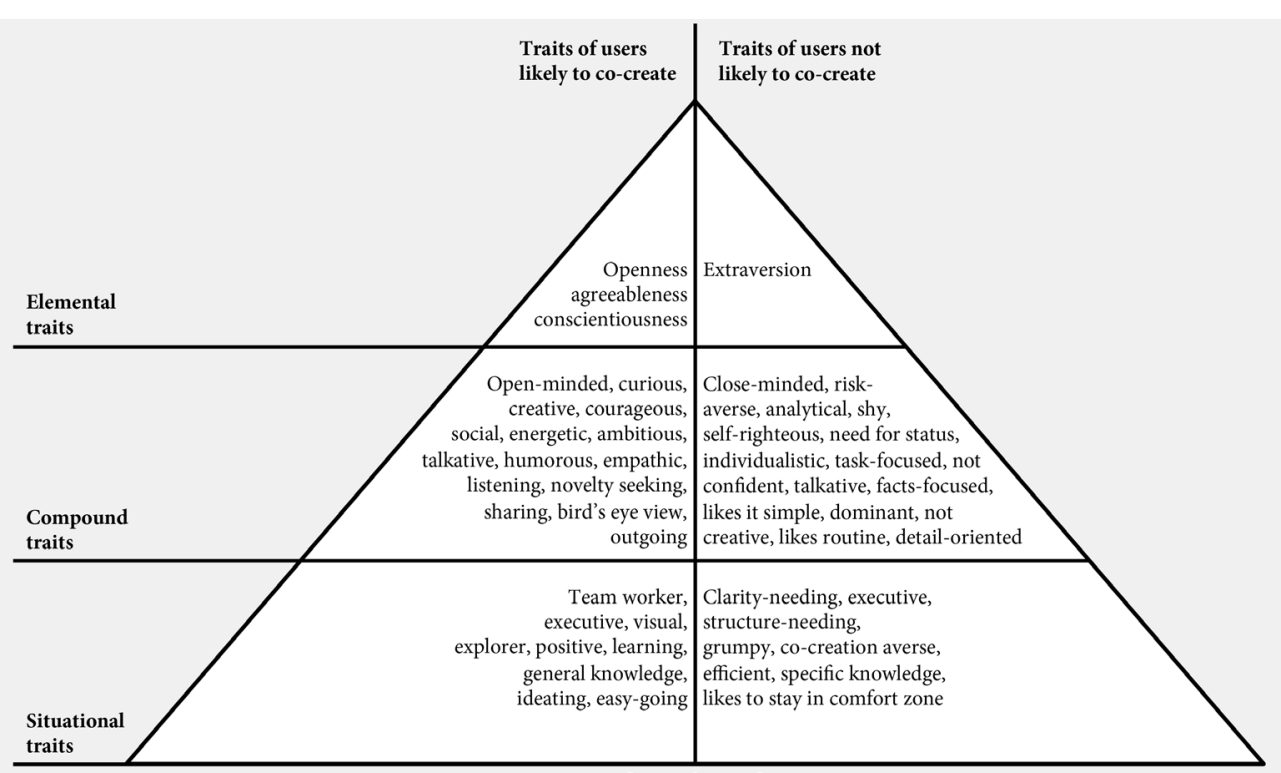

Figure 2.4. Users' likelihood to co-create based on elemental, compound, and situational traits

creation performance. Finally, situational traits, such as being teamwork oriented, influence the likelihood that during co-creation, the person will work well with others.

However, not every person who is (not) likely to co-create will possess all the traits in Figure 2.4. Rather, these traits offer an indication of users' likelihood to co-create, according to Studies 1 and 2. They represent different types of users. This point helps explain some of the surprising findings from Study 1. For example, extraversion has a negative effect on users' participation behaviours during co-creation, which seems counterintuitive, in that an extraverted, outgoing personality often has been positively associated with idea creation, divergent thinking, and engagement-all positive indicators of co-creation (ChamorroPremuzic and Reichenbacher, 2008; Mondak et al., 2010; Sergeeva and Radosavljevic, 2012). However, as discussed in Study 1, extraverted people can also be dominant and overly talkative (Toegel and Barsoux, 2012), two compound traits listed in Figure 2.4 of users not likely to co-create.

\section{Theoretical Implications}

First, this chapter follows proposed research agendas (Gemser and Perks, 2015; Mustak et al., 2016) regarding the different antecedent categories of participation in co-creation. It quantitatively examined situational, demographic, and dispositional factors and their influence on participation and citizenship behaviours. The results show that younger women with an 
agreeable, conscientious, and open but less extraverted personality are most likely to exhibit participation behaviours during services co-creation. Younger women with less education and an agreeable and open nature likely engage in citizenship behaviours. These findings thus address calls for more attention to the influences of a person's personality (Merz et al., 2018; Wu, 2011; Zhang et al., 2018) and age and gender (Neghina et al., 2017; Sigala, 2009); they highlight the importance of dispositional and demographic factors for determining users' cocreation behaviours.

Second, the qualitative exploration of the drivers and inhibitors of engagement in co-creation advances scholarly insights about what causes users to engage in co-creation (Füller et al. 2008; Hoyer et al., 2010; Neghina et al., 2017). The findings show that co-creation engagement is driven or inhibited by factors that depend on the person, the task, and the surrounding context; they also are contingent on the participating or facilitating party. More specifically, co-creation engagement is dependent on users' personal experiences, motivations, and mindsets, among other participant-related factors. However, the facilitating role of the service designer or service provider is also critical; users' co-creation engagement depends on how well the facilitating party is prepared, the preparation of the context surrounding the co-creation activity, and the preparation of the task itself. This enhanced understanding is essential for marketing success amid current difficulties of engaging users in co-creation (Fu et al., 2018; Hoyer et al., 2010).

Third, the proposed typology of personas and anti-personas specifies users' likelihood to engage in co-creation, given their traits and demographics. Users with profiles similar to the imaginative adventurer, enthusiastic people connector, or empowering leader likely engage in co-creation; those users similar to the routine conservative, forthright authority, and number-crunching corporate will require more effort to engage them in co-creation. These findings support conscious segmentation choices for users willing to engage in co-creation (Carbonell et al., 2012; Enkel et al., 2005), which should reduce the time and money cost associated with identifying suitable participants (Mahr et al., 2014).

\section{Practical Implications}

This research provides several important insights for practitioners, that is, service designers and service providers. First, distinct demographic and dispositional factors must be accounted for when designing co-creation activities, to ensure that participants will engage in favourable behaviours. If a targeted segment consists of older men, who exhibit extraversion and dominan behaviours, they generally are less likely to co-create, so practitioners must develop the cocreation activity explicitly to encourage the engagement of this target group. For example, they could integrate a longer introduction period into the task, familiarise participants with cocreation, and introduce quick activities that encourage teamwork.
Second, practitioners must be mindful of the influential factors that they control, such as the purpose of the context, whether employees receive training for facilitating co-creation, and preparing the co-creation activity. In terms of the environment, practitioners should ensure that the physical surroundings encourage co-creation and that participants experience a conducive psychological environment or safe space to co-create.

Third, considering the time-consuming, costly nature of recruiting and motivating potential collaborators for co-creation (Mahr et al., 2014), suitable participants should be purposefully selected. Practitioners can apply the proposed typology of personas and anti-personas to determine users' likelihood to engage in services co-creation and thereby find a segment of users who have appropriate traits. Such efforts should foster successful co-creation outcomes. Knowing the demographics, traits, and characteristics of appropriate participants can help service designers and service providers formulate attractive value propositions for them that encourage them to engage in services co-creation.

\section{Limitations and Further Research}

Some limitations of this study provide fruitful avenues for further research. First, the scenario in Study 1 operationalise co-creation for later stages of the service process, that is, for coproduction (Oertzen et al., 2018). The results could vary for other forms of co-creation that include more innovative activities, such as co-ideation or co-design. Some of the Study 1 results are confirmed by Study 2, which leverages co-creation more broadly, but continued research still should explore users' behaviours in other phases of the service process. The conceptual model also would benefit from an extension to different service sectors, such as healthcare or finance. The influences of situational, demographic, and dispositional factors arguably may differ, depending on the level of emotional intensity attached to the service context Accordingly, users' co-creation behaviours could differ across service sectors.

Second, the participants in Study 1 did not actually design their own shoes but instead tried to envision how they would behave in such a situation, which is common in scenario-based studies (Xie et al., 2008). Still, empirical confirmation is needed, with studies of users' actual behaviours and over extended periods. Behaviours fluctuate over time; as users become more familiar with a co-creation activity, they might be more inclined to help others for example.

Third, this research would benefit from examining further influencing factors on users behaviours and their engagement in services co-creation. Constructs such as social anxiety (Dabholkar and Bagozzi, 2002) or user savvy, including characteristics like technologica sophistication and self-efficacy (Macdonald and Uncles, 2007), may provide interesting avenues for future research. 
Fourth, the findings of the qualitative Study 2, with its generative techniques, may offer limited validity and reliability (Trischler et al., 2018b). Using design professionals helps increase the robustness of the results, over a wide variety of service sectors, co-creation forms, and profiles. Still, further research should extend the current findings by directly investigating users and their engagement in co-creating services. It also would be interesting to examine quantitatively the effect of service provider-related factors on users' engagement in co-creation, such as the preparation of the physical context or its facilitating skills.

\section{Chapter 2. Appendix}

Appendix A. Scenario description (adapted from Heidenreich et al., 2015)

In the newspaper, you read that a new service is being offered at your favourite sports outfitter: "DYS-Design-Your-Shoes". This service allows you to design a sports shoe using special computer software. After placing the order, the shoes can be collected on site after a maximum period of 14 days. In order to facilitate the ordering process as much as possible, an employee assists you with the handling of the computer program as well as with the choice of shoes and the final order.

Please picture the following situation. You visit the sports outfitter in order to give the new offer "DYS-Design-Your-Shoes" a try and to order a pair of sports shoes. After arriving at the store, you ask an employee about the new service "DYS-Design-Your-Shoes". The employee leads you to a computer and offers to assist you with navigating through the menu. Together you start the program.

The employee explains that you have to create a profile in order to use "DYS—Design Your Shoes".

Comparison of the scenarios

\begin{tabular}{ll}
\hline Scenario 1: Low level of service customisation & Scenario 2: High level of service customisation \\
\hline $\begin{array}{l}\text { This requires your name, e-mail address, and } \\
\text { shoe size. }\end{array}$ & $\begin{array}{l}\text { This requires your name, address, email, telephone } \\
\text { number, shoe size, body height, and weight. } \\
\text { Additionally, you are asked for which sport you will } \\
\text { wear the shoes as well as how often (hours per week) } \\
\text { and at which level (Beginner/Intermediate/Expert) you } \\
\text { practice the sport. }\end{array}$ \\
Together with the employee you enter the information \\
into the provided template.
\end{tabular}


Appendix B. Demographic profile for Study $1(n=633)$

\begin{tabular}{llll}
\hline Item & & Number of participants & Percentage \\
\hline Gender & Male & 337 & $53.2 \%$ \\
\multirow{3}{*}{ Age } & Female & 296 & $46.8 \%$ \\
& $<30$ & 103 & $16.3 \%$ \\
& $30-39$ & 89 & $14.1 \%$ \\
& $40-49$ & 94 & $14.8 \%$ \\
\multirow{3}{*}{ Education } & $50-59$ & 124 & $19.6 \%$ \\
& $60+$ & 223 & $35.2 \%$ \\
& Low & 207 & $32.7 \%$ \\
& Middle & 219 & $34.6 \%$ \\
& High & 207 & $32.7 \%$
\end{tabular}

Appendix C. Intercorrelations of the first-order constructs

\begin{tabular}{lllllllll}
\hline Construct & $(1)$ & $(2)$ & $(3)$ & $(4)$ & $(5)$ & (6) & (7) & (8) \\
\hline (1) Extraversion & 0.75 & & & & & & & \\
(2) Agreeableness & 0.44 & 0.75 & & & & & & \\
(3) Conscientiousness & 0.51 & 0.44 & 0.73 & & & & & \\
(4) Openness & 0.54 & 0.32 & 0.47 & 0.73 & & & & \\
(5) Neuroticism & -0.48 & -0.29 & -0.45 & -0.32 & 0.76 & & & \\
(6) Personal interaction & 0.19 & 0.36 & 0.33 & 0.26 & -0.17 & 0.96 & & \\
(7) Responsible behaviour & 0.16 & 0.25 & 0.23 & 0.22 & -0.09 & 0.58 & 0.92 & \\
(8) Information sharing & 0.18 & 0.33 & 0.32 & 0.22 & -0.16 & 0.62 & 0.62 & 0.94 \\
(9) Feedback & 0.32 & 0.33 & 0.34 & 0.32 & -0.25 & 0.58 & 0.51 & 0.64 \\
(10) Tolerance & 0.08 & 0.27 & 0.11 & 0.13 & -0.05 & 0.42 & 0.48 & 0.42 \\
(11) Helping & 0.16 & 0.29 & 0.08 & 0.16 & 0.02 & 0.34 & 0.40 & 0.34 \\
(12) Advocacy & 0.25 & 0.34 & 0.20 & 0.22 & -0.07 & 0.42 & 0.55 & 0.48 \\
\hline
\end{tabular}

Note: Square root of the AVE in italics on the diagonal 
Appendix D. HTMT values

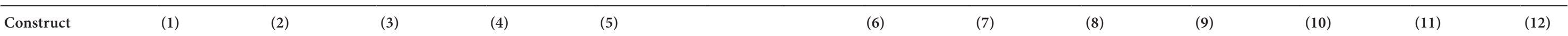

(1) Extraversion

(2) Agreeableness $0.56[0.48 ; 0.65]$

(3) Conscientiousness $0.66[0.59 ; 0.73] \quad 0.57[0.47 ; 0.67]$

(4) Openness $\quad 0.63[0.55 ; 0.71] \quad 0.38[0.29 ; 0.48] \quad 0.57[0.48 ; 0.66]$

$\begin{array}{lllll}\text { (5) Neuroticism } & 0.65[0.58 ; 0.71] & 0.35[0.27 ; 0.45] & 0.55[0.46 ; 0.62] & 0.36[0.29 ; 0.44]\end{array}$

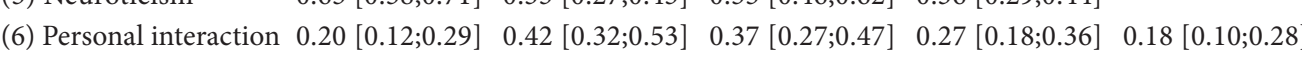

(7) Responsible behaviour $0.16[0.08 ; 0.26] \quad 0.30[0.19 ; 0.41] \quad 0.27[0.17 ; 0.37] \quad 0.22[0.13 ; 0.32] \quad 0.09[0.05 ; 0.19]$

(8) Information sharing $0.20[0.11 ; 0.29] \quad 0.40[0.29 ; 0.51] \quad 0.37[0.25 ; 0.47] \quad 0.23[0.14 ; 0.33] \quad 0.18[0.08 ; 0.27]$

(9) Feedback $\quad 0.40[0.30 ; 0.49] \quad 0.43[0.31 ; 0.55] \quad 0.44[0.32 ; 0.55] \quad 0.37[0.27 ; 0.47] \quad 0.32[0.21 ; 0.42]$

(10) Tolerance $\quad 0.10[0.06 ; 0.19] \quad 0.35[0.23 ; 0.46] \quad 0.13[0.06 ; 0.24] \quad 0.15[0.09 ; 0.26] \quad 0.09[0.06 ; 0.17]$

$\begin{array}{lllllll}\text { (11) Helping } & 0.16[0.09 ; 0.25] & 0.35[0.25 ; 0.44] & 0.10[0.05 ; 0.19] & 0.18[0.09 ; 0.27] & 0.05[0.04 ; 0.14\end{array}$

$0.60[0.52 ; 0.68]$

$0.65[0.56 ; 0.72] \quad 0.66[0.57 ; 0.74]$

$0.67[0.59 ; 0.75] \quad 0.60[0.51 ; 0.69] \quad 0.77[0.68 ; 0.84]$

$0.48[0.39 ; 0.57] \quad 0.56[0.47 ; 0.65] \quad 0.50[0.39 ; 0.60] \quad 0.50[0.39 ; 0.60]$

$0.35[0.27 ; 0.43] \quad 0.42[0.34 ; 0.50] \quad 0.36[0.27 ; 0.44] \quad 0.42[0.33 ; 0.50] \quad 0.52[0.44 ; 0.60]$

$\begin{array}{lllllll}\text { (12) Advocacy } & 0.25[0.17 ; 0.35] & 0.41[0.32 ; 0.49] & 0.24[0.15 ; 0.32] & 0.24[0.14 ; 0.32] & 0.07[0.04 ; 0.16\end{array}$

$0.44[0.36 ; 0.52] \quad 0.58[0.51 ; 0.65] \quad 0.51[0.42 ; 0.59] \quad 0.58[0.50 ; 0.66] 0.54[0.45 ; 0.62] \quad 0.64[0.57 ; 0.70]$

Note: Values in brackets represent the lower and higher bounds of the 95 percent confidence interval

Appendix E. Interactive research workshop protocol

\begin{tabular}{|c|c|c|c|c|c|c|}
\hline \multirow{2}{*}{$\begin{array}{l}\text { Phase } \\
\text { Part }\end{array}$} & \multicolumn{4}{|l|}{ Phase A } & \multicolumn{2}{|l|}{ Phase B } \\
\hline & Part 1. Recalling a Stimulus & Part 2. Clustering & Part 3. Prioritising and categorising & Part 4. Facilitated discussion & Part 5. Drawing a stimulus & Part 6. Facilitated discussion \\
\hline $\begin{array}{l}\text { Main } \\
\text { technique }\end{array}$ & Critical incident technique & $\begin{array}{l}\text { Affinity mapping } \\
\text { technique }\end{array}$ & Affinity mapping technique & $\begin{array}{l}\text { Layered cake discussion } \\
\text { technique }\end{array}$ & Projective technique & Layered cake discussion technique \\
\hline Description & $\begin{array}{l}\text { Participants filled out } \\
\text { a template to describe their } \\
\text { best and worst experiences } \\
\text { when engaging users in co- } \\
\text { creation with three questions } \\
\text { (what, where, why) }\end{array}$ & $\begin{array}{l}\text { Participants clustered } \\
\text { the why responses for } \\
\text { the best and worst } \\
\text { experiences into drivers } \\
\text { and inhibitors and gave } \\
\text { the clusters labels }\end{array}$ & $\begin{array}{l}\text { Participants transferred their } \\
\text { cluster labels to a template and } \\
\text { prioritised the importance of drivers } \\
\text { and inhibitors. Next, participants } \\
\text { classified the drivers and inhibitors } \\
\text { as task-, person-, or context-related }\end{array}$ & $\begin{array}{l}\text { Subgroups presented the three } \\
\text { most important drivers and } \\
\text { inhibitors, followed by a } \\
\text { facilitated discussion }\end{array}$ & $\begin{array}{l}\text { Participants crafted personas } \\
\text { likely to engage in co-creation } \\
\text { and anti-personas unlikely to, } \\
\text { including their demographics, } \\
\text { characteristics, and skills }\end{array}$ & $\begin{array}{l}\text { Subgroups presented the } \\
\text { similarities and differences of their } \\
\text { personas, followed by a facilitated } \\
\text { discussion }\end{array}$ \\
\hline Working level & Individual & Subgroup & Subgroup & Group & Individual & Group \\
\hline Tools & $\begin{array}{l}\text { One pre-printed template } \\
\text { per person }\end{array}$ & $\begin{array}{l}\text { One pre-drawn flipchart } \\
\text { template per subgroup, } \\
\text { Post-It notes }\end{array}$ & $\begin{array}{l}\text { One pre-printed template per } \\
\text { subgroup, stickers }\end{array}$ & - & Two templates per person & - \\
\hline Output & $\begin{array}{l}38 \text { templates with } 76 \\
\text { incidents }\end{array}$ & 10 templates & 10 templates & - & 76 templates & - \\
\hline $\begin{array}{l}\text { Exemplary } \\
\text { template }\end{array}$ & 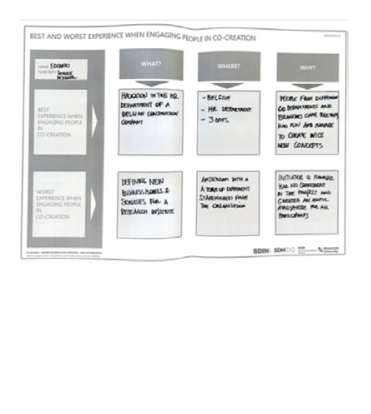 & 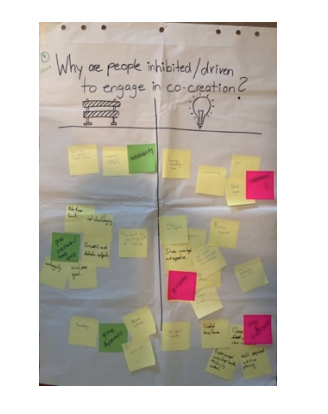 & 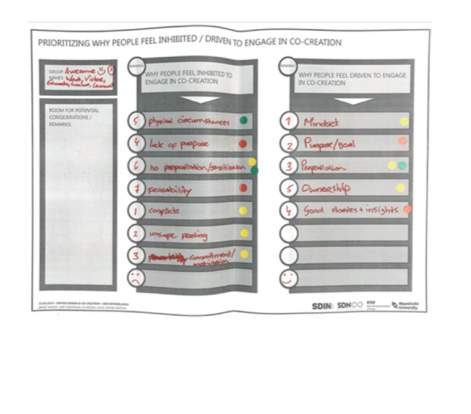 & & 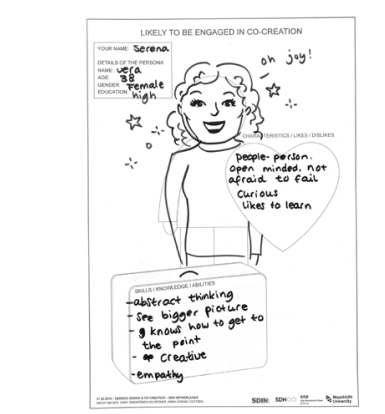 & \\
\hline
\end{tabular}


Appendix F. Analyses of the interactive research workshops

Phase A

(Part) Description

Result

Illustration

(1) The ten templates of Part 3 of 39 drivers (green the data collection (Appendix E) Post-It notes) were used as starting points. All and 36 inhibitors driver and inhibitor labels were copied on Post-It notes, including notes) their prioritisation and unique Post-It group number.

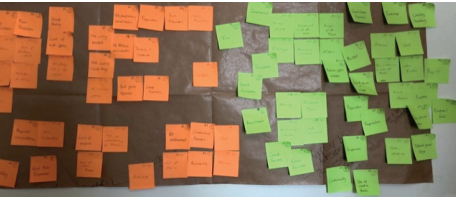

(2) The drivers and inhibitors were 13 factors with 78 clustered around common themes observation into factors. Three drivers/

inhibitors were split (yellow

Post-It notes) because they

included two dissimilar labels (e.g.

participation/mind-set)

(3) During Part 3 of the data collection 78 observations (Appendix E), participants including 110 added colour-coding to drivers colour codes

and inhibitors to classify them

as person-dependent (yellow)

context-dependent (green), or

task-dependent (red). This colour-

coding subsequently was added to

the observations.

(4) Omitting ten observations that did not fit the respective factors refined the clusters. Labels were added to the factors. A label was used multiple times if the factor included multiple colour-coding with each colour code appearing at least twice (e.g., facilitation ca be person-, context-, or taskdependent, so it got three labels).

(5) The factors and their drivers and inhibitors were organised into a matrix framework, according to dependence on the participating or facilitating party and on the person, context, or task
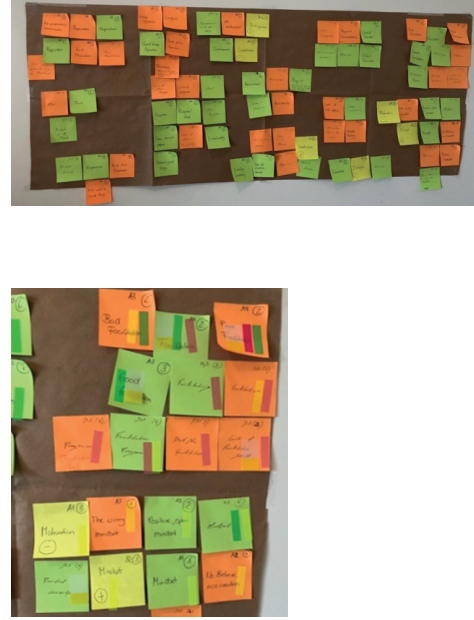

18 labels for 68 observations with 91 colour codes

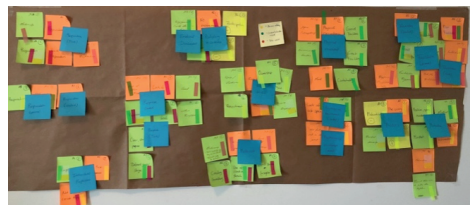

Figure 2.2 illustrates the

Figure 2.2 Factors driving and inhibiting engagement in

riving or services co-creatio

inhibiting users engagement in services co-
Appendix F. (continued)

Phase B

(Part) Description

Result

Illustration

(6) For personas likely to engage in 225 co-creation, all written attributes characteristics, were transferred to Post-It notes, clustered, and labelled. likes, dislikes (pink and orange) The demographics were analysed. and 152 skills, knowledge,
abilities (yellow); 40 labels

(7) For anti-personas not likely to 204 engage, all written attributes were transferred to Post-It notes, clustered, and labelled. characteristics, likes, dislikes (pink and orange) The demographics were analyse and 124 skills, knowledge, abilities (yellow); 39 labels

(8) The 40 persona labels and 39 anti- 24 labels for persona labels were classified as personas; 24 minor ( $\leq 5$ observations), medium labels for anti(6-10 observations), or major ( $\geq 11$ personas; Figure observations). Commonalities 2.3 illustrating between medium and major labels three persona were organised into a typology of and three antipersonas and anti-personas. personas

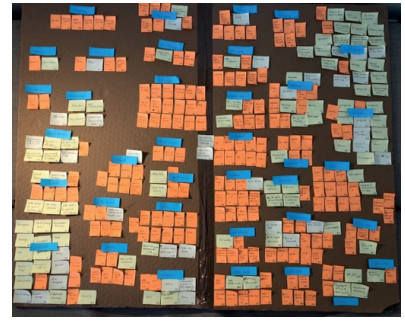

Figure 2.3 Traits and demographics of personas and anti-personas for engagement in services co-creation

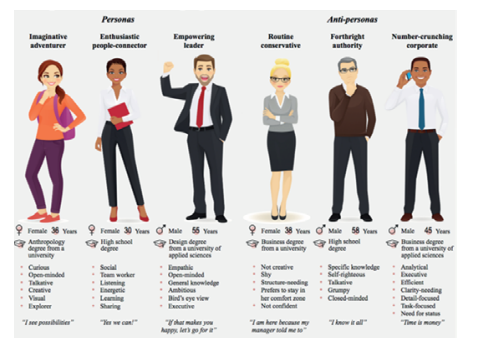




\section{Chapter 3}

Live and Let Live: Integrating Lived Experience through Co-Creation in Healthcare Innovation

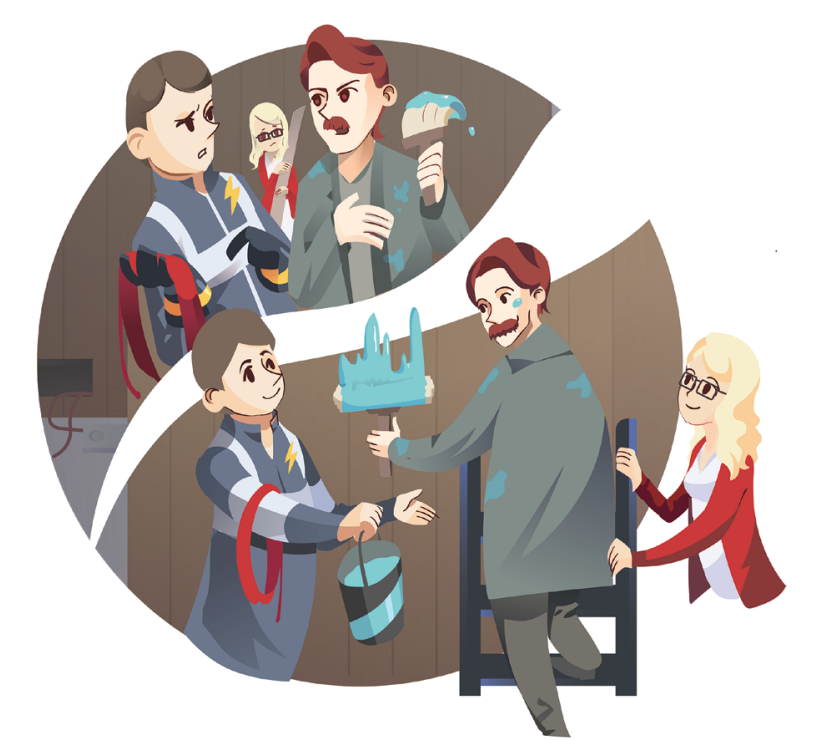

Different abilities are required to build a house. Workers are sought after and hired because of their unique knowledge, related to how to build certain elements of a house. However, tensions may arise from efforts to integrate these different knowledge sources, whether due to power dynamics or misunderstandings. To navigate integrate these different knowledge sources, whether due to power dynamics or misunderstandings. To navigate
these tensions, several, often unconscious strategies can apply, such as empathising with someone else's position or actively exchanging experiences. Along these lines, this chapter offers detailed insights into how to integrate lived experience-people's first-hand understanding of a certain condition, situation, or identity-through co-creation It focuses specifically on integrating lived experience for healthcare innovation, because the need to integrate the situated insights of people into the design of services that affect them is even more crucial in healthcare than in other service industries, due to its sensitive, often urgent nature. Accordingly, through phenomenological interviews with patients, family caregivers, designers, and healthcare professionals, this chapter explores the tensions of integrating lived experience through co-creation and related strategies. 


\section{Chapter 3}

\section{Live and Let Live: Integrating Lived Experience through}

Co-Creation in Healthcare Innovation

Anna-Sophie Oertzen ${ }^{1,2}$, Josina Vink ${ }^{3}$, Gaby Odekerken-Schröder ${ }^{1}$,

Birgit Mager ${ }^{2}$, and Salomé Azevedo ${ }^{6,7}$

'Department of Marketing and Supply Chain Management, School of Business and Economics, Maastricht University, Maastricht, The Netherlands

${ }^{2}$ Köln International School of Design, Technical University of Applied Sciences Cologne, Cologne, Germany ${ }^{3}$ Oslo School of Architecture and Design, Oslo, Norway

${ }^{4}$ Centre for Service Research, Karlstad University, Karlstad, Sweden

${ }^{5}$ Experio Lab, County Council of Värmland, Karlstad, Sweden

${ }^{6} \mathrm{UCP}$ - Católica Lisbon School of Business and Economics, Lisbon, Portugal

${ }^{7}$ Patient Innovation Association, Pinhancos, Portugal 


\section{Introduction}

"I was the perfect patient and the perfect tester, because I had gone through it. I had gone through mastectomy surgery, I had woken up with no breasts. I had gone through infections, and I had gone through having those drains in my body so many times, and the pain and the fear of getting those drains wet. So when I tested that product, like I said, I wasn't a generic research and development person that was testing a product for patients who might need it.... Instead, I was that perfect patient that knew exactly what to look for." - Patient working on an innovation to improve recovery after breast cancer

Chapter 1 showed that the concept of co-creating services has gained increasing traction across academia and practice alike and that it involves collaborative activities between two or more people associated with the service interface (Oertzen et al., 2018). It further highlighted the many beneficial outcomes of co-creation, such as increased well-being, the development of new ideas, and improvements in organisational performance (Engström and Elg, 2015; Kim et al., 2019; Witell et al., 2011). While the first two chapters of this dissertation explored cocreation across the entire service process, this chapter focuses on co-creation between multiple people when innovating services (Kazadi et al., 2016).

In Western healthcare systems in particular, there is a growing demand for involving patients, families, and healthcare staff in co-creating integrated, people-centred health services (Lukersmith et al., 2016; World Health Organization, 2016). Actively involving stakeholders to co-create healthcare services has been shown to improve healthcare experiences and treatment outcomes (Vahdat et al., 2014). To co-create services that are inclusive and tailored to the needs of the people affected by these services, purposefully integrating their lived experience during innovation efforts is a critical necessity (Berry, 2019; Vink and Oertzen, 2018). This research defines lived experience as a direct, first-hand understanding of a certain condition, situation, or identity. Lived experience is holistic, shaped by contextual factors, and unfolds over time (Gallan et al., 2019). As the introductory quote illustrates, a woman who has survived breast cancer has specific lived experience that involves a deep, personal understanding of what it feels like to be diagnosed, receive treatment, and continue living after cancer (Williams and Jeanetta, 2016). Her lived experience can inform the design of services that women with breast cancer require, for instance by inviting the woman to co-creation workshops to gather ideas, by asking her to provide feedback on early prototypes of a new service, or by lending her resources to innovate for herself.

Although people's lived experience is being recognised as a fundamental element of co-creation in healthcare innovation (Bate and Robert, 2006; Berry, 2019), there is a scarcity of research detailing the approaches for meaningfully integrating their lived experience into the innovation process (McColl-Kennedy et al., 2017a; Ocloo and Matthews, 2016). Without an in-depth 
understanding of the dynamics of integrating lived experience through co-creation, efforts to involve patients, family caregivers, and healthcare professionals risk tokenising those involved by marginalising their contributions. This leads to establishing a participation façade, which (1) reinforces existing power imbalances as well as the pre-existing perspectives and strategies of people with dominant roles, (2) increases patient alienation and frustration, and (3) may even lead to serious healthcare failings (Farrington, 2016; Ocloo and Matthews, 2016). Greater knowledge of what it takes to integrate lived experience, amid the power relations that dominate healthcare settings, is needed to support the re-orientation of care towards co-created peoplecentred health services (Donetto et al., 2015; World Health Organization, 2016). The objective of this research thus is to investigate the complex dynamics involved in integrating people's lived experience through co-creation in healthcare innovation and how this integration can be supported. To this end, the following research questions are guiding this study:

RQ1. What are the tensions related to the integration of people's lived experience through cocreation in healthcare innovation?

RQ2. What are strategies for integrating people's lived experience through co-creation in healthcare innovation, amid the tensions?

To explore these two research questions, this chapter reports on hermeneutic analyses of 23 phenomenological interviews with patients, family caregivers, designers, and healthcare professionals, who were involved in co-creation efforts during diverse healthcare innovation initiatives. Through this investigation, this research develops a conceptual framework that exhibits six tensions and seven strategies for integrating people's lived experience through cocreation in healthcare innovation. In doing so, this chapter offers three main contributions. First, this research identifies the underlying dynamics of integrating people's lived experience during co-creation efforts by providing an overview of the interacting tensions, which is essential for supporting genuine services co-creation that transcends a participation façade and for appropriately managing the often-neglected risks of co-creation (Farrington, 2016; Heidenreich et al., 2015). Second, this study offers seven strategies used to integrate people's lived experience through co-creation in healthcare innovation, responding to recent calls for more research on how patients and family caregivers can contribute to service innovation (McColl-Kennedy et al., 2017a). Finally, this study contributes to the transformation of healthcare systems towards people-centred care by guiding practitioners regarding the possible implications of the strategies they employ when co-creating in healthcare innovation.

\section{Theoretical Background}

\section{Co-Creation in Healthcare Innovation}

The role of patients is changing from being passive recipients of care to actively contributing personal resources and engaging in diverse activities within healthcare systems (Lukersmith et al., 2016; McColl-Kennedy et al., 2017a). The World Health Organization advocates for the cocreation of healthcare services that transcends mere dialogue to genuine partnerships between patients, healthcare professionals, and other affected people, as part of the transformation towards people-centred and integrated health services to improve shared decision-making and healthcare quality (Lukersmith et al., 2016; World Health Organization, 2015). Research suggests that co-creative practices between patients, family caregivers, and healthcare professionals during the management of health positively affect individuals' well-being and quality of life, while simultaneously holding the potential to decrease the burden on the healthcare system (McColl-Kennedy et al., 2012; McColl-Kennedy et al., 2017b).

Besides contributing to the delivery of healthcare services, there is growing awareness of the importance of involving patients and family caregivers during healthcare innovation (McColl-Kennedy et al., 2017a). Patients and family caregivers have situated and unique understandings of their own health contexts, and prior studies have demonstrated their interest and potential to contribute effective ideas in service innovation (McColl-Kennedy et al., 2017a Tian et al., 2014). Participating in healthcare innovation gives patients, their families, an healthcare staff opportunities to reflect on and shape their healthcare experience and provide input into the redesign of the overall system (Donetto et al., 2015). The resulting range of cocreation processes might include inviting diverse people to workshops to inform the design of prosthetics (Hussain et al., 2012) or partnering with patients and healthcare staff to co-create a new service for people living with diabetes (Freire and Sangiorgi, 2012). Underlying these co-creation processes in healthcare innovation is the integration of lived experience of people, who have a unique understanding of their own particular circumstances (Berry, 2019; Tian et al., 2014; Vink and Oertzen, 2018).

\section{Integrating Lived Experience through Co-Creation in Healthcare Innovation}

The concept of lived experience has recently emerged in the growing field of patient experience (Gallan et al., 2019), but has a much longer history in the discourse related to psychiatry and mental health (e.g., Deegan, 1988). Lived experience is subjective and tacit understanding that results from people's interactions within a given environment (Jaziri, 2019). Lived experience spans across the four dimensions of experience: (1) physical-the sensory aspects of a person in a context; (2) praxiological - the actions and interactions of a person within their environment 3) rhetoric-the creation of meaning based on a person's interpretations of their experience; and (4) temporal-a person's relationship with time during their experience (Jaziri, 2019; Roederer, 2012). The concept of lived experience is holistic and multidimensional, integrating people's responses over time across the different dimensions of experience (McColl-Kennedy et al., 2017c). While certainly intertwined, this research refers to "lived experience" as opposed to "patient experience," as lived experience is not specific to those in the role of the patient, but encompasses experience held by all people in healthcare, including, for example, family 
members (Wagner, 2004), healthcare professionals (McSherry et al., 2007), and designers (Cipolla and Bartholo, 2014).

There is growing recognition that co-creation in healthcare requires the integration of people's lived experience to support uplifting transformation. Lived experience has been recognised as an important foundation for improving community well-being (Gallan et al., 2019). Recent research acknowledges that lived experience is a critical source of knowledge for organisations looking to innovate (Jaziri, 2019). Scholars also suggest that investigating and building awareness of the contradictions between lived experience and cultural values can reveal possibilities for action (Murray et al., 2019). In healthcare innovation, in order to balance the risks of solely employing empathic or projective approaches that rely on second-hand knowledge (Bove, 2019), there is a need to integrate people's first-hand lived experience (Vink and Oertzen, 2018). While research in this area is limited, there are a number of emerging approaches being used within healthcare to draw out people's lived experience and inform healthcare innovation processes so that the final services most effectively meet the needs of affected people (e.g., Nakarada-Kordic et al., 2017).

However, the integration of lived experience in healthcare innovation can be contentious as it opposes the traditional bio-medical model (Sangiorgi et al., 2019). To realise people-centred health services, there is a need to transition from the paternalistic relationships between healthcare professionals and patients that are often characteristic of the bio-medical model towards shared decision-making (Lukersmith et al., 2016). In reality though, many healthcare innovation initiatives lack a critical understanding of the power relations related to integrating lived experience in healthcare contexts and, as such, risk reproducing oppressive and exclusive practices (Donetto et al., 2015). While lived experience has immense value in deepening the understanding of needs and context, it can be challenging to combine different knowledge sources and perspectives in healthcare (Lehoux et al., 2011; Trischler et al., 2018c). Conflict may appear when working with multiple truth regimes, for instance when integrating the lived experience of patients with traditional forms of expertise, such as the medical knowledge of physicians (Carr et al., 2009; Sellen, 2018). In addition, within healthcare innovation, some people may experience barriers to participation, such as patients with dementia, who require a thoughtful and sensitive approach to collaboration (Tobiasson et al., 2015). As such, to support uplifting transformation in healthcare, there is a need to better understand the tensions of integrating lived experience through co-creation and how they can be addressed in health innovation initiatives.

\section{Methodology - Phenomenological Interviews \\ Data Collection}

Noting the lack of empirical insights into integrating lived experience through co-creation in healthcare innovation, this qualitative study is informed by rich existential-phenomenological descriptions of people's life-worlds (Thompson et al., 1990). Phenomenological research acknowledges the way people are naturally involved in their own life-worlds, which denotes how people perceive and experience their own socially constructed totalities (Husserl, 1970). Phenomenology is well-suited to explore complex issues that necessitate deeper insights beyond surface responses (Goulding, 2005); thus, it is commonly used to study lived experience (Alfakhri et al., 2018). Phenomenological researchers seek to extract people's lived experience based on the way a person describes their experience and perceives meaning in this experience (Bevan, 2014).

This research follows the most frequently used method in phenomenological research and employs in-depth, semi-structured interviews (Alfakhri et al., 2018) to understand how people integrate lived experience through co-creation in healthcare innovation. In phenomenological research, the sampling frame is purposive, as participants are selected based on their lived experience (Goulding, 2005). To this end, the authors of this research immersed themselves in two healthcare organisations to gain a deeper meaning of the general context and the diverse spectrum of lived experience of different people. The active immersion lasted between five months to one year at the local premises of Experio Lab in Sweden and Patient Innovation in Portugal. Both organisations represent examples of the growing global movement towards people-centred health services in Western healthcare systems. The innovation of healthcare services in Experio Lab is typically initiated from inside the healthcare system by designers and healthcare professionals. Using a service design approach to healthcare innovation, designers and healthcare professionals at Experio Lab facilitate co-creation with patients, families, healthcare providers, and other related stakeholders to transform the Swedish healthcare system (Vink et al., 2019). Where as, at the international non-profit platform Patient Innovation, healthcare innovation is driven and initiated by patients and family caregivers. Patient Innovation exemplifies user innovation, as patients and their family caregivers, who are often underserved by pharmaceutical firms and other medical suppliers, design healthcare services for themselves with support from others (Oliveira et al., 2015). Conducting interviews across both contexts helped account for the diversity of co-creation efforts in healthcare innovation and the different constellations by which the lived experience of different people can be integrated.

Based on the researchers' in-depth knowledge of the context, participants were purposefully selected together with organisational gatekeepers at Experio Lab and Patient Innovation to achieve maximum variation in the sense of information-rich, diverse representations of lived experience in co-creation (Merriam and Tisdell, 2015), as well as facilitate the interviews in 
terms of language proficiency. Care was taken to ensure that the interviewed participants represented active participants in co-creation efforts driven by designers and healthcare professionals as well as active participants in co-creation efforts driven mainly by patients and family caregivers. Over a 12 -week period, semi-structured interviews were conducted in English with 23 participants: five patients, seven family caregivers, seven designers, and four healthcare professionals (Table 3.1). Interviews focused on one of the 18 different healthcare innovation initiatives that participants had been involved in. For instance, designers and healthcare professionals were interviewed, who had facilitated co-creation processes to innovate maternity care, mental health, or the recovery from a heart attack. Among others, the interviewed patients and caregivers had led the designs of innovations focused on diverse situations, such as bladder control, supporting breast cancer recovery, and helping people with visual impairments. The sample size reflects general recommendations $(n=12-20)$ for interview studies regarding maximum variation (Kuzel, 1992). After obtaining approval for the research protocol from an ethical review committee, half the interviews were conducted face-to-face with participants in healthcare contexts and the other half through video calls with participants in their homes or offices. All participants received an information letter, detailing the objectives of the research, and signed an informed consent form before answering any questions. Participants were not provided with any monetary remuneration, and partaking in the study was voluntary; the researchers found that participants were intrinsically motivated to share their stories. The interviews were audio recorded and lasted on average 64 minutes.

The three phases of phenomenological interviewing of Bevan (2014) were employed to develop the interview protocol and systematically allow for the description and thematisation of lived experience (Table 3.2). The same interview protocol was used for all interviews. First, to understand the contextual ground of people's lived experience (Thompson et al., 1990), the opening interview questions were descriptive and narrative, eliciting the life-worlds of the participants (Bevan, 2014). Among other questions, participants were asked to describe the kind of healthcare innovation initiative they were working on, including what motivated them to innovate, their involvement, others' involvement, and the goals of the innovation. Second, to apprehend the phenomenon of interest - integrating people's lived experience through co-creation in healthcare innovation - participants were asked descriptive and structural questions related to who was involved in the co-creation process, how their own and others knowledge or experience was shared and integrated in the process, and the challenges they encountered during the collaboration. Finally, the third phase was aimed at clarifying the phenomenon of interest by generating deeper meaning through imaginative variation this phase included probing into particular aspects of people's lived experience by variational questioning (Bevan, 2014). After listening and reflecting on participants' descriptions, they were asked about how they would engage in particular situations differently given the knowledge they have today, if they would collaborate with people differently, and what could have improved their collaboration during the healthcare innovation initiative.
Table 3.1. Overview of the participants $(n=23)$

\begin{tabular}{|c|c|c|}
\hline ID & Participant type & Healthcare domain \\
\hline (P1) & Patient & Bladder control \\
\hline (P2) & Patient & Arrhythmic heart monitoring \\
\hline (P3) & Patient & Breast cancer support \\
\hline (P4) & Patient & Visual impairment support \\
\hline (P5) & Patient & Breast cancer support \\
\hline (P6) & Designer & Maternity care \\
\hline (P7) & Designer & Recovery after heart attack \\
\hline (P8) & Designer & Dementia care \\
\hline (P9) & Designer & Mental healthcare \\
\hline (P10) & Designer & Client welfare \\
\hline (P11) & Designer & Electroconvulsive therapy (ECT) \\
\hline (P12) & Designer & Maternity care \\
\hline (P13) & Family caregiver & Parkinson support \\
\hline (P14) & Family caregiver & Autism care \\
\hline (P15) & Family caregiver & Mobility support \\
\hline (P16) & Family caregiver & Developing a robotic assistive arm \\
\hline (P17) & Family caregiver & Developing a symptom checker \\
\hline (P18) & Family caregiver & Scoliosis support \\
\hline (P19) & Family caregiver & Breast cancer support \\
\hline (P20) & Healthcare professional & Supporting family caregivers \\
\hline (P21) & Healthcare professional & Mental healthcare \\
\hline (P22) & Healthcare professional & Electroconvulsive therapy (ECT) \\
\hline (P23) & Healthcare professional & Recovery after heart attack \\
\hline
\end{tabular}

\section{Data Analysis}

Thompson's (1997) pragmatic considerations of hermeneutic analysis were used to explore, thematise, and synthesise the existential-phenomenological descriptions of people's lived experience. Hermeneutic analyses interpret each interview individually after which common patterns, or so-called themes, are identified across interviews (Thompson et al., 1990). Table 3.3 exhibits the four stages of the analysis based on the processes outlined by Goulding (2005) and Thompson (1997). During the first stage, interviews were summarised upon their completion and audio files were transcribed verbatim. Next, the summaries and transcripts were read to get an overall understanding of the data and the underlying narratives. In the second stage, two members of the author team worked independently and iteratively on intratext analysis to locate and mark significant text segments as facets of integrating lived experience and approaches to integrating lived experience. Findings were contrasted and complemented between the researchers to support researcher triangulation (Flick, 2018). The third stage included an iterative part-to-whole analysis, whereby significant text segments were related to the whole and interpretations were continuously revised (Thompson, 1997). 
Table 3.2. Phenomenological interview structure based on Bevan (2014)

\begin{tabular}{|c|c|c|}
\hline Interview structure & Questioning type & Exemplary questions \\
\hline $\begin{array}{l}\text { Phase } 1 . \\
\text { Contextualise the } \\
\text { phenomenon } \\
\text { of interest }\end{array}$ & $\begin{array}{l}\text { Descriptive } \\
\text { and narrative } \\
\text { questioning }\end{array}$ & $\begin{array}{l}\text { - Please describe the innovation you have been working on. } \\
\text { - What is the goal of the innovation? } \\
\text { - What motivated you to take part/lead this innovation? } \\
\text { - Who else is or was involved? }\end{array}$ \\
\hline $\begin{array}{l}\text { Phase } 2 . \\
\text { Understand the } \\
\text { phenomenon } \\
\text { of interest }\end{array}$ & $\begin{array}{l}\text { Descriptive } \\
\text { and structural } \\
\text { questioning }\end{array}$ & $\begin{array}{l}\text { - What previous experience/knowledge did you have that } \\
\text { you were able to contribute in developing the innovation? } \\
\text { - What knowledge or experience was needed from other } \\
\text { people that you did not have yourself? } \\
\text { - How was their knowledge or experience shared/ } \\
\text { integrated into the innovation process? } \\
\text { - How did you work together in the innovation process? } \\
\text { - How would you describe your collaboration with } \\
\text { the other people involved? } \\
\text { - Did you experience any problems in your collaboration } \\
\text { with other people? }\end{array}$ \\
\hline $\begin{array}{l}\text { Phase } 3 . \\
\text { Refine the } \\
\text { phenomenon } \\
\text { of interest }\end{array}$ & $\begin{array}{l}\text { Imaginative } \\
\text { variation } \\
\text { questioning }\end{array}$ & $\begin{array}{l}\text { - If you could do it all over again, what would you } \\
\text { do differently? } \\
\text { - Would you collaborate with other people differently? } \\
\text { - What could have improved the collaboration? } \\
\text { - ... }\end{array}$ \\
\hline
\end{tabular}

Based on this intertext analysis, common themes were established that are meaningful to the research questions. The authors derived six underlying tensions of integrating lived experience through co-creation in healthcare innovation grounded in the conflicting facets identified through the intratext analysis. Furthermore, seven strategies to integrate different degrees of lived experience through co-creation in healthcare innovation were assembled based on the conscious and unconscious approaches named by the participants. Finally, in the fourth stage, the author team acknowledged that all identified themes are a fusion of horizons between the participants' descriptions and the researchers' interpretations (Goulding, 2005; Thompson, 1997). To ensure the themes' credibility (Thompson et al., 1990), they were critically evaluated by members of Experio Lab and Patient Innovation, which resulted in adaptations of the wording.

\section{Findings}

\section{Examples of Integrating People's Lived Experience through Co-Creation in}

\section{Healthcare Innovation}

To contextualise and illustrate the rich existential-phenomenological descriptions of the interviewed participants' lived experience, the findings section commences by describing
Table 3.3. Data analysis process based on Goulding (2005) and Thompson (1997)

\begin{tabular}{|c|c|}
\hline Stages & Procedures \\
\hline $\begin{array}{l}\text { Stage } 1 . \\
\text { Familiarisation }\end{array}$ & $\begin{array}{l}\text { - Created a summary upon completion of each interview by using handwritten notes } \\
\text { taken during the interview on the progression of the interview, notable statements, } \\
\text { and perceived emotions } \\
\text { - Transcribed the interview audio files verbatim } \\
\text { - Read through the transcripts and summaries several times to understand } \\
\text { the underlying narratives of people's descriptions of their lived experience } \\
\text { - Result: } 23 \text { interview summaries and } 321 \text { single-spaced transcript pages }\end{array}$ \\
\hline $\begin{array}{l}\text { Stage } 2 . \\
\text { Intratext analysis }\end{array}$ & $\begin{array}{l}\text { - Interpreted each interview individually } \\
\text { - Located significant text segments relevant to the phenomenon of interest, i.e., } \\
\text { integrating people's lived experience through co-creation in healthcare innovation } \\
\text { - Marked a text segment as a facet of integrating lived experience if it included } \\
\text { a particular characteristic of conveying or utilising a first-hand understanding } \\
\text { - Marked a text segment as an approach if participants discussed a way of dealing } \\
\text { with the complexity of integrating lived experience. } \\
\text { - Result: } 116 \text { text segments referring to facets of integrating lived experience and } 189 \\
\text { text segments referring to approaches to integrating lived experience. }\end{array}$ \\
\hline $\begin{array}{l}\text { Stage } 3 . \\
\text { Intertext analysis }\end{array}$ & $\begin{array}{l}\text { - Conducted a part-to-whole analysis by relating significant text segments of } \\
\text { the individual interviews to the whole } \\
\text { - Iteratively moved back and forth between individual text segments and } \\
\text { the meaning of the whole and continuously revised interpretation while doing so } \\
\text { - Identified recurrent themes among the interview transcripts that were meaningful } \\
\text { to the research questions on the tensions of and strategies for integrating people's } \\
\text { lived experience through co-creation in healthcare innovation } \\
\text { - Result: Six underlying tensions of integrating lived experience and seven strategies } \\
\text { for integrating different degrees of lived experience through co-creation in health } \\
\text { care innovation }\end{array}$ \\
\hline $\begin{array}{l}\text { Stage } 4 . \\
\text { Fusion of } \\
\text { horizons }\end{array}$ & $\begin{array}{l}\text { - Recognised that the identified themes represent a fusion of meaning between } \\
\text { the phenomenological-existential descriptions of the participants and the frame of } \\
\text { reference of the researchers } \\
\text { - Subjected the identified themes to critical evaluation by members of Experio Lab } \\
\text { and Patient Innovation } \\
\text { - Result: Slight adaptations of the wording of the identified themes }\end{array}$ \\
\hline
\end{tabular}

two exemplary healthcare innovation initiatives and reflecting on participants' challenges when integrating lived experience through co-creation. The first example is aimed at improving the experience of a particular therapy for people with mental health issues and the second is addressing the need for bladder control. While in the former example healthcare professionals and designers were guiding the co-creation efforts to innovate, the latter reports on co-creation efforts steered by a patient. Pseudonyms are used to protect participants' anonymity 


\section{Example 1: Improving the Experience of Electroconvulsive Therapy (ECT)}

Electroconvulsive therapy (ECT) involves putting electrodes on a patient's head to stimulate seizure-like activity in the brain as a treatment for serious mental health issues. The manager of a local ECT unit came to Experio Lab to get help with improving the experience of patients and families, who were often apprehensive about receiving this service. Experio Lab designer, Mr. Nilsson, planned a re-enactment of the ECT patient journey process, in which doctors, nurses, managers, and operations staff would walk through each step of the patient process, from the waiting room to departure. However, when the manager tried to recruit ECT patients to join this re-enactment, none of the contacted patients were available and willing to join the co-creation activity.

"The intention was to have one or two patients in the journey too, but we didn't get them. The biggest problem was that we didn't have the real patient perspective. You can always feel and get empathy but it is not the same if you don't get them on board." (Mr. Nilsson)

The designer, managers, and healthcare staff involved recognised that with the stigma of mental illness, the unpleasantness of this process, and the current condition of patients, there were many barriers to their participation. Therefore, Mr. Nilsson played the role of the patient and asked the staff to reflect on what the patient experience might be like at every stage of the process. Lacking lived experience specific to this process, the Experio Lab team decided to reach out to ECT patients and conduct interviews after the enactment. Ms. Lindgren, a healthcare communications professional who conducted some of these interviews, noted some patients' inability to share their experience during the interviews. Ms. Lindgren sensed that one patient did not remember her experience well and was not able to share it meaningfully.

"I almost immediately got the feeling that this woman is not well. That was a strange feeling for me. I am not a clinical person.... She had difficulties explaining how it was and when it happened. She needed more help.... She couldn't answer me clearly... It took me a little while to digest..." (Ms. Lindgren)

When comparing what the patients said their lived experience was like against what the staff who re-enacted the journey believed the experience was, Mr. Nilsson and Ms. Lindgren saw some major discrepancies and misunderstandings.

Reflecting on the above example suggests several challenges of integrating people's lived experience during co-creation efforts. There were significant barriers related to memory, health, and stigma that challenged patients' ability to share their lived experience. There was also a push and pull struggle between involving patients and families directly or indirectly in the healthcare innovation initiative, due to their condition and circumstances. The emphasis on indirect sharing of lived experience led to misunderstandings between staff and patients and families.

\section{Example 2: Addressing the Need for Bladder Control}

Mr. Jones has an incurable illness that limits his daily life due to its symptoms, such as having to visit the bathroom unexpectedly and frequently. While on holidays with his family, Mr. Jones experienced a critical need for a toilet, but it took him over an hour to find one. Realising that his quality of life and that of his family had become dependent on his sanitary needs, $\mathrm{Mr}$. Jones searched available products and services to find a solution. However, he could not find anything to help control his bladder, which prompted him to design a solution himself-an interactive app that could be used to predict the likelihood of critical moments. He needed further support to develop this solution. Specifically, Mr. Jones required technical knowledge from developers, more in-depth knowledge about the target segment of people like himself, medical knowledge about how to predict critical moments, and financial insights regarding how to fund the undertaking. While developing the solution, Mr. Jones encountered some contextual challenges, such as geographical distance from the software developers, located in Asia:

"I had the sketch of the idea, but I have no knowledge of IT and all the dealings of the app.... For me its too difficult to manage the Skypes with [the software developers in Asia]. We have a 5.5 hours time difference. Most of the time, it's 4:00 am in the morning and I am talking to them. I realise that for me as a patient, I need to rest a lot. It's quite difficult to manage all by myself." (Mr. Jones)

His own experience enabled Mr. Jones to relate to and empathise with other patients suffering from the same symptoms, and he decided to make the app accessible for everyone in the community. During Mr. Jones's enduring efforts, he has been very emotionally and physically involved in the co-creation process. Even though his experience with the illness motivates and drives him, Mr. Jones is exhausted from all the work, which he must perform even while still dealing with the symptoms of his illness:

"I'm too tired. I'm tired. I'm very tired, because I'm the ambassador of the project." (Mr. Jones)

In this second example, the patient, Mr. Jones, had to innovate to improve his own well-being, due to the lack of availability of ready-made solutions. He had knowledge of his own condition and experience; however, he could not proceed with the design of the solution without more technical knowledge about how to develop the app. Because the software developers he found were located in Asia, the time difference and virtual nature of their interaction challenged 
the co-creation process. Additionally, the patient was physically exhausted and so emotionally attached that he found it difficult to detach and relinquish some control over the initiative. While the success of the initiative was driven by his commitment and determination to stay in control of every aspect, he was experiencing fatigue and sleepless nights, which had negative implications on his health.

\section{Tensions of Integrating Lived Experience through Co-Creation}

Upon systematically analysing the facets of integrating lived experience through co-creation from all interviews during the part-to-whole analysis (Table 3.3), the authors encountered several contradicting patterns that were synthesised into six tensions when integrating people's lived experience through co-creation in healthcare innovation: in/ability, im/partiality, dis connection, in/direct, dis/similarity, and mis/understanding (Table 3.4). A slash is used in the name of each tension to acknowledge that these tensions include the facets that are often seen as opposing, yet they are not necessarily dichotomous. The tensions are also not mutually exclusive; they often are interconnected and influence one another.

A prominent tension that came forward when analysing participants' descriptions, "in/ability," reflects the contradiction that people with lived experience are wholly and uniquely capable of sharing their direct knowledge in particular situations, but that they also may face significant barriers that limit their ability to integrate their experience through co-creation in healthcare innovation. Some participants with lived experience were able to design for themselves with minimal outside resources. For example, one patient (P2) had developed a device to measure his arrhythmic heartbeat. Notably, this patient encountered a need rooted in his own lived experience of having an arrhythmic heart, and also had a background of working in a field that allowed him to come up with a device to monitor it. But other participants mentioned various barriers to leveraging their lived experience, such as sickness. In addition, in one of Experio Lab's healthcare innovation initiatives exploring maternity care, memory issues were highlighted as women discussed forgetting aspects of their experience of being pregnant after their baby's arrival.

Another frequently mentioned tension, "im/partiality," pertains to the divide between the value of using personal feelings and perspectives and the need for objectivity in professiona healthcare settings. While recognising the value of understanding the lived experience of others to inform healthcare innovation, designers, in particular, found it challenging to deal with and integrate their own lived experience. Many argued that their formal role as a designer requires suppressing their own experience and keeping clear boundaries between the personal and professional realms of one's life. The issue of suppressing one's lived experience to be objective was also reinforced by healthcare professionals, who often felt they needed to put their own lived experience aside in order to be professional.
The third tension that participants confronted, "dis/connection," includes the push and pull between being too connected or too disconnected with the mission or context of a healthcare innovation initiative due to one's own lived experience. Some participants emphasised the importance of a close, personal connection to drive innovation and indicated that their lived experience fuels their persistence and determination. Other patients and family caregivers who innovate for their own well-being expressed feeling exhausted from the emotional investment of sacrificing themselves for the cause. In the bladder control example, the patient considered his personal dedication the engine of his innovation, but at the same time he felt physically exhausted and overwhelmed. Participants expressed their need for others with similar connections for emotional and operational support, but worried that other people might not share the same level of connection. Designers also voiced an emotional toll of being too connected when co-creating in relation to a particular innovation initiative because of their own lived experience as patients. In one case, a designer felt the need to detach and not work on certain healthcare projects as a result of their own lived experience in that area.

The fourth tension, "in/direct," relates to the struggle between having people with lived experience present to share their first-hand perspectives versus using representation and projective approaches. The participants recognised the value of having people with lived experience participate directly in the co-creation process. In particular, they underscored the advantages of people's physical presence in co-creation and the value of communicating through body language, in addition to spoken language. Yet in certain situations, including the patients' or family caregivers' experience directly was not possible due to ethical considerations or sickness, such as in the example of improving the experience of the ECT patient journey process.

The fifth tension that arose is related to the alignment between the lived experience of different people in the co-creation process, or what this research refers to as "dis/similarity." Some participants proposed that their story was the same as the stories of many people with a particular illness or condition. On the other hand, many participants highlighted the uniqueness of people's experience. Designers reflected upon falsely assuming that someone else's experience was similar to their own, which resulted in them missing certain questions when investigating a particular experience. There was consensus on the importance of involving people with diverse experience through co-creation in healthcare innovation, although recruiting a diverse set of people with lived experience of a particular condition, situation, or identity was recognised as a major challenge.

For the final tension, "mis/understanding," the analysis of the interviews revealed that people were unsure whether it is possible to truly understand the lived experience of others. 


\begin{tabular}{|c|c|c|c|}
\hline Tension & Definition & Practical example & Illustrative quotes \\
\hline In/ability & $\begin{array}{l}\text { The contradiction between people being } \\
\text { uniquely capable of leveraging their first- } \\
\text { hand experience, but also facing significant } \\
\text { barriers that limit their capacity to do so. }\end{array}$ & $\begin{array}{l}\text { A patient having relevant lived experience, } \\
\text { but having problems sharing it with others } \\
\text { due to memory loss, trauma, or stigma. }\end{array}$ & $\begin{array}{l}\text { "It's hard to remember what your concerns were when you were pregnant after you have your baby." (P6) } \\
\text { "You may not remember what happened because you were really depressed." (P11) }\end{array}$ \\
\hline $\mathrm{Im} /$ partiality & $\begin{array}{l}\text { The divide between using personal feelings and } \\
\text { perspectives and the need for objectivity and } \\
\text { acting based on facts. }\end{array}$ & $\begin{array}{l}\text { A designer, who is also a mother, trying to } \\
\text { facilitate the co-creation of a maternity care } \\
\text { service without integrating her own lived } \\
\text { experience. }\end{array}$ & $\begin{array}{l}\text { "I often struggle what's personal and what's professional and I often feel like, oh no, now I'm unprofessional } \\
\text { again because I'm sharing too much." (P7) } \\
\text { "It's hard to put yourself aside, but that's what a designer has to do." (P8) }\end{array}$ \\
\hline Dis/connection & $\begin{array}{l}\text { The push and pull between being too attached } \\
\text { or too detached to the mission or context } \\
\text { of the co-creation effort as a result of a lived } \\
\text { experience. }\end{array}$ & $\begin{array}{l}\text { A father's lived experience driving him to } \\
\text { innovate for his child's well-being, but at } \\
\text { the same time wearing him out physically } \\
\text { and emotionally. }\end{array}$ & $\begin{array}{l}\text { "The experience obviously makes it different, it makes it a mission." (P17) } \\
\text { "I don't want to work with projects related to that because it's too close to heart." (P9) }\end{array}$ \\
\hline In/direct & $\begin{array}{l}\text { Challenges related to having people with lived } \\
\text { experience present to share their knowledge } \\
\text { versus secondarily "presencing" them through } \\
\text { empathic methods. }\end{array}$ & $\begin{array}{l}\text { A designer fictionally presencing patients } \\
\text { through empathic methods, such as role- } \\
\text { playing, but not capturing all aspects of } \\
\text { patients' lived experience. }\end{array}$ & $\begin{array}{l}\text { "There's a huge benefit in being there in person. There's a lot of communication that happens through body } \\
\text { language." (P16) } \\
\text { "It's easy to think that you know what the patients feel about the whole journey and it's very good to have them } \\
\text { there to talk directly ... that they can be able to talk for themselves and not that someone talks for them." (P23) }\end{array}$ \\
\hline Dis/similarity & $\begin{array}{l}\text { The contradiction between seeing someone's } \\
\text { lived experience as related } \\
\text { to someone else's experience versus } \\
\text { recognising that every experience is unique } \\
\text { and different. }\end{array}$ & $\begin{array}{l}\text { A healthcare professional wanting to integrate } \\
\text { the lived experience of patients to co-create } \\
\text { a mental health service, but struggling to } \\
\text { integrate the broad spectrum of peopless lived } \\
\text { experience. }\end{array}$ & $\begin{array}{l}\text { "My story is the same story of } 85 \% \text { of the ... community." (P1) } \\
\text { "Everyone is very different. I mean, the issues experienced by one person are not necessarily the same as } \\
\text { the experience by the next person. So we'd still need to go out and speak to a wider audience, even if we had } \\
\text { one person [with lived experience in the team]." (P13) }\end{array}$ \\
\hline $\begin{array}{l}\text { Mis/ } \\
\text { understanding }\end{array}$ & $\begin{array}{l}\text { Being able to comprehend } \\
\text { the lived experience of other people, but also } \\
\text { considering it impossible to wholly } \\
\text { know and comprehend someone } \\
\text { elses experience. }\end{array}$ & $\begin{array}{l}\text { A patient pointing out the necessity of } \\
\text { being included in co-creating breast cancer } \\
\text { support, because other people can only } \\
\text { relate but not truly understand her lived } \\
\text { experience. }\end{array}$ & $\begin{array}{l}\text { "There's no way somebody can understand." (P15) } \\
\text { "I haven't had that in my life but I've had experiences of close relatives or family where the body has been } \\
\text { affected a lot. ... I feel like it's somehow embodied in me. I've experienced the body being fragile." (P7) }\end{array}$ \\
\hline
\end{tabular}

Some patients and family caregivers considered it impossible for others to fully understand their lived experience, but some suggested it is possible for others to gain this understanding through their own related experience. Designers and healthcare professionals in particular reflected on identifying with the experience of others and understanding the experience of others by using their own, albeit divergent, experience. However, as the ECT example shows, it happens that people believe they understand someone else's lived experience, while in reality they misunderstand important aspects.

\section{Strategies for Integrating Lived Experience through Co-Creation}

During the interviews, many participants suggested conscious and unconscious approaches to dealing with the complexity of integrating their own and others' lived experience. Grounded in these observations, the authors assembled seven strategies of integrating lived experience hrough co-creation in healthcare innovation. These strategies were applied in response to the different tensions of integrating lived experience within a particular healthcare context. Table 3.5 provides an overview of these strategies in ascending order from the lowest to the highest levels of autonomy that the strategy enables for the people that have lived experience relevant to the healthcare innovation. That is, the strategies vary in the extent to which they integrate lived experience, leading to different benefits and drawbacks. In addition, the strategies are not mutually exclusive, but may be combined or enacted sequentially.

Integrating patients or family caregivers to leverage their first-hand experience through cocreation in healthcare innovation is challenging for various reasons, such as memory loss or the pain of remembering. In these cases, designers or healthcare professionals may try to 
temporarily employ the "simulating" strategy to replicate the lived experience of others, such as by role-playing a certain situation. Although a viable approach if the people that the healthcare innovation targets are unavailable, it runs the risk of falsely representing their lived experience or projecting other people's mental models onto their experience.

The second strategy, "presencing," also does not directly include the active participation of the people with lived experience targeted by the respective innovation. With this approach, people use empathy and knowledge from their second-hand experience to represent others. Storytelling is commonly used to instil a sense of presence, which helps people understand and design for others and the situations they face. Although this strategy integrates the lived experience of others indirectly, it only draws on second-hand knowledge, which may still lead to false representations of the lived experience of the people whom the innovation is intended to benefit.

"Templating" is the first strategy that integrates first-hand, lived experience when co-creating in healthcare innovation. It provides a structured procedure or format for documenting people's lived experience, such as a standardised form with blank spaces that encourage people to report their own experience. This strategy often starts with a relatively unrestrained approach, then narrows down to semi-structured templates, because participants' descriptions differ in their degree of clarity and elaboration. This approach produces focused and structured data, but first-hand experience is often challenging to communicate in such a controlled and restricted format, and the data gathered inherently reflect the assumptions of the people who created the template.

The fourth strategy, "sharing," allows for the integration of first-hand knowledge in a les restricted and controlled format by asking people to be present and directly communicate their lived experience, such as during interviews. The result is a richer understanding of the lived experience of others. However, it still only offers a partial account of the firsthand perspective because such knowledge sharing generally is confined to a few interviews, one-off storytelling, or one-time workshop participation. This strategy also creates a potential risk of misinterpretation, because of the lack of clarification and dialogue in a one-way sharing process.

"Exchanging" elevates the integration of lived experience from one-directional communication to a multi-directional process of reciprocal communication. It comprises dialogue among two or more people who share similar or different lived experience, leading to processes of contrasting, relating, and reflecting on one's own experience and the experience of others. With this strategy, people can better understand the first-hand knowledge associated with multiple perspectives, and people with lived experience can contextualise their experience relative to those of others. For example, some patients described designing an initial prototype of a solution to meet their needs, then asking other people in a similar situation to try it and give feedback, which improved the initial solution. However, the duration of this strategy is typically relatively short; beyond sharing experience, it allows for limited exchanges of other resources.

Unlike the prior strategies, the sixth strategy, "allying," is long-term in nature. People engage in continuous partnerships with others and receive ongoing support. For example, those with firsthand knowledge might participate throughout the course of a project to develop a healthcare innovation that is steered by a designer. As another example, people with lived experience could design for themselves and others, while closely partnering over the long term with others to access the support, knowledge, tools, or funding that they lack. This form of partnering leads to continuous sharing of experience, but it can be slow and resource consuming, due to it complexity, such that it may not be appropriate for some innovation initiatives in healthcare. Furthermore, power dynamics continue to influence these partnerships, which may constrain how lived experience is integrated within these partnerships.

Finally, "resourcing" comprises the highest level of autonomy for people with lived experience who are the main beneficiaries of the healthcare innovation. This strategy provides people with lived experience the assets they need to design the change they seek. People might take full control over designing an innovation that improves their well-being, while co-creating with others to receive, for example, technical, medical, or legal resources. With this strategy, people with lived experience often become user innovators and entrepreneurs, who lead the development of the services and systems that affect them. In many cases, the adoption of this strategy is not planned by people with lived experience but rather is born out of necessity. Patients who need specific solutions that are not readily available on the market may decide to develop them on their own, which usually requires resources from others. In some case though, resourcing is not possible or desirable, whether due to the graveness of patients illness or policy barriers. Furthermore, providing resources without ongoing allyship and connections to larger networks likely limits the potential influence of innovations resulting from a resourcing strategy.

Examining these strategies in relation to the two practical examples (described at the beginning of the findings section) shows that the design team for improving the ECT experience adopted a simulating strategy, in that Mr Nilsson role-played the experience of patients in the ECT patient journey process to build empathy. However, recognising the limitations of this approach the team complemented the insights from the simulation with a sharing strategy, facilitated by the patient interviews. The team then used the insights from both approaches to compare findings and challenge existing assumptions about the lived experience of ECT patients and family members. There was palpable frustration about how the complexity of the situation limited the team's ability to integrate lived experience through more dialectic approaches. 


\begin{tabular}{|c|c|c|c|}
\hline Strategy & Definition & Practical example & Illustrative quotes \\
\hline Simulating & $\begin{array}{l}\text { Staging a temporary process of mimicking or } \\
\text { replicating a particular lived experience. }\end{array}$ & $\begin{array}{l}\text { Role-playing a certain situation with people } \\
\text { who have not experienced the situation. }\end{array}$ & $\begin{array}{l}\text { "Then we did role-playing, so one in each group was the patient and they did a scenario that they made up } \\
\text { themselves." (P8) } \\
\text { "The way we did it, because we didn't have any patients in the room, was that I was both. I was both } \\
\text { the patient and also the moderator." (P11) }\end{array}$ \\
\hline Presencing & $\begin{array}{l}\text { Sharing second-hand perspectives on lived } \\
\text { experience in the absence } \\
\text { of someone with relevant lived experience } \\
\text { present. }\end{array}$ & $\begin{array}{l}\text { Drawing an empathy map of people with } \\
\text { lived experience to make them "present" in } \\
\text { the room. }\end{array}$ & $\begin{array}{l}\text { "We started with the empathy map, because we wanted to lift the target group into the room to have them } \\
\text { present." (P21) } \\
\text { "I am responsible for telling [the patients'] story in a way that maybe they are not capable of or maybe they } \\
\text { are not listened to." (P9) }\end{array}$ \\
\hline Templating & $\begin{array}{l}\text { Creating a standardised procedure or format in } \\
\text { which people can share their lived experience. }\end{array}$ & $\begin{array}{l}\text { Filling in the blank spaces in a provided } \\
\text { document to template people's experience. }\end{array}$ & $\begin{array}{l}\text { "I felt the workshop was very controlled. It was even the start of a phrase, like the first words were set and } \\
\text { then they were going to fill that in." (P7) } \\
\text { "We gave them papers with pre-printed questions." (P8) }\end{array}$ \\
\hline Sharing & $\begin{array}{l}\text { A one-way process of directly communicating } \\
\text { one's own lived experience, of value for others. }\end{array}$ & $\begin{array}{l}\text { Someone sharing their own lived experience } \\
\text { through interviews. }\end{array}$ & $\begin{array}{l}\text { "I have this person that I call Lisa.... She is telling the story and we listen to when she talked about how her } \\
\text { life had been." (P10) } \\
\text { "We went to this day with midwives ... just to listen in and to get some voices from midwives about their role } \\
\text { and how they see the future of midwifery." (P12) }\end{array}$ \\
\hline Exchanging & $\begin{array}{l}\text { A multi-directional process of sharing and } \\
\text { relating the lived experience of several people. }\end{array}$ & $\begin{array}{l}\text { Reciprocal dialogue among diverse people } \\
\text { with similar and different lived experience } \\
\text { to test and improve an innovation. }\end{array}$ & $\begin{array}{l}\text { "It's important that you get new people involved that have not been part of it before, because very soon you } \\
\text { take something for granted." (P4) } \\
\text { "During the interviews ... when you're alone with this woman and her story, she's also very alone with her } \\
\text { story. But when we put women together making them share stories, it's more about empowering each other. } \\
\text { It becomes more like a shared experience." (P12) }\end{array}$ \\
\hline Allying & $\begin{array}{l}\text { Ongoing partnership and corresponding } \\
\text { support between people with relevant lived } \\
\text { experience and others. }\end{array}$ & $\begin{array}{l}\text { A collaboration between someone with lived } \\
\text { experience and other people to develop an } \\
\text { innovation. }\end{array}$ & $\begin{array}{l}\text { "We decided to do everything under equality.... Our interests are perfectly aligned. ... We like to collaborate } \\
\text { and we both don't like to fight." (P14) } \\
\text { "I think that both sides have to be open and honest about what they're expecting from a collaboration, and } \\
\text { what they want to achieve out of it." (P13) }\end{array}$ \\
\hline Resourcing & $\begin{array}{l}\text { Providing people with lived experience } \\
\text { the assets they need to lead the design of } \\
\text { the changes that affect them. }\end{array}$ & $\begin{array}{l}\text { Using resources from others to design for } \\
\text { oneself as an entrepreneur. }\end{array}$ & $\begin{array}{l}\text { "They need to know what you want and they put it to work." (P1) } \\
\text { "I was the perfect patient to create it, or the perfect patient to test it, but when it came to the business side, } \\
\text { I drew on nothing except common sense and faith ... so I had to reach out to the Washington DC attorney, } \\
\text { who ... pulled it off for us." (P5) }\end{array}$ \\
\hline
\end{tabular}

In the bladder control example, $\mathrm{Mr}$ Jones employed a resourcing strategy, because he took the lead to innovate for his own well-being, drawing from the resources of others, such as technical knowledge from app developers in Asia. Although he was designing for a solution that truly matched his own needs and desires, as well as those of people suffering from similar illnesses, he was restricted in his ability to develop it, due to his lack of expertise and the symptoms of his illness. Allying with someone else could have eased this burden, but it also denoted a loss of control. Allowing others to continuously participate in developing this innovation increased the risk that the ultimate solution would not meet his needs. As this dilemma realistically illustrates, the tensions of integrating lived experience cannot be resolved by a single, readily available strategy but instead must be navigated through careful consideration of the implications of various strategies within the given healthcare context. 


\section{Discussion}

Conceptual Framework for Integrating Lived Experience through Co-Creation in Healthcare Innovation

This research phenomenologically explored the complex dynamics involved in integrating lived experience through co-creation in healthcare innovation. Figure 3.1 displays a conceptua framework that summarises the findings based on 23 interviews with patients, family caregivers, designers, and healthcare professionals involved in co-creation efforts during various healthcare innovation initiatives. In no particular order, six tensions of integrating lived experience through co-creation were identified, with influence on one another and that vary depending on the situation. Grounded in participants' conscious and unconscious approaches to dealing with the complexity of integrating lived experience, the authors further assembled seven strategies that are available individually or combined as responses to different tensions, again depending on the context. The strategies are displayed on a spectrum corresponding to increasing levels of autonomy of the people with relevant lived experience to the healthcare innovation initiative. Although the strategies used to integrate lived experience are influenced by the tensions, the strategies employed also affect the tensions present during co-creation.

This conceptual framework helps explain the limitations of co-creation efforts in healthcare innovation, in that they must confront the practical tensions of integrating lived experience. The six tensions that this research identified can provide a baseline for expanding and dissembling key challenges of co-creation in healthcare innovation, including those suggested in existent literature. For example, Trischler and colleagues (2018c) indicate the difficulty of combining different knowledge sources, and Sellen (2018) suggests that conflict might arise from working with multiple truth regimes. These challenges reflect the mis/understanding tension, because different people struggle to comprehend and accept the lived experience of others. The im/partiality tension may add to this complexity, resulting from the contradiction between the acceptability of subjective perspectives and objective reasoning. The conceptual framework further illustrates that these tensions influence the strategies used when co-creating in a particular healthcare innovation context, and vice versa. In outlining strategies and concrete practices such as role-playing or workshops to enact them, this research suggests practical ways to meaningfully integrate varying degrees of lived experience, for instance the lived experience of patients and family caregivers in healthcare innovation initiatives (Berry, 2019; McCollKennedy et al., 2017a; Ocloo and Matthews, 2016).

\section{Theoretical and Practical Implications}

First, this research extends the discourse on the process of co-creation when innovating services (Gustafsson et al., 2012; Payne et al., 2008) by unveiling the underlying complex dynamics of integrating people's lived experience. Through in-depth empirical research, this chapter provides an overview of six interacting tensions at play when integrating the lived experience of people during co-creation efforts. Understanding the challenges of integrating lived experience when innovating services is essential for strategically moving beyond tokenistic approaches to support genuine services co-creation that does not marginalise the contributions of vulnerable people (Ocloo and Matthews, 2016). Furthermore, by appreciating the related tensions, researchers gain insights into the under-studied risks of co-creation to aid practitioners in more appropriately managing the process (Heidenreich et al., 2015). Especially in healthcare, co-creation efforts run the risk of resembling a mere participation façade, as healthcare continues to be affected by an unbalanced division of power between patients and healthcare professionals, which can lead to serious service failings (Farrington, 2016; Lukersmith et al., 2016). A better comprehension of the potential tensions of integrating people's lived experience can support the authentic encouragement of people to share their experience in co-creation

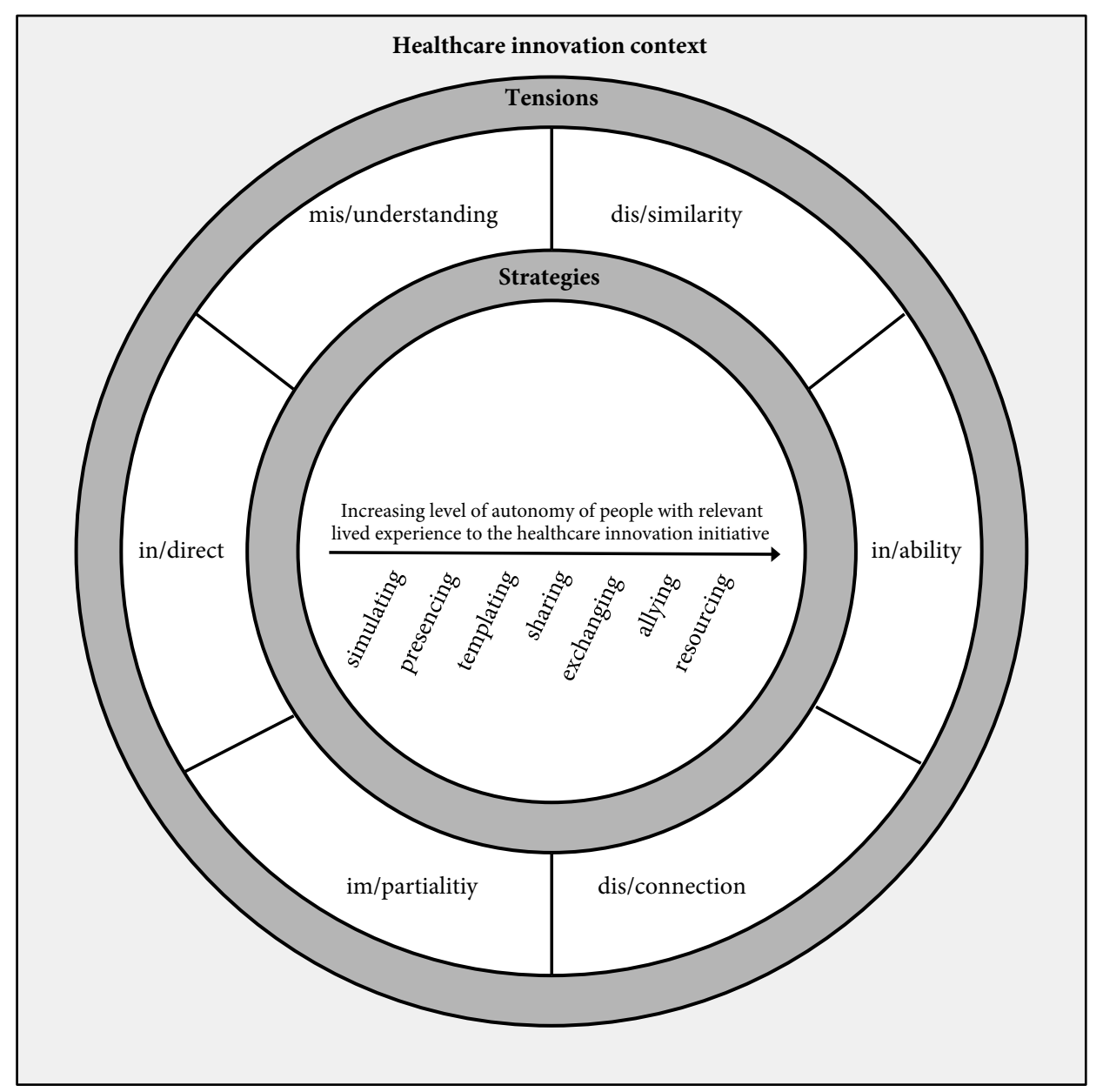

Figure 3.1. Conceptual framework of the dynamics of integrating lived experience through co-creation in healthcare innovation 
(Berry, 2019), ultimately resulting in healthcare innovations that are inclusive and tailored to the needs of their main beneficiaries as well as other stakeholders.

Second, this study responds to recent calls for more research on how patients and family caregivers can contribute to healthcare innovation (McColl-Kennedy et al. 2017a). The author provide seven strategies used to integrate people's lived experience through co-creation, which support the inclusion of patients and families in service innovation to varying degrees, an effort which is urgently needed in healthcare (Berry, 2019). Practical examples of each strategy, from completing empathy maps to supporting entrepreneurs with lived experience, are listed in Table 3.5 that can inspire practitioners around how they can bring these strategies to life. Each strategy entails different benefits and drawbacks and should be chosen according to the context of the co-creation effort, the situation of the people with lived experience, and the tensions that affect co-creation for that particular healthcare innovation. By evaluating the benefits and drawbacks of each strategy, practitioners can better anticipate the potential implications of the strategies they employ when planning co-creation processes in healthcare nnovation. Furthermore, those involved in co-creation in healthcare innovation can use the spectrum of strategies to evaluate the extent to which lived experience was integrated within a specific initiative from various perspectives, why that was the case, and what they may do differently next time to better support the integration of people's lived experience in the co-creation process.

Third, through the formulation of possible ways of integrating people's lived experience through co-creation, this research helps guide practitioners in their efforts to support the transformation of healthcare systems (Gallan et al., 2019). The Word Health Organization $(2015,2016)$ advocates the transition towards people-centred health services, which requires re-conceptualising people as active agents that participate in the design, development, and delivery of health services (Tsekleves and Cooper, 2017). By discussing the dynamics involved during the integration of people's lived experience through co-creation in healthcare innovation and potential ways to navigate them, this research contributes to better understanding the complexities of changing the healthcare system from a paternalistic model to a shared decision-making model (Lukersmith et al., 2016). As such, this research contributes to transformative service research, which advocates for the creation of uplifting changes to improve individual and collective well-being (Anderson et al., 2013). While it highlights practical strategies for supporting this transformation, it does not ignore the risks associated with such a process. In doing so, it provides a more balanced view of addressing the challenges of working towards people-centred health services through co-creation in healthcare innovation.

\section{Future Research and Limitations}

To support the transformation towards people-centred care through thoughtful co-creation processes in healthcare innovation, future research should explore in which contexts and conditions the different strategies are appropriate and also evaluate their contextual implications. Such research is critical for further informing how practitioners can plan healthcare innovation initiatives. While this research spanned multiple countries, the focus was on Western healthcare cultures. As such, future research could investigate the applicability of this conceptual framework in non-Western cultures, as well as other tensions and strategies that may apply in these contexts. Additionally, the interviewed participants were already involved in co-creation efforts in healthcare innovation initiatives. Further research should examine and extend the identified tensions and strategies when seeking to integrate the lived experience of people that may not want to co-create due to various reasons.

While an interview study was suitable to build a foundational understanding of the dynamics of integrating lived experience, participatory action research (Ozanne and Saatcioglu, 2008) could be an appropriate way to put insights from this research into practice and to further develop the understanding on integrating lived experience through co-creation while supporting uplifting transformation in healthcare. In addition, although there are a number of established empathic methods and tools to support service innovation, such as empathy maps (Gray et al., 2010), further development is needed of contextual methods that thoughtfully support the direct integration of lived experience, particularly related to the strategies of sharing, exchanging, allying, and resourcing. Especially the long tradition of Scandinavian participatory design and its contemporary developments (e.g., Bjögvinsson et al., 2012) could be a valuable source of inspiration in advancing these practical approaches. By continuing to advance the discussion on the integration of people's lived experience through co-creation in healthcare nnovation, there is great potential to catalyse the much-needed transformation towards more people-centred health services in a way that is safe, inclusive, and strategic. 


\section{Chapter 4}

\section{Achieving Continued Usage in Online Banking:}

A Post-Adoption Study

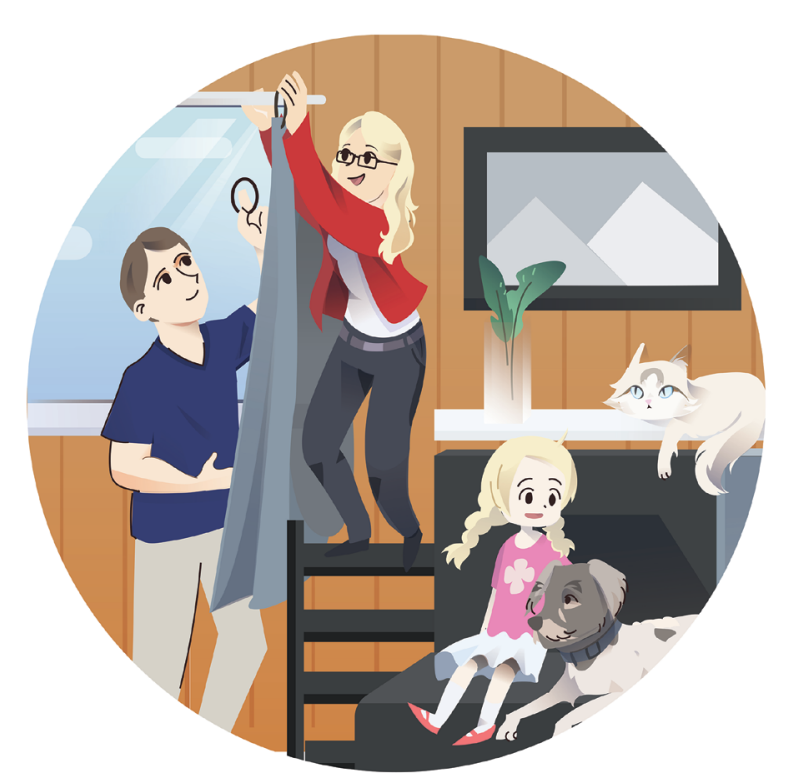

Following the building phase, the new residents need to tailor the house to their needs and preferences. After moving in, they continuously interact with the different elements of the house and other people. In the long term the relationships that people form with and within the house turn this newly built structure into a true home. Comparably, following the initial adoption of a service, relationships form during the subsequent post-adoption phase. Noting the scarcity of studies of the post-adoption phase of services, this chapter proposes a new conceptual model of post-adoption drivers, attitudes, and behaviours. The service studied is a co-creative feature of online banking, which transcends one-time interactions and holds the potential for long-term, reciprocal relationships

between the bank and its customers. Whereas the previous chapter explored co-creation in early phases of the service process, related to innovating services, this chapter zooms in on co-creation in later phases of service processes that involve customer-specific service events or encounters, which can occur repetitively and have great value for building long-term relationships. 


\section{Chapter 4}

\section{Achieving Continued Usage in Online Banking:}

A Post-Adoption Study

Anna-Sophie Oertzen ${ }^{1,2}$ and Gaby Odekerken-Schröder ${ }^{1}$ University, Maastricht, The Netherlands 


\section{Introduction}

Digitalisation of financial systems pressures banks to undergo the largest transformation in their history (Laukkanen, 2017), moving from physical brick-and-mortar stores to virtual environments (Martovoy and Santos, 2012). As one of the main drivers of digitalisation, online banking has become commonly accepted (Patel and Patel, 2018) and is integral to customers' lives, largely because it offers round-the-clock availability, easy transactions, and avoidance of queues (Al-Somali et al., 2009). Online banking refers to a secure website offered by the bank to conduct financial transactions and leverage other financial services; it can be accessed via Internet banking over a laptop or desktop PC or via m-banking over mobile devices (Lee, 2009; Martins et al., 2014; Shaikh and Karjaluoto, 2015). Compared with online purchases, online banking adoption is more complex, because it usually implies a long-term, relational exchange between the customer and the bank (Lee, 2009). The adoption decision of online banking and the factors influencing it thus have received substantial attention from financial services scholars, whereas the post-adoption phase - or the period after the initial adoption decision largely has been ignored (Al-Somali et al., 2009; Jasperson et al., 2005; Lee, 2009; Martins et al., 2014; Tam and Oliveira, 2017a). Yet customers may start using more functional digital features only in the post-adoption phase, after they have gained some experience with online banking (Hsieh et al., 2011; Tam and Oliveira, 2017b). Continued usage throughout the post-adoption phase ultimately determines the success of online banking (Patel and Patel, 2018).

Therefore, this chapter seeks to investigate post-adoption phases in general, including their drivers, attitudes, and behaviours, and specifically examines the post-adoption phase for the electronic postbox (e-postbox), which is a functional feature of the online banking services offered by most sizable banks. An e-postbox represents an incremental innovation that typically offers online bank statements, security papers, a personal messenger, customised offerings, and a notification service. Customers may use each of these modules individually. Although the institutionalisation of virtual environments has prompted many customers to adopt online banking already, relatively fewer customers engage with functional online banking features beyond online transactions. Nonetheless, encouraging continued usage of these additional modules is important to banks, as this intensifies co-creation of services. Especially the in Chapter 1 introduced operative co-creation of services, denoting collaborative activities in the customer-provider interface associated with later stages in the service process (Oertzen et al., 2018), is fostered by stimulating the involved customers to participate and engage in the service process to meet their own needs (Mainardes et al., 2017). Due to the continual, relational, and interactive properties of services (Matthing et al., 2004), co-creation offers a highly effective way to retain customers (Mainardes et al., 2017), embodying both innovation and improved banking services (Martovoy and Santos, 2012).

In a context of increased competition and intensifying, volatile customer demands (Devlin, 2001), ensuring customers' continued usage in the post-adoption phase of financial services, 
such that they engage in successful, prolonged co-creation with the bank, is indispensable In response to calls for more research on the post-adoption phase of online banking and cocreation in the banking sector (Mainardes et al., 2017; Tam and Oliveira, 2017a), the curren research aims to develop and test a comprehensive model of the post-adoption phase of a specific co-creative feature of online banking. In turn, this chapter provides four main contributions: first, the newly developed model offers a way to examine drivers, attitudes, and behaviours in the post-adoption phase of online banking services, thereby proposing which elements can foster continued usage by current customers and attract new customers. The resulting multifaceted model suggests the importance of three types of post-adoption drivers: task-related, organisation-related, and interpersonal communication-related. To holistically explain the rational and emotional decision-making processes in the post-adoption phase, task-related drivers (e.g., perceived usefulness) are important, but so are organisationrelated drivers (e.g., affective commitment) and interpersonal communication-related drivers (e.g., receiving WOM). Second, the authors argue for a dual perspective on interpersonal communication in post-adoption models that includes both receiving WOM as well as sending WOM. This dual perspective can increase understanding of current customers' attitudes, intentions, and behaviours towards online banking services. Third, this research extends the technology acceptance model (TAM; Davis, 1993) to the post-adoption stage in the context of online banking services and shows both mediated and direct effects on current customers' post-adoption behaviours. Finally, age emerges as a significant determinant of post-adoption behaviours, suggesting salient differences between younger and older customers.

This chapter begins with a literature review that spans information systems, bank marketing, services marketing, and relationship management and leads to the proposed post-adoption model, as well as complementary hypotheses. The methodology section then details the data collection process, the sample, and the checks for bias. Next, the analysis and results section evaluates the measurement and structural model, including a comparison with a rival model. Finally, this chapter concludes with a discussion of the findings and implications for theory and practice.

\section{Literature Review and Hypotheses Development}

Ample literature has focused on the adoption of technological, information-rich services and the factors leading up to the adoption decision (Patel and Patel, 2018). In the domain of information systems research, technology adoption has been one of the most widely and comprehensively studied topics with extant literature exploring it on the individual, group, and organisational levels (Venkatesh, 2006). Especially research on the individual-level technology adoption is one of the most thoroughly researched streams in terms of the drivers of adoption and adoption decisions (Venkatesh, 2006). Originating from social psychology (Venkatesh et al., 2007), some of the most prominent theories and models to explore information technology adoption have been the theory of reasoned action (TRA; Fishbein and Ajzen, 1975), the TAM (Davis et al., 1989; Davis, 1993), the theory of planned behaviour (TPB; Ajzen, 1991), the decomposed TPB (Taylor and Todd, 1995), the extended TAM (TAM2; Venkatesh and Davis, 2000), the unified theory of acceptance and use of technology (UTAUT; Venkatesh et al. 2003), the TAM3 (Venkatesh and Bala, 2008), and the extended unified theory of acceptance and use of technology (UTAUT2; Venkatesh et al., 2012). Among these extensively studied theories and models, the TAM has been the dominant model to understand technology adoption and the factors leading up to the adoption decision (Tam and Oliveira, 2017a; Venkatesh et al., 2007; Venkatesh and Bala, 2008). Based on the TRA of Fishbein and Aizen (1975), the TAM predicts that external variables influence cognitive responses (perceived usefulness; perceived ease of use), which triggers an affective response (attitude towards using), which in turn forms intentions (behavioural intentions to use), and ultimately determines behaviour (actual system use) (Davis et al., 1989; Davis, 1993).

Also for information-intensive technologies in bank marketing, the TAM has been widely used to investigate the adoption decision and its antecedents, for instance of automated teller machines (ATMs), Internet banking, mobile banking, and telephone banking (Çelik, 2008 Cheng et al., 2006; Patel and Patel, 2018; Reid and Levy, 2008; Wasswa Katono, 2011). Tam and Oliveira (2017a) demonstrate in their review that the TAM has been the most widely applied model to assess the adoption decision of mobile banking and the determinants that lead to the adoption decision. However, their review also points towards the negligence of the postadoption phase of online banking and necessitates more research on the drivers of the postadoption phase to retain current customers and attract potential new customers (Tam and Oliveira, 2017a)

Drawing on bank marketing, services marketing, information systems, and relationship management literature, the authors of the present research develop a model for the postadoption phase of online banking, specifically for the e-postbox, a recently introduced co creative feature of online banking. To investigate the relatively unexplored post-adoption phase and to develop a post-adoption model for the e-postbox, the current research leverages the traditional TAM as it is the most common model to study online banking (e.g., Tam and Oliveira, 2017a), it has been comprehensively validated and verified (e.g., Venkatesh et al., 2007; Venkatesh and Bala, 2008), and it is more parsimonious than other models or theories, such as the UTAUT, allowing this research to add further post-adoption drivers (e.g., Van Raaij and Schepers, 2008). Specifically, this research includes the TAM's cognitive (perceived usefulness) affective (attitude towards using the e-postbox), intentional (continuance intention), and behavioural (actual usage) properties. Recognising the value of the consistently proven subjective norm construct reflecting social influence processes that is absent in the traditiona TAM, but an integral part of the TRA, TPB, and TAM2 (Venkatesh and Davis, 2000), this research further includes the variable receiving WOM to resemble customers' perceptions of 
what other people think. Figure 4.1 depicts the relationships among the key constructs, as elaborated on subsequently.

\section{The Post-Adoption Attitude}

Attitudes are considered a relatively stable construct over time and have been an integral part in many technology acceptance models and theories for decades due to their strong effect on intentions and behaviours (Ajzen, 1991; Davis, 1993; Fishbein and Ajzen, 1975). The attitude towards using refers to "the degree of evaluative affect that an individual associates with using the target system" (Davis, 1993, p. 476). Hence, the attitude towards using reflects customers' positive or negative feelings (evaluative affect) about performing a specific behaviour (Fishbein and Ajzen, 1975). As such, attitude towards using a particular product or service represents an affective response that is influenced by cognitive stimuli and that determines intentions and behavioural responses. In bank settings, the TAM predicts that the attitude towards using is a function of the perceived usefulness of a digitalised financial service, and in turn determines whether a customer actually uses this financial service (Çelik, 2008). Attitude towards using the e-postbox might evoke beneficial or detrimental behaviours; a favourable attitude should allow customers to use the e-postbox and communicate positively about it, but an unfavourable attitude could cause them to discontinue using the e-postbox and communicate negatively about it.

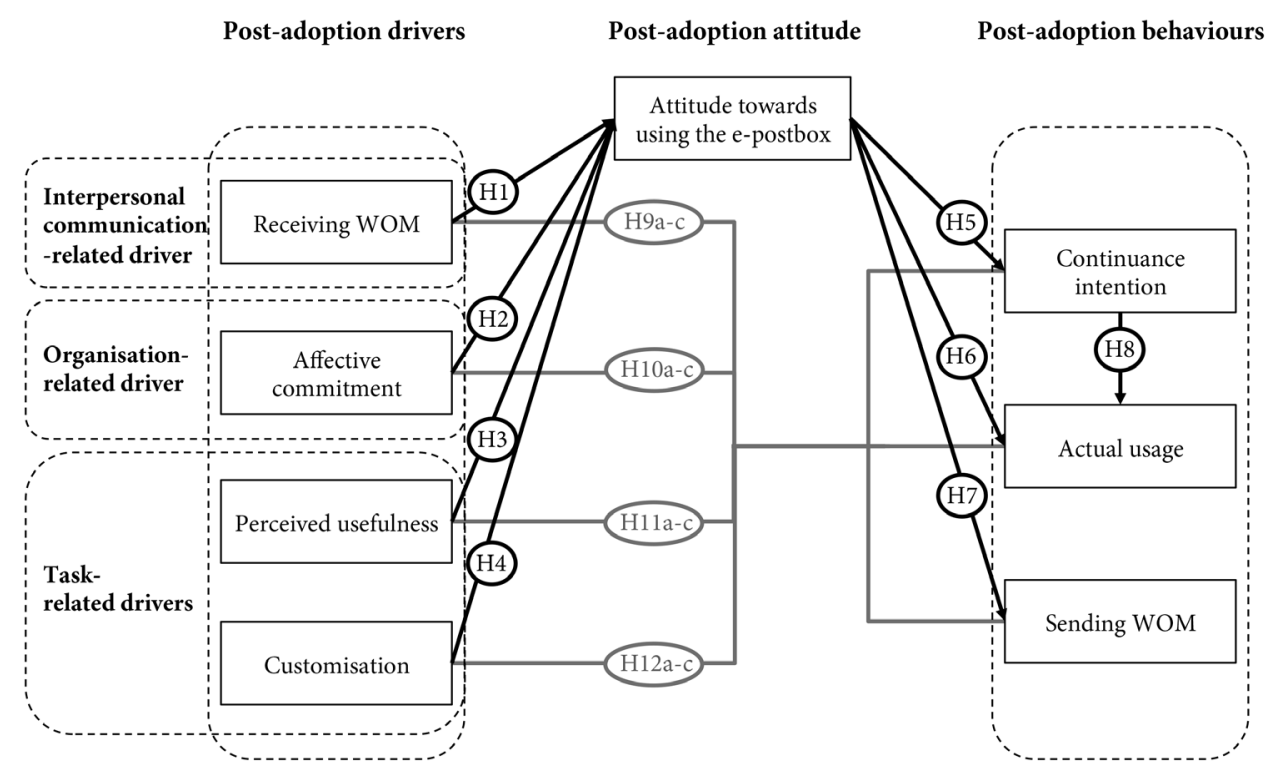

Figure 4.1. Conceptual model

\section{The Effect of Post-Adoption Drivers on Post-Adoption Attitude}

Following the call for more research on the drivers of the post-adoption phase (Tam and Oliveira, 2017a), this research considers three categories of drivers that likely influence the post-adoption attitude: first, task-related drivers pertaining to the e-postbox itself (e.g., perceived usefulness, customisation; Coelho and Henseler, 2012; Davis, 1993), second, organisation-related drivers associated with the bank (e.g., affective commitment; Meyer et al., 2002), and third, interpersonal communication-related drivers (e.g., receiving WOM; Sweeney et al., 2012). Including different post-adoption drivers is important to provide a holistic view of post-adoption behaviour variance (Çelik, 2008). Extending the general TAM to the post adoption phase of digital service systems would have limited use for explaining customers' attitudes and behavioural intentions beyond task-related drivers for example, as the TAM only indirectly includes other external variables through their effects on perceived usefulness and ease of use (Mohammadi, 2015; Venkatesh and Davis, 2000). Therefore, this research integrates affective commitment as an organisation-related driver, which acknowledges that customer do not only adopt a digitalised financial service based on rational decision-making pertaining to the features of the service, but also through affective decision-making steered by their emotions towards the bank (Malhotra and Galletta, 2005). Besides, in an innovation context such as the newly introduced e-postbox, interpersonal communication is essential, as personal sources are often deemed more trustworthy than external marketing efforts of the bank due to the newness and unfamiliarity of the service (Godes and Mayzlin, 2004). Receiving WOM from others likely drives customers' post-adoption attitudes and behaviours and thus constitutes the third type of post-adoption driver - the interpersonal communication-related driver.

\section{Receiving WOM}

Active, interpersonal communication involves two perspectives: receiving WOM from other and sending WOM to others (De Matos and Rossi, 2008; Gilly et al., 1998). The present study defines receiving WOM, or receiving influence, as being given comments about the e-postbox (Sweeney et al., 2012). Customers' perceptions of what other people think is a widely used concept in technology acceptance used by prominent theories and models, such as the TRA TPB, and TAM2 (Ajzen, 1991; Fishbein and Ajzen, 1975; Venkatesh and Davis, 2000). Receiving WOM plays an important role in the adoption of technological services as it shapes customers attitudes (Brown and Reingen, 1987; Meuter et al., 2013). Some scholars even argue that rationa agents may favour interpersonal information over their own private information (Godes and Mayzlin, 2004), because those sources appear more trustworthy; they often have greater impacts on customers' attitudes than banks' marketing efforts. This influence is especially important for digitalised services, which increase customers' need for personal sources to overcome the intangible nature of virtual environments (Murray, 1991). Given that receiving WOM is widely considered an important determinant of technology adoption (Venkatesh and Davis, 2000) and respective customers' attitudes (Brown and Reingen, 1987; Herr et al., 1991; 
Meuter et al., 2013), it is reasonable to assume that it is also critical when making choices in the post-adoption phase of online banking. For instance, Karjaluoto et al. (2002) demonstrate that the attitude towards using online banking is influenced by interpersonal communication with reference groups, such as families and friends. Hence, this research considers receiving WOM as an interpersonal communication-related driver of post-adoption and posits:

H1. Receiving WOM has a positive effect on the attitude towards using the e-postbox.

\section{Affective Commitment}

There are two different types of commitment driving technology adoption: affective commitment "an emotional attachment to, identification with, and involvement in the organization" (Meyer et al., 2002, p. 21) - and continuance commitment - "the perceived costs associated with leaving the organization" (Meyer et al., 2002, p. 21). With regard to the voluntary use of informationintensive service technologies, affective commitment is considered a positive driver of usage behaviour, whereas continuance commitment has a negative effect (Malhotra and Galletta 2005). These two commitment constructs differ in that affective commitment occurs when customers like and identify with an organisation, and hence develop attitudes towards that organisation, which are steered through the salience of the relationship, irrespective of the actual service (Cater and Zabkar, 2009; Malhotra and Galletta, 2005). On the contrary, the cognitive construct continuance commitment is based on the costs that customers associate with not using a particular service, such as investments or lack of alternatives, and does no further tell about customers' attitudes towards the respective service or the organisation (Meyer and Allen, 1984). Since this research aims to investigate customers' affective responses to the e-postbox, specifically their attitudes towards using the e-postbox, this study focuses solely on customers' affective commitment to the bank, because only this type of commitment is theorised to significantly impact customers' attitudes through internalisation and identification with the financial institution (Malhotra and Galletta, 2005). Thus, the model considers customers' affective commitment an organisation-related driver of post-adoption, which positively influences customers' attitudes towards using the e-postbox:

H2. Affective commitment to the bank has a positive effect on the attitude towards using the e-postbox.

\section{Perceived Usefulness}

As a task-related driver of online banking, perceived usefulness is the degree to which customers believe that using the e-postbox will enhance their task performance (Davis, 1989), perhaps through benefits such as increased efficiency or reduced effort (Patel and Patel, 2018), which improves their subsequent attitudes towards using online banking (Çelik, 2008). Thus, a service with high perceived usefulness steers customers' beliefs in a positive use-performance relationship (Davis, 1989). The TAM predicts that perceived usefulness mediates the effect of external variables, such as system characteristics or training, on attitudes and usage intentions (Davis et al., 1989; Venkatesh and Davis, 2000). As Davis (1993) describes this line of thinking system design is an external stimulus that suggests that an action will result in usefulness and ease of use. This cognitive response then triggers an affective response, namely, attitude towards using it. However, the current study only includes the cognitive perceived usefulness construct as a predictor of attitude towards using the e-postbox; perceived ease of use is not directly included in this research, because it is nearly fully mediated by the perceived usefulness of a digital banking system. Studies of Internet banking also indicate its mixed effects (cf. Cheng et al., 2006; Makanyeza, 2017; Mohammadi, 2015):

H3. Perceived usefulness of the e-postbox has a positive effect on the attitude towards using it.

\section{Customisation}

Drawing from services marketing, customisation in an online banking context refers to the degree to which the e-postbox is tailor-made or personalised to fulfil heterogeneous customer demands (Anderson et al., 1997). Considerable variation occurs in the customisation of online banking services across financial institutions, due to the differing capabilities of the banks and varying expectations of their customers (Wang et al., 2017). Generally, customisation forms customers' attitudes according to the experience they have when reviewing information from the service provider (Ho and Bodoff, 2014). It also shapes the attitude towards using, because customers tend to be more satisfied with a customised service in the long term (Arora et al., 2008; Coelho and Henseler, 2012). Formally, customisation provides a task-related driver of the post-adoption phase:

H4. Customisation of the e-postbox has a positive effect on the attitude towards using it.

\section{The Effect of Post-Adoption Attitude on Post-Adoption Behaviours}

Several post-adoption behaviours are likely influenced by customers' existing attitudes towards using the e-postbox.

\section{Continuance Intention}

An important post-adoption behaviour related to digital services is continued adoption vs. discontinuance (Parthasarathy and Bhattacherjee, 1998). This research uses customers' intentions to continue using the e-postbox as a proxy of the potential for customers discontinuance. As Libai et al. (2009) note, customers may discontinue their relationship with 
the service organisation or stop using the service altogether. Although customers' continuance intentions are fundamental to the post-adoption phase, services marketing literature notes that they have been largely overlooked, and current models do not account for customers leaving the service (Libai et al., 2009; Shi et al., 2014). For the current conceptualisation, continuance intention emerges in the decision-making stage, such that customers consider continuing their use of the e-postbox. This intention cannot guarantee that customers actually continue using the e-postbox, but this approach supports a cross-sectional analysis and has been validated by previous research (Bhattacherjee, 2001; Hellier et al., 2003; Mittal and Lassar, 1998). Generally, the more favourable customers' attitudes towards a given behaviour, the stronger will be their intentions to engage in the behaviour (Ajzen, 1991). Customers' favourable attitudes toward using the e-postbox thus should positively affect their intentions to use and continue using the e-postbox (Lee, 2009). By examining customers' continuance intentions and revealing their decision-making processes after adopting the e-postbox, banks can better leverage strategies that encourage continued usage:

H5. The attitude towards using the e-postbox has a positive effect on the intention to continue using it.

\section{Actual Usage}

For online banking, the TAM behavioural response of actual usage refers to customers' selfreported use of the e-postbox (Davis, 1993). According to Fishbein and Ajzen (1975), individual beliefs about the consequences of performing a specific behaviour directly influence attitudes towards that behaviour, which affect behavioural responses, such as the practical use of the e-postbox. Robey (1979) affirms the strong relation between attitude and actual usage, such that usage depends on intuitions, beliefs, and attitudes; it is a behavioural response following an affective stimulus. Customers' attitudes influence their intentions to use a digitalised service, as well as their behavioural use (Davis et al., 1989; Sreejesh et al., 2016; Teo, 2011; Venkatesh and Davis, 2000). In particular, customers' favourable attitudes towards using online banking positively influence their actual usage (Ayo et al., 2016; Karjaluoto et al., 2002). Therefore:

H6. The attitude towards using the e-postbox has a positive effect on actual usage.

\section{Sending WOM}

Complementing the receipt of WOM from others, a second interpersonal communication construct in this post-adoption model is sending WOM. Using Harrison-Walker's (2001) definition, sending WOM refers to interpersonal, informal communication from a noncommercial communicator to others and in this study denotes customers' giving comments about the financial institution to others. Although WOM activities have been widely investigated, most research takes the receiver's perspective (De Matos and Rossi, 2008; HarrisonWalker, 2001), yet by definition, any social exchange of information involves at least two parties (Gilly et al., 1998). Research that considers WOM as a behavioural outcome demonstrates that it increases with customer loyalty and that the most satisfied or dissatisfied customers are most likely to engage in it (Anderson, 1998; Bowman and Narayandas, 2001). In an early study on post-purchase behaviour, Westbrook (1987) already evidenced that positive affect leads to more WOM activity. Thus, a positive affective response, such as a positive attitude towards using the e-postbox, likely has a positive influence on the behavioural response of sending favourable WOM:

H7. The attitude towards using the e-postbox has a positive effect on sending WOM.

\section{The Effect of Continuance Intention on Actual Usage}

Fishbein and Ajzen (1975) suggest as part of their established TRA that an intention towards a certain behaviour is a major and immediate determinant of that behaviour. Extensive literature in information systems has validated the effect of intentions on behaviours (Ajzen, 1991; Taylor and Todd, 1995; Venkatesh and Bala, 2008); specifically, the strong causal relationship between intentions to use a technology and actual usage of that technology (Sheppard et al., 1988; Venkatesh and Morris, 2000). Behavioural intentions often act as a mediator between attitudinal variables and the resulting behaviours. Therefore, behavioural intentions predict future behaviours relatively accurately (Fishbein and Ajzen, 1975; Ajzen, 1991; Taylor and Todd, 1995). Also in online banking, usage intentions are considered a direct determinant to usage behaviour (Arenas-Gaitán et al., 2015; Farah et al., 2018):

H8. The intention to continue using the e-postbox has a positive effect on actual usage.

\section{The Direct Effects of Post-Adoption Drivers on Post-Adoption Behaviours}

The Effect of Receiving WOM on the Post-Adoption Behaviours

Receiving comments from others on the e-postbox will also have direct effects on the subsequen post-adoption behaviours. Meuter et al. (2013) suggest a strong, positive effect between receiving WOM and behavioural intentions. Brown and Reingen (1987) propose that WOM communications significantly affect customers' behaviours. In a review on WOM, Nyilasy (2006) supports both arguments by reporting on the power of WOM to influence awareness, attitude change, behavioural intentions, and behaviours. Given these effects on customers intentions and behaviours, this research theorises a positive relationship between receiving WOM and the post-adoption behaviours: 
H9. Receiving WOM has positive effects on (a) intention to continue using the e-postbox, (b) actual usage of the e-postbox and (c) sending WOM.

\section{The Effect of Affective Commitment on the Post-Adoption Behaviours}

In their review on WOM communications, De Matos and Rossi (2008) evidence that customers' commitment to the service provider is the strongest predictor of sending WOM. The authors propose that committed customers are likely to be more satisfied, which leads to positive WOM. In the case of a low satisfaction condition, customers' commitment to the provider also leads to positive WOM to reduce their own cognitive dissonance. In addition, the current research argues that affective commitment also influences the actual use of services. This is in line with Malhotra and Galletta (2005), who propose that the emotional attachment, involvement, and identification with a provider have a sustained positive effect on usage behaviour. Also in the banking sector, the emotional bond that customers form to the bank based on their affective commitment is suggested to steer subsequent intentions and behaviours, such as sending WOM (Bloemer and Odekerken-Schröder, 2003; Sumaedi et al., 2015). Thus:

H10. Affective commitment has positive effects on (a) intention to continue using the e-postbox, (b) actual usage of the e-postbox and (c) sending WOM.

\section{The Effect of Perceived Usefulness on the Post-Adoption Behaviours}

Previous research suggests that cognitions have direct effects on behavioural intentions and actual behaviours (Sabherwal et al., 2006; Venkatesh and Davis, 2000; Venkatesh and Bala, 2008). First, in existing literature a positive link between the perceived usefulness of online banking and usage and continuance intention is established, which provides evidence of an effect of cognition on intention (Bhattacherjee, 2001; Çelik, 2008; Patel and Patel, 2018). Second, the positive influence of perceived usefulness on actual usage of online banking is demonstrated, which implies an influence of cognition on behaviour (Pikkarainen et al., 2004). And finally, Moldovan et al. (2011) investigated the impact of usefulness on the valence of sending WOM, which exemplifies the effects of cognition on sending WOM. Hence, this research posits:

H11. Perceived usefulness of the e-postbox has positive effects on (a) intention to continue using the e-postbox, (b) actual usage of the e-postbox and (c) sending WOM.

\section{The Effect of Customisation on the Post-Adoption Behaviours}

Literature on the outcomes of service customisation is generally scarce (Coelho and Henseler, 2012) and few studies have investigated how customisation affects customers' decision processes in a technological context (Tam and Ho, 2005). The exceptional studies that did assess the effect of service customisation have suggested that it influences usage intentions through more satisfied customers ( $\mathrm{Li}$ and Yeh, 2009), as well as subsequent behaviours due to bettermatched preferences (Tam and Ho, 2005). Given the significant positive effect of customisation on customers' satisfaction (Coelho and Henseler, 2012) and the significant positive effect of customers' satisfaction on WOM communications (De Matos and Rossi, 2008), this research postulates that the customisation of the e-postbox also has an influence on sending WOM. Hence, the degree to which the e-postbox is tailor-made is expected to steer all three postadoption behaviours:

12. Customisation of the e-postbox has positive effects on (a) intention to continue using the e-postbox, (b) actual usage of the e-postbox and (c) sending WOM.

\section{Methodology - Cross-Sectional Survey}

To develop and test the proposed model of drivers, attitudes, and behaviours in the postadoption phase of a co-creative feature of online banking, the data collection was quantitative and cross-sectional.

\section{Data Collection Procedure and Measurement Scales}

The data collection relied on an online survey. The introduction outlined the purpose of the study, followed by questions about how often respondents used their e-postbox. The second part focused on participants' interpersonal communications and its impacts on their decisionmaking. Next, the survey asked respondents to indicate their feelings towards the e-postbox and the financial institution at large. Finally, the survey gathered demographic information.

The data collection took place within a single bank in Germany, which corresponds to extant approaches (Karahanna et al., 1999; Wang et al., 2017), in that investigating a single institution controls for organisational differences, such as the features or layout of the online banking site. The questionnaire was developed in English and then translated to German, after which it was cross-validated by the authors. An expert panel of representatives from the investigated bank evaluated each question for its applicability and face and content validity. Their feedback led to the exclusion of two items and some alterations to the wording. The revised version was pretested with a sample of 20 respondents, spread evenly across gender and age groups, who completed the questionnaire via e-mail, phone, or in face-to-face interviews. These respondents indicated the level of understanding of the intention of the questions, cited any problems with the wording or content, and provided their overall impression of the survey in terms of its sequence, format, layout, and instructions. As a result of their feedback, the questionnaire was slightly adjusted. 
The questionnaire items used existing scales, adapted to the online banking context. Table 4.1 ists the measurement constructs and their sources. For actual usage, the original scale by Davis (1993) was rephrased to correspond to an interval scale, rather than open-worded items. For receiving WOM, the authors used the scale of Gilly et al. (1998) on episodic influence that provides a rich understanding of the effect of social influence processes beyond the mere receipt of comments from others. All scales were adapted to fit seven-point Likert scales, and most response options ranged from 1 ("strongly disagree") to 7 ("strongly agree"). Finally, the control variables age, gender, and years with the bank were surveyed, using one item per construct.

\section{Sample}

The focal e-postbox is part of the online banking system of a large German bank and was introduced six months before the data collection. It offers several free-of-charge digital modules, such as bank statements, security papers, a personal messenger, customised offerings, and a notification service. The bank introduced this innovation to save time, be sustainable, be secure, and build closer relationships with customers. The e-postbox represents continued services co-creation in the consumption stage; customers can co-create with the bank's employees during tailored consultations and discussions to produce a customised economic plan for the customer, which strengthens a long-term customer-bank relationship.

Among nearly 200,000 private customers, around 40,000 customers use the bank's onlin banking. After excluding customers who denied receiving any messages from the bank, a sample of approximately 13,000 customers remained; they received the questionnaire via an embedded link in a personalised e-mail. The first week produced 430 responses; a reminder e-mail then increased the total to 750 responses. Overall, the 5.80 percent response rate is higher than is conventional for similar surveys by banks in Germany, according to the participating bank As Table 4.2 shows, the sample features variance in gender, age, and years as a customer; many customers are younger but have been customers for at least ten years.

Table 4.1. Validated scales

\begin{tabular}{lll}
\hline Constructs & Sources & Number of items \\
\hline Receiving WOM & Gilly et al. (1998) & 6 \\
Affective commitment & Harrison-Walker (2001) & 10 \\
Perceived usefulness & Davis (1989) & 6 \\
Customisation & Coelho and Henseler (2012) & 3 \\
Attitude towards using the e-postbox & Davis (1993) & 5 \\
Continuance intention & Bhattacherjee (2001) & 3 \\
Actual usage & Davis (1993) & 2 \\
Sending WOM & Harrison-Walker (2001) & 6 \\
\hline
\end{tabular}

\begin{tabular}{llll}
\multicolumn{2}{l}{ Table 4.2. Demographics of respondents $(n=750)$} & Number of respondents & Percentage \\
\hline Item & & 425 & 56.7 \\
Gender & Male & 325 & 43.3 \\
\multirow{2}{*}{ Age } & Female & 299 & 39.9 \\
& $<30$ & 96 & 12.8 \\
& $30-40$ & 104 & 13.9 \\
& $41-50$ & 109 & 14.5 \\
Years with bank & $51-60$ & 142 & 18.9 \\
& $61+$ & 37 & 4.9 \\
& $0-1$ year & 87 & 11.6 \\
& $2-5$ years & 123 & 16.4 \\
& $6-10$ years & 503 & 67.1 \\
\hline
\end{tabular}

\section{Non-Response Bias and Common-Method Bias}

To assess the potential for non-response bias, early respondents (first 20 percent) were compared with late respondents (last 20 percent) (Armstrong and Overton, 1977). The lack of significant differences in the means for the constructs across the two groups suggests that non-response bias is not a concern in this study. The check for common method bias relied on Harman's single-factor test, followed by a common latent factor (CLF) test (Podsakoff et al. 2003). The CLF was added to the conceptual model and linked to all the construct indicators. The paths from the CLF initially were left equivalent and unrestrained, then constrained to 0.00 . The $\chi^{2}$ difference test of the unconstrained and constrained models yields a non-significant result at the 1.00 percent level, indicating that common method variance is not significant. The results of both tests suggest common method bias is not a concern.

\section{Analysis and Results}

The test of the conceptual model relied on structural equation modelling (SEM) in AMOS Version 25. For this research, the parameter estimation of SEM entails applying a maximum likelihood estimation to the covariance matrix.

\section{Measurement Model Evaluation}

To purify the measurement model and establish unidimensionality, an exploratory factor analysis was conducted that excluded items that loaded less than 0.70 on the main factor or cross-loaded more than 0.30 on other factors (Hulland, 1999; Kleijnen et al., 2007). This step led to the exclusion of three items, namely, the eighth item of affective commitment, the first item of customisation, and the fifth item of sending WOM. Table 4.3 displays the final items of the latent variables used in this model. After this step, the model exhibited a satisfactory overall 
fit $\left(\chi^{2}=1,679.88\right.$, degrees of freedom $=624, \chi^{2} / \mathrm{df}=2.69$, goodness-of-fit index $=0.90$, adjusted goodness-of-fit index $=0.88$, confirmatory fit index $(\mathrm{CFI})=0.97$, Tucker-Lewis index $=0.96$, roo mean square error of approximation $=0.05$ )

To ensure construct reliability, an analysis using Cronbach's alpha $(\alpha)$ and composite reliability was conducted. The internal consistency reliability estimates ( $\alpha$ values) vary between 0.80 and 0.98 , surpassing the suggested threshold for acceptable reliability of 0.70 (Nunnally, 1978). The composite reliability values range between 0.90 and 0.98 , exceeding the cut-off value of 0.60, as proposed by Bagozzi and Yi (1988). Convergent validity was evaluated by considering the item loadings on the respective factors. All items have standardised loadings of 0.70 or more (Hulland, 1999), and the average variance extracted (AVE) of each construct is higher than the proposed value of 0.50 (Bagozzi and Yi, 1988; Fornell and Larcker, 1981), supporting convergent validity. Discriminant validity was evidenced through four approaches. First, the cross-factor loadings were not substantial (Hulland, 1999). Second, the square root of the AVE for each construct was used to examine whether a latent variable captures more variance from its indicators relative to the amount due to other constructs representing different indicators (Chin, 1998).

\section{Table 4.3. Measurement model}

\section{Construct items (mean; standard deviation)}

FL $\quad \alpha \quad$ CR $\quad$ AVE

Receiving WOM (4.02; 1.18)

- This person provided little new information.

$\begin{array}{lll}0.97 & 0.98 & 0.89\end{array}$

The opinion of this person influenced my choice about continuing/using

the e-postbox.

- This person mentioned some things I had not considered.

- This person provided some different ideas than other sources.

0.93

- This person really didn't change my mind about continuing/using the e-postbox a 0.91

- This person helped me make a decision about continuing/using the e-postbox. 0.94

Affective commitment $(5.06 ; 1.08)$

- For me, this is one of the best banks of its kin

I am proud that I use the services of this bank

solicies and procedures on important matters. 0.82

- This is a good bank to use.

- I like the way the bank operates.

- The bank understands my needs.

- I like the bank.

I have a special relationship with the bank.

- Doing business with the bank is enjoyable.

- I do business with the bank because I like it.
Table 4.3. (continued)

Construct items (mean; standard deviation)

FL $\quad \alpha$

Perceived usefulness $(3.87 ; 1.46)$

- Using the e-postbox enables me to accomplish tasks more quickly.

0.92

- Using the e-postbox improves my performance.

0.92

- Using the e-postbox increases my productivity.

0.93

- Using the e-postbox makes it easier to do my tasks.

- I find the e-postbox useful.

0.97

0.96

0.94

Customisation $(3.58 ; 1.19)$

The e-postbox of the bank satisfies my specific needs.

- I couldn't find the e-postbox at another bank.

Attitude towards using the e-postbox (4.69; 1.47)

All things considered, my use of the electronic postbox is:

- Good

- Favourable

- Beneficial

0.95

0.96

0.96

Continuance intention $(4.48 ; 1.49)$

I want to continue using the e-postbox rather than discontinue its use.

My intentions are to continue using the e-postbox rather than any alternative means. 0.84

- I use my e-postbox frequently.

- I spend a considerable amount of time using the e-postbox each week.

Sending WOM $(3.48 ; 1.45)$

- I mention the bank to others quite frequently.

I've told more people about the bank than I've told about most other banks.

- I seldom miss an opportunity to tell others about the bank.

0.86

0.91

- I 0.86

- I have only good things to say about the bank

- I am proud to tell others that I use this bank.

0.85

Notes: e-postbox, electronic postbox: FL, factor loading; $\alpha$, Cronbach's alpha; CR, composite reliability; AVE, average variance extracted. ${ }^{a}$ Reverse coded; Ittem omitted from analysis 
Table 4.4. Intercorrelations of the latent variables

\begin{tabular}{lllllllll}
\hline Construct & (1) & (2) & (3) & (4) & (5) & (6) & (7) & (8) \\
\hline (1) Receiving WOM & 0.94 & & & & & & & \\
(2) Affective commitment & 0.22 & 0.86 & & & & & & \\
(3) Perceived usefulness & 0.31 & 0.28 & 0.92 & & & & & \\
(4) Customisation & 0.22 & 0.42 & 0.53 & 0.90 & & & & \\
(5) Attitude towards using the e-postbox & 0.35 & 0.28 & 0.72 & 0.40 & 0.96 & & & \\
(6) Continuance intention & 0.37 & 0.25 & 0.73 & 0.34 & 0.83 & 0.86 & & \\
(7) Actual usage & 0.38 & 0.15 & 0.53 & 0.24 & 0.56 & 0.66 & 0.92 & \\
(8) Sending WOM & 0.23 & 0.64 & 0.27 & 0.35 & 0.18 & 0.19 & 0.18 & 0.88
\end{tabular}

8) Sending WOM

Note: Square root of the AVE in italics on the diagonal

As Table 4.4 reveals, the square root of the AVE exceeds the correlations of the respective construct with other constructs in the model, indicating discriminant validity (Fornell and Larcker, 1981). Third, given that some of the intercorrelations of the latent variables are fairly high, the authors conducted a confirmatory factor analysis (CFA) and assessed whether pairs of constructs in the model were correlated less than unity (De Ruyter et al., 2001). For that the estimated correlation parameter between two constructs was constrained to 1.00 for one pair at a time (Anderson and Gerbing, 1988). $\chi^{2}$ difference tests $\left(\Delta \chi^{2}\right)$ with one degree of freedom that analysed the difference between the unrestrained and restrained models were all statistically significant $(p<0.001)$. Thus, even though some latent variables demonstrate fairly high correlations, they must be considered distinct, which substantiates discriminan validity (Bagozzi and Phillips, 1982). Finally, confidence intervals for the estimates of the intercorrelations among the constructs were constructed from the robust standard errors yielded by the CFA (Schepers et al., 2008). In support of discriminant validity, the value 1.00 is not included in the confidence intervals of the correlations for any of the construct pairs (Anderson and Gerbing, 1988). Based on these four approaches, the authors conclude that all constructs display satisfactory discriminant validity.

\section{Structural Model Evaluation}

After testing the measurement model, the next step is to estimate the structural model. The control variables function as exogenous variables in the model (Lin and Hsieh, 2011), supporting the predictions about the other latent constructs. Figure 4.2 and Table 4.5 display the results.

The model offers good explanatory power; the variance explained (squared multiple correlations) is greater than 45 percent for each construct. As hypothesised, receiving WOM, affective commitment to the bank, and perceived usefulness of the e-postbox significantly increase the attitude towards using the e-postbox, in support of $\mathrm{H} 1-\mathrm{H} 3$. Customisation of the e-postbox does not have a significant effect on this attitude though, so $\mathrm{H} 4$ is not supported. While the data further substantiate the predicted positive relationship of the attitude towards using the e-postbox with continuance intention in support of H5, there is no statistical relationship between the attitude towards using the e-postbox and actual usage, indicating that $\mathrm{H} 6$ is not supported. The predicted positive link between the attitude towards using the e-postbox and sending WOM does not receive support in the theorised direction the attitude towards using the e-postbox has a negative effect on sending WOM. Thus, H7 cannot be supported.

There is a strong positive relationship between continuance intention and actual usage of the e-postbox, which supports H8. Additionally, several post-adoption drivers exert direct effects on post-adoption behaviours. Receiving WOM and perceived usefulness of the e-postbox have significant positive effects on all three post-adoption behaviours, in support of $\mathrm{H} 9 \mathrm{a}-\mathrm{c}$ and H11a-c. Affective commitment to the bank only positively influences sending WOM so though H10c receives support, $\mathrm{H} 10 \mathrm{a}$ and $\mathrm{H} 10 \mathrm{~b}$ do not. Customisation of the e-postbox similarly has a positive impact on sending WOM (H12c supported), but it has a negative

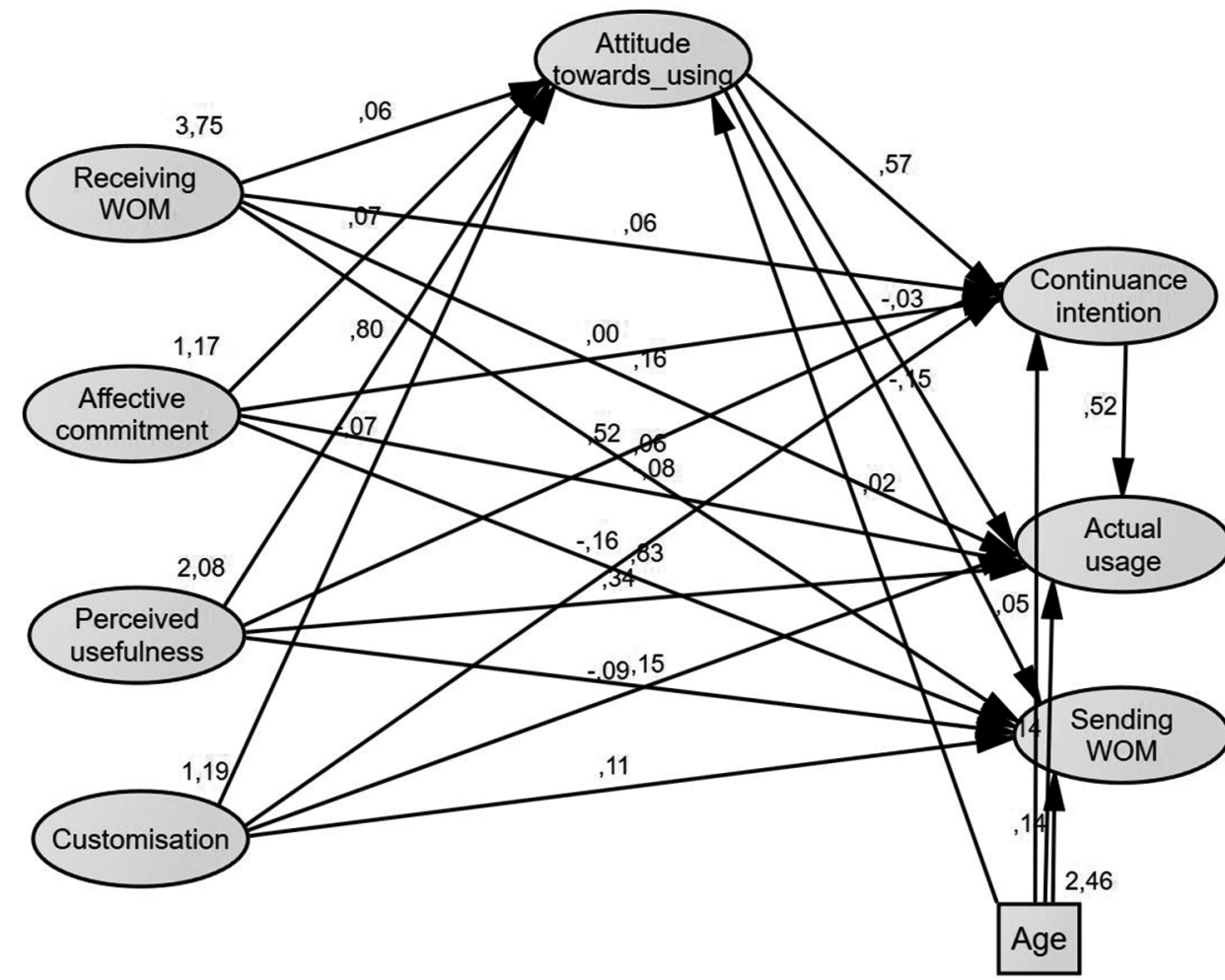

igure 4.2. Validated model, including unstandardised estimates 
effect on continuance intention and no effect on actual usage (H12a significant in an opposite direction to predictions; H12b not supported). Customisation also is the only post-adoption driver that is not partially mediated by the attitude towards using the e-postbox.

Finally, this analysis suggests that the control variables gender and years with the bank have no considerable influence on the model, but age positively influences the relationships with al post-adoption behaviours. To explore this impact, the data set was split into five age groups,

\section{Table 4.5. Structural model}

\begin{tabular}{|c|c|c|c|}
\hline \multirow{2}{*}{$\frac{\text { Hypothesis }}{\text { H1 }}$} & \multirow{2}{*}{$\begin{array}{l}\text { Path } \\
\text { Receiving WOM } \rightarrow \text { attitude towards using the e-postbox }\end{array}$} & \multicolumn{2}{|c|}{ Estimate (SE) $p$-value } \\
\hline & & $0.06(0.02)$ & $0.001^{* x}$ \\
\hline $\mathrm{H} 2$ & Affective commitment $\rightarrow$ attitude towards using the e-postbox & $0.07(0.04)$ & $0.059^{*}$ \\
\hline $\mathrm{H} 3$ & Perceived usefulness $\rightarrow$ attitude towards using the e-postbox & $0.80(0.04)$ & $* * *$ \\
\hline $\mathrm{H} 4$ & Customisation $\rightarrow$ attitude towards using the e-postbox & $-0.07(0.05)$ & ns \\
\hline H5 & Attitude towards using the e-postbox $\rightarrow$ continuance intention & $0.57(0.04)$ & $* * *$ \\
\hline H6 & Attitude towards using the e-postbox $\rightarrow$ actual usage & $-0.03(0.08)$ & ns \\
\hline $\mathrm{H} 7$ & Attitude towards using the e-postbox $\rightarrow$ sending WOM & $-0.15(0.05)$ & $0.002^{* *}$ \\
\hline $\mathrm{H} 8$ & Continuance intention $\rightarrow$ actual usage & $0.52(0.08)$ & $* * *$ \\
\hline $\mathrm{H} 9 \mathrm{a}$ & Receiving WOM $\rightarrow$ continuance intention & $0.06(0.02)$ & $0.001^{* *}$ \\
\hline $\mathrm{H} 9 \mathrm{~b}$ & Receiving WOM $\rightarrow$ actual usage & $0.16(0.03)$ & $* * *$ \\
\hline $\mathrm{H} 9 \mathrm{c}$ & Receiving WOM $\rightarrow$ sending WOM & $0.06(0.02)$ & $0.008^{* x}$ \\
\hline H10a & Affective commitment $\rightarrow$ continuance intention & $0.00(0.04)$ & ns \\
\hline $\mathrm{H} 10 \mathrm{~b}$ & Affective commitment $\rightarrow$ actual usage & $-0.08(0.06)$ & ns \\
\hline $\mathrm{H} 10 \mathrm{c}$ & Affective commitment $\rightarrow$ sending WOM & $0.84(0.05)$ & $* * *$ \\
\hline H11a & Perceived usefulness $\rightarrow$ continuance intention & $0.52(0.05)$ & $* * *$ \\
\hline H11b & Perceived usefulness $\rightarrow$ actual usage & $0.34(0.09)$ & $* * *$ \\
\hline $\mathrm{H} 11 \mathrm{c}$ & Perceived usefulness $\rightarrow$ sending WOM & $0.15(0.06)$ & $0.009^{* x}$ \\
\hline H12a & Customisation $\rightarrow$ continuance intention & $-0.16(0.05)$ & $* * *$ \\
\hline $\mathrm{H} 12 \mathrm{~b}$ & Customisation $\rightarrow$ actual usage & $-0.09(0.08)$ & ns \\
\hline $\mathrm{H} 12 \mathrm{c}$ & Customisation $\rightarrow$ sending WOM & $0.11(0.06)$ & $0.047^{* *}$ \\
\hline \multicolumn{4}{|c|}{ Control variables } \\
\hline & Age $\rightarrow$ attitude towards using & $0.02(0.02)$ & ns \\
\hline & Age $\rightarrow$ continuance intention & $0.05(0.02)$ & $0.035^{* x}$ \\
\hline & Age $\rightarrow$ actual usage & $0.14(0.04)$ & $* * *$ \\
\hline & Age $\rightarrow$ sending WOM & $0.14(0.03)$ & $* * *$ \\
\hline & Gender & ns & \\
\hline & Years with the bank & ns & \\
\hline \multicolumn{2}{|c|}{ Squared multiple correlations for structural equations } & Estimate & \\
\hline \multicolumn{2}{|c|}{ Attitude towards using the e-postbox } & 0.64 & \\
\hline \multicolumn{2}{|c|}{ Continuance intention } & 0.76 & \\
\hline \multicolumn{2}{|l|}{ Actual usage } & 0.47 & \\
\hline \multicolumn{2}{|c|}{ Sending WOM } & 0.50 & \\
\hline
\end{tabular}

Notes: SE, standard error; ns, not significant. ${ }^{*}, * * * * *$ Significant at the 10,5 , and 1 percent levels, respectively
Table 4.6. Age-based multi-group analysis

\begin{tabular}{|c|c|c|c|c|c|c|}
\hline Path & $<30$ Est. & $30-40$ Est. & $41-50$ Est. & $51-60$ Est. & $61+$ Est. & Model Est \\
\hline $\begin{array}{l}\text { Receiving WOM } \rightarrow \\
\text { continuance intention }\end{array}$ & $0.08^{* *}$ & 0.09 & 0.03 & $0.14^{\star \star}$ & -0.03 & $0.06^{* *}$ \\
\hline $\begin{array}{l}\text { Customisation } \rightarrow \\
\text { continuance intention }\end{array}$ & -0.07 & -0.08 & $-0.24^{\star}$ & -0.03 & $-0.22^{\star *}$ & $-0.16^{* * *}$ \\
\hline $\begin{array}{l}\text { Perceived usefulness } \rightarrow \\
\text { continuance intention }\end{array}$ & $0.40^{* * *}$ & $0.35^{* *}$ & $0.61^{* * *}$ & $0.65^{\star * *}$ & $0.64^{\star \star \star}$ & $0.52^{\star * \star}$ \\
\hline $\begin{array}{l}\text { Attitude towards using } \\
\text { the e-postbox } \rightarrow \text { continuance } \\
\text { intention }\end{array}$ & $0.66^{* * *}$ & $0.71^{\star * *}$ & $0.53^{* * *}$ & $0.43^{* *}$ & $0.48^{* * *}$ & $0.57^{\star * *}$ \\
\hline $\begin{array}{l}\text { Continuance intention } \rightarrow \\
\text { actual usage }\end{array}$ & $0.39^{* *}$ & $0.57^{* *}$ & $0.67^{\star * *}$ & $0.37^{* *}$ & $0.90^{* \star}$ & $0.52^{\star * \star}$ \\
\hline $\begin{array}{l}\text { Receiving WOM } \rightarrow \\
\text { actual usage }\end{array}$ & $0.23^{* * *}$ & $0.25^{* *}$ & -0.06 & -0.01 & $0.21^{\star *}$ & $0.16^{* * *}$ \\
\hline $\begin{array}{l}\text { Perceived usefulness } \rightarrow \\
\text { actual usage }\end{array}$ & $0.51^{* * *}$ & $0.37^{\star}$ & 0.27 & $0.56^{* *}$ & -0.10 & $0.34^{* * *}$ \\
\hline $\begin{array}{l}\text { Receiving WOM } \rightarrow \\
\text { sending WOM }\end{array}$ & $0.07^{*}$ & $0.15^{*}$ & 0.08 & 0.09 & -0.01 & $0.06^{* *}$ \\
\hline $\begin{array}{l}\text { Affective commitment } \rightarrow \\
\text { sending WOM }\end{array}$ & $0.84^{* * *}$ & $0.89^{* * *}$ & $0.73^{* * *}$ & $0.84^{* * *}$ & $0.73^{* * *}$ & $0.84^{* * *}$ \\
\hline $\begin{array}{l}\text { Perceived usefulness } \rightarrow \\
\text { sending WOM }\end{array}$ & $0.35^{* * *}$ & 0.17 & 0.11 & -0.11 & 0.10 & $0.15^{* *}$ \\
\hline $\begin{array}{l}\text { Customisation } \rightarrow \\
\text { sending WOM }\end{array}$ & 0.14 & 0.12 & 0.11 & 0.09 & 0.03 & $0.11^{* *}$ \\
\hline $\begin{array}{l}\text { Attitude towards using } \\
\text { the e-postbox } \rightarrow \text { sending WOM }\end{array}$ & $-0.31^{* * *}$ & $-0.26^{\star}$ & -0.08 & 0.14 & -0.13 & $-0.15^{\star *}$ \\
\hline
\end{tabular}

the 10,5 , and 1 percent levels, respectively

and the analysis was re-run with all significant links to continuance intention, actual usage, and sending WOM. The results of the multi-group analysis in Table 4.6 reveal that only four relationships are significant across all groups. Generally, younger age groups indicate a higher percentage of significant relationships than older ones; for example, only customers aged younger than 30 years report a significant, positive effect of perceived usefulness on sending WOM. A one-way, between-group analysis of variance, to determine whether the five age groups differ significantly across constructs, reveals significant differences for six of the eight 
constructs. On average, younger customers ( $<30$ years) are most likely to perceive the e-postbox as useful, consider it customised, have a favourable attitude towards using it, and intend to continue using it; customers older than 60 years of age use the e-postbox the most and send more WOM than customers of any other age group.

\section{Comparison with a Rival Model}

To increase the meaningfulness and robustness of the results, this study also considers rival models (De Wulf et al., 2001). The significant, direct effects between several post-adoption drivers and post-adoption behaviours suggest the need to assess an alternative model without mediation by the attitude towards using the e-postbox. As suggested by Morgan and Hunt (1994), the structural models are compared using four criteria: overall fit measured by the CFI, which compares the sampled covariance matrix with the implied covariance matrix; the percentage of statistically significant parameters hypothesised in the model; parsimony, as measured by the parsimonious normed fit index (PNFI); and $R^{2}$ values for the endogenous constructs.

Table 4.7 indicates that the initially theorised model is more parsimonious than the rival model, even though both models exhibit the same percentage of statistically significant parameters and similar CFI statistics. The hypothesised model also explains more of the variance in two out of three endogenous constructs, with the third construct being fairly similar across models. It is justifiable to retain attitude towards using the e-postbox as a mediator in the model, not only because of its empirical meaningfulness and robustness in contrast to the rival model, but also because of its theoretical merits as the mediating effect of attitude has a long withstanding history in technology acceptance research (Davis, 1993; Fishbein and Ajzen, 1975).

Table 4.7. Analysis of competing structural models

\begin{tabular}{llll}
\hline Criterion & Measure & Proposed model & Rival model \\
\hline (1) Model fit (CFI) & CFI & 0.964 & 0.963 \\
(2) Significant parameters & Percentage of model & $(18) /(24) \times 100=75.00 \%$ & $(12) /(16) \times 100=75.00 \%$ \\
(3) Parsimony (PNFI) & PNFI & 0.837 & 0.826 \\
(4) Explained variance & Squared multiple correlations & & \\
& Continuance intention & 0.763 & 0.668 \\
& Actual usage & 0.470 & 0.471 \\
& Sending WOM & 0.496 & 0.487 \\
\hline
\end{tabular}

\section{Discussion and Implications}

The main objective of this study was to develop and test a model of drivers, attitudes, and behaviours in the post-adoption phase of a co-creative feature of online banking. To achieve this objective, the authors developed a new model for the post-adoption phase of the e-postbox, which includes post-adoption drivers, post-adoption attitudes, and post-adoption behaviours, and then empirically validated this model. The collected data $(n=750)$ of current customers of the e-postbox of a large German bank indicate that post-adoption drivers (receiving WOM, affective commitment, perceived usefulness, and customisation) and post-adoption attitudes (attitude towards using the e-postbox) influence post-adoption behaviours (continuance intention, actual usage, and sending WOM).

As Brown and Reingen (1987) predict, receiving WOM positively affects customers' attitudes towards using the e-postbox, which underscores the significance of including interpersonal communication as a post-adoption driver. Surprisingly though, this attitude has a negative effect on the post-adoption behaviour of sending WOM. The age-based multi-group analysis shows that younger customers with favourable attitudes towards using the e-postbox are less likely than older customers with favourable attitudes to send WOM. A potential explanation comes from extant literature (cf. Anderson, 1998; Bowman and Narayandas, 2001; Chen et al., 2011), which argues that dissatisfied customers are more active in spreading WOM online or offline than moderately satisfied customers due to negatively experienced emotions, such as anger and frustration (Bonifield and Cole, 2007; Sweeney et al., 2005). The contrasting finding of a positive impact of receiving WOM on the attitude towards using the e-postbox and a negative influence of this attitude on sending WOM, suggests that these two interpersona communication constructs do not necessarily move into the same direction. While customers may receive favourable WOM from others, they in turn may not spread favourable WOM even though they have a favourable attitude towards using the online banking. The opposing directions of effect highlight the need to investigate interpersonal communication from two perspectives in post-adoption models of banking services: receiving WOM as a post-adoption driver and sending WOM as a post-adoption behaviour.

With regard to the organisation-related driver of the post-adoption phase, the data reveal a positive relationship between affective commitment to the bank and the attitude towards using the e-postbox. Apparently, customers' emotional attachment and identification with their bank nurtures their favourable attitudes towards using the bank's services. Furthermore, affective commitment positively influences sending WOM, in a link that is significant for all ages; emotional attachment to the bank has a strong and robust positive effect on sending WOM. This finding contrasts the previously discussed negative association reported between attitude towards using the e-postbox and sending WOM. As suggested by Harrison-Walker (2001) despite customers' attitudes towards a specific service, affective commitment to the overall organisation enhances their WOM. De Matos and Rossi (2008) propose that even if customers 
experience lower levels of satisfaction with a service, they still may send favourable WOM if they are committed to the organisation, in an effort to reinforce their initial decision to enter the relationship, maintain cognitive consistency, and justify their organisational identification (Brown et al., 2005). This emotional aspect of decision-making in the post-adoption phase thus underscores the necessity to include organisation-related drivers in post-adoption models that go beyond a focus on the functional elements of a financial service.

The significant effects of the TAM variables support the integration of cognitive, affective, and behavioural constructs into post-adoption models of digitalised financial services (Davis, 1993). The task-related driver perceived usefulness indirectly affects post-adoption behaviours through the attitude towards using the e-postbox, but it also has strong, direct effects on al three post-adoption behaviours. Further studies of digitalised financial services thus should go beyond analysing the mediated effects of the TAM and integrate the direct impacts as well. The empirical examination of the newly developed post-adoption model also reveals strong support for the link between continuance intention and actual usage of the e-postbox which is in line with prominent technology adoption research suggesting that intentions affect behaviours (Ajzen, 1991; Davis et al., 1989; Fishbein and Ajzen, 1975). In the online banking context, customers' intention to continue using the e-postbox is a direct predictor of customers' actual usage behaviour. Adding the link from continuance intention to actual usage to the model renders the link between attitude towards using the e-postbox and actual usage insignificant; continuance intention fully mediates the effect of attitude on usage behaviour. Thus, banks' marketing efforts are encouraged to specifically target the continuance intentions of their customers in order to foster actual usage behaviour of the e-postbox.

In contrast to H12a, greater customisation of the e-postbox decreases customers' intention to continue using the e-postbox. Wang et al. (2017) predict a positive relationship between customisation and intention to continue using online banking, but they also suggest that this effect is mediated by customers' decreased effort expectancy and increased performance expectancy. A potential explanation for the negative link that emerges in the current study is that customers actually must exert increased effort to use the e-postbox, due to its relative newness and unfamiliar service attributes. Cheung et al. (2000) suggest that greater complexity leads to less usage; digitalised services that are still relatively new might be perceived a more complex and thus customers may decide to discontinue their use. Yet even though customisation negatively influences continuance intention, it has a positive effect on sending WOM, which demonstrates that post-adoption drivers may affect post-adoption behaviours in opposing directions.

Finally, intention to continue using the e-postbox increases with customers' attitude towards using it, receiving WOM from others, and how useful customers perceive the e-postbox to be. These findings reaffirm extant calls to account better for customers who discontinue their relationships with service organisations (Libai et al., 2009; Shi et al., 2014). The intensifying competition among banks and volatile customer demands (Mainardes et al., 2017) mandate a better understanding of how to achieve continued usage and retain customers, such as by improving the perceived usefulness of a service. Integrating continuance intention in postadoption models also is fundamental in light of the importance of co-creation; it empowers a customer-centred premise of an inherently relational exchange between the bank and customers through continued usage. If customers intend to discontinue using the provided services, long-term relationships are unlikely to result, such that these customers likely engage in exchanges with transaction-like features or churn to competing financial institutions.

\section{Implications for Theory}

This study provides several implications for theory. It offers a novel exploration of the postadoption phase of a co-creative feature of online banking and thus informs both service and banking literature in four main ways. First, it responds to calls for more research on the postadoption phase and co-creation in financial services (Mainardes et al., 2017; Tam and Oliveira, 2017a) and develops a testable model of this post-adoption phase for a co-creative feature of online banking, in order to foster customers' continued usage and attract new customers. Responding to the need for more research on the drivers of the post-adoption phase (Tam and Oliveira, 2017a), the proposed model suggests a multifaceted picture of post-adoption that includes two task-related drivers (customisation and perceived usefulness), an organisationrelated driver (affective commitment), and an interpersonal communication-related driver (receiving WOM). These different types of drivers are essential to holistically predict postadoption behaviours, because they consider rational decision-making based on functional features of the e-postbox, but also emotional decision-making directed by affect.

Second, the empirical tests of the model confirm the importance of a dual perspective on interpersonal communication (Gilly et al., 1998; Harrison-Walker, 2001) and also respond to calls for more research by integrating the perspectives of both the WOM recipient and the WOM sender (De Matos and Rossi, 2008). To assess continued usage of a digitalised financial service, it is essential to account for the interpersonal communication-related driver of customers receiving WOM from others and how that affects their attitudes, intentions, and behaviours. Complementarily, sending WOM by current customers is a critical post-adoption behaviour that increases the potential to acquire new customers.

Third, this research extends the general applicability of the TAM (Patel and Patel, 2018; Tam and Oliveira, 2017a) to the post-adoption phase of an innovative, co-creative feature of online banking. The underlying model is supported in this novel context. In addition, this study shows that researchers risk ignoring important findings if they fail to analyse direct effects together with mediated effects (e.g., perceived usefulness directly influences all three post-adoption 
behaviours). Diligent scrutiny of the post-adoption phase also requires the consideration of organisation-related and interpersonal communication-related drivers, in addition to the taskrelated drivers of the TAM; for example, besides perceived usefulness, receiving WOM, and affective commitment have strong, significant influences on the TAM variable attitude towards using.

Fourth, this study contradicts findings that suggest that the TAM constructs are generally invariant across age (Cheng et al., 2006; Lai and Li, 2005); it instead supports and extends studies that propose that customers' age significantly affects online banking constructs and relationships (Chau and Ngai, 2010; Mohammadi, 2015). Six of the eight constructs in the proposed model reveal significant differences across age groups; all TAM constructs are influenced by age. Customers younger than 30 years score highest on perceived usefulness, customisation, attitude towards using, and continuance intention; customers older than 60 years exhibit higher actual usage and send the most WOM.

\section{Implications for Practice}

The findings also are interesting for bank managers and marketers who aim to encourage continued usage of their co-creative, digitalised services. Financial institutions must realise that the stage after customers' adoption decision is critical for the success of their digital services, in that it determines the potential for long-term, mutually beneficial relationships. Essentially, post-adoption behaviours determine the worth of current customers, in terms of their actual usage and continuance intentions, as well as the opportunity to attract new customers through WOM. Therefore, bank managers must consider not only how potential customers receive WOM but also what kind of WOM their current customers are sending. Banks should develop specific incentives to encourage customers to send favourable WOM, especially for customers in their 30s and 40s, because these age groups are least likely to send WOM.

As part of a strategic goal to minimise customer churn, banks are also encouraged to identify and recover dissatisfied customers by determining which factors influence their intentions to discontinue using the service, before customers actually leave. Perceived usefulness, receiving WOM, and the attitude towards using the e-postbox have positive effects on continuance intention, so these concepts should be the primary targets of banks' marketing efforts.

Finally, this research demonstrates that in some cases, the customisation of a digitalised financial service can diminish intentions to continue using it. This negative effect potentially relates to the relative newness of the service feature, which increases customers' perceptions of complexity and unfamiliarity. Therefore, banks have to take care to explain and support customers' usage of newly introduced service features, to mitigate their negative perceptions of complexity and increased effort expectancy.

\section{Limitations and Recommendations for Further Research}

This research has some limitations that suggest avenues for further research. The proposed post-adoption model offers a practical application to foster continued usage of a co-creative, digitalised service by current customers and improves on existing models by including representative task-, organisation-, and interpersonal communication-related drivers. Yet it also might benefit from further extensions, such as the addition of other organisation-related drivers (e.g., customers' loyalty, trust in the bank) or task-related drivers (e.g., perceived security, enjoyment). Customer-related drivers, such as attitude towards using technology or need for interaction with a bank employee, also may shed light on the post-adoption phase of online banking by addressing customers' already established attitudes and dispositions. The relative importance of the post-adoption drivers also may fluctuate over time. The postadoption phase can continue infinitely, but the perceived novelty of the digitalised financial service decreases with relationship duration. Additional studies might explore whether customisation of the digitalised financial service continues to exert a negative effect on continuance intention later, once the customer has moved from novice to experienced user (Venkatesh and Morris, 2000). Perhaps customisation initially exerts a negative influence on continuance intention, which gradually becomes positive - a potential trend that requires further research consideration.

\section{Conclusion}

The adoption of online banking and the factors leading to it have received ample research attention, to the neglect of the post-adoption phase that follows after the initial adoption decision. However, the post-adoption phase is critical for banks that face volatile customer demands and increasing competition, because continued usage of online banking increases the potential to develop long-term, mutually beneficial customer-bank relationships, which ultimately determine a bank's success. To help banks foster customers' continued usage of their online banking services and attract new customers, this study has developed and tested a model of drivers, attitudes, and behaviours in the post-adoption phase of a co-creative feature of online banking, namely, the e-postbox. The empirical analysis identifies three types of postadoption drivers that influence post-adoption attitudes and behaviours: task-related drivers, such as perceived usefulness and customisation of the e-postbox; organisation-related drivers, such as customers' affective commitment to the bank; and interpersonal communicationrelated drivers, such as receiving WOM. This research evidences effects of the post-adoption drivers on the post-adoption attitude towards using the e-postbox and further on three postadoption behaviours (intention to continue using the e-postbox, actual usage of the e-postbox, and sending WOM). Finally, this study shows that age has a significant effect on severa constructs and relationships. 


\section{Conclusion}

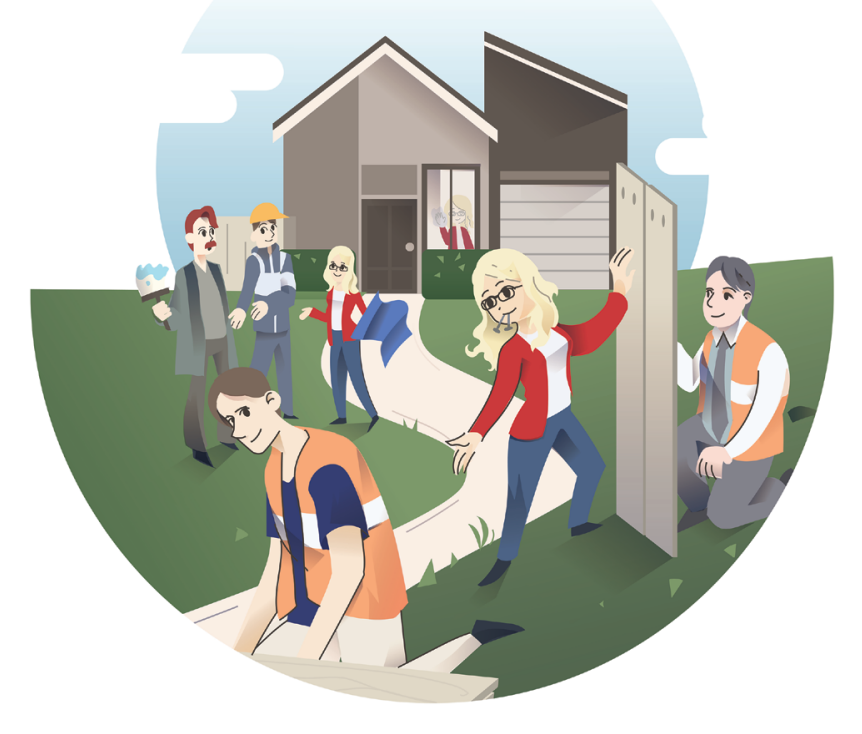




\section{Conclusion}

With this dissertation, I aim to clarify, empirically validate, and advance understanding of the benefits and process of co-creating services by leveraging an interdisciplinary, multi-method research approach that draws on the disciplines of service management/marketing, service innovation, and service design. In this final chapter, I provide a synopsis of the key premises of each chapter (Table C.1), then synthesise these premises into eight holistic conclusions about co-creating services.

\section{Synopsis}

My dissertation includes four empirical chapters. Their interrelation is metaphorically represented by the sequential progression of building a house. First, the housing concept gets designed and planned with the people who have a stake in it, leading to a vision of the final outcome (Chapter 1). Second, the next step involves selecting and engaging the needed workers to build the house together (Chapter 2). Third, tensions may arise when integrating different knowledge sources during the construction phase, so potential strategies need to be enacted to navigate them (Chapter 3). Fourth, the people moving into the new house tailor it to their needs and form relationships with and within it, making the house a home (Chapter 4). Analogously, this dissertation commences by exploring a shared definition of the concept of co-creating services and its possible outcomes, cites the drivers of co-creation behaviours and engagement, identifies underlying dynamics in the form of tensions and strategies for integrating people's lived experience, and acknowledges the continued usage of co-creative services (Table C.1).

Chapter 1 resonates with two identified research gaps: the lack of a definition for the cocreation of services that can establish a shared, less abstract understanding (Galvagno and Dalli, 2014; Saarijärvi et al., 2013) and the lack of an overview of the outcomes from co-creating services to better understand what co-creation could lead to (Voorberg et al., 2015; Woodruft and Flint, 2006). Through a focused literature review of five service research journals, Chapter 1 introduces a new definition of co-creating services including related terminology, and it provides a differentiated overview of the potential outcomes, according to six dimensions (Oertzen et al., 2018)

Chapter 2 seeks to amend the incomplete understanding of what drives people to co-create (Füller, 2010; Jaakkola et al., 2015) by identifying the factors influencing their co-creation behaviours and engagement through quantitative and qualitative analyses of between-subjects, scenario-based experiments with 633 participants and interactive research workshops with 38 design professionals. The findings include predictions of factors that influence users' cocreation behaviours, a framework of the drivers and inhibitors of users' engagement in services co-creation, and a typology of the likelihood of different types of users to engage in co-creation, according to their personality traits and demographics. 


\begin{tabular}{|c|c|c|c|}
\hline Part & Gap & Research question & Key premises \\
\hline Chapter 1 & $\begin{array}{l}\text { Lack of a definition of } \\
\text { the co-creation of services } \\
\text { Lack of an overview of } \\
\text { the outcomes from co- } \\
\text { creating services }\end{array}$ & $\begin{array}{l}\text { RQ1. How does the concept of the "co-creation of services" relate } \\
\text { to other terms that address the collaboration of the service provider } \\
\text { and the customer(s) in a service process or a service event? } \\
\text { RQ2. How can the co-creation of services be defined? } \\
\text { RQ3. What outcomes may follow from co-creating services? }\end{array}$ & $\begin{array}{l}\text { As a novel definition based on extant service research, co-creating services is defined as collaborative activities } \\
\text { in the service interface, influenced by a contextual, multi-actor network. This definition recognises involvement, } \\
\text { engagement, and participation as necessary pre-requisites of co-creation. It classifies co-ideation, co-valuation, } \\
\text { co-design, co-testing, and co-launching as regenerative co-creation, and then includes co-production and co- } \\
\text { consumption as operative co-creation. Both beneficial and counterproductive outcomes following co-creation can } \\
\text { be categorised according to personal, social, hedonic, cognitive, economic, and pragmatic dimensions. }\end{array}$ \\
\hline Chapter 2 & $\begin{array}{l}\text { Incomplete understanding } \\
\text { of what drives people } \\
\text { to co-create }\end{array}$ & $\begin{array}{l}\text { RQ1. What factors influence users' behaviours during } \\
\text { services co-creation? } \\
\text { RQ2a. What drivers and inhibitors affect users' engagement in } \\
\text { services co-creation? } \\
\text { RQ2b. Which types of users are more or less likely to engage in } \\
\text { services co-creation, according to their personality traits } \\
\text { and demographics? }\end{array}$ & $\begin{array}{l}\text { The behaviours of users participating in services co-creation are influenced by demographic and } \\
\text { dispositional factors. Their co-creation engagement is driven or inhibited by factors related to the task, } \\
\text { person, and context, and dependent on the participating or facilitating party. The likelihood of different } \\
\text { types of users to engage in co-creation can be predicted on the basis of their personality traits and } \\
\text { demographics. This likelihood to co-create, according to personality traits, then can be predicted according } \\
\text { to users' elemental, compound, and situational traits. }\end{array}$ \\
\hline Chapter 3 & $\begin{array}{l}\text { Missing insights on } \\
\text { the underlying dynamics of } \\
\text { co-creating services }\end{array}$ & $\begin{array}{l}\text { RQ1. What are the tensions related to the integration of people's } \\
\text { lived experience through co-creation in healthcare innovation? } \\
\text { RQ2. What are strategies for integrating people's lived experience } \\
\text { through co-creation in healthcare innovation, amid the tensions? }\end{array}$ & $\begin{array}{l}\text { People co-create by integrating their own lived experience and the lived experience of others. Integrating } \\
\text { lived experience in co-creation during healthcare innovation is affected by six tensions, which may be } \\
\text { navigated by seven strategies, depending on the healthcare innovation context. }\end{array}$ \\
\hline Chapter 4 & $\begin{array}{l}\text { Insufficient knowledge about } \\
\text { the post-adoption phase of } \\
\text { co-creative services }\end{array}$ & $\begin{array}{l}\text { RQ1. What drives customers' behaviours in the post-adoption } \\
\text { phase of a co-creative, digitalised service? }\end{array}$ & $\begin{array}{l}\text { Customers' behaviours in the post-adoption phase of a co-creative service include actual usage of the service, } \\
\text { continuance intentions, and sending word-of-mouth. These behaviours are predicted by task-related, } \\
\text { organisation-related, and interpersonal communication-related drivers, and by customers' attitudes. }\end{array}$ \\
\hline $\begin{array}{l}\text { Chapter } 3 \\
\text { designers, } \\
\text { co-creatin } \\
\text { to evaluate } \\
\text { 2018). The } \\
\text { experience } \\
\text { that vary i. }\end{array}$ & $\begin{array}{l}\text { reports on phenomenol } \\
\text { and healthcare professional } \\
\text { g services (Gustafsson et al } \\
\text { the integration of lived ex } \\
\text { descriptions in the interv } \\
\text { through co-creation in } \mathrm{h} \\
\mathrm{n} \text { the degree to which they }\end{array}$ & $\begin{array}{l}\text { ogical interviews with } 23 \text { patients, family caregivers, } \\
\text { ls to generate new insights on the underlying dynamics of } \\
\text {., 2012; Payne et al., 2008). Specifically, this chapter aims } \\
\text { perience during services co-creation (Vink and Oertzen, } \\
\text { iews suggest six interacting tensions of integrating lived } \\
\text { ealthcare innovation and a spectrum of seven strategies } \\
\text { integrate people's lived experience. }\end{array}$ & $\begin{array}{l}\text { Synthesis } \\
\text { Currently, co-creating services is in vogue-a buzzword used widely and an ideal cited } \\
\text { by many practitioners who aspire to carry out co-creation activities within and across their } \\
\text { organisations and by a multitude of scholars who research the topic. This dissertation offers } \\
\text { a positive assessment of co-creation as indispensible, but it also urges potential co-creators } \\
\text { to consider purposefully how they should conduct, facilitate, and participate in services co- } \\
\text { creation activities. Without such considerations, the risk is that co-creation will become, } \\
\text { metaphorically, an empty, abandoned house, with little effect for transforming services and } \\
\text { the surrounding systems and potentially even counterproductive outcomes. By synthesising } \\
\text { the key premises of the previous four chapters, this section formulates eight holistic conclusions } \\
\text { reflecting new theoretical insights into the benefits and process of co-creating services and its } \\
\text { practical applications. }\end{array}$ \\
\hline
\end{tabular}

of current custome, in terns of their actal usage and conting the opportunity to attract new customers through word-of-mouth (Oertzen and OdekerkenSchröder, 2019). 
Holistic Conclusion 1: Genuine services co-creation is based on multi-directional communication and collaboration among the involved parties, who must actively participate and engage in the co-creation process.

The process of co-creating services demands multi-directional communication and collaboration between two or more parties. The term "genuine services co-creation" helps denote co-creation efforts that transcend a participation façade that actually reinforces power imbalances and marginalises people's contributions (Chapter 3). Continuous, reciprocal dialogue during co-creation efforts in turn requires the involvement, participation, and engagement of participating actors (Chapter 1). Establishing these requirements represents an advance in service research, in that it clarifies the conceptual pluralism surrounding the concept of co-creating services (Oertzen et al., 2018). It also responds to calls for more research on how to avoid simply allowing co-creation activities to confirm and reinforce pre-existing mind-sets (Farrington, 2016). It is not sufficient for service providers to take a one-sided perspective, enquire about customers' specifications at the beginning of a service experience, and then confirm this experience at the end (Ramaswamy and Gouillart, 2010); that would be like a builder designing a house solely according to the builder's preferences, asking about the homeowner's wishes and needs once before starting the construction, and then asking for an evaluation only after the construction has finished. But homeowners are not passive recipients; they want to participate actively in shared decision-making during the building process. Genuine services co-creation, truly taking the needs and experiences of all participating people into account, demands careful efforts to avoid a participation façade and reinforcements of prior perspectives (Farrington, 2016). Doing so means encouraging co-creation engagement among all involved actors through specific efforts, such as defining the purpose and preparing the task and context (Chapter 2). Practitioners can use a range of strategies to integrate their own lived experience and that of others in co-creation efforts (Chapter 3). Also in the postadoption phase, which often entails repetitive, day-to-day activities, care should be taken to integrate the insights of the people who use the services to ensure their retention and possibly motivate new users (Chapter 4).

Holistic Conclusion 2: The human-centred perspective of service design contributes to co-creation as a process, a toolbox, and a mind-set.

My findings extend academic discourse on co-creating services by identifying the triple contribution of service design, grounded in its holistic, contextual, interactive, and collaborative properties (SDN, 2019). First, Chapter 1 investigates specific forms of co-creation, such as co-design, which is a central concept in service design (Trischler et al., 2018c). Among all the examined co-creation forms, co-design places the strongest emphasis on the process of joint creation in a multi-actor environment (Oertzen et al., 2018). It takes a holistic perspective that fosters practices to engage many actors, typically transcending the dyad (Quero and Ventura, 2015). Second, the interactive and collaborative nature of service design offers great potential as a toolbox; the interactive research workshops in Chapter 2 employ generative and mapping techniques, such that they enable theory development through inclusion and active interaction (Denzin and Lincoln, 2008). Third, as a mind-set rooted in a human-centred perspective, service design is pragmatic and hands-on, considers the user first, and tests assumptions (Stickdorn et al., 2018). It is thus essential for co-creating services, especially in a service setting with vulnerable people (Chapter 3 ). To innovate services, the lived experience of all people affected by these services, such as patients and their families, must be actively integrated to ensure that the inclusive services are tailored to their actual needs. An illustration using the house-building metaphor helps explain the interrelation of co-creation with service design as a process, a toolbox, and a mind-set. When a municipality decides to build new public housing, it can rely on a toolbox informed by service design principles to co-create with citizens, such as collaborative user journeys and value propositions. These tools help create a common understanding and make the implicit explicit; however, they have little value without a service design mind-set and process (Stickdorn et al., 2018). The service design mind-set is needed to reveal others' genuine and holistic insights, integrate them, and strategically generate benefits for all involved parties, including the municipality, builder, workers, citizens, and others. The process of service design, driven by the mind-set, then can iteratively leverage cocreation in a multi-actor network, such as by integrating loops of feedback with citizens in the early concept phase of building the housing, during the prototyping and testing phases, and then again in the implementation stage.

Holistic Conclusion 3: Co-creating services takes place in earlier phases of the service process related to innovating services and in later phases that comprise specific service events, which may occur repetitively.

Drawing on service management/marketing, service innovation, and service design disciplines, Chapter 1 establishes two terms: regenerative co-creation, encompassing earlier phases of the service process related to innovating services, and operative co-creation, capturing a specific service event or encounter that may occur several times and that leads, at most, to incremental innovation. The specific co-creation forms referred to as co-ideation, $\mathrm{co}_{-}$ valuation, co-design, co-testing, and co-launching are classified as regenerative co-creation; the specific co-creation forms of co-production and co-consumption are classified as operative co-creation (Oertzen et al., 2018). Accordingly, co-creation can take place in the design and development of new services (Kazadi et al., 2016), as well as in the delivery and consumption of existing services (McColl-Kennedy et al., 2017a). For example, a healthcare service, such as the GE Healthcare Adventure Series for MR scanning, can be jointly ideated by designers, developers, children, parents, and doctors (Kelley and Kelley, 2013); an instance of regenerative co-creation. Operative co-creation occurs when the child and parents interact with the nurses and doctors during the MR scan, which may include sharing information or building relations (McColl-Kennedy et al., 2017a). Many key premises of this dissertation support this conclusion, including evidence that regenerative co-creation supports innovations in healthcare services, 
such as co-creating to improve the design of a particular therapy (Chapter 3). Instances of operative co-creation during service delivery might take the form of customers designing a sports shoe together with their local sports outfitter (Chapter 2); during service consumption, it might involve the post-adoption phase of a co-creative feature of online banking (Chapter 4) By describing how the overall concept of co-creating services relates to its specific co-creation forms, this dissertation helps clarify and consolidate the terminology around co-creation, adding consistency and potentially accelerating the development of further contributions (Oertzen et al., 2018).

Holistic Conclusion 4: The innovation process is a contextual stage for co-creating services, and the co-creation process results in innovative outcomes.

Drawing on the service innovation discipline, within the interdisciplinary frame for this dissertation, and the chapters' key premises, I propose that innovation is both a contextual stage and an outcome of co-creation. The homeowner and builder might co-create a building plan during the house's design phase; the physical house with its innovative design might succeed prolonged co-creation efforts. This reasoning is evident in Chapter 1, which describes cocreation taking place during the innovation process, for instance in the forms of co-ideation, co-design, or co-testing (Russo-Spena and Mele, 2012), and then outlines innovative outcomes following the co-creation process, such as new services or improvements to existing ones (Hu and McLoughlin, 2012; Ryzhkova, 2015). Chapter 3 substantiates this conclusion: A patient co-creates with developers to design a service for bladder control during the innovation process, which results in an innovative app to predict critical moments. These findings contribute to theorising about co-creation as part of the innovation process (Witell et al. 2011), as well as innovative outcomes emerging from the co-creation process (Ordanini and Parasuraman, 2011).

Holistic Conclusion 5: Co-creating services depends on the participating party and the facilitating party.

The need to co-create with "normal" users, rather than lead users or professional developers is increasingly clear (Enkel et al., 2005; Magnusson, 2009). Chapter 2 shows that users' behaviours and engagement in services co-creation depend on their demographics, such as their age and gender, and dispositions (i.e., personality traits). Chapter 4 supports this premise; it demonstrates the influence of customers' age on their post-adoption behaviours for a co-creative financial service. However, a common one-sided perception in academia and practice assumes that co-creation outcomes mostly depend on the types of participants, such as lead or relationally close users (Carbonell et al., 2012). The current findings certainly do not negate that idea that participants influence co-creation, but this dissertation highlights the concomitant need to understand that such efforts also are contingent on the facilitating party, such as the service designer or provider. Building a house requires contributions and demand from the homeowner, but it also demands a well-prepared builder who engages with these contributions. As Chapter 2 shows, users' engagement in services co-creation is driven or inhibited by factors related to themselves, such as their motivation or prior experience, but also to the facilitating party, such as preparation, facilitation, and the purpose of co-creation activities.

Holistic Conclusion 6: There is no one best way to initiate co-creation; the first step can be taken by various actors, such as users, designers, or service providers, with different implications.

There are two generations of thought on co-creation (Chapter 1). According to the first generation, the service provider enables co-creation and invites customers into the process (Normann and Ramirez, 1993). In the second generation, co-creation can be initiated by a host of actors, such as the customer, provider, or actors beyond organisational boundaries (Kazadi et al., 2016; Oliveira and von Hippel, 2011; Zwass, 2010). Regenerative co-creation in a healthcare service setting thus might be steered by patients, family caregivers, designers, or healthcare professionals (Chapter 3). Patients and caregivers often have a deep, situated understanding of their own circumstances, and they can use this lived experience to design services tailored to their needs. Yet they also might be impaired by their health condition, limited by the absence of a larger network, or unable to realise innovations due to a lack of technical skillsets. Designers can elicit lived experience through empathic approaches, then apply their profound technical expertise to develop valuable innovations. When empathically integrating insights from other people though, they risk projecting their own assumptions onto others' experiences (Vink and Oertzen, 2018). In this sense, there may not be a clear, eligible option for who should initiate co-creation. A patient lacking a ready-made solution to improve personal well-being may have to initiate co-creation efforts to innovate a solution (Chapter 3), but a service provider also might prompt co-creation by inviting users into service delivery and consumption stages, after having pre-installed certain technical and economical options (Chapter 2, 4). Understanding the implications of which dominant entity initiates and orchestrates services co-creation is important for reducing the risks of co-creation, such as non-feasible solutions or tokenistic approaches (Farrington, 2016). The classification of tensions and strategies in Chapter 3 can help to inform the appropriate management of the co-creation process, especially for regenerative co-creation. When building a house for example, an allying strategy might enable the builder and homeowner to continuously exchange information and make join decisions in the long term and thus avoid any mismatch between the builder's constraints and the homeowner's expectations. 
Holistic Conclusion 7: Genuine services co-creation supports institutional change by generating legitimacy through its beneficial outcomes.

Facilitating genuine services co-creation that holistically includes the experiences and needs of all involved people without marginalising their contributions can reshape socially constructed roles and ways of working, leading to institutional change. It does so by building legitimacy, or the state in which other alternatives appear less suitable or attractive (Dacin et al., 2002), by communicating and evidencing the beneficial outcomes that can follow from co-creation efforts. Taking the healthcare sector as an example, for decades Western healthcare systems have tried to implement people-centred care that emphasises shared decision-making and empowerment (Lukersmith et al., 2016; World Health Organization, 2015, 2016). Yet progress has been slow and sticky (Ocloo and Matthews, 2016), partially due to the deeply anchored institutional norms of healthcare, where doctors take an authoritarian role and patients conform to socially constructed, compliant roles (Frosch et al., 2012). Based on its key premises, this dissertation argues that facilitating genuine services co-creation, beyond tokenistic approaches, should prompt meaningful conversations and help reconfigure the imbalance of power and control across patients, doctors, and other actors, which in turn can support intentional institutional change towards people-centred care (Patrício et al., 2019). As Chapter 1 shows, benefits following from co-creation include positive effects on people's well-being, relationship quality, and empowerment and ownership, which should increase patient agency and thus re-balance power relations in healthcare settings (Tsekleves and Cooper, 2017). The interacting tensions involved in integrating lived experience through co-creation, as identified in Chapter 3, expand and dissemble some of the challenges of realising people-centred care, such as the difficulty of combining different knowledge sources or working with multiple truth regimes (Sellen, 2018; Trischler et al., 2018c). In response to these tensions, Chapter 3 also suggests leveraging purposefully informed strategies to integrate the lived experience of all involved people during co-creation efforts, which then can help realise authentic, people-centred health services. Taken together, genuine services co-creation leads to beneficial outcomes, which generate legitimacy, supporting institutional creation and transformation.

Holistic Conclusion 8: Co-creating services requires paradoxical thinking.

Finally, the process of co-creating services requires paradoxical thinking. The theoretical and empirical findings of this research include several premises that appear straightforward in isolation but contradictory when considered as part of a whole picture (Lewis, 2000). For example, the tensions of integrating people's lived experience during co-creation efforts cannot be resolved simply with a one-size-fits-all, readily available strategy (Chapter 3). Rather, they must be navigated through careful consideration of the implications of different available strategies within the particular context. It may be necessary to integrate some people in cocreation efforts to learn from their situated understanding, but as the electroconvulsive therapy example from Chapter 3 reveals, sometimes it is not possible to integrate patients, due to thei current physical or mental condition. Paradoxes originate from mental construction and socia interactions and change according to the examined person, time, and context (Luscher et al, 2006). Thus, what creates tension for one person may appear straightforward to another; what seems viable in one context may not be feasible in another. This paradoxical nature also informs my Holistic Conclusion 6, because there is no one best way to initiate co-creation. Service providers might want to initiate co-creation efforts for economic, feasibility, or intellectual property reasons, but if they limit the process to their own initiation efforts, they risk reinforcing pre-set assumptions and marginalising the contributions of other participants. Understanding and facilitating co-creation requires mastery of paradoxical thinking, which leverages "bothand" rather than "either-or" thinking-in line with the goals of interdisciplinary research (Gustafsson and Bowen, 2017, p. 213) and the foundational approach of this dissertation.

\section{Final Thoughts}

This dissertation focuses on a topic that has received much attention, both theoretically and practically. To understand the co-creation of services, I draw on an interdisciplinary, multimethod research approach and thereby clarify some benefits and the process of co-creating services by empirically establishing and validating its different stages. The resulting conclusions suggest that service researchers and practitioners must leverage paradoxical thinking and the human-centred perspective of service design to facilitate the co-creation context, engage participants, and navigate the underlying dynamics of the co-creation process. In highlighting the beneficial nature of co-creating services and its potential to drive institutional change, this dissertation regards co-creation not as an optional path for the future but rather as a contemporary necessity.

Let us build a house, let us make this house our homeTogether, let us co-create the future! -Anna-Sophie Oertzen 
References 


\section{References}

Ajzen, I. (1991), "The theory of planned behavior", Organizational Behavior and Human Decision Processes, Vol. 50 No. 2, pp. 179-211.

Akaka, M.A. and Vargo, S.L. (2015), "Extending the context of service: from encounters to ecosystems", Journal of Services Marketing, Vol. 29 Nos 6/7, pp. 453-462.

Åkesson, M., Skåleén, P., Edvardsson, B., and Stålhammar, A. (2016), "Value proposition test-driving for service innovation: how frontline employees innovate value propositions", Journal of Service Theory and Practice, Vol. 26 No. 3, pp. 338-362.

Al-Somali, S.A., Gholami, R., and Clegg, B. (2009), "An investigation into the acceptance of online banking in Saudi Arabia", Technovation, Vol. 29 No. 2, pp. 130-141.

Alam, I. (2011), "Process of customer interaction during new service development in an emerging country", The Service Industries Journal, Vol. 31 No. 16, pp. 2741-2756.

Alfakhri, D., Harness, D., Nicholson, J., and Harness, T. (2018), "The role of aesthetics and design in hotelscape: a phenomenological investigation of cosmopolitan consumers", Journal of Business Research, Vol. 85, pp. 523-531.

Alves, H. (2013), "Co-creation and innovation in public services", The Service Industries Journal, Vol. 33 Nos 7/8, pp. 671-682.

Anderson, E.W. (1998), "Customer satisfaction and word of mouth", Journal of Service Research, Vol. 1 No. 1, pp. 5-17.

Anderson, E.W., Fornell, C., and Rust, R.T. (1997), "Customer satisfaction, productivity, and profitability: differences between goods and services", Marketing Science, Vol. 16 No. 2, pp. 129-145.

Anderson, J.C. and Gerbing, D.W. (1988), "Structural equation modeling in practice a review and recommended two-step approach", Psychological Bulletin, Vol. 103 No. 3, pp. 411-423.
Anderson, L., Ostrom, A.L., Corus, C., Fisk, R.P. Gallan, A.S., Giraldo, M., Mende, M., Mulder, M., Rayburn, S.W., Rosenbaum, M.S., Shirahada, K. and Williams, J.D. (2013), "Transformative service research: an agenda for the future", Journal of Business Research, Vol. No. 8, 66, pp. 1203-1210

Anderson, S., Nasr, L., and Rayburn, S. W. (2018), "Transformative service research and service design: synergistic effects in healthcare", The Service Industries Journal, Vol. 38 Nos 1/2, pp. 99-113.

Arenas-Gaitán, J., Peral-Peral, B., and RamónJerónimo, M. (2015), "Elderly and Internet banking: an application of UTAUT2", Journal of Internet Banking and Commerce, Vol. 20 No. 1, pp. 1-23.

Armstrong, J.S. and Overton, T.S. (1977), "Estimating nonresponse bias in mail surveys", Journal of Marketing Research, Vol. 14 No. 3, pp. 396-402.

Arora, N., Dreze, X., Ghose, A., Hess, J.D., Iyengar, R., Jing, B., Joshi, Y., Kumar, V., Lurie, N., Neslin, S. Sajeesh, S., Su, M., Syam, N., Thomas, J., and Zhang, Z.J. (2008), "Putting one-to-one marketing to work: personalization, customisation, and choice", Marketing Letters, Vol. 19 Nos 3/4, pp. 305-321.

Auh, S., Bell, S.J., McLeod, C.S., and Shih, E. (2007), "Co-production and customer loyalty in financial services", Journal of Retailing, Vol. 83 No. 3, pp. 359-370.

Ayo, C.K., Oni, A.A., Adewoye, O.J., and Eweoya, I.O. (2016), "E-banking users' behaviour: e-service quality, attitude, and customer satisfaction" International Journal of Bank Marketing, Vol. 34 No. 3, pp. 347-367.

Babin, B.J., Darden, W.R., and Griffin, M. (1994), "Work and/or fun: measuring hedonic and utilitarian shopping value", Journal of Consumer Research, Vol. 20 No. 4, pp. 644-656.

Bagozzi, R.P. and Phillips, L.W. (1982), "Representing and testing organizational theories: a holistic construal", Administrative Science Quarterly, Vol. 27 No. 3, pp. 459-489. 
Bagozzi, R.P. and Yi, Y. (1988), “On the evaluation of structural equation models", Journal of the Academy of Marketing Science, Vol. 16 No. 1, pp. 74-94.

Bartl, M., Jawecki, G., Bilgram, V., and Wiegandt, P. (2013), "The BMW Group co-creation lab: from co-creation projects to programmes", in $\mathrm{P}$. Augsdörfer, J. Bessant, K. Möslein, B. von Stamm, and F. Piller (Eds.), Discontinuous Innovation: Learning to Manage the Unexpected, Imperial College Press, London, England, pp. 179-204.

Bate, P. and Robert, G. (2006), "Experience-based design: from redesigning the system around the patient to co-designing services with the patient", BMJ Quality \& Safety, Vol. 15 No. 5, pp. 307-310.

Bendapudi, N. and Leone, R.P. (2003) "Psychological implications of customer participation in co-production", Journal of Marketing, Vol. 67 No. 1, pp. 14-28.

Berry, L.L. (2019), "Service innovation is urgent in healthcare", AMS Review, Vol. 9 Nos 1/2, pp. 1-15.

Bevan, M.T. (2014), "A method of phenomenological interviewing", Qualitative Health Research, Vol. 24 No. 1, pp. 136-144.

Bhattacherjee, A. (2001), "An empirical analysis of the antecedents of electronic commerce service continuance", Decision Support Systems, Vol. 32 No. 2, pp. 201-214

Bitner, M.J., Booms, B.H., and Tetreault, M.S (1990), "The service encounter: diagnosing favorable and unfavorable incidents", Journal of Marketing, Vol. 54 No. 1, pp. 71-84.

Bjögvinsson, E., Ehn, P., and Hillgren, P.A. (2012), "Design things and design thinking: contemporary participatory design challenges", Design Issues, Vol. 28 No. 3, pp. 101-116.

Bloemer, J. and Odekerken-Schröder, G. (2003), "Antecedents and consequences of affective commitment", Australasian Marketing Journal, Vol. 11 No. 3, pp. 33-43.

Bone, S.A., Fombelle, P.W., Ray, K.R., and Lemon, K.N. (2015), "How customer participation in B2B peer-to-peer problem-solving communities influences the need for traditional customer service, Journal of Service Research, Vol. 18 No. 1, pp. 23-38. Bonifield, C. and Cole, C. (2007), "Affective Besponses to service failure: anger regret, and retaliatory versus conciliatory responses", Marketing Letters, Vol. 18 No. 1, pp. 85-99.

Booth, A., Sutton, A., and Papaioannou, D. (2016) Systematic Approaches to a Successful Literature Review, Sage, London, England.

Bove, L.L. (2019), "Empathy for service: benefits, unintended consequences, and future research agenda", Journal of Services Marketing, Vol. 33 No. 1, pp. 31-43.

Bove, L. and Mitzifiris, B. (2007), "Personality traits and the process of store loyalty in a transactiona prone context", Journal of Services Marketing Vol. 21 No. 7, pp. 507-519.

Bove, L.L., Pervan, S.J., Beatty, S.E., and Shiu, E. (2009), "Service worker role in encouraging customer organizational citizenship behaviors", Journal of Business Research, Vol. 62 No. 7, pp. 698-705.

Bowman, D. and Narayandas, D. (2001), “Managin customer-initiated contacts with manufacturer the impact on share of category requirements and word-of-mouth behavior", Journal of Marketing Research, Vol. 38 No. 3, pp. 281-297.

Braun, V. and Clarke, V. (2006), "Using thematic analysis in psychology", Qualitative Research in Psychology, Vol. 3 No. 2, pp. 77-101.

Brown, J.J. and Reingen, P.H. (1987), "Social ties and word-of-mouth referral behavior", Journal of Consumer Research, Vol. 14 No. 3, pp. 350-362.

Brown, T.J., Barry, T.E., Dacin, P.A., and Gunst, R.F. (2005), "Spreading the word: investigating antecedents of consumers' positive word-of-mouth intentions and behaviors in a retailing context", Journal of the Academy of Marketing Science, Vol. 33 No. 2, pp. 123-138.

Bryson, J.R. and Taylor, M. (2010)

"Competitiveness by design and inimitability

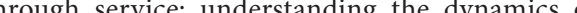
firm-based competition in the West Midland jewellery and lock industries", The Service Industries Journal, Vol. 30 No. 4, pp. 583-596.

Burdon, S., Mooney, G.R., and Al-Kilidar, H. (2015), "Navigating service sector innovation using co-creation partnerships", Journal of Service Theory and Practice, Vol. 25 No. 3, pp. 285-303.

Čaić, M., Odekerken-Schröder, G., and Mahr, D. (2018), "Service robots: value co-creation and codestruction in elderly care networks", Journal of Service Management, Vol. 29 No. 2, pp. 178-205.

Cambra-Fierro, J., Pérez, L., and Grott, E. (2017) "Towards a co-creation framework in the retail banking services industry: do demographics influence?", Journal of Retailing and Consumer Services, Vol. 34 No., pp. 219-228.

Cambra-Fierro, J., Berbel-Pineda, J.M., RuizBenítez, R., and Vazquez-Carrasco, R. (2011), "Managing service recovery processes: the role of customers' age", Journal of Business Economics and Management, Vol. 12 No. 3, pp. 503-528.

Carbonell, P., Rodriguez-Escudero, A.I., and Pujari, D. (2012), "Performance effects of involving lead users and close customers in new service development", Journal of Services Marketing, Vol. 26 No. 7, pp. 497-509.

Carr, V., Sangiorgi, D., Büscher, M., and Junginger, S. (2009), "Clinicians as service designers?
Reflections on current transformation in the UK Reflections on current transformation in the UK health services", in Clatworthy, S., Nisula, J.-V., and Holmlid, S. (Eds.), Proceedings of the 1st Service Design and Innovation Conference on DeThinking Service, ReThinking Design in Oslo, Norway, 24-26 November 2009, Linköping University Electronic Press, Linköping, Sweden, pp. 31-42.

Cater, B. and Zabkar, V. (2009), "Antecedents and consequences of commitment in marketing research services: the client's perspective", Industrial Marketing Management, Vol. 38 No. 7, pp. 785-797.

Çelik, H. (2008), "What determines Turkish customers' acceptance of Internet banking?" International Journal of Bank Marketing, Vol. 26 No. 5, pp. 353-370.
Cermak, D.S., File, K.M., and Prince, R.A. (1994), "Customer participation in service specificatio and delivery", Journal of Applied Business Research, Vol. 10 No. 2, pp. 90-97.

Chamorro-Premuzic, T. and Reichenbacher, L (2008), "Effects of personality and threat of evaluation on divergent and convergent thinking", Journal of Research in Personality, Vol. 42 No. 4, pp. 1095-1101.

Chang, C.W., Tseng, T.H., and Woodside, A.G (2013), "Configural algorithms of patient satisfaction, participation in diagnostics, and treatment decisions influences on hospital loyalty", Journal of Services Marketing, Vol. 27 No. 2, pp. 91-103.

Chang, W. and Taylor, S.A. (2016) "The effectiveness of customer participation in new product development: a meta-analysis", Journal of Marketing, Vol. 80 No. 1, pp. 47-64

Chathoth, P., Altinay, L., Harrington, R.J., Okumus, F., and Chan, E.S. (2013), "Co-production versus co-creation: a process based continuum in the hotel service context", International Journal of Hospitality Management, Vol. 32, pp. 11-20.

Chau, V.S. and Ngai, L.W.L.C. (2010), "The youth market for Internet banking services: perceptions attitude and behaviour", Journal of Services Marketing, Vol. 24 No. 1, pp. 42-60.

Chen, J.-S., Kerr, D., Tsang, S.-S., and Sung, Y.C. (2015), "Co-production of service innovatio through dynamic capability enhancement", The Service Industries Journal, Vol. 35 Nos 1/2, pp. 96-114.

Chen, Y., Fay, S., and Wang, Q. (2011), "The role of marketing in social media: how online consumer reviews evolve", Journal of Interactive Marketing Vol. 25 No. 2, pp. 85-94.

Chen, Y.-H., Wu, J--J., and Chien, S.-H. (2016), "Impact of initial trust, involvement, and mood on trusting belief: evidence from the financia industry in Taiwan", Journal of Service Theory and Practice, Vol. 26 No. 1, pp. 91-108.

Cheng, C.C., Chen, J.S., and Tsou, H.T. (2012) "Market-creating service innovation: verification and its associations with new service development 
and customer involvement", Journal of Services Marketing, Vol. 26 No. 6, pp. 444-457.

Cheng, T.C.E., Lam, D.Y.C., and Yeung, A.C.L. (2006), "Adoption of Internet banking: an empirical study in Hong Kong", Decision Support Systems, Vol. 42 No. 3, pp. 1558-1572.

Chesbrough, H.W. (2011), "Bringing open innovation to services", MIT Sloan Management Review, Vol. 52 No. 2, pp. 85-90.

Cheung, W., Chang, M.K., and Lai, V.S. (2000), "Prediction of Internet and World Wide Web usage at work: a test of an extended Triandis model", Decision Support Systems, Vol. 30 No. 1, pp. 83-100

Chien, S.-H. and Chao, M.-C. (2011), "Intellectual capital and new product sale performance of the financial services industry in Taiwan", The Service Industries Journal, Vol. 31 No. 16, pp. 2641-2659

Chien, S.-H. and Chen, J.-j. (2010), "Supplier involvement and customer involvement effect on new product development success in the financial service industry", The Service Industries Journal, Vol. 30 No. 2, pp. 185-201.

Chin, W.W. (1998), "The partial least squares approach to structural equation modeling", in Marcoulides, G.A. (Ed.), Modern Methods for Business Research, Lawrence Erlbaum Associates, Mahwah, NJ, pp. 295-336.

Choi, L. and Lotz, S. (2016), "Motivations leading to customer citizenship behavior in services: scale development and validation", Journal of Consumer Marketing, Vol. 33 No. 7, pp. 539-551.

Cipolla, C. and Bartholo, R. (2014), "Empathy or inclusion: a dialogical approach to socially responsible design", International Journal of Design Vol. 8 No. 2, pp. $87-100$

Coelho, P.S. and Henseler, J. (2012), “Creating customer loyalty through service customisation," European Journal of Marketing, Vol. 46 Nos 3/4, pp. 331-356.

Comrey, A.L. and Lee, H.B. (1992), A First Course in Factor Analysis (2nd ed.), Psychology Press, New York, NY.

Cossío Silva, F.J., Revilla Camacho, M.A., and Vega Vázquez, M. (2013) "Heterogeneity of customers of personal image services: a segmentation based on value co-creation", International Entrepreneurship and Management Journal, Vol. 9 No. 4, pp. 619-630 Costa, P.T.J. and McCrae, R.R. (1995), "Persons, places, and personality: career assessment using the revised NEO personality inventory", Journal of Career Assessment, Vol. 3 No. 2, pp. 123-139.

Crandell, C. (2016), "Customer co-creation is the secret sauce to success", available at: https://www. forbes.com/sites/christinecrandell/2016/06/10 customer_cocreation_secret_sauce/\#8bc747e5b6dc (accessed 25 May 2019).

Dabholkar, P.A. (1990), "How to improve perceived service quality by improving custome participation", in Dunlap, B.J. (Ed.), Development in Marketing Science, Academy of Marketing Science, Cullowhee, NC, pp. 483-487.

Dabholkar, P.A. and Bagozzi, R.P. (2002), "An attitudinal model of technology-based selfservice: moderating effects of consumer traits and situational factors", Journal of the Academy of Marketing Science, Vol. 30 No. 3, pp. 184-201.

Dabholkar, P.A. and Sheng, X. (2012), "Consumer participation in using online recommendation agents: effects on satisfaction, trust, and purchase intentions", The Service Industries Journal, Vol. 32 No. 9, pp. 1433-1449.

Dacin, M.T., Goodstein, J., and Scott, W.R. (2002), "Institutional theory and institutional change: introduction to the special research forum", Academy of Management Journal, Vol. 45 No. 1, pp. 45-56.

Davis, F.D. (1989), "Perceived usefulness, perceived ease of use, and user acceptance of informatio technology", MIS Quarterly, Vol. 13 No. 3, pp. 319-340

Davis, F.D. (1993), "User acceptance of information technology: system characteristics, user perceptions and behavioral impacts", International Journal of Man-Machine Studies, Vol. 38 No. 3, pp. 475-487.

Davis, F.D., Bagozzi, R.P., and Warshaw, P.R (1989), “User acceptance of computer technology: a comparison of two theoretical models", Management Science, Vol. 35 No. 8, pp. 982-1003.

De Matos, C.A. and Rossi, C.A.V. (2008), "Wordof-mouth communications in marketing: a metaanalytic review of the antecedents and moderators", Journal of the Academy of Marketing Science, Vol. 36 No. 4, pp. 578-596.

De Ruyter, K., Wetzels, M., and Feinberg, R. (2001), "Role stress in call centers: its effects on employee performance and satisfaction", Journal of Interactive Marketing, Vol. 15 No. 2, pp. 23-35.

De Wulf, K., Odekerken-Schröder, G., and Iacobucci, D. (2001), "Investments in consumer relationships: a cross-country and cross-industry exploration", Journal of Marketing, Vol. 65 No. 4, pp. 33-50.

Deegan, P.E. (1988), "Recovery: the lived experience of rehabilitation", Psychosocial Rehabilitation Journal, Vol. 11 No. 4, pp. 11-19.

Delpechitre, D., Beeler-Connelly, L.L., and Chaker, N. (2018), "Customer value co-creation behavior: a dyadic exploration of the influence of salesperson emotional intelligence on customer participation and citizenship behavior", Journal of Business Research, Vol. 92 No., pp. 9-24.

Denzin, N.K. and Lincoln, Y.S. (2008), The Landscape of Qualitative Research, (3rd ed.), Sage, Thousand Oaks, CA.

Deutsche Post DHL Group (2017), "DHL Parcelcopter 3.0", available at: www.dpdhl.com/ en/media_relations/specials/parcelcopter.html (accessed 28 August 2017).

Devlin, J.F. (2001), "Consumer evaluation and competitive advantage in retail financial services: a research agenda", European Journal of Marketing, Vol. 35 Nos 5/6, pp. 639-660

DHL Solutions \& Innovations (2017), "A closer look", available at: http://dsi.bach-partner.com/en/ aboutus/index (accessed 28 August 2017).

Dietz, D. (2012), “Transforming healthcare for children and their families: Doug Dietz at TEDxSanJoseCA 2012, available at: https://www.youtube.com/ watch?v=jajduxPD6H4 (accessed 26 July 2019).
Dijkstra, T.K. and Henseler, J. (2015), "Consisten partial least squares path modeling", MIS Quarterly Vol. 39 No. 2, pp. 297-316.

Donetto, S., Pierri, P., Tsianakas, V., and Robert G. (2015), "Experience-based co-design an healthcare improvement: realizing participator design in the public sector", The Design Journal, Vol. 18 No. 2, pp. 227-248.

Dong, B. (2015), "How a customer participates matters: 'I am producing' versus 'I am designing' ", Journal of Services Marketing, Vol. 29 Nos 6/7, pp. 498-510.

Dong, B. and Sivakumar, K. (2015), "A processoutput classification for customer participation in services", Journal of Service Management, Vol. 26 No. 5, pp. 726-750.

Dong, B. and Sivakumar, K. (2017), "Customer participation in services: domain, scope, and boundaries", Journal of the Academy of Marketing Science, Vol. 45 No. 6, pp. 944-965.

Dong, B., Sivakumar, K., Evans, K.R., and Zou, S. (2015), "Effect of customer participation on service outcomes: the moderating role of participation readiness", Journal of Service Research, Vol. 18 No. 2, pp. 160-176.

Durrande-Moreau, A. and Usunier, J.-C. (1999), "Time styles and the waiting experience: an exploratory study", Journal of Service Research, Vol. 2 No. 2, pp. 173-186.

Edvardsson, B., Tronvoll, B., and Gruber, T. (2011) "Expanding understanding of service exchange and value co-creation: a social construction approach", Journal of the Academy of Marketing Science, Vol. 39 No. 2, pp. 327-339.

Edvardsson, B., Meiren, T., Schäfer, A., and Witell, L. (2013), "Having a strategy for new service development-does it really matter?", Journal of Service Management, Vol. 24 No. 1, pp. 25-44.

Eisingerich, A.B., Auh, S., and Merlo, O (2014), "Acta Non Verba? The role of customer participation and word of mouth in the relationship between service firms' customer satisfaction and sales performance", Journal of Service Research, Vol. 17 No. 1, pp. 40-53. 
Elg, M., Engström, J., Witell, L., and Poksinska, B. (2012), "Co-creation and learning in healthcare service development", Journal of Service Management, Vol. 23 No. 3, pp. 328-343.

Engström, J. and Elg, M. (2015), "A selfdetermination theory perspective on customer participation in service development", Journal of Services Marketing, Vol. 29 Nos 6/7, pp. 511-521.

Enkel, E., Kausch, C., and Gassmann, O. (2005), "Managing the risk of customer integration", European Management Journal, Vol. 23 No. 2, pp. 203-213.

Etgar, M. (2008), "A descriptive model of the consumer co-production process", Journal of the Academy of Marketing Science, Vol. 36 No. 1, pp. 97-108.

Falk, A. and Fischbacher, U. (2006), "A theory of reciprocity", Games and Economic Behavior, Vol. 54 No. 2, pp. 293-315

Farah, M.F., Hasni, M.J.S., and Abbas, A.K. (2018), "Mobile-banking adoption: empirical evidence from the banking sector in Pakistan", International Journal of Bank Marketing, Vol. 36 No. 7, pp. 1386-1413.

Farrington, C.J. (2016), "Co-designing healthcare systems: between transformation and tokenism", Journal of the Royal Society of Medicine, Vol. 109 No. 10 , pp. 368-371.

Fereday, J. and Muir-Cochrane, E. (2006), "Demonstrating rigor using thematic analysis a hybrid approach of inductive and deductive coding and theme development", International Journal of Qualitative Methods, Vol. 5 No. 1, pp. 80-92.

Ferguson, R.J., Paulin, M., and Bergeron, J. (2010), "Customer sociability and the total service experience: antecedents of positive word-of-mouth intentions", Journal of Service Management, Vol. 21 No. 1, pp. 25-44.

Fishbein, M. and Ajzen, I. (1975), Belief, Attitude, Intention, and Behavior: An Introduction to Theory and Research, Addison-Wesley, Reading, MA.

Fisher, D. and Smith, S. (2011), "Cocreation is chaotic what it means for marketing when no one has control", Marketing Theory, Vol. 11 No. 3, pp. 325-350.
Fisher, R.J. and Grégoire, Y. (2006), "Gender differences in decision satisfaction within established dyads:- effects of competitive and cooperative behaviors", Psychology \& Marketing Vol. 23 No. 4, pp. 313-333.

Flick, U. (2018), “Triangulation", in Denzin, N.K. an Lincoln, Y.S. (Eds.), The SAGE Handbook of Qualitative Research, Sage, London, England, pp. 777-804.

Fornell, C. and Larcker, D.F. (1981), "Evaluating structural equation models with unobservable variables and measurement error", Journal of Marketing Research, Vol. 18 No. 1, pp. 39-50.

Fournier, S. and Lee, L. (2009), "Getting brand communities right", Harvard Business Review, Vol. 87 No. 4, pp. 105-111.

Freire, K. and Sangiorgi, D. (2012), "Service design and healthcare innovation: from consumption to co-production to co-creation" in Holmlid, $S$, Nisula, J.-V., and Clatworthy, S. (Eds.), Proceedings of the 2nd Service Design and Service Innovation Conference on Exchanging Knowledge in Linköping Sweden, 1-3 December 2010, Linköping University Electronic Press, Linköping, Sweden, pp. 39-49.

Frosch, D.L., May, S.G., Rendle, K.A.S., Tietbohl, C., and Elwyn, G. (2012), "Authoritarian physicians and patients' fear of being labeled 'difficult' among key obstacles to shared decision making", Health Affairs, Vol. 31 No. 5, pp. 1030-1038.

Frow, P., Nenonen, S., Payne, A., and Storbacka, K. (2015), "Managing co-creation design: a strategic approach to innovation", British Journal of Management, Vol. 26 No. 3, pp. 463-483.

Fu, J., Hsu, C.W., and I-Wei, L. (2018), "Understanding why customers engage in cocreation behaviors-a psychological ownership perspective", in Tanabu, M. and Senoo, D. (Eds.), Proceedings of the 22 $2^{\text {nd }}$ Pacific Asia Conference on Information Systems on Opportunities and Challenges for the Digitized Society: Are We Ready? in Yokohama, Japan, 26-30 June, 2018, AIS eLibrary, pp. 1-14.

Fuchs, V.R. (1968), The Service Economy, Columbi University Press, New York, NY.
Fujitsu. (2019), "Co-creation in action", available at: https://www.fujitsu.com/global/themes/cocreation/ (accessed 25 May 2019).

Füller, J. (2010), "Refining virtual co-creation from a consumer perspective", California Management Review, Vol. 52 No. 2, pp. 98-122.

Füller, J., Matzler, K., and Hoppe, M. (2008), “Brand community members as a source of innovation", Journal of Product Innovation Management, Vol. 25 No. 6, pp. 608-619.

Gallan, A.S., McColl-Kennedy, J.R., Barakshina, Hibbert, S, Luca, N Roy, S, Spanjol, J. and Winklhofer, H. (2019), "Transforming community well-being through patients' lived experiences", Journal of Business Research, Vol. 100, pp. 376-391.

Galvagno, M. and Dalli, D. (2014), "Theory of value co-creation: a systematic literature review", Managing Service Quality: An International Journal, Vol. 24 No. 6, pp. 643-683.

Gatzweiler, A., Blazevic, V., and Piller, F.T. (2013), "When users take control: managing the dark side of customer co-creation", The ISPIM Magazine, Vol. 3 No. 3, pp. 1-2.

Gatzweiler, A., Blazevic, V., and Piller, F.T. (2017), "Dark side or bright light: destructive and constructive deviant content in consumer ideation contests", Journal of Product Innovation Management, Vol. 34 No. 6, pp. 772-789.

Gebauer, H., Johnson, M., and Enquist, B. (2010), "Value co-creation as a determinant of success in public transport services: a study of the Swiss Federal Railway operator (SBB)", Managing Service Quality: An International Journal, Vol. 20 No. 6, pp. 511-530.

Gemser, G. and Perks, H. (2015), "Co-creation with customers: an evolving innovation research field", Journal of Product Innovation Management, Vol. 32 No. 5, pp. 660-665.

Giannopoulou, E., Gryszkiewicz, L., and Barlatier, P.-J. (2014), "Creativity for service innovation: a practicebased perspective", Managing Service Quality: An International Journal, Vol. 24 No. 1, pp. 23-44.
Gill, L., White, L., and Cameron, I.D. (2011), "Service co-creation in community-based aged healthcare", Managing Service Quality: An International Journal, Vol. 21 No. 2, pp. 152-177.

Gilly, M.C., Graham, J.L., Wolfinbarger, M.F., and Yale, L.J. (1998), "A dyadic study of interpersonal information search", Journal of the Academy of Marketing Science, Vol. 26 No. 2, pp. 83-100.

Godes, D. and Mayzlin, D. (2004), "Using online conversations to study word-of-mouth communication" Marketing Science, Vol. 23 No. 4, pp. 545-560.

Gonzalez, J. (2015), "The big list of class discussion strategies", available at: https:// www.cultofpedagogy.com/speaking-listening techniques/ (accessed 23 April 2019).

Goodman, J.K. and Paolacci, G. (2017), "Crowdsourcing consumer research", Journal of Consumer Research, Vol. 44 No. 1, pp. 196-210.

Gottfridsson, P. (2014), "Different actors' roles in small companies service innovation", Journal of Services Marketing, Vol. 28 No. 7, pp. 547-557.

Goulding, C. (2005), "Grounded theory ethnography and phenomenology: a comparative analysis of three qualitative strategies for marketing research", European Journal of Marketing, Vol 39 Nos 3/4, pp. 294-308.

Graf, A. (2007), "Changing roles of customers consequences for HRM", International Journal of Service Industry Management, Vol. 18 No. 5, pp 491-509.

Gray, D., Brown, S., and Macanufo, J. (2010), Gamestorming: A Playbook for Innovators, Rulebreakers, and Changemakers, O'Reilly Media, Sebastopol, CA.

Green, M.H., Davies, P., and Ng. I.C. (2017), "Two strands of servitization: a thematic analysis of traditional and customer co-created servitizatio and future research directions", International Journal of Production Economics, Vol. 192, pp. 40-53.

Greenhalgh, T., Jackson, C., Shaw, S., and Janamian, T. (2016), "Achieving research impact through co-creation in community-based health services: 
literature review and case study", The Milbank Quarterly, Vol. 94 No. 2, pp. 392-429.

Gremler, D.D. (2004), "The critical incident technique in service research", Journal of Service Research, Vol. 7 No. 1, pp. 65-89

Grönroos, C. (2006), "Adopting a service logic for marketing", Marketing Theory, Vol. 6 No. 3, pp. 317-333.

Grönroos, C. (2008), "Service logic revisited: who creates value? And who co-creates?", European Business Review, Vol. 20 No. 4, pp. 298-314.

Grönroos, C. (2011), "Value co-creation in service logic: a critical analysis", Marketing Theory, Vol. 11 No. 3, pp. 279-301.

Grönroos, C. (2012), "Conceptualising value co-creation: a journey to the 1970 s and back to the future", Journal of Marketing Management, Vol. 28 Nos 13/14, pp. 1520-1534.

Grönroos, C. and Helle, P. (2010), “Adopting a service logic in manufacturing: conceptual foundation and metrics for mutual value creation", Journal of Service Management, Vol. 21 No. 5, pp. 564-590.

Grönroos, C. and Ravald, A. (2011), "Service as business logic: implications for value creation and marketing", Journal of Service Management, Vol. 22 No. 1, pp. 5-22.

Grönroos, C. and Voima, P. (2013), "Critical service logic: making sense of value creation and co-creation", Journal of the Academy of Marketing Science, Vol. 41 No. 2, pp. 133-150.

Guo, L., Arnould, E.J., Gruen, T.W., and Tang, C. (2013), "Socializing to co-produce: pathways to consumers' financial well-being", Journal of Service Research, Vol. 16 No. 4, pp. 549-563.

Guo, L., Lotz, S.L., Tang, C., and Gruen, T.W. (2015), "The role of perceived control in customer value cocreation and service recovery evaluation", Journal of Service Research, Vol. 19 No. 1, pp. 39-56. Gustafsson, A. and Bowen, D.E. (2017), "The curious case of interdisciplinary research deficiency: Cause or symptom of what truly ails us?", Journal of Business Research, Vol. 79, pp. 212-218.

Gustafsson, A., Kristensson, P., and Witell, L. (2012), "Customer co-creation in service innovation: a matter of communication?", Journa of Service Management, Vol. 23 No. 3, pp. 311-327.

Gustafsson, A., Högström, C., Radnor, Z., Friman, M., Heinonen, K., Jaakkola, E., and Mele, C. (2016), "Developing service research - paving the way to transdisciplinary research", Journal of Service Management, Vol. 27 No. 1, pp. 9-20.

Gyrd-Jones, R.I. and Kornum, N. (2013), "Managing the co-created brand: value and cultural complementarity in online and offline multi-stakeholder ecosystems", Journal of Business Research, Vol. 66 No. 9, pp. 1484-1493.

Hair, J.F., Black, W.C., Babin, B.J., and Anderson, R.E. (2014), Multivariate Data Analysis, (7th ed.), Pearson Education Limited, Essex, England.

Haire, M. (1950), "Projective techniques in marketing research", Journal of Marketing, Vol. 14 No. 5, pp. 649-656.

Hausman, A. and Johnston, W.J. (2014), "The role of innovation in driving the economy: lessons from the global financial crisis", Journal of Business Research, Vol. 67 No. 1, pp. 2720-2726.

Harrison-Walker, L.J. (2001), "The measurement of word-of-mouth communication and an investigation of service quality and customer commitment as potential antecedents", Journal of Service Research, Vol. 4 No. 1, pp. 60-75.

Harwood, T. and Garry, T. (2015), "An investigation into gamification as a customer engagement experience environment", Journal of Services Marketing, Vol. 29 Nos 6/7, pp. 533-546.

Heidenreich, S., Wittkowski, K., Handrich, M. and Falk, T. (2015), "The dark side of custome co-creation: exploring the consequences of failed co-created services", Journal of the Academy of Marketing Science, Vol. 43 No. 3, pp. 279-296.
Hellier, P.K., Geursen, G.M., Carr, R.A., and Rickard, J.A. (2003), "Customer repurchase intention: a general structural equation model", European Journal of Marketing, Vol. 37 Nos 11/12, pp. $1762-1800$.

Henseler, J. (2017), "Partial least squares path modeling", in P.S.H. Leeflang, J.E. Wieringa, T.H.A. Bijmolt, and K.H. Pauwels (Eds.), Advanced Methods for Modeling Markets, Springer, Berlin, Germany, pp. 361-381.

Herr, P.M., Kardes, F.R., and Kim, J. (1991), "Effects of word-of-mouth and product-attribute information on persuasion: an accessibilitydiagnosticity perspective", Journal of Consumer Research, Vol. 17 No. 4, pp. 454-462.

Ho, S.Y. and Bodoff, D. (2014), "The effects of web personalization on user attitude and behavior: an integration of the elaboration likelihood model and consumer search theory", MIS Quarterly, Vol. 38 No. 2, pp. 497-520.

Hoffman, D.L., Kopalle, P.K., and Novak, T.P. (2010), "The 'right' consumers for better concepts: identifying consumers high in emergent nature to develop new product concepts", Journal of Marketing Research, Vol. 47 No. 5, pp. 854-865.

Hoyer, W.D., Chandy, R., Dorotic, M., Krafft, M. and Singh, S.S. (2010), "Consumer cocreation in new product development", Journal of Service Research, Vol. 13 No. 3, pp. 283-296.

Hsieh, A.T. and Yen, C.H. (2005), "The effect of customer participation on service providers' job stress", The Service Industries Journal, Vol. 25 No. 7, pp. 891-905.

Hsieh, A.T., Yen, C.H., and Chin, K.C. (2004), "Participative customers as partial employees and service provider workload", International Journal of Service Industry Management, Vol. 15 No. 2, pp. 187-199.

Hsieh, J.K., Chiu, H.C., Wei, C.P., Yen, H.R., and Cheng, Y.C. (2013), "A practical perspective on the classification of service innovations", Journal of Services Marketing, Vol. 27 No. 5, pp. 371-384.

Hsieh, J.P.-A., Rai, A., and Xu, S.X. (2011), "Extracting business value from IT: a sensemaking perspective of post-adoptive use", Management Science, Vol. 57 No. 11, pp. 2018-2039.

Hu, Y. and McLoughlin, D. (2012), "Creating new market for industrial services in nascent fields", Journa of Services Marketing, Vol. 26 No. 5, pp. 322-331.

Hulland, J. (1999), "Use of partial least squares (PLS) in strategic management research: a review of four recent studies", Strategic Management Journal, Vol. 20 No. 2, pp. 195-204.

Hurmelinna-Laukkanen, P. and Ritala, P. (2010), "Protection for profiting from collaborative service innovation", Journal of Service Management, Vol. 21 No. 1, pp. 6-24.

Hussain, S., Sanders, E.B.-N., and Steinert, M (2012), "Participatory design with marginalized people in developing countries: challenges and opportunities experienced in a field study in Cambodia", International Journal of Design, Vol. 6 No. 2, pp. 91-109.

Husserl, E. (1970), The Crisis of European Sciences and Transcendental Phenomenology: An Introduction to Phenomenological Philosophy (D. Carr, Trans.). Northwestern University Press, Evanston, IL.

Hwang, J. and Kim, S. (2011), "Factors affecting successful innovation by content-layer firms in Korea", The Service Industries Journal, Vol. 31 No. 7, pp. 1093-1107.

Ind, N. and Coates, N. (2013), "The meanings of co-creation", European Business Review, Vol. 25 No. 1, pp. 86-95.

Institute for Healthcare Improvement. (2019), "Idea generation tools: brainstorming, affinity grouping, and multivoting", available at: http://www.ihi.org/resources/Pages/Tools/ BrainstormingAffinityGroupingandMultivoting. aspx (accessed 23 April 2019).

Jaakkola, E. and Alexander, M. (2014), "The role of customer engagement behavior in value cocreation: a service system perspective", Journal of Service Research, Vol. 17 No. 3, pp. 247-261. 
Jaakkola, E., Helkkula, A., and AarikkaStenroos, L. (2015), "Service experience cocreation: conceptualization, implications, and future research directions", Journal of Service Management, Vol. 26 No. 2, pp. 182-205.

Jahn, B. and Kunz, W. (2012), "How to transform consumers into fans of your brand", Journal of Service Management, Vol. 23 No. 3, pp. 344-361,

Jasperson, J., Carter, P.E., and Zmud, R.W. (2005), "A comprehensive conceptualization of postadoptive behaviors associated with information technology enabled work systems", MIS Quarterly, Vol. 29 No. 3, pp. 525-557.

Jaziri, D. (2019), "The advent of customer experiential knowledge management approach (CEKM): the integration of offline \& online experiential knowledge", Journal of Business Research, Vol. 94, pp. 241-256.

John, O.P. and Srivastava, S. (1999), "The Bis Five trait taxonomy: history, measurement, and theoretical perspectives", in L.A. Pervin and O.P. John (Eds.), Handbook of Personality: Theory and Research, Vol. 2, The Guilford Press, New York, NY, pp. 102-138.

Kallio, K. and Lappalainen, I. (2015), "Organizational learning in an innovation network: enhancing the agency of public service organizations", Journal of Service Theory and Practice, Vol. 25 No. 2, pp. 140-161.

Karahanna, E., Straub, D.W., and Chervany, N.L. (1999), "Information technology adoption across (I) a cross-sectional comparison of pre-adoption and post-adoption beliefs", MIS Quarterly, Vol. 23 No. 2, pp. 183-213.

Karjaluoto, H., Mattila, M., and Pento, T. (2002), Factors underlying attitude formation towards online banking in Finland", International Journal of Bank Marketing, Vol. 20 No. 6, pp. 261-272.

Kazadi, K., Lievens, A., and Mahr, D. (2016), "Stakeholder co-creation during the innovation process: identifying capabilities for knowledge creation among multiple stakeholders", Journal of Business Research, Vol. 69 No. 2, pp. 525-540.
Kelley, S.W., Donnelly, J.H. Jr, and Skinner, S.J. (1990), "Customer participation in service 66 No. 3, pp. 315-335.

Kelley, T. and Kelley, D. (2013), Creative Confidence: Unleashing the Creative Potential Within Us All, Crown Business, New York, NY.

Kellogg, D.L. and Chase, R.B. (1995) "Constructing an empirically derived measure for customer contact", Management Science, Vol. 41 No. 11, pp. 1734-1749

Kim, D.W., Trimi, S., Hong, S.G., and Lim, S. (2019), "Effects of co-creation on organizational performance of small and medium manufacturers", Journal of Business Research, in press.

Kleijnen, M., de Ruyter, K., and Wetzels, M. (2007), "An assessment of value creation in mobile service delivery and the moderating role of time consciousness", Journal of Retailing, Vol. 83 No. 1 pp. 33-46.

Kock, N. and Lynn, G. (2012), "Lateral collinearity and misleading results in variance-based SEM an illustration and recommendations", Journal of the Association for Information Systems, Vol. 13 No. 7, pp. 546-580.

Koelling, M., Neyer, A.-K., and Moeslein, K.M. (2010) "Strategies towards innovative services: findings from the German service landscape", The Service Industries Journal, Vol. 30 No. 4, pp. 609-620.

Kristal, S., Baumgarth, C., and Henseler, J. (2018), “'Brand play' versus 'Brand attack': the subversion of brand meaning in non-collaborative co-creation by profession Journal of Product \& Brand Management, Vol. 27 No. 3, pp. 334-347.

Kristal, S., Baumgarth, C., Behnke, C., and Henseler, J. (2016), "Is co-creation really a booster for brand equity? The role of co-creation in observer-based brand equity (OBBE)", Journal of Product \& Brand Management, Vol. 25 No. 3, pp. 247-261.

Kuzel, A.J. (1992), "Sampling in qualitative inquiry", in B. Crabtree and W. Miller (Eds.), Doing Qualitative Research, Sage, Newbury Park, CA, pp. 31-44.
Lai, V.S. and Li, H. (2005), "Technology acceptance model for Internet banking: an invariance analysis", Information

Landis, J.R. and Koch, G.G. (1977), “The measurement of observer agreement for categorical data", Biometrics, Vol. 33 No. 1, pp. 159-174.

Laukkanen, T. (2017), "Mobile banking", International Journal of Bank Marketing, Vol. 35 No. 7, pp. 1042-1043.

Lee, M.-C. (2009), "Factors influencing the adoption of Internet banking: an integration of TAM and TPB with perceived risk and perceived benefit", Electronic Commerce Research and Applications, Vol. 8 No. 3, pp. 130-141.

Lehoux, P., Hivon, M., Williams-Jones, B., and Urbach, D. (2011), "The worlds and modalities of engagement of design participants: a qualitative case study of three medical innovations", Design Studies, Vol. 32, No. 4, pp. 313-332.

Levitt, T. (1976), "Industrialization of service", Harvard Business Review, Vol. 54 No. 5, pp. 63-74.

Lewis, M.W. (2000), "Exploring paradox: toward a more comprehensive guide", Academy of Management Review, Vol. 25 No. 4, pp. 760-776.

Li, Y.-M. and Yeh, Y.-S. (2009), "Service quality's impact on mobile satisfaction and intention to use $3 \mathrm{G}$ service", in Sprague, R.H.Jr. (Ed.), Proceedings of the 42nd Hawaii International Conference on System Sciences in Waikoloa, Hawaii, 5-8 January 2009, The Institute of Electrical and Electronics Engineers, Piscataway, NJ, pp. 1140-1149.

Libai, B., Muller, E., and Peres, R. (2009), "The diffusion of services", Journal of Marketing Research, Vol. 46 No. 2, pp. 163-175.

Lin, J.S.C. and Hsieh, C.C. (2011), "Modeling service friendship and customer compliance in high-contact service relationships, Journal of Service Management, Vol. 22 No. 5, pp. 607-631.

Lovelock, C.H. and Young, R.F. (1979), "Look to consumers to increase productivity", Harvard Business Review, Vol. 57 No. 3, pp. 168-178.
Lukersmith, S., Schneider, C.H., Salvador-Carulla, L., Sturmberg, J., Wilson, A., and Gillespie, (2016). What is the State of the Art in PersonCentred Care? An Expert Commentary Brokered by the Sax Institute for the Australian Commissio on Safety and Quality in Health Care. Sax Institute, Ultimo, Australia.

Lusch, R. F. and Nambisan, S. (2015), "Service innovation: a service-dominant logic perspective", MIS Quarterly, Vol. 39 No. 1, pp. 155-175.

Lusch, R.F. and Vargo, S.L. (2006), "Service-dominan logic: reactions, reflections and refinements" Marketing Theory, Vol. 6 No. 3, pp. 281-288.

Luscher, L.S., Lewis, M., and Ingram, A. (2006) "The social construction of organizational change paradoxes", Journal of Organizational Change Management, Vol. 19 No. 4, pp. 491-502.

Lynch, J. G. (1999), "Theory and external validity", Journal of the Academy of Marketing Science, Vol. 27 No. 3, pp. 367-376.

Macdonald, E.K. and Uncles, M.D. (2007), "Consumer savvy: conceptualisation and measurement", Journal of Marketing Management, Vol. 23 No. 5-6, pp. 497-517.

MacInnis, D.J. (2011), "A framework for conceptual contributions in marketing", Journal of Marketing Vol. 75 No. 4, pp. 136-154.

Mager, B. and Sung, T.-J.D. (2011), "Special issue editorial: designing for services", Internationa Journal of Design, Vol. 5 No. 2, pp. 1-3.

Maglio, P.P. and Spohrer, J. (2008), "Fundamentals of service science", Journal of the Academy of Marketing Science, Vol. 36 No. 1, pp. 18-20.

Magnusson, P.R. (2009), "Exploring the contribution of involving ordinary users in ideation of technologybased services", Journal of Product Innovation Management, Vol. 26 No. 5, pp. 578-593.

Magnusson, P.R., Matthing, J., and Kristensson, P. (2003), "Managing user involvement in service innovation: experiments with innovating end users", Journal of Service Research, Vol. 6 No. 2, pp. 111-124. 
Mahr, D., Lievens, A., and Blazevic, V. (2014), "The value of customer cocreated knowledge during the innovation process", Journal of Produc Innovation Management, Vol. 31 No. 3, pp. 599-615.

Mainardes, E.W., Aridelmo, T., and Silveira, R.P.C.d. (2017), "Determinants of co-creation in banking services", International Journal of Bank Marketing, Vol. 35 No. 2, pp. 187-204.

Makanyeza, C. (2017), "Determinants of consumers' intention to adopt mobile banking services in Zimbabwe", International Journal of Bank Marketing, Vol. 35 No. 6, pp. 997-1017.

Malhotra, Y. and Galletta, D. (2005) "A multidimensional commitment model of volitional systems adoption and usage behavior", Journal of Management Information Systems, Vol. 22 No. 1, pp. 117-151

Martins, C., Oliveira, T., and Popovič, A. (2014), "Understanding the Internet banking adoption: a unified theory of acceptance and use of technology and perceived risk application", International Journal of Information Management Vol. 34 No. 1, pp. 1-13.

Martovoy, A. and Santos, J.D. (2012), "Co-creation and co-profiting in financial services", International Journal of Entrepreneurship and Innovation Management, Vol. 16 Nos 1/2, pp. 114-135.

Matthing, J., Sandén, B., and Edvardsson, B. (2004) "New service development: learning from and with customers", International Journal of Service Industry Management, Vol. 15 No. 5, pp. 479-498.

Matthing, J., Kristensson, P., Gustafsson, A., and Parasuraman, A. (2006), "Developing successful technology-based services: the issue of identifying and involving innovative users", Journal of Services Marketing, Vol. 20 No. 5, pp. 288-297.

McColl-Kennedy, J.R., Daus, C.S., and Sparks, B.A. (2003), "The role of gender in reactions to service failure and recovery", Journal of Service Research, Vol. 6 No. 1, pp. 66-82.

McColl-Kennedy, J.R., Hogan, S.J., Witell, L., and Snyder, H. (2017b), "Cocreative customer practices: effects of health care customer value cocreation practices on well-being", Journal of Business Research, Vol. 70, pp. 55-66.

McColl-Kennedy, J.R., Vargo, S.L., Dagger, T.S Sweeney, J.C., and van Kasteren, Y. (2012), "Health care customer value cocreation practice styles", Journal of Service Research, Vol. 15 No. 4, pp. 370-389.

McColl-Kennedy, J.R., Danaher, T.S., Gallan, A.S., Orsingher, C., Lervik-Olsen, L., and Verma R. (2017c), "How do you feel today? Managing patient emotions during health care experiences to enhance well-being", Journal of Business Research, Vol. 79, pp. 247-259.

McColl-Kennedy, J.R., Snyder, H., Elg, M., Witell, L. Helkkula, A., Hogan, S.J., and Anderson, L. (2017a), "The changing role of the health care customer: review, synthesis and research agenda", Journal of Service Management, Vol. 28 No. 1, pp. 2-33.

McSherry, R., Mudd, D., and Campbell, S. (2007), "Evaluating the perceived role of the nurse consultant through the lived experience of healthcare professionals", Journal of Clinical Nursing, Vol. 16 No. 11, pp. 2066-2080.

Mele, C., Colurcio, M., and Russo-Spena, T (2014), "Research traditions of innovation: goodsdominant logic, the resource-based approach, and service-dominant logic", Managing Service Quality: An International Journal, Vol. 24 No. 6 , pp. 612-642.

Melton, H.L. and Hartline, M.D. (2010), "Custome and frontline employee influence on new service development performance", Journal of Service Research, Vol. 13 No. 4, pp. 411-425.

Melton, H. and Hartline, M.D. (2015), "Customer and employee co-creation of radical service innovations", Journal of Services Marketing, Vol. 29 No. 2, pp. 112-123.

Mende, M. and van Doorn, J. (2015), "Coproduction of transformative services as a pathway to improved consumer well-being: findings from a longitudinal study on financial counseling", Journal of Service Research, Vol. 18 No. 3, pp. 351-368.

Merriam, S.B. and Tisdell, E.J. (2015), Qualitative Research: A Guide to Design and Implementation, (4th ed.), Jossey-Bass - A Wiley Brand, San Francisco, CA.

Merz, M.A., Zarantonello, L., and Grappi, S. (2018), "How valuable are your customers in the brand " a customer co-creation value (CCCV) scale", Journal of Business Research, Vol. 82, pp. 79-89.

Meuter, M.L., McCabe, D.B., and Curran, J.M. (2013), "Electronic word-of-mouth versus interpersonal word-of-mouth: are all forms of word-of-mouth equally influential?" Services Marketing Quarterly, Vol. 34 No. 3, pp. 240-256.

Meyer, G.J., Finn, S.E., Eyde, L.D., Kay, G.G. Moreland, K.L., Dies, R.R., Eisman, E.J., Kubiszyn, T.W., and Reed, G.M. (2001), "Psychological testing and psychological assessment: a review of evidence and issues", American Psychologist, Vol. 56 No. 2, pp. 128-165.

Meyer, J.P. and Allen, N.J. (1984), "Testing the 'side-bet theory' of organizational commitment: some methodological considerations", Journal of Applied Psychology, Vol. 69 No. 3, pp. 372-378

Meyer, J.P., Stanley, D.J., Herscovitch, L., and Topolnytsky, L. (2002), "Affective, continuance, and normative commitment to the organization: a meta-analysis of antecedents, correlates, and consequences", Journal of Vocational Behavior Vol. 61 No. 1, pp. 20-52

Mills, P.K. and Morris, J.H. (1986), "Clients as 'partial' employees of service organizations: role development in client participation", Academy of Management Review, Vol. 11 No. 4, pp. 726-735.

Mittal, B. and Lassar, W.M. (1998), "Why do customers switch? The dynamics of satisfaction versus loyalty", Journal of Services Marketing, Vol. 12 No. 3, pp. 177-194.

Moeller, S., Ciuchita, R., Mahr, D., OdekerkenSchröder, G., and Fassnacht, M. (2013), "Uncovering collaborative value creation patterns and establishing corresponding customer roles", Journal of Service Research, Vol. 16 No. 4, pp. 471-487.

Mohammadi, H. (2015), "A study of mobile banking usage in Iran", International Journal of Bank Marketing, Vol. 33 No. 6, pp. 733-759.
Moldovan, S., Goldenberg, J., and Chattopadhyay A. (2011), "The different roles of product originality and usefulness in generating wordof-mouth" International Journal of Research in Marketing, Vol. 28 No. 2, pp. 109-119.

Moliner-Velázquez, B., Ruiz-Molina, M.-E., and Fayos-Gardó, T. (2015), "Satisfaction with service recovery: moderating effect of age in word-ofmouth", Journal of Consumer Marketing, Vol. 32 No. 6, pp. 470-484.

Mondak, J.J., Hibbing, M.V., Canache, D., Seligson, M. A and Anderson, M.R. (2010), "Personality and civic engagement: an integrative framework for the study of trait effects on political behavior", American Political Science Review, Vol. 104 No. 1 pp. 85-110.

Morgan, R.M. and Hunt, S.D. (1994), "The commitmenttrust theory of relationship marketing", Journal of Marketing, Vol. 58 No. 3, pp. 20-38

Mowen, J.C. (2000), The 3M Model of Motivation and Personality: Theory and Empirical Applications to Consumer Behavior, Springer Science \& Business Media, New York, NY

Mukherjee, A. and Malhotra, N. (2006), "Does role clarity explain employee-perceived service quality? A study of antecedents and consequences in call centres", International Journal of Service Industry Management, Vol. 17 No. 5, pp. 444-473.

Mulder, M.R., Rapp, J.M., Hamby, A., and Weaver, T. (2015), "Consumer transformation throug volunteer service experiences", The Service Industries Journal, Vol. 35 Nos 15/16, pp. 865-882.

Murray, J.B., Brokalaki, Z., Bhogal-Nair, A., Cermin, A., Chelekis, J., Cocker, H., Eagar, T., McAlexander, B., Mitchell, N., Patrick, R. Robinson, T., Scholz, J., Thyroff, A., Zavala, M., and Zuniga, M.A. (2019), "Toward a processual theory Zf transformation" Journal of Business Research Vol. 100, pp. 319-326.

Murray, K.B. (1991), "A test of services marketing theory: consumer information acquisition activities", Journal of Marketing, Vol. 55 No. 1, pp. 10-25.

Mustak, M., Jaakkola, E., and Halinen, A. (2013) "Customer participation and value creation: 
a systematic review and research implications, Managing Service Quality: An International Journal, Vol. 23 No. 4, pp. 341-359.

Mustak, M., Jaakkola, E., Halinen, A, and Kaartemo, V. (2016), "Customer participation management: developing a comprehensive framework and a research agenda", Journal of Service Management, Vol. 27 No. 3, pp. 250-275.

Nakarada-Kordic, I., Hayes, N., Reay, S.D., Corbet, C., and Chan, A. (2017), "Co-designing for mental health: creative methods to engage young people experiencing psychosis", Design for Health, Vol. 1 No. 2, pp. 229-244.

Navarro, S., Llinares, C., and Garzon, D. (2016), "Exploring the relationship between co-creation and satisfaction using QCA", Journal of Busines Research, Vol. 69 No. 4, pp. 1336-1339.

Neghina, C., Bloemer, J., van Birgelen, M., and Caniëls, M.C. (2017), "Consumer motives and willingness to co-create in professional and generic services", Journal of Service Management, Vol. 28 No. 1, pp. 157-181.

Neghina, C., Caniëls, M.C., Bloemer, J.M., and an Birgelen, MJ. (2015), "Value cocreation in service interactions: dimensions and antecedents", Marketing Theory, Vol. 15 No. 2, pp. 221-242.

Nielsen, J. (2006), "The 90-9-1 rule for participation inequality in social media and online communities", available at: https://www.nngroup com/articles/participation-inequality/ (accessed 20 March 2019).

Niessen, C., Swarowsky, C., and Leiz, M. (2010), “Age and adaptation to changes in the workplace", Journal of Managerial Psychology, Vol. 25 No. 4, pp. 356-383.

Normann, R. and Ramirez, R. (1993), "From value chain to value constellation: designing interactive strategy", Harvard Business Review, Vol. 71 No. 4, pp. 65-77.

Nunnally, J. (1978), Psychometric Theory, (2nd ed.), McGraw-Hill, New York, NY

Nyilasy, G. (2006), "Word of mouth: what we really know - and what we don't", in Kirby, J. and Marsden, P. (Eds.), Connected Marketing:
The Viral, Buzz and Word of Mouth Revolution, Elsevier, Oxford, London, pp. 161-184.

O’Brien, I.M., Jarvis, W., and Soutar, G.N. (2015), "Integrating social issues and customer engagement to drive loyalty in a service organisation", Journal of Services Marketing, Vol. 29 Nos 6/7, pp. 547-559.

O'Cass, A. and Ngo, L.V. (2011), "Achieving customer satisfaction in services firms via branding capability and customer empowerment", Journal of Services Marketing, Vol. 25 No. 7, pp. 489-496.

O'Hern, M.S. and Rindfleisch, A. (2010), "Customer co-creation: a typology and research agenda", in Malhotra, N.K. (Ed.), Review of Marketing Research, Vol. 6, M.E. Sharpe, New York, NY, pp. 84-106.

Ocloo, J. and Matthews, R. (2016) "From tokenism to empowerment: progressing patient and public involvement in healthcare improvement", $B M$ Qual Saf, Vol. 25 No. 8, pp. 626-632.

Oertzen, A.-S. and Odekerken-Schröder, G. (2019), "Achieving continued usage in online banking. a post-adoption study", International Journal of Bank Marketing, Vol. 37 No. 6, pp. 1394-1418.

Oertzen, A.-S., Odekerken-Schröder, G., Brax S.A., and Mager, B. (2018), "Co-creating servicesconceptual clarification, forms and outcomes" Journal of Service Management, Vol. 29 No. 4, pp. 641-679.

Ogawa, S. and Piller, F.T. (2006), "Reducing the risks of new product development", MIT Sloa Management Review, Vol. 47 No. 2, pp. 65-71.

Oliveira, P. and von Hippel, E. (2011), "Users as service innovators: the case of banking services", Research Policy, Vol. 40 No. 6, pp. 806-818.

Oliveira, P., Zejnilovic, L., Canhão, H., and von Hippel, E. (2015), "Innovation by patients with rare diseases and chronic needs", Orphanet Journal of Rare Diseases, Vol. 10 No. 41, pp. 1-9.

Ordanini, A. and Parasuraman, A. (2011), "Service innovation viewed through a service-dominant logic lens: a conceptual framework and empirical analysis" Journal of Service Research, Vol. 14 No. 1, pp. 3-23.
Osei-Frimpong, K., Wilson, A., and Lemke, F. (2018), "Patient co-creation activities in healthcare service delivery at the micro level: the influence of online access to healthcare information", Technological Forecasting and Social Change, Vol. 126, pp. 14-27.

Osei-Frimpong, K., Wilson, A., and OwusuFrimpong, N. (2015), "Service experiences and dyadic value co-creation in healthcare service delivery: a CIT approach", Journal of Service Theory and Practice, Vol. 25 No. 4, pp. 443-462.

Ostrom, A.L., Parasuraman, A., Bowen, D.E., Patrício Loss, C.A. and Lemon, K. (2015), "Service research priorities in a rapidly changing context", Journal of Service Research, Vol. 18 No. 2, pp. 127-159.

Oxford Dictionaries (2018), "Definition of creation in English", available at: https://en.ox forddictionaries.com/definition/creation (accessed 2 March 2018).

Ozanne, J.L. and Saatcioglu, B. (2008), "Participatory action research", Journal of Consumer Research, Vol. 35 No. 3, pp. 423-439.

Ozment, J. and Morash, E.A. (1994), "The augmented service offering for perceived and actual service quality", Journal of the Academy of Marketing Science, Vol. 22 No. 4, pp. 352-363.

Parthasarathy, M. and Bhattacherjee, A. (1998), "Understanding post-adoption behavior in the context of online services", Information Systems Research, Vol. 9 No. 4, pp. 362-379.

Patel, K.J. and Patel, H.J. (2018), "Adoption of Internet banking services in Gujarat: an extension of TAM with perceived security and social influence", International Journal of Bank Marketing, Vol. 36 No. 1, pp. 147-169.

Patrício, L., Teixeira, J.G., and Vink, J. (2019), "A service design approach to healthcar innovation: from decision-making to sensemaking and institutional change", AMS Review Vol. 9 Nos 1/2, pp. 115-120.

Pavlou, P.A., Liang, H., and Xue, Y. (2007), "Understanding and mitigating uncertainty in online exchange relationships: a principal-agent perspective", MIS Quarterly, Vol. 31 No. 1, pp. 105-136.
Payne, A.F., Storbacka, K., and Frow, P. (2008), "Managing the co-creation of value", Journal of the Academy of Marketing Science, Vol. 36 No. 1 ,pp. 83-96.

Pikkarainen, T., Pikkarainen, K., Karjaluoto, H. and Pahnila, S. (2004), "Consumer acceptance of online banking: an extension of the technology acceptance model", Internet Research, Vol. 14 No. 3, pp. 224-235.

Pinho, N., Beirão, G, Patrício, L., and Fisk, R.P. (2014), "Understanding value co-creation in complex services with many actors", Journal of Service Management, Vol. 25 No. 4, pp. 470-493.

Pirinen, A. (2016), "The barriers and enablers of co-design for services" International Journal of Design, Vol. 10 No. 3, pp. 27-42.

Podsakoff, P.M., MacKenzie, S.B., and Podsakoff N.P. (2012), "Sources of method bias in social science research and recommendations on how to control it", Annual Review of Psychology, Vol. 63, pp. 539-569.

Podsakoff, P.M., MacKenzie, S.B., Lee, J.-Y. and Podsakoff, N.P. (2003), "Common metho biases in behavioral research: a critical review of the literature and recommended remedies", Journa of Applied Psychology, Vol. 88 No. 5, pp. 879-903.

Prahalad, C.K. (2004), "The co-creation of value-invited commentaries on 'evolving to a new dominant logic for marketing' ", Journal of Marketing, Vol. 68 No. 1, p. 23.

Prahalad, C.K. and Ramaswamy, V. (2000), "Coopting customer competence", Harvard Business Review, Vol. 78 No. 1, pp. 79-90.

Prahalad, C.K. and Ramaswamy, V. (2004a), "Cocreating unique value with customers", Strategy e Leadership, Vol. 32 No. 3, pp. 4-9,

Prahalad, C.K. and Ramaswamy, V. (2004b), "Cocreation experiences: the next practice in value creation", Journal of Interactive Marketing, Vol. 18 No. 3, pp. 5-14.

Prpić, J., Shukla, P.P., Kietzmann, J.H., an McCarthy, I.P. (2015), "How to work a crowd 
developing crowd capital through crowdsourcing", Business Horizons, Vol. 58 No. 1, pp. 77-85.

Quero, M.J. and Ventura, R. (2015), "The role of balanced centricity in the Spanish creative industries adopting a crowd-funding organisational model", Journal of Service Theory and Practice, Vol. 25 No. 2, pp. 122-139.

Ramaswamy, V. and Gouillart, F.J. (2010), The Power of Co-Creation: Build It With Them to Boost Growth, Productivity, and Profits, Free Press, New York, NY.

Ramirez, R. (1999), "Value co-production intellectual origins and implications for practice and research", Strategic Management Journal, Vol. 20 No. 1, pp. 49-65.

Ranjan, K.R. and Read, S. (2016), "Value cocreation: concept and measurement", Journal of the Academy of Marketing Science, Vol. 44 No. 3 pp. 290-315.

Reid, M. and Levy, Y. (2008), "Integrating trust and computer self-efficacy with TAM: an empirical assessment of customers' acceptance of banking information systems (BIS) in Jamaica", Journal of Internet Banking and Commerce, Vol. 12 No. 3, pp. 1-17.

Reinholds, A. (2019), "Lessons from Think 2019: co-creating to change the world", available at https://developer.ibm.com/blogs/lessons-fromthink-2019-co-creating-to-change-the-world/ (accessed 25 May 2019).

Revilla-Camacho, M.Á., Vega-Vázquez, M., and Cossío-Silva, F.J. (2015), "Customer participation and citizenship behavior effects on turnove intention", Journal of Business Research, Vol. 68 No. 7, pp. 1607-1611.

Roberts, B.W., Kuncel, N.R., Shiner, R., Caspi, A., and Goldberg, L.R. (2007), "The power of personality: the comparative validity of personality traits, socioeconomic status, and cognitive ability for predicting important life outcomes", Perspective on Psychological Science, Vol. 2 No. 4, pp. 313-345.

Robey, D. (1979), "User attitudes and management information system use", Academy of Managemen ournal, Vol. 22 No. 3, pp. 527-538.
Roederer, C. (2012), "A contribution to conceptualizing the consumption experience: emergence of the dimensions of an experience en Marketing (English ed.), Vol. 27 No. 3, pp. 81-95.

Romero, D. and Molina, A. (2011), "Collaborative networked organisations and custome communities: value co-creation and co-innovation in the networking era", Production Planning \& Control, Vol. 22 Nos 5/6, pp. 447-472.

Rudman, L.A. and Glick, P. (2001), "Prescriptive gender stereotypes and backlash toward agentic women", Journal of Social Issues, Vol. 57 No. 4, pp. $743-762$.

Rusanen, H., Halinen, A., and Jaakkola, E. (2014) "Accessing resources for service innovationthe critical role of network relationships", Journal of Service Management, Vol. 25 No. 1, pp. 2-29.

Russell-Bennett, R., Mulcahy, R., Letheren, K., McAndrew, R., Swinton, T., Horrocks, N., and Ossington, R. (2017), "Innovating energy markets: a hybrid persona/segment approach", in Robinson L., Brennan, L., and Reid, M. (Eds.), Proceedings of the ANZMAC 2017 Conference on Marketing of Impact in Melbourne Australia, 4-6 December,

Russo-Spena, T. and Mele, C. (2012), "'Five co-s' in innovating: a practice-based view", Journal of Service Management, Vol. 23 No. 4, pp. 527-553.

Ryzhkova, N. (2015), "Does online collaboration with customers drive innovation performance?" Journal of Service Theory and Practice, Vol, 25 No. 3, pp. 327-347.

Saarijärvi, H., Kannan, P., and Kuusela, H. (2013), "Value co-creation: theoretical approaches and practical implications", European Business Review Vol. 25 No. 1, pp. 6-19.

Sabherwal, R., Jeyaraj, A., and Chowa, C. (2006), "Information system success: individual and organizational determinants", Management Science, Vol. 52 No. 12 , pp. 1849-1864.

Sangiorgi, D., Farr, M., McAllister, S., Mulvale, G., Sneyd, M., Vink, J., and Warwick, L (2019), "Designing in highly contentious areas perspectives on a way forward for menta healthcare transformation", The Design Journal, Vol. 22 No. sup1, pp. 309-330.

Sargen, D. (2018), "The power of co-creation" available at: https:/wwwibm.com/services/ insights/the-power-of-co-creation (accessed 25 May 2019).

Sarstedt, M., Ringle, C.M., and Hair, J.F. (2017), "Partial least squares structural equation modeling", in Homburg C., Klarmann M., and Vomberg A. (Eds.), Handbook of Market Research, Springer, Cham, Switzerland, pp. 1-40.

Schepers, J., de Jong, A., Wetzels, M., and de Ruyter, K. (2008), "Psychological safety and social support in groupware adoption: a multi-level assessment in education", Computers \& Education, Vol. 51 No. 2, pp. 757-775.

Schumpeter, J.A. (1934), Theories of Economic Development, Harvard University Press, Cambridge, MA.

SDN. (2019), "About service design and SDN what is service design?", available at: https://www. service-design-network.org/about-service-design (accessed 26 July 2019).

Segelström, F. (2013). Stakeholder Engagement for Service Design: How Service Designers Identify and Communicate Insights. ( $\mathrm{PhD}$ thesis), Linköping University Electronic Press, Linköping, Sweden.

Sellen, K. (2018), "Problem based learning. developing competency in knowledge integration in health design", Design and Technology Education: , Deurnal, Vol. 23 No. 3, pp. 86-95.

Sergeeva, N. and Radosavljevic, M. (2012), "Creative participation in construction firms: bridging creativity and innovation", Organization, Technology \& Management in Construction: An International Journal, Vol. 4 No. 2, pp. 490-506.

Shaikh, A.A. and Karjaluoto, H. (2015), "Mobile banking adoption: a literature review", Telematics and Informatics, Vol. 32 No. 1, pp. 129-142.

Sheng, X. and Zolfagharian, M. (2014), "Consumer participation in online product recommendation services: augmenting the technology acceptance model', Journal of Services Marketing, Vol. 28 No. 6, pp. 460-470.
Sheppard, B.H., Hartwick, J., and Warshaw, P.R. (1988), "The theory of reasoned action: a metaanalysis of past research with recommendations for modifications and future research", Journal of Consumer Research, Vol. 15 No. 3, pp. 325-343.

Shi, X., Chumnumpan, P., and Fernandes, K. (2014), "A diffusion model for service products", Journal of Services Marketing, Vol. 28 No. 4, pp. 331-341.

Sigala, M. (2009), "E-service quality and Web 2.0: expanding quality models to include customer participation and inter-customer support", The Service Industries Journal, Vol. 29 No. 10, pp. 1341-1358

Simcock, P., Sudbury, L., and Wright, G. (2006), “Age, perceived risk and satisfaction in consumer decision making: a review and extension", Journal of Marketing Management, Vol. 22 Nos 3/4, pp. 355-377.

Simon, F. and Usunier, J.-C. (2007), "Cognitive, demographic, and situational determinants of service customer preference for personnel-in-contact ove self-service technology", International Journal of Research in Marketing, Vol. 24 No. 2, pp. 163-173.

So, K.K.F., King, C., Sparks, B.A., and Wang Y. (2016), "Enhancing customer relationships with retail service brands: the role of customer engagement", Journal of Service Management Vol. 27 No. 2, pp. 170-193.

Sreejesh, S., Anusree, M.R., and Amarnath, M. (2016), "Effect of information content and form on customers' attitude and transaction intention in mobile banking: moderating role of perceived privacy concern", International Journal of Bank Marketing, Vol. 34 No. 7, pp. 1092-1113.

Steen, M., Manschot, M., and Koning, N.D. (2011) "Benefits of co-design in service design projects", International Journal of Design, Vol. 5 No. 2, pp. 53-60. Stickdorn, M., Hormess, M.E., Lawrence, A., an Schneider, J. (2018), This is Service Design Doing Applying Service Design Thinking in the Real World, O’Reilly Media, Sebastopol, CA.

Strandvik, T., Holmlund, M., and Edvardsson, B. (2012), "Customer needing: a challenge for the seller offering", Journal of Business \& Industrial Marketing, Vol. 27 No. 2, pp. 132-141. 
Sumaedi, S., Juniarti, R.P., and Bakti, I.G.M.Y. (2015), "Understanding trust \& commitment of individual saving customers in Islamic banking: the role of ego involvement", Journal of Islamic Marketing, Vol. 6 No. 3, pp. 406-428.

Sweeney, J.C., Danaher, T.S., and McColl-Kennedy J.R. (2015), "Customer effort in value cocreation activities: improving quality of life and behavioral intentions of health care customers", Journal of Service Research, Vol. 18 No. 3, pp. 318-335.

Sweeney, J.C., Soutar, G.N., and Mazzarol, T. (2005), "The difference between positive and negative word-of-mouth - emotion as a differentiator", in Purchase, S. (Ed.), Proceedings of the ANZMAC 2005 Conference on Broadening the Boundaries in Fremantle, Western Australia, 5-7 December 2005, The University of Weste Australia, Perth, Australia, pp. 331-337.

Sweeney, J.C., Soutar, G.N., and Mazzarol, T. (2012), "Word of mouth: measuring the power of individual messages", European Journal of Marketing, Vol. 46 Nos 1/2, pp. 237-257.

Tabachnick, B.G. and Fidell, L.S. (2013), Using Multivariate Statistics (6th ed.), Pearson, Boston, MA.

Tam, C. and Oliveira, T. (2017a), "Literature review of mobile banking and individual performance", International Journal of Bank Marketing, Vol. 35 No. 7, pp. 1044-1067.

Tam, C. and Oliveira, T. (2017b), "Understanding mobile banking individual performance: the DeLone \& McLean model and the moderating effects of individual culture", Internet Research, Vol. 27 No. 3 , pp. 538-562.

Tam, K.Y. and Ho, S.Y. (2005), "Web personalization as a persuasion strategy: an elaboration likelihood model perspective", Information Systems Research Vol. 16 No. 3, pp. 271-291.

Tari Kasnakoglu, B. (2016), "Antecedents and consequences of co-creation in credence-based service contexts", The Service Industries Journal, Vol. 36 Nos 1/2, pp. 1-20.

Taylor, S. and Todd, P.A. (1995), “Understanding information technology usage: a test of competing models", Information Systems Research, Vol. 6 No. 2, pp. 144-176.

Teo, T. (2011), "Factors influencing teachers" intention to use technology: model development and test", Computers \& Education, Vol. 57 No. 4 pp. 2432-2440

Terziovski, M. and Dean, A. (1998), "Best predictors of quality performance in Australia service organisations", Managing Service Quality: An International Journal, Vol. 8 No. 5, pp. 359-366.

Thomas, D.R. (2006), "A general inductive approach for analyzing qualitative evaluation data", American Journal of Evaluation, Vol. 27 No. 2, pp. 237-246.

Thomas, J. and Harden, A. (2008), "Methods for the thematic synthesis of qualitative research in systematic reviews", BMC Medical Research Methodology, Vol. 8 No. 45, pp. 1-10.

Thompson, C.J. (1997), "Interpreting consumers: a hermeneutical framework for deriving marketing insights from the texts of consumers' consumption stories", Journal of Marketing Research, Vol. 34 No. 4, pp. 438-455.

Thompson, C.J., Locander, W.B., and Pollio, H.R. (1990), "The lived meaning of free choice an existential-phenomenological description of everyday consumer experiences of contemporary married women", Journal of Consumer Research Vol. 17 No. 3, pp. 346-361.

Thomson Reuters (2015), "Web of Science Socia Sciences Citation Index", available at: http://ip science.thomsonreuters.com/mjl/publist_ssci.pdf (accessed 1 December 2016).

Tian, K., Sautter, P., Fisher, D., Fischbach, S., LunaNevarez, C., Boberg, K., Kroger, J., and Vann, R. (2014), "Transforming health care: empowering therapeutic communities through technologyenhanced narratives", Journal of Consumer Research, Vol. 41 No. 2, pp. 237-260

Tobiasson, H.M., Sundblad, Y., Walldius, Å., and Hedman, A. (2015), "Designing for active life: moving and being moved together with dementia patients" International Journal of Design, Vol. 9 No. 3, pp. 47-62.
Toegel, G. and Barsoux, J.-L. (2012), "How to become a better leader", MIT Sloan Managemen Review, Vol. 53 No. 3, pp. 51-60.

Toivonen, M. and Tuominen, T. (2009), "Emergence of innovations in services", The Service Industries Journal, Vol. 29 No. 7, pp. 887-902.

Tommasetti, A., Troisi, O., and Vesci, M. (2017), "Measuring customer value co-creation behavior: developing a conceptual model based on servicedominant logic", Journal of Service Theory and Practice, Vol. 27 No. 5, pp. 930-950.

Trischler, J., Kristensson, P., and Scott, D. (2018a), "Team diversity and its management in a co-design team", Journal of Service Management, Vol. 29 No. 1, pp. 120-145.

Trischler, J., Zehrer, A., and Westman, J. (2018b), "A designerly way of analyzing the customer experience", Journal of Services Marketing, Vol. 32 No. 7, pp. 805-819.

Trischler, J., Pervan, S.J., Kelly, S.J., and Scott, D.R. (2018c), "The value of codesign: the effect of customer involvement in service design teams", Journal of Service Research, Vol. 21 No. 1, pp. 75-100.

Tsekleves, E. and Cooper, R. (2017), "Emerging trends and the way forward in design in healthcare: an expert's perspective", The Design Journal, Vol. 20 No. sup1, pp. 2258-2272.

Tung, W., Liang, A.R.-D., and Chen, S.-C. (2014), "The influence of service orientation and interaction orientation on consumer identification", The Service Industries Journal, Vol. 34 No. 5, pp. 439-454.

Vahdat, S., Hamzehgardeshi, L., Hessam, S., and Hamzehgardeshi, Z. (2014) "Patient involvement in health care decision making: a review”, Iranian Red Crescent Medical Journal, Vol. 16 No. 1, pp. 1-7.

Van Raaij, E.M. and Schepers, J.J. (2008), "The acceptance and use of a virtual learning environment in China" Computers \& Education Vol. 50 No. 3, pp. 838-852.

Vargo, S.L. and Lusch, R.F. (2004), "Evolving to a new dominant logic for marketing", Journal of Marketing, Vol. 68 No. 1, pp. 1-17.
Vargo, S.L. and Lusch, R.F. (2008), “Service-dominant logic: continuing the evolution", Journal of the Academ of Marketing Science, Vol. 36 No. 1, pp. 1-10.

Vargo, S.L. and Lusch, R.F. (2016), "Institution and axioms: an extension and update of servicedominant logic", Journal of the Academy of Marketing Science, Vol. 44 No. 1, pp. 5-23.

Vargo, S.L., Maglio, P.P., and Akaka, M.A. (2008) "On value and value co-creation: a service systems and service logic perspective", European Management Journal, Vol. 26 No. 3, pp. 145-152.

Vega-Vazquez, M., Revilla-Camacho, M.A., and Cossío-Silva, F.J. (2013), "The value co-creatio process as a determinant of customer satisfaction Management Decision, Vol. 51 No. 10, pp. 1945-1953.

Venkatesh, V. (2006), "Where to go from here? Thoughts on future directions for research on individual-level technology adoption with a focu on decision making", Decision Sciences, Vol. 37 No. 4, pp. 497-518.

Venkatesh, V. and Bala, H. (2008), "Technology acceptance model 3 and a research agenda on interventions", Decision Sciences, Vol. 39 No. pp. 273-315.

Venkatesh, V. and Davis, F.D. (2000), "A theoretica extension of the technology acceptance model four longitudinal field studies", Management Science, Vol. 46 No. 2, pp. 186-204.

Venkatesh, V. and Morris, M.G. (2000), "Why don't me ever stop to ask for directions? Gender, social influence and their role in technology acceptance and usage behavior,"MIS Quarterly, Vol. 24 No. 1, pp. 115-139.

Venkatesh, V., Davis, F., and Morris, M.G. (2007), "Dead or alive? The development, trajectory and future of technology adoption research", Journal of the Association for Information Systems, Vol. 8 No. 4, pp. 267-286.

Venkatesh, V., Thong, J.Y., and Xu, X. (2012), "Consumer acceptance and use of information technology: extending the unified theory of acceptance and use of technology", MIS Quarterly, Vol. 36 No. 1, pp. 157-178. 
Venkatesh, V., Morris, M.G., Davis, G.B., and Davis, F.D. (2003), "User acceptance of information technology: toward a unified view", MIS Quarterly Vol. 27 No. 3, pp. 425-478.

Verhoef, P.C., Beckers, S.F., and van Doorn, J. (2013), "Understand the perils of co-creation", Harvard Business Review, Vol. 91 No. 9, p. 28.

Verleye, K. (2015), "The co-creation experience from the customer perspective: its measurement and determinants", Journal of Service Management Vol. 26 No. 2, pp. 321-342.

Verrinder, J. (2012), "E.ON and 100\% open launch crowdsourcing project", available at: www. research-live.com/article/news/eon-and-100openlaunch-crowdsourcing-project/id/4006939 (accessed 3 November 2016).

Vink, J. and Oertzen, A.-S. (2018), "Integrating empathy and lived experience through co-creation in service design", in Meroni, A., Ospina Medina, A.M., and Villari, B. (Eds.), Proceedings of the 6th Service Design and Innovation Conference on Proof of Concept in Milano, Italy, 18-20 June 2018, Linköping University Electronic Press, Linköping, Sweden, pp. 471-483.

Vink, J., Edvardsson, B., Wetter-Edman, K., and Tronvoll, B. (2019), "Reshaping mental models enabling innovation through service design", Journal of Service Management, Vol. 30 No. 1, pp. 75-104.

Von Hippel, E. (1986), "Lead users: a source of novel product concepts", Management Science, Vol. 32 No. 7, pp. 791-805.

Voorberg, W.H., Bekkers, V.J., and Tummers, L.G. (2015), "A systematic review of co-creation and coproduction: embarking on the social innovation journey", Public Management Review, Vol. 17 No. 9 pp. 1333-1357.

Vroom, V.H. (1964), Work and Motivation, John Wiley \& Sons, New York, NY.

Wagner, J.M. (2004), "Lived experience of critically ill patients' family members during cardiopulmonary resuscitation", American Journal of Critical Care, Vol. 13 No. 5, pp. 416-420.
Wang, M., Cho, S., and Denton, T. (2017), "The impact of personalization and compatibility with past experience on e-banking usage", with past experience on e-baking 35 No. 1, pp. 45-55.

Wasswa Katono, I. (2011), "Student evaluation of e-service quality criteria in Uganda: the case of automatic teller machines", International Journal of Emerging Markets, Vol. 6 No. 3, pp. 200-216.

Weijters, B., Rangarajan, D., Falk, T., and Schillewaert, N. (2007), "Determinants and outcomes of customers' use of self-service technology in a retail setting", Journal of Service Research, Vol. 10 No. 1, pp. 3-21.

Westbrook, R.A. (1987), "Product/consumptionbased affective responses and postpurchas processes", Journal of Marketing Research, Vol. 24 No. 3, pp. 258-270.

Wetzels, M., Odekerken-Schröder, G., and van Oppen, C. (2009), "Using PLS path modeling for assessing hierarchical construct models: guideline and empirical illustration", MIS Quarterly, Vol. 33 No. 1, pp. 177-195.

Williams, F. and Jeanetta, S.C. (2016), "Lived experiences of breast cancer survivors after diagnosis, treatment and beyond. qualitative study", Health Expectations, Vol. 19 No. 3, pp. 631-642

Witell, L., Kristensson, P., Gustafsson, A., an Löfgren, M. (2011), "Idea generation: custome co-creation versus traditional market research techniques", Journal of Service Management, Vol. 22 No. 2, pp. 140-159.

Witell, L., Snyder, H., Gustafsson, A., Fombelle, P., and Kristensson, P. (2016), "Defining service innovation: a review and synthesis", Journal of Business Research, Vol. 69 No. 8, pp. 2863-2872.

Woodruff, R.B. and Flint, D.J. (2006), "Marketing's service-dominant logic and customer value", in R.F. Lusch and S.L. Vargo (Eds.), The Service-Dominant Logic of Marketing: Dialog, Debate, and Directions, Routledge, New York, NY, pp. 183-195.

World Health Organization. (2015), People-Centred and Integrated Health Services: An Overview of the Evidence. World Health Organization, Geneva, Switzerland.

World Health Organization. (2016), "Framework on integrated, people-centred health services", available t: http://apps who int/gb/ebwha/pdf files/WHA69/ A69_39-en.pdf?ua=1 (accessed 30 May 2019).

Wu, C.H.-J. (2011), "A re-examination of the antecedents and impact of customer participation in service", The Service Industries Journal, Vol. 31 No. 6, pp. 863-876.

Xia, L. and Suri, R. (2014), "Trading effort for money: consumers' cocreation motivation and the pricing of service options", Journal of Service Research, Vol. 17 No. 2, pp. 229-242.

Xie, C., Bagozzi, R.P., and Troye, S.V. (2008), Trying to prosume: toward a theory of consumers as co-creators of value", Journal of the Academy of Marketing Science, Vol. 36 No. 1, pp. 109-122.

Xu, Y., Marshall, R., Edvardsson, B., and Tronvoll, B. (2014), "Show you care: initiating co-creation in service recovery”, Journal of Service Management, Vol. 25 No. 3, pp. 369-387.

Yee, K. (2019), "Interactive techniques", available at: https://www.usf.edu/atle/documents/handoutinteractive-techniques.pdf (accessed 2304 2019).

Yen, H.J.R., Gwinner, K.P., and Su, W. (2004), "The impact of customer participation and service expectation on locus attributions following service failure", International Journal of Service Industry Management, Vol. 15 No. 1, pp. 7-26.

Yi, Y. and Gong, T. (2013), "Customer value co-creation behavior: scale development and validation," Journal of Business Research, Vol. 66 No. 9, pp. 1279-1284.

Yim, C.K., Chan, K.W., and Lam, S.S. (2012), "Do customers and employees enjoy service participation? Synergistic effects of self-and other-efficacy", Journal of Marketing, Vol. 76 No. 6, pp. 121-140.

Yoon, M.H., Seo, J.H., and Yoon, T.S. (2004), "Effects of contact employee supports on critical employee responses and customer service evaluation", Journal of Services Marketing, Vol. 18 No. 5, pp. 395-412.

Zaichkowsky, J.L. (1985), "Measuring the involvement construct", Journal of Consumer Research, Vol. 12 No. 3, pp. 341-352.

Zeithaml, V.A., Bitner, M.J., and Gremler, D.D. (2017), Services Marketing: Integrating Customer Focus Across the Firm, (7th ed.), McGraw-Hill Education, New York, NY.

Zhang, T., Lu, C., Torres, E., and Chen, P.-J. (2018), "Engaging customers in value co-creation or codestruction online", Journal of Services Marketing Vol. 32 No. 1, pp. 57-69.

Zwass, V. (2010), "Co-creation: toward a taxonom and an integrated research perspective", International Journal of Electronic Commerce, Vol. 15 No. 1, pp. 11-48.

Zwick, D., Bonsu, S.K., and Darmody, A. (2008), "Putting consumers to work: co-creation and new marketing govern-mentality", Journal of Consumer Culture, Vol. 8 No. 2, pp. 163-196. 


\section{Valorisation Addendum}




\section{Knowledge Valorisation}

In order to disseminate the research beyond academic boarders and make it more accessible for other audiences, doctoral dissertations at Maastricht University include an addendum of valorisation. As stated in Appendix 4, Article 22, of the Regulation Governing the Attainmen of Doctoral Degrees, this knowledge valorisation refers to the "process of creating value from knowledge, by making knowledge suitable and/or available for social (and/or economic) use and by making knowledge suitable for translation into competitive products, services, processes and new commercial activities" (Waardevol: Indicatoren voor Valorisatie report by the National Valorisation Committee, 2011, p. 8). In this dissertation's addendum, I thus outline how knowledge valorisation was pursued and discuss the relevance of the newly generated knowledge for other stakeholders, such as service managers, service designers, policy makers, educators, and society at large.

\section{Knowledge Valorisation Pursuit}

Generating new knowledge applicable for different audiences was encapsulated in the interwoven academic and practical elements of my Ph.D. position, which included being an Early Stage Researcher in the Service Design for Innovation Network (SDIN), a Marie Curie training network funded by the European Union's Horizon 2020 Research and Innovation Programme. The objective of SDIN was to create agents of change that leapfrog service innovation in European organisations through service design. SDIN held bi-annual meetings with academic and non-academic partners, which shaped the practical and academic relevance of this dissertation's research. My specific position at SDIN involved being employed by the Köln International School of Design in Germany and being enrolled at the School of Business and Economics at Maastricht University in the Netherlands. Besides these interdisciplinary academic affiliations, I engaged in a substantial amount of non-academic training through two almost five-months-long research visits at the Service Design Network (SDN) in Cologne, Germany and Patient Innovation in Lisbon, Portugal. Both secondments significantly broaden the applicability of my research for different audiences. Being at the headquarters of the international SDN, strengthened my understanding of the importance of service design for services co-creation and the way designers leverage service design as a process, a toolbox, and a mind-set. The visit at the non-profit platform Patient Innovation allowed me to explore how patients and caregivers use co-creation in the development of innovations, fuelling institutiona transformation towards people-centred care in the process.

Besides being located at interdisciplinary, international, and innovative organisation throughout my Ph.D., I disseminated my research to different audiences by publishing in academic journals (e.g., Journal of Service Management, International Journal of Bank Marketing) and non-academic journals (e.g., Touchpoint). As Table C.2 illustrates, I presented the research findings at various international academic- and practitioner-oriented events, 
which supported me to establish feedback loops, evolving this research by taking different perspectives into account

\section{Knowledge Valorisation Content}

Chapter 1. Amid the complexity of leveraging co-creation efforts in practice, this chapter provides important implications for service managers, service designers, and people participating in co-creation efforts by reviewing and clarifying the conceptual properties, forms, and outcomes of the concept of co-creating services. First, the conceptual pluralism surrounding co-creating services leaves practitioners wondering about its practical relevance. Through integrative work, this chapter generates a less abstract understanding of co-creation by connecting it to topics that are more familiar than "value," such as the phases of the service process and the experience-centric typology of outcomes. By providing industry practices for different co-creation forms, this chapter shows that co-creation may take place in earlier phases of the service process (regenerative co-creation) or in later phases (operative cocreation). Practitioners can leverage co-creation to find new ideas through idea crowdsourcing or by involving lead users in early stages of the service process. Co-creation workshops are a great way to co-design solutions that improve the service experience; for instance, DHL invites selected stakeholders to participate in co-creation workshops, which have resulted in innovative solutions such as the Parcelcopter, a drone enabling rapid parcel delivery. Open

\section{Table VA.1. Exemplary academic- and practitioner-oriented events}

\begin{tabular}{|c|c|}
\hline Exemp & xemplary practitioner-oriented events \\
\hline & - \\
\hline Wo & am, Netherlands (2016) \\
\hline - Presentation at the & - Panel member at the Service Design for Innovation \\
\hline Naples, Italy (2017) & Conference in Cologne, Germany (2017) \\
\hline - Presentation at the International Research & e Köln \\
\hline vice Excellence in Management & International School of Design on Service Design \\
\hline Conference in Port & Basics in Colo \\
\hline Present & n Service \\
\hline Group & (2019) \\
\hline $\begin{array}{l}\text { - Presentation at the Service Design and } \\
\text { Innovation Conference in Milan, Italy (2018) }\end{array}$ & $\begin{array}{l}\text { - Presentation at the Service Design for Innovation } \\
\text { Conference in Porto, Portugal (2019) }\end{array}$ \\
\hline $\begin{array}{l}\text { - Presentation at the Australia and New Zealand } \\
\text { Marketing Conference in Adelaide, } \\
\text { Australia (2018) }\end{array}$ & $\begin{array}{l}\text { Workshop and presentation at a Service Design } \\
\text { and Co-Creation Event hosted on the premises } \\
\text { of Koos Service Design together with the Dutch } \\
\text { SDN Chapter in Amsterdam, Netherlands (2019) }\end{array}$ \\
\hline $\begin{array}{l}\text { - Presentation and collaboration at the Co- } \\
\text { Creation in Service and Customer Engagement } \\
\text { Symposium in Adelaide, Australia (2018) }\end{array}$ & $\begin{array}{l}\text { - Panel member at the Bauhaus } 4.0 \text { meets Service } \& \\
\text { Interaction Design event organised by the Deutscher } \\
\text { Designtag in Bremen, Germany (2019) }\end{array}$ \\
\hline
\end{tabular}

service innovation enables firms to co-test their solutions, and services can be co-launched by sharing responsibility for advertising with customers. In later stages of the service process, practitioners can encourage co-creation through co-producing experiences (i.e., IKEA coproducing family living by guiding its customers to assemble their own furniture) or coconsuming an experience in brand communities (i.e., Harley-Davidson interacting with its customers in the Harley Owners Group, HOG). By evaluating the desired co-creation outcomes, practitioners can understand in which phase(s) of the service process to encourage co-creation efforts. For instance, co-creation in very early phases of the service process can lead to novel ideas, in somewhat later phases it helps to innovate service experiences, subsequently it may be used to validate and refine service concepts, while towards the end it supports service delivery and consumption. Second, Chapter 1 develops a typology of the potential beneficial and counterproductive outcomes following co-creating services. This typology provides service managers and service designers with an important rationale to garner top-level management support for their co-creation endeavours due to the beneficial outcomes following co-creation. Practitioners seeking to co-create may emphasise a better provider image following co-creation increased job satisfaction, the potential for improving contract retention of customers, or accelerated market performance and service quality performance. Additionally, the findings of this chapter help practitioners in their search for appropriate incentives for the people participating in co-creation efforts. For instance, service managers may encourage customers participation and engagement in co-creation efforts by highlighting either the recognition customers can get from co-creating, the personal enjoyment, or the monetary compensation. At the same time, the typology raises awareness for the counterproductive outcomes, for which service managers and policy makers may need to install appropriate strategies. Co-creation efforts can require clarification and service protection to diffuse uncertainty about service ownership, or they may need additional practices to reduce employees' job stress, role conflict, and perceived workload.

Chapter 2. While practitioners generally praise co-creation efforts, the reality is that only very few users are willing to be engaged in services co-creation. This chapter provides practitioners with important implications for designing the co-creation activity, inviting participants, and encouraging them to engage in co-creation. To do so, it explores the drivers of co-creation behaviours and engagement of "normal" users, that is, non-lead users. Scenario-based experiments with 633 participants evidence that users' personality traits and demographics, such as age and gender, influence their behaviours during co-creation. Interactive research workshops with 38 design professionals further confirm that users' co-creation engagement is affected by their personality traits and demographics. Service managers and service designers need to take these insights into account when designing co-creation activities. If a co-creation activity seeks to involve participants that are generally more challenging to engage in cocreation efforts, such as older men who are highly extraverted and exhibit dominant behaviours, it should be explicitly designed to encourage favourable behaviours and engagement of this target group. This can be done by allowing more time for task introduction or integrating quick 
activities that encourage teamwork. Second, while this chapter suggests that users' co-creation engagement is dependent on the participating party, it is further reliant on the facilitating party guiding the co-creation activity, which could be a service manager or service designer. This is an important finding that necessitates practitioners to devote close attention to the factors that they control, such as the purpose of the context or whether employees receive training for facilitating co-creation. The physical and psychological environment of the co-creation activity should be designed to encourage a conducive and safe space to co-create, which practitioners can achieve by encouraging teamwork, ensuring that every voice is heard, reducing hierarchica thinking, and building an atmosphere that is playful, but not childish. Additionally, this chapter holds a substantial economic consequence pertaining to the costly nature of identifying, recruiting, and motivating potential collaborators for co-creation. Service managers and service designers can leverage the newly developed typology of personas and anti-personas to identify and select users with a high likelihood to co-create based on their traits and demographics. For instance, the "enthusiastic people-connector" or "empowering leader" are users possessing attributes that make them likely to co-create, such as being social and empathic, preferring teamwork over individual work, and empowering and triggering enthusiasm in others. On the other hand, the "forthright authority" or "number-crunching corporate" represent users that are less likely to engage in co-creation due to their tendencies to be dominant, clarityneeding, generally more close-minded, and focused on facts and details. Deliberately choosing participants and formulating attractive value propositions for them can increase the chances that they will be actively engaged in the co-creation activity and display favourable behaviours, fostering successful co-creation outcomes.

Chapter 3. I would like to demonstrate this chapter's value by asking the following question:

"Imagine you are travelling through the hospital in a wheelchair as part of a service design activity. Does this really help you understand what the experience is like for patients, who use a wheelchair every day, possibly for the rest of their lives?"

Most people that I have asked this question have suggested that this activity would help them empathise with the patients, but not ensure that they truly understand the patients' experience. To innovate services that are a close match with people's needs, it is essential to integrate their lived experience. By zooming in on how to integrate people's lived experience through cocreation in healthcare innovation, the third chapter provides implications for practitioners, policy makers, educators, and society at large. Based on 23 phenomenological interviews with patients, family caregivers, designers, and healthcare professionals, this research suggests six tensions and seven strategies for integrating people's lived experience through co-creation in healthcare innovation. On a micro-level, these findings guide practitioners regarding the possible implications of the strategies they employ during co-creation amid complex healthcare dynamics. For instance, the "simulating" strategy replicates the lived experience of others through activities such as role-playing a situation, and the "presencing" strateg uses empathy and knowledge from second-hand experience to represent others. While both strategies are viable approaches when people with first-hand experience are not available, the recruitment is overly costly, or the process is too time-consuming, they run the risk of falsely representing people's lived experience. On the other hand, "allying" is a long-term strategy that enables continuous partnerships, such as when someone with first-hand knowledge participates throughout the course of a healthcare innovation project that is steered by a designer. Although this strategy allows for truly integrating people's lived experience through continuous sharing, it can be slow, resource consuming, and is still influenced by power dynamics inherent in the partnership. Raising awareness of the interacting tensions of integrating lived experience is essential for supporting genuine services co-creation that goes beyond tokenistic approaches and avoids a participation façade. On a macro-level, the insights contribute to the transformation of healthcare systems towards people-centred care. The World Health Organization has been advocating for integrated people-centred health services for decades, however progress has been slow. Unveiling the underlying dynamics of integrating people's lived experience helps explain the limitations of existing co-creation initiatives in healthcare innovation. This knowledge can inform policy makers and educators in establishing more conducive practices that reduce power imbalances and allow for multi-directional communication, fostering genuine services co-creation between patients, caregivers, healthcare professionals, and other actors, and ultimately contributing to the institutional change towards people-centred care.

Chapter 4. In practice, innovating and launching services generally receives much more attention than the post-adoption phase of these services. However, economic profits from services are often made in the phase after the initial adoption decision, when users continuously engage with different features of the service and build a long-term relationship to the service provider. Chapter 4 offers several implications by developing and testing a post-adoption model of a co-creative financial service with 750 current customers of a large bank. First, this research demonstrates to service managers that the post-adoption phase of services is decisive in determining the worth of current customers and the potential to attract new customers. For instance, practitioners need to consider the dual perspective of word-of-mouth (WOM) that includes how current customers receive WOM, but also how the sending of WOM may affect potential customers. A second finding is the substantial influence of customers' age on their post-adoption behaviours. While younger customers exhibited the most favourable attitudes towards and highest intentions to continue using the examined service, older customers used it more and shared more WOM. This finding affirms the effect of demographics found in Chapter 2 and highlights to managers the importance of using different strategies for corresponding demographic profiles. For the post-adoption phase of the examined co-creative financial service, managers could incentivise customers in their 30s and 40s through loyalty programs to send WOM, because these age groups are least likely to do so. Customers in their 50s should be subject to strategies that emphasise the usefulness of the service, for instance by explaining its advantages and different functions, as this age group scored lowest on 
perceived usefulness. Third, in contrast to goods, services are usually not a one-time purchase decision, but characterised by multiple exchanges. Service managers seeking to build long-term relationships with their customers are encouraged to form strategic goals to minimise custome churn, for instance by identifying and recovering dissatisfied customers and the factors influencing their intentions to discontinue using the service. The findings of Chapter 4 show that the perceived usefulness of a service, customers' attitude towards using it, and the WOM they receive, positively predict their intentions to continue using it. Therefore, these concepts should be the primary targets of service managers' efforts to reduce customer churn in the postadoption phase of a co-creative service.

In conclusion, this dissertation advises service managers, service designers, policy makers, and educators who want to leverage co-creation efforts, to purposefully evaluate the benefits and process of co-creating services. The typology of outcomes of Chapter 1 demonstrates the benefits of co-creation for the organisation, such as a better image, increased job satisfaction, or accelerated market performance, which practitioners can use to gather organisational buy-in. People participating in co-creation efforts can be incentivised through monetary compensation, recognition, or purely by the enjoyment experienced during cocreating. However, practitioners should also prepare strategies for potential counterproductive outcomes, such as installing service protection mechanisms to diffuse uncertainty about service ownership. To determine at which stage of the service process to engage in co-creation efforts, it is recommendable to envision the desired co-creation outcomes. In very early phases of the service process, co-creation can lead to novel ideas; in somewhat later phases, it helps to innovate, validate, and refine service concepts; towards the end, it supports a smooth service delivery and a superior consumption experience. To evaluate the likelihood of participants to co-create, Chapter 2 provides insights into people's demographics and personality traits and their effects on co-creation engagement and behaviours. While some user profiles, such as the "enthusiastic people-connector," are relatively easy to engage in co-creation, users simila to the "number-crunching corporate" are more challenging to engage in co-creation and necessitate more effort, for instance through allowing more time to familiarise participants with co-creation. Besides carefully evaluating the co-creation participants, practitioners are advised to devote close attention to factors that the facilitating party controls. For example, preparing the physical facilities and creating a safe psychological space for co-creation by encouraging teamwork and building an atmosphere that is playful but not childish, are drivers of participants' co-creation engagement that can be controlled by the facilitating party. Chapter 3 identifies the contextual tensions that practitioners should be mindful of when integrating their own experience and the experience of others. It further supplies a spectrum of different strategies to integrate lived experience in healthcare innovation with varying implications. While some strategies require limited resources but risk falsely representing people's lived experience, other strategies can truly integrate people's lived experience but may be slow and resource consuming. It is important that practitioners are aware of these tradeoffs to install practices and policies that foster genuine services co-creation, by reducing powe imbalances and allowing for multi-directional communication. Finally, Chapter 4 recommends the implementation of strategies for the post-adoption phase after the initial adoption decision of a co-creative service to influence the worth of current customers and the potential to attract new ones. 
About the Author 
Anna-Sophie Oertzen was born in Hamburg, Germany, on 5 January 1993. Supported by an academic scholarship, she completed her high school education at King's College Taunton in the United Kingdom, earning her best graduate in Business Studies in 2010. She went on to receive her Bachelor degree in International Business with distinction (cum laude) from the School of Business and Economics of Maastricht University in the Netherlands, which included an exchange semester at Copenhagen Business School in Denmark. Thereafter, she started a double degree program, resulting in a Master's degree with distinction (cum laude) in International Business, specialising in Strategy and

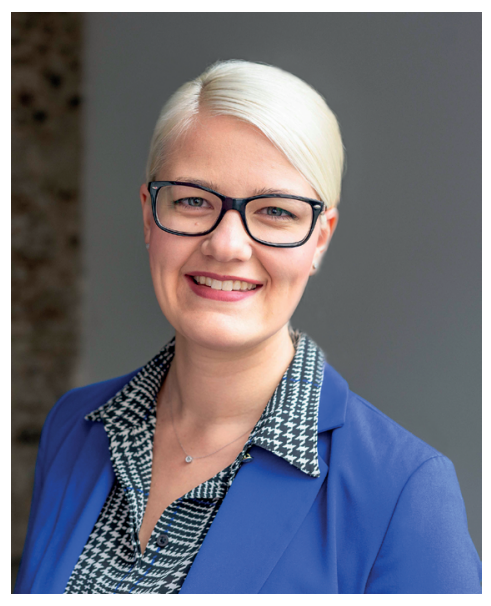

Innovation, from the School of Business and Economics of Maastricht University, together with a Master's degree in Management from the School of Business and Economics at Universidade Nova de Lisboa in Lisbon, Portugal.

In addition to her studies, Anna-Sophie spent several months at the Service Science Factory, a service design and innovation consultancy initiated by Maastricht University. During this time, she learned about developing value-added service portfolios and customer-centric business models through a service design approach. Intrigued by this new domain, she joined the Service Design for Innovation Network (SDIN) funded by the European Union's Horizon 2020 research and innovation programme, as an Early Stage Researcher in May 2016. This position included being installed as a Marie Curie Fellow and a Ph.D. Candidate at the Köln International School of Design at the Technical University of Applied Science Cologne in Germany and the Department of Marketing and Supply Chain Management at Maastricht University.

As part of her SDIN training, Anna-Sophie spent about five months at the headquarters of the international Service Design Network in Cologne, Germany, to gain in-depth practical and theoretical insights on service design. As an embedded design researcher, she was located at Patient Innovation in Lisbon, Portugal for another five months to explore how patients and family caregivers used co-creation to innovate. Then as a visiting scholar, she spent a semester at the Faculty of Engineering of the University of Porto in Porto, Portugal.

Fortunate to draw on the best of the service design and service marketing worlds, Anna-Sophie's research on co-creating services has been guided by Prof. Dr. Gaby Odekerken-Schröder and Prof. Birgit Mager. Along with presenting her work to academics and practitioners at events in numerous countries, including Germany, the Netherlands, Italy, Portugal, France, Sweden, Norway, the United States, and Australia, she has published in Journal of Service Management Journal of Services Marketing, and International Journal of Bank Marketing.

As an accredited Service Design Trainer by the Service Design Network, Anna-Sophie trains and coaches practitioners on service design and co-creation. In January 2020, she joins the client-facing innovation team of Salesforce in Munich, Germany. 
